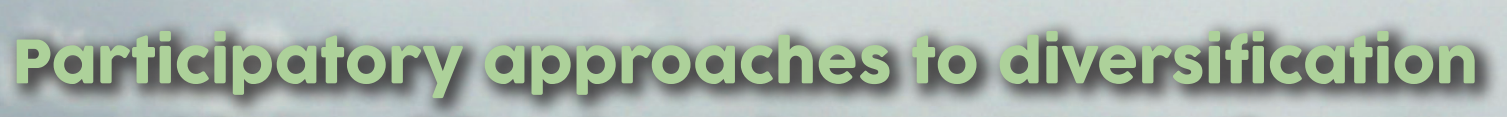
and thiensiffication of srop production on smallinolder torms to vallowi

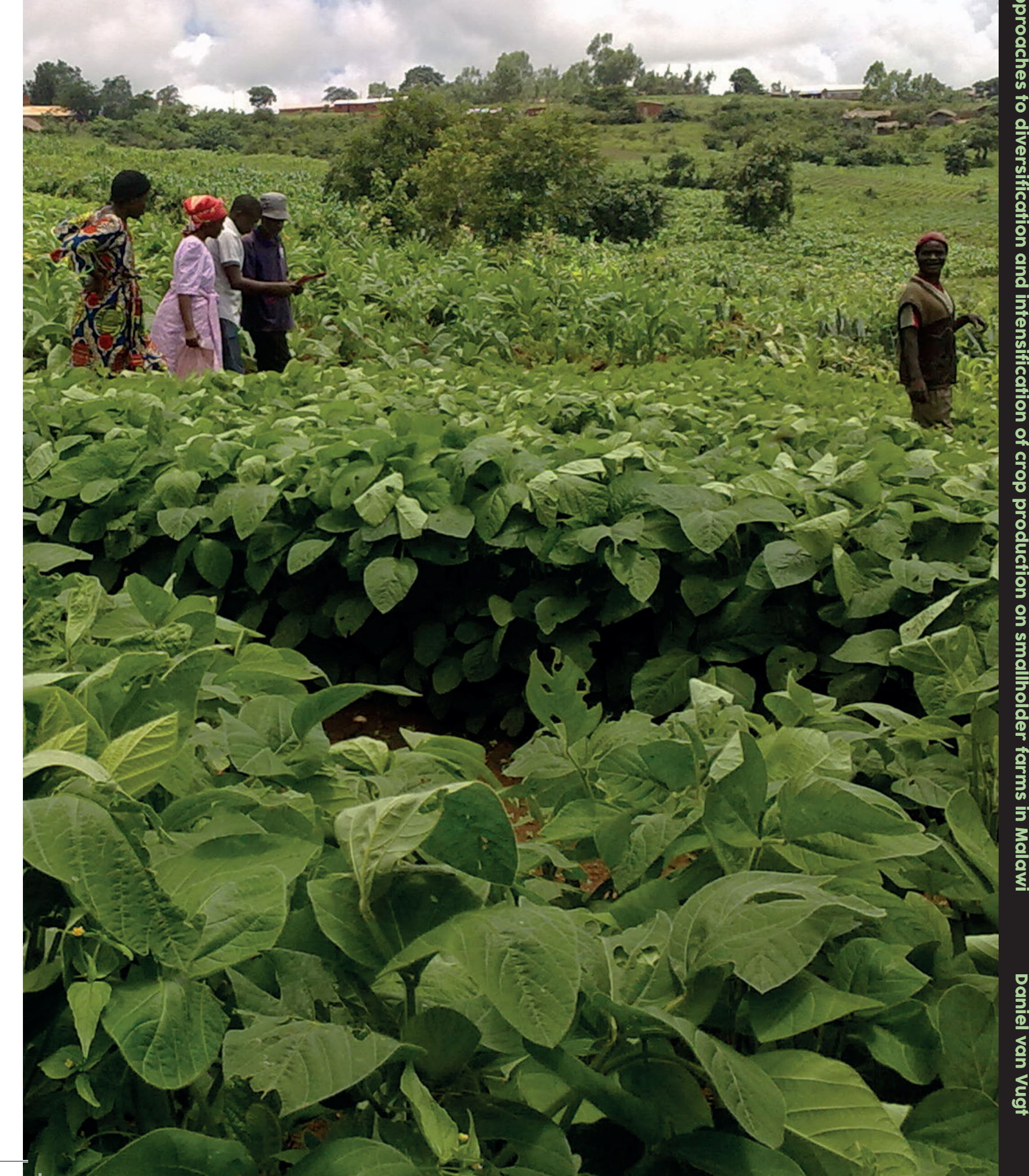

\section{INVITATION}

You are cordially invited to attend the public defence of my PhD thesis

Participatory approaches to diversification and intensification of crop production on smallholder farms in Malawi

On Wednesday 12 September 2018 at 11:00 hours in the Aula of Wageningen University Generaal Foulkesweg 1a, Wageningen

After the defence there will be a reception

Daniel van Vugt daniel.vanvugt@wur.nl

\section{Paranymphs}

Luuk van Dijk luuk.vandijk@wur.nl

Geerte van der Meijden geertevandermeijden@gmail.com 


\section{Propositions}

1. Agricultural development efforts should focus more on farmers with resources and less on poor farmers.

(this thesis)

2. Without access to credit, inputs and markets, smallholder farmers are unlikely to invest in options for diversification and sustainable intensification of crop production.

(this thesis)

3. Micronutrient deficiencies in soils contribute to child mortality, stunting and poor brain development in Malawi.

4. Poverty in Africa would be reduced if each village sets its own poverty line.

5. Development programs in Africa sweep the health risks of soybean and groundnut consumption under the carpet.

6. Smallholder farmers should be viewed as partners in rural development projects rather than as beneficiaries.

Propositions belonging to the thesis, entitled

"Participatory approaches to diversification and intensification of crop production on smallholder farms in Malawi"

Daniel van Vugt

Wageningen, 12 September 2018 


\section{Participatory approaches to diversification and intensification of crop production on smallholder farms in Malawi}

Daniel van Vugt 


\section{Thesis committee}

\section{Promotor}

Prof. Dr K.E. Giller

Professor of Plant Production Systems

Wageningen University \& Research

\section{Co-promotor}

Prof. Dr A.C. Franke

Professor of Soil, Crop and Climate Sciences

University of the Free State, South Africa

\section{Other members}

Prof. Dr Ir P.C. Struik, Wageningen University \& Research

Dr Ir C.J.M. Almekinders, Wageningen University \& Research

Dr R. Harawa, Alliance for a Green Revolution in Africa (AGRA), Kenya

Dr M. de Vries, Solynta

This research was conducted under the auspices of the C.T. de Wit Graduate School of Production Ecology and Resource Conservation 


\title{
Participatory approaches to diversification and intensification of crop production on smallholder farms in Malawi
}

\author{
Daniel van Vugt
}

Thesis

submitted in fulfilment of the requirements for the degree of doctor

at Wageningen University

by the authority of the Rector Magnificus

Prof. Dr A.P.J. Mol,

in the presence of the

Thesis Committee appointed by the Academic Board

to be defended in public

on Wednesday 12 September 2018

at 11 a.m. in the Aula. 
Daniel van Vugt

Participatory approaches to diversification and intensification of crop production on smallholder farms in Malawi, 153 pages.

$\mathrm{PhD}$ thesis, Wageningen University, Wageningen, the Netherlands (2018)

With references, with summary in English

ISBN: 978-94-6343-321-1

DOI: https://doi.org/10.18174/456315 
Crop production by smallholder farmers in Malawi is characterized by cultivation of maize on a large share of the agricultural land with limited nutrient input. There is need for productive farming systems that are better adapted to a changing climate, and that produce more diverse food to achieve both food and nutrition security. The aim of this thesis was to explore options for sustainable intensification and diversification of maize-based farming systems in central Malawi with legumes and sweet potato.

Farmers participating in on-farm soybean agronomy trials ranked eight technologies in descending order of preference as 1. Early planting 2. Plant population 3. Variety choice 4. Compost manure 5. Weeding 6. Inoculant 7. Fertilizer and 8. Spraying. A combination of inoculation, inorganic fertilizer $\left(10 \mathrm{~N}, 8 \mathrm{P}, 20 \mathrm{~K}\right.$ in $\left.\mathrm{kg} \mathrm{ha}^{-1}\right)$, and $6 \mathrm{t}$ $\mathrm{ha}^{-1}$ compost manure increased yields from $0.86 \mathrm{t} \mathrm{ha}^{-1}$ under farmers' practice to 1.56 $\mathrm{t} \mathrm{ha}^{-1}$ and resulted in average profits of $222 \mathrm{USD} \mathrm{ha}^{-1}$. Increased plant populations and biocide spraying also increased yields. Low investment costs make inoculants, compost manure and increased plant populations interesting options, unlike inorganic fertiliser.

Locally sourced soybean varieties obtained a larger \% Ndfa $(65 \%)$ than the 'improved' variety Nasoko (53\%). The \%Ndfa was positively associated with soil sand content, sowing date, plant population and biomass accumulation. Quantities of $\mathrm{N}_{2}$ fixed differed between regions and years, and was enhanced by applying inoculant and fertiliser together, leading to more biomass accumulation and larger grain yields. Soil available $\mathrm{P}$ and exchangeable $\mathrm{K}$ contents also increased the total amount of $\mathrm{N}_{2}$ fixed. Average yield in continuous maize was $2.5 \mathrm{t} \mathrm{ha}^{-1}$, while maize after soybean produced $3.5 \mathrm{t} \mathrm{ha}^{-1}$. Fields of soybean and maize that received adequate nutrient inputs and good management to ensure good yields benefitted most in terms of quantities of $\mathrm{N}_{2}$ fixed by the legume and the yield response of the following maize crop.

Evaluation of six orange-fleshed sweet potato varieties on 221 farmers' fields showed large variability across fields. The average attainable fresh root yield ranged from $18 \mathrm{t} \mathrm{ha}^{-1}$ for variety Zondeni to $32 \mathrm{t} \mathrm{ha}^{-1}$ for Mathuthu, against actual yields of 5 to 9 $\mathrm{t} \mathrm{ha}^{-1}$. Elevation, planting date, rainfall and crop establishment could explain only 28 percent of the average yield gap. Varieties differed in average yields and taste preferences. Timely planting was crucial to attain good root yields by making better use of the available rainfall. Kaphulira was most affected by weevils and weevil control is required for market-oriented producers. Male host farmers received better 
quality cuttings and planted in better soil moisture conditions, resulting in better establishment and vine yields.

In multi-location input trials excellent mean trial yields of $5.0 \mathrm{t} \mathrm{ha}^{-1}$ for maize, $3.4 \mathrm{t}$ $\mathrm{ha}^{-1}$ for soybean, $2.5 \mathrm{t} \mathrm{ha}^{-1}$ for groundnuts and $13.2 \mathrm{t} \mathrm{ha}^{-1}$ for sweet potato were achieved. Responses to various combinations of inorganic fertilizer and lime were highly variable, but applications enhanced yields in all crops. Although maize production and investments in maize fertilizer were not as profitable as the other crops, fertilizer application to maize gave the best returns of food per amount of money invested. Investments in fertiliser and lime in soybean was more worthwhile than in groundnut, though the financial benefits were somewhat hidden by high groundnut prices.

While there is potential to derive better financial returns from diversification and intensification with legumes and sweet potato, farmers prioritize maize in terms of land area and resource allocation. The participatory research approach demonstrated that there is a wide range of technologies with different levels of human and financial investment costs that smallholder farmers can adopt to enhance yields and profits. There is large variability between farmers in the potential for adoption and the benefits that can be derived from sustainable intensification. Approaches to enhance crop diversification and intensification should address the main constraints of lack of awareness of the benefits of nutrient application to legumes and sweet potato, unstable markets, and access to inputs and credit. 
Contents

$\begin{array}{lll}\text { Chapter } 1 & \text { General introduction } & 1\end{array}$

$\begin{array}{lll}\text { Chapter } 2 & \text { Participatory research to close the soybean yield gap on } & 7\end{array}$ smallholder farms in Malawi

Chapter 3 Understanding variability in the benefits of N2-fixation in soybean-maize rotations on smallholder farmers' fields in Malawi

Chapter 4 Exploring the yield gap of orange-fleshed sweet potato varieties on smallholder farmers' fields in Malawi

Chapter 5 Exploring fertilizer use with maize, legumes and sweet potato to intensify and diversify cropping systems in Malawi

Chapter 6 General discussion

References

Summary

Acknowledgements

About the author

PE\&RC Education certificate

Financial support 


\section{Chapter 1}

General introduction

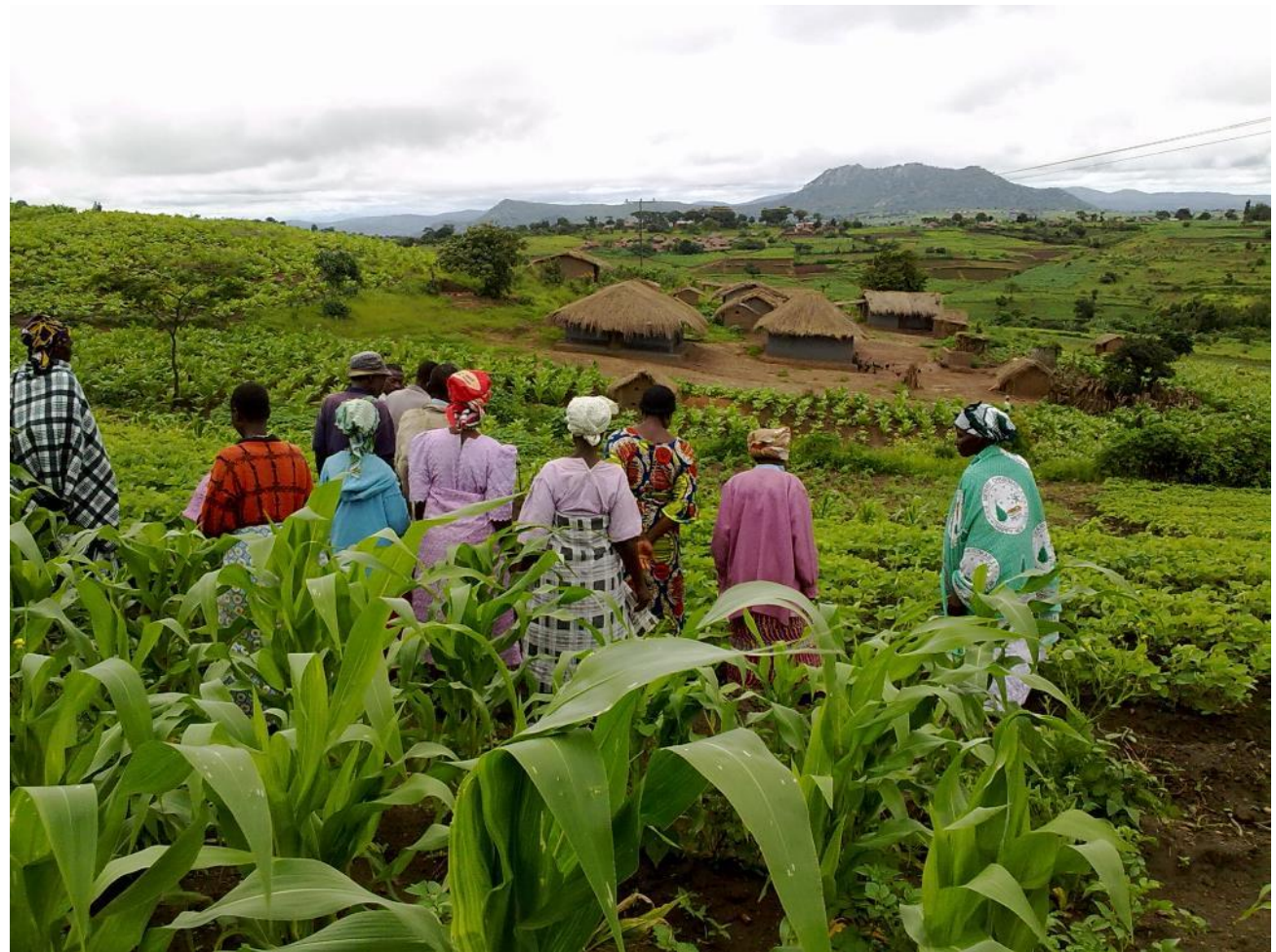




\subsection{Background}

Malawi is a landlocked country in sub-Saharan Africa. Of its population of 18.6 million, $65 \%$ are below the age of 24 and the population is expected to increase up to 41.7 million by 2050 (UN, 2017). Eighty-five percent of the population lives in the rural areas of whom 94 percent engage in agricultural activities (NSO, 2012). The average smallholder landholding size has reduced from 1.5 hectares in 1968 to 0.8 hectares in 2011 with more than $70 \%$ of current land cultivated with maize (IFAD, 2011; Nalivata et al., 2017; NSO, 2012). Most rural farmers depend on the single rainy season from December to March as only 0.5 percent of the fields are irrigated (NSO, 2012). Limited crop diversity and overdependence on maize can result in diets that are lacking important vitamins and minerals (Haddad et al., 2016). The prevalence of micronutrient deficiencies such as iron, iodine and vitamin A are a major health concern to children and pregnant women caused by limited dietary diversity (WHO, 2018). Twenty-six percent of the population in Malawi is undernourished, $42 \%$ of children are stunted and the prevalence of anaemia of women of reproductive age is $34 \%$ (FAO et al., 2017). To achieve the second sustainable development goal (SDG2) to end hunger, achieve food security and improved nutrition and promote sustainable agriculture by 2030, we need to 'rethink how we grow, share and consume our food' (UN, 2018).

The average maize yield achieved by smallholders in Malawi is only $2 \mathrm{t} \mathrm{ha}^{-1}$ (IFDC, 2013). While fallow areas have largely disappeared due to expanding arable farming, cropping intensity is still low (Binswanger-Mkhize and Savastano, 2017). If the overdependence on low-input maize cultivation is not addressed, continued soil nutrient depletion may eventually result in severe soil degradation (Tittonell and Giller, 2013). Sustainable intensification (SI), is often considered a possible avenue to enhance productivity to meet the future demand for food, fuel and fibre while protecting environmental services and increasing resilience to shocks (Snapp et al., 2018; Vanlauwe et al., 2014). While there is limited general consensus on what SI exactly entails (Petersen and Snapp, 2015), several options are promoted. These include integrated nutrient management with mineral and organic fertilizers, agroforestry, green manures, conservation agriculture and diversification with legumes (Droppelmann et al., 2017). The scope of SI can be more broadly defined to include social and human conditions such as gender dynamics and farmer preferences (Snapp et al., 2018). It is in this context that this thesis explores several options to enhance productivity and to diversify cropping systems in Malawi.

\subsection{Crop diversification with legumes and sweet potato}

Crop diversification forms an important part of the National Agricultural Policy of Malawi (MAIWD, 2016a). It can benefit the overall farming system productivity, enhance resilience to climate variability and change, and improve food and nutrition security (Bezner Kerr et al., 2007; Kankwamba et al., 2012). There is a positive association between food crop 
production diversification and both dietary diversity and households' access to micronutrients in Malawi (Mazunda et al., 2018). In the context of maize based smallholder farming systems, increasing the role of legumes such as soybean (Glycine max (L.) Merr.) and groundnuts (Arachis hypogaea L.) is considered as an important component of sustainable intensification (Mhango et al., 2013). For every ton of shoot dry matter produced, legumes fix on average 30 to $40 \mathrm{~kg}$ of freely available atmospheric nitrogen (Peoples et al., 2009). This can contribute to soil fertility especially when crop residues are incorporated in the soil (Giller, 2001; Sanginga, 2003; Sisworo et al., 1990). In southern Africa, legumes enhance the following cereal yields by an average of 42 percent due to the rotational benefits (Franke et al., 2018). In terms of building resilience to climate change, root and tuber crops are considered more tolerant to drought and are projected to be less affected by global warming than grain crops (Adhikari et al., 2015). Therefore, sweet potato (Ipomoea batatas [L.] Lam) is often considered an important food security crop (Motsa et al., 2015) as evidenced by frequent mass distributions of planting material to rural households in response to droughts or floods (Kapinga et al., 2005).

Enhanced legume and sweet potato production may result in more diverse diets. Legumes can contribute to the essential protein needs of rural households (Snapp et al., 2014; Bezner Kerr et al., 2007; Jones and Divine, 1944). Sweet potato is a rich source of carbohydrates, protein, calcium, iron, potassium, carotenoids, dietary fibre, and vitamins, and very low in fat and sodium (Bovell-Benjamin, 2007). The leaves are also edible and very nutritious. The orange-fleshed sweet potato varieties have the additional benefit that they are rich in betacarotene which is converted into vitamin A in the human body (Low et al., 2017). Its production and consumption has proven to reduce vitamin A deficiency in breast feeding mothers and young children in southern Africa (Low et al., 2017; Tanumihardjo et al., 2017).

\subsection{Rationale of the research}

The benefits of legumes and sweet potato to smallholder farmers may be enhanced by boosting the productivity and subsequent profitability of these crops. Planting improved varieties would be a good starting point but farmers often do not derive the intended benefits from genetic improvement due to other yield limiting and reducing factors (Tittonell and Giller, 2013). To quantify the yield gaps for different crops, production ecological concepts are commonly used to determine the potential, water or nutrient limited yields and the actual yields (Van Ittersum and Rabbinge, 1997). To enhance productivity, the main factors that contribute to the yield gaps should be understood and addressed by targeting the right interventions. This goes beyond agronomy because the actual yields on farmers' fields are a result of many interacting biophysical, socio-economic and management constraints (Fermont et al., 2009). There can be regional variation in biotic stresses such as pests, diseases and weeds or abiotic stresses such as nutrient deficiencies and drought (Wairegi et 
al., 2010). For example in the case of legumes, the agro-ecological conditions affect the amounts of nitrogen fixation (Ojiem et al., 2007) and legume adoption is generally more beneficial to farmers in areas with good soils and rainfall (Ojiem et al., 2014).

For productivity enhancing technologies to be adopted, farmer preferences and socioeconomic conditions must be in the forefront in the process of technology development (Snapp and Silim, 2002). Common socio-economic constraints to technology adoption reported in Malawi include limited access to input and output markets, labour constraints, financial resources to procure seeds, fertilizer, inoculant in the case of soybean and plant protection agents (Mhango et al., 2013; Van den Brand, 2011; Franke et al., 2014; Snapp et al., 2002). Because biophysical and socio-economical characteristics of smallholder farms are very heterogeneous (Ojiem et al., 2006), a 'one-size-fits-all' approach to technology scaling may not achieve the intended results. Each technology will fit best in its specific socio-ecological niche (Ojiem et al., 2006). This has implications for targeting of interventions that aim to sustainably intensify and diversify cropping systems. Once potential yield enhancing technologies are identified, there is need to look beyond average yield responses and explore the variability in performance caused by the diversity of smallholder farmers environments and practices (Vanlauwe et al., 2016). This can be achieved by testing and evaluating technologies together with smallholders through multi-locational on-farm experiments.

\subsection{Objectives}

The aim of this thesis is to explore options for sustainable intensification and diversification of maize-based farming systems in central Malawi with legumes and sweet potato. I hypothesize that farmers can substantially increase their productivity and incomes through crop diversification with legumes and sweet potato and through application of improved agronomic practices and technologies. Specific objectives were to:

1. Quantify the effects of a range of nutrient and crop management practices on soybean yields and financial returns, and understand farmers' perceptions and rankings of these technologies.

2. Understand the variability and factors behind the benefits of $\mathrm{N}_{2}$-fixation in soybeanmaize rotations on smallholder farmers' fields.

3. Assess the performance of six orange-fleshed sweet potato varieties in different agro-ecological conditions and explore the factors that contribute to the yield gap on smallholder farmers' fields.

4. Explore the benefits of fertilizer use with maize, legumes and sweet potato to intensify and diversify cropping systems 


\subsection{Summary of research approach}

The research methodology consisted of the establishment of a range of multi-locational onfarm agronomic trials and demonstrations. Multiple technology options to enhance soybean productivity were tested in 144 on-farm sites, biological nitrogen fixation by soybean was quantified in 150 plots under different inputs levels and varieties, and the rotational effect of soybean on maize was assessed on 53 farmers' fields. The variability in yield performance of six orange-fleshed sweet potato varieties was explored based on data from 221 on-farm demonstration sites. In partnership with a private sector company, the effect of different combinations of fertilizer and lime was assessed in 50 maize trials, 28 soybean trials, 24 groundnut trials and 26 sweet potato trials. The large number of locations allowed capturing the large variability in productivity and yield responses to technologies. To identify some of the factors underlying this variability, a wide range of biophysical and socio-economic data were collected including soil characteristics, climatic data, data on crop components, pests and disease scoring and household characteristics. Mixed linear models and multivariate boundary line models were used to explore which biophysical and socio-economic factors contribute to yield gaps, yield variability, and variability in responses to technologies. Participatory approaches including pairwise technology ranking and focus group discussions were used to explore farmers' perceptions on technologies and on crop diversification. Secondary data collection on costs of technologies and farm-gate prices of commodities allowed for the calculation of partial gross margins for farmers' investments in intensification and crop diversification. The interdisciplinary approach of combining agronomic work with farmers' perceptions and economic evaluations allowed me to capture a wide range of considerations that will determine technology adoption. This provided important lessons for targeting and scaling out technologies, which can benefit development of policy and new partnership approaches to stimulate crop diversification and intensification.

\subsection{Outline of the thesis}

Chapter 2 explores crop management and nutrient management technologies that can contribute to closing the soybean yield gap on smallholder farmers' fields. Through a combination of multi-location on-farm trials and participatory evaluations with farmers, the constraints and opportunities for the adoption of early planting, plant population, variety choice, compost manure, weeding, inoculant, fertilizer and spraying were assessed. A comparative evaluation of yield responses, economic benefits and farmers' perceptions shows there are options to enhance productivity, but these require different levels of human and financial investments.

Chapter 3 places the benefits of soybean intensification in the context of the cropping system in terms of $\mathrm{N}_{2}$-fixation by soybean and the rotational benefit of soybean on maize productivity. Through quantification of biological nitrogen fixation (BNF) for different 
soybean varieties and input treatments in multiple sites and seasons, factors behind the variability in BNF could be explored. The effects of socio-economic and biophysical characteristics on the rotational benefits of planting maize after soybean are also presented. The results shed light on the conditions under which BNF and crop rotation will be most beneficial to smallholder farmers.

Chapter 4 provides an assessment of the performance of six orange-fleshed sweet potato varieties based on many demonstrations established in a technology scaling project. Factors that affect crop establishment, vine yields, storage root formation, root yields, percentage of marketable root yield, and weevil infestation are identified. A range of biophysical, climatic, management and socio-economic factors and variables was included in a multivariate boundary line model to identify the most yield limiting factors affecting sweet potato production on smallholder farmers' fields.

Chapter 5 compares the performance of maize, soybean, groundnut and sweet potato in multilocational input trials in central Malawi. This includes an assessment of the effects of different levels of fertilizer application and lime on yields and economic benefits of each crop. The chapter demonstrates the importance of including farmer perceptions as farmers consider factors beyond plot level yield and economic benefits of technologies.

In Chapter 6, I discuss whether farmers can increase productivity and incomes by intensification and crop diversification. I explore the implications of variability in performance of technologies across farms and the perceptions of farmers on intensification and diversification. I discuss the role sustainable intensification can play towards the achievement of SDG 1 and 2. Finally, I discuss approaches to technology scaling that consider the large variability in yield performance encountered, and that match the constraints and the context in which smallholder farmers operate. 


\section{Chapter 2}

Participatory research to close the soybean yield gap on smallholder farms in Malawi

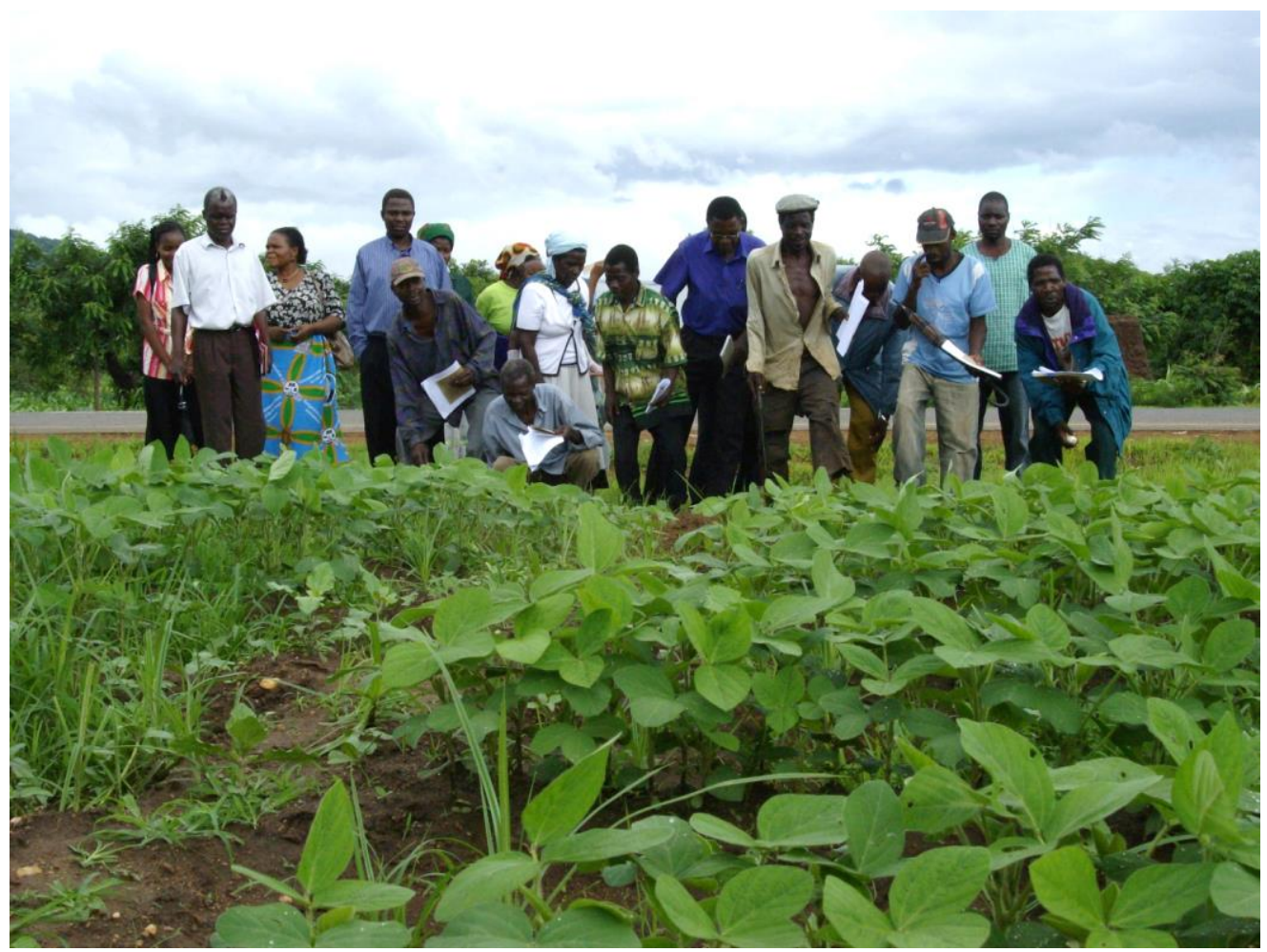

This chapter is published as:

Van Vugt, D., Franke, A.C., Giller, K.E., 2017. Participatory research to close the soybean yield gap on smallholder farms in Malawi. Experimental Agriculture 53(3), 396-415. 


\begin{abstract}
Soybean yields on smallholder farmers' fields in Malawi are constrained by poor soil fertility, limited application of external inputs and poor crop husbandry. We tested crop management practices through on-farm experimentation and participatory technology evaluation. Two agronomic soybean trials were established in 2009 and 2010 in three contrasting agroecologies resulting in 72 replications per trial. Treatments in the first trial included several combinations of inoculation with Bradyrhizobium japonicum, inorganic fertilizer application and compost manure. In the second trial, farmers tested an improved variety, optimal weeding regime, increased plant population and chemical pest and disease control. A combination of inoculation, inorganic fertilizer $\left(10 \mathrm{~N}, 8 \mathrm{P}, 20 \mathrm{~K}\right.$ in kg ha-1), and $6 \mathrm{t} \mathrm{ha}{ }^{-1}$ compost manure increased yields from $0.86 \mathrm{t} \mathrm{ha}^{-1}$ under farmers' practice to $1.56 \mathrm{t} \mathrm{ha}^{-1}$ and resulted in average profits of $222 \mathrm{USD} \mathrm{ha}^{-1}$. Increased plant populations and biocide spraying also resulted in substantial yield increases. All technologies except planting Nasoko and weed management were profitable with a value to cost ratio (VCR) $>1$ but only inoculation and increased plant population resulted in an average VCR $>2$. Spraying was only beneficial where leaf rust was present. Low investment costs make inoculants, compost manure and increased plant populations interesting options, whereas adoption of inorganic fertiliser application in soybean may be limited due to high costs and low VCR. Farmers' technology rankings considered factors such as purchasing power, access to inputs, the role of soybean in the cropping system, labour availability and risks associated with variability in yield responses to technology. The farmers ranked eight technologies in descending order of preference as 1 . Early planting 2. Plant population 3. Variety choice 4. Compost manure 5. Weeding 6. Inoculant 7. Fertilizer and 8. Spraying. Our participatory research approach demonstrated that there is a wide range of technologies with different levels of human and financial investment costs that smallholder farmers can adopt to enhance their soybean yields and profits.
\end{abstract}

Keywords: Rhizobium inoculation, nitrogen fixation, phosphorus deficiency, crop management, technology ranking. 


\subsection{Introduction}

Smallholder farming systems in southern Africa are dominated by the staple crop maize (Zea mays L.) which is cropped on over $80 \%$ of smallholder land area in some areas (Giller et al., 2011). Soil organic matter (SOM) inputs produced on-farm are insufficient to maintain soil fertility and mineral fertilizers are expensive and often unavailable (Bloem et al., 2009). Legumes such as soybean (Glycine max (L.) Merr.) can contribute to improved soil fertility through biological nitrogen fixation when crop residues are incorporated into the soil (Sanginga, 2003; Sisworo et al., 1990; Peoples et al., 2009; Giller, 2001). Incorporation of legumes into maize-based systems can help reduce biotic stresses in cereals such as Asiatic witch weed (Striga asiatica (L.) Kuntze) (Kabambe et al., 2008), improve household nutrition by adding essential amino acids to diets (Bezner Kerr et al., 2007) and provide additional cash income if markets are available (Giller et al., 2011).

Between 2003 and 2014 soybean yields in Malawi averaged only $0.88 \mathrm{t} \mathrm{ha}^{-1}$ - substantially less than in Zimbabwe (1.47 $\left.\mathrm{t} \mathrm{ha}^{-1}\right)$ or South Africa $\left(1.67 \mathrm{t} \mathrm{ha}^{-1}\right)$ during this period (FAO, 2016). An array of interacting constraints limit soybean yields. These include biophysical constraints such as rainfall distribution and poor soil phosphorus availability as well as socioeconomic constraints such as limited market opportunities, labour constraints and limited availability of cash for seeds, fertilizer, inoculant and plant protection agents (Van den Brand, 2011; Snapp et al., 2002; Mhango et al., 2013). Local demand for soybeans has increased substantially over the past 20 years due to increasing demand for poultry feed and processing into infant and baby formula (Tinsley, 2009). This provides opportunities for smallholder farmers to produce soybean as a cash crop. Yet to be profitable, soybean productivity needs to be enhanced.

Several technologies can contribute to closing the yield gap between actual and attainable yields. Inoculation with Bradyrhizobium japonicum, fertilizer application and the use of compost manure can increase soybean yields (Hati et al., 2006; Ndakidemi et al., 2006). Farmers need to select good quality seed of a genotype that matches the agro-ecological conditions in which the crop is grown. Without access to inoculant, farmers can benefit from growing promiscuous varieties with an improved ability to nodulate with Bradyrhizobium naturally present in the soil (Mpepereki et al., 2000). Timely planting allows the crop to make optimal use of the available growing season (Summerfield et al., 1996; Parker et al., 1981; Davis, 1979). Matching soybean genotypes with their optimal row spacing and plant populations can result in larger yields if water and nutrients are in sufficient supply (Alessi and Power, 1982; Taylor, 1980). Pests such as termites, caterpillars and pod suckers attack soybeans (Haile et al., 1998) and their control can enhance production (Sastawa et al., 2004). The most destructive disease in soybeans in southern Africa is leaf rust (Phakopsora pachyrhizi), which can be controlled by fungicides (Levy, 2005) or by growing rust-tolerant 
genotypes (Jarvie and Shanahan, 2009). Finally, weed control is required to maximize soybean yields (Odeleye et al., 2007).

Current crop management recommendations in Malawi are largely based on a set of onstation agronomic trials that were conducted without farmer participation (Davis, 1979). Yields reported on research stations are often higher than on farm due to better soil fertility and crop management (Mugwe et al., 2009). Therefore yield response to treatments such as fertilizer, inoculant, manure and plant spacing will be different under on farm conditions. New threats such as leaf rust should also be included in agronomic research. A technology is unlikely to be adopted by farmers unless it fits their socio-ecological niche (Ojiem et al., 2006) and farmers' preferences are at the forefront (Snapp and Silim, 2002). Therefore technologies should be tested and evaluated together with smallholders on their farms (Chamango, 2001).

We report a set of on-farm experiments conducted in central Malawi to: 1) quantify the effects of inoculation, fertilizer, compost manure, improved variety, weed management, plant population and pest and disease control on soybean yields, 2) assess the economic benefits of these technologies and 3) understand farmers' perceptions and rankings of these technologies.

\subsection{Materials and methods}

\subsubsection{Study areas and farmer selection}

Experiments were conducted in three contrasting agro-ecological zones in the central region of Malawi. In Mchinji district, the trials were established at an altitude of 1050-1150 meters above sea level (masl) in a radius of $10 \mathrm{~km}$ around Kachamba village (13 $\left.{ }^{\circ} 44^{\prime} \mathrm{S}, 33^{\circ} 20^{\prime} \mathrm{E}\right)$, in Dowa district at an altitude of 1200-1400 masl in a radius of $15 \mathrm{~km}$ around Msakambewa trading centre $\left(13^{\circ} 33^{\prime} \mathrm{S}, 33^{\circ} 54^{\prime} \mathrm{E}\right)$, and in Salima at an altitude of 550-650 masl in a radius of $5 \mathrm{~km}$ around Chitala research station $\left(13^{\circ} 40^{\prime} \mathrm{S}, 34^{\circ} 15^{\prime} \mathrm{E}\right)$. Malawi has a unimodal rainfall distribution with rains starting early December and continuing for about four months. Average long term precipitation across the three regions are in the range of $900-950 \mathrm{~mm}$ per year (Hijmans et al., 2005). The dominant soil types are Chromic luvisols in Mchinji and Dowa and Eutric cambisols in Salima.

Participatory agronomic soybean trials were conducted with 120 farmers in total. Farmers were selected in consultation with local field technicians, lead farmers and village chiefs, based on their experience with growing soybeans, motivation to participate, and diversity in gender, age and resource endowment. Structured household surveys were conducted with the participating farmers to gather information on available family labour in men equivalents (ME where an adult male $>15$ years counts 1 , an adult female 0.8 and children between 5 and 
15 years are 0.5 ME), arable land area (ha), total value of assets, and quality of housing score based on material used for walls, floor and roof.

\subsubsection{On-farm experimental design}

Two sets of trials were established in the 2009/10 and 2010/11 growing seasons (hereafter referred to as the 2010 and 2011 seasons respectively) on a total of 144 farmers' fields on plots cultivated with maize in the previous season. In each region and year, one nutrient management (NM) trial and one crop management (CM) trial was established. The trial design was a random controlled block design (RCBD) with 12 farmers per season per region hosting a single replicate block with five treatments. Trials were researcher-designed and implemented by farmers with assistance of a field technician responsible for monitoring, data collection and the weeding and spraying treatments during the growing season. Some farmers participated in both seasons using a different plot in the second season.

Each NM block consisted of five plots of 10 by 10 m each that were all planted with soybean variety Nasoko, a common specifically-nodulating grain type variety widely available in Malawi. Treatments represented a stepwise increase in intensity, namely T1) farmers practice, T2) inoculation, T3) inoculation plus fertilizer rate 1, T4) inoculation plus fertilizer rate 2, T5) inoculation plus fertilizer rate 1 plus compost manure. This design was chosen to enable farmers to evaluate various nutrient management options in one block. The inoculant containing Bradyrhizobium japonicum strain MAR 1491 was sourced from Zimbabwe and did not contain additional nutrients. Compound fertilizer Super D was applied 2 weeks after planting (WAP) at a rate of $100 \mathrm{~kg} \mathrm{ha}^{-1}\left(10 \mathrm{~kg} \mathrm{~N} \mathrm{ha}^{-1}, 8 \mathrm{~kg} \mathrm{P} \mathrm{ha}^{-1}\right.$ and $\left.20 \mathrm{~kg} \mathrm{~K} \mathrm{ha}^{-1}\right)$ for rate 1 (T3 and T5) and $300 \mathrm{~kg} \mathrm{ha}^{-1}$ (30 kg N ha-1, $24 \mathrm{~kg} \mathrm{P} \mathrm{ha}^{-1}$ and $60 \mathrm{~kg} \mathrm{~K} \mathrm{ha}^{-1}$ ) for rate 2 (T4). Compost (T5) was sourced locally and was made mainly from maize and legume crop residues. In 2010 three sub-samples of compost were collected from each region and chemical analysis showed an average $\mathrm{pH}$ of $7.5,4.2 \% \mathrm{OC}, 0.013 \% \mathrm{P}, 0.21 \% \mathrm{~N}$ and an ash content of $10.0 \%$. The manure was incorporated at a rate of $6 \mathrm{t} \mathrm{ha}^{-1}$ in the surface $20 \mathrm{~cm}$ of soil two weeks before planting. Farmers were free to follow their own practices regarding row spacing, sowing rate, planting date, weeding date and frequency, and pest and disease control as long as these practices were constant across all plots.

Each CM block also consisted of five plots of 10 by $10 \mathrm{~m}$ reflecting a stepwise increase in management intensity with treatments T1) local variety, T2) improved variety, T3) as T2 but with improved weed management, T4) as T3 with increased plant population, T5) as T4 with pest and disease control. This design was chosen to demonstrate options to enhance soybean yields without application of fertilizer or manure. T1 was planted with unsorted soybean grains of unknown variety locally procured from traders or farmers in each region and T2T5 were planted with variety Nasoko. The field technician weeded T3-T5 manually at two and six weeks after planting. Farmers followed their own weeding regime in T1 and T2. In 
T1-T3 farmers were free to decide on their preferred ridge spacing, plant population and planting methods. In T4 and T5 soybean was planted in two lines (20 cm between lines; 5 $\mathrm{cm}$ between seeds) on ridges spaced $75 \mathrm{~cm}$ apart. This resulted in a seeding rate of about 533,000 seeds ha ${ }^{-1}$ aiming for approximately 400,000 plants ha ${ }^{-1}$ at $75-80 \%$ germination. In T5 caterpillars (loopers) were controlled by spraying $300 \mathrm{ml} \mathrm{ha}^{-1}$ Cypermethrin at 3, 7 and 11 WAP and leaf rust was prevented by spraying $500 \mathrm{ml} \mathrm{ha}^{-1}$ Folicur (tebuconazole 250 $\left.\mathrm{g}^{-1}\right)$ at 7 and 11 WAP. Seeds in all treatments were inoculated at planting.

\subsubsection{Soil sampling and data collection}

Five topsoil samples $(0-20 \mathrm{~cm})$ were collected from each block and combined in a composite sample, which was mixed, air-dried, crushed and passed through a 2-mm sieve. Samples were analysed at IITA-Malawi and Chitedze Research Station for SOC\% (Walkley-Black), total $\mathrm{N} \%$ (micro-Kjeldahl), available $\mathrm{P}$ (Bray-1), $\mathrm{K}$ (Mehlich-3 method), soil $\mathrm{pH}\left(\mathrm{CaCl}_{2}\right)$ and texture. In each region, the field technician collected rainfall data using a rain gauge and three farmers using a calibrated water bottle and a ruler. The date of effective planting rains, defined as the date at which at least $25 \mathrm{~mm}$ of accumulated rainfall was received within 10 days, not followed by a period of 10 consecutive days with an accumulated rainfall less than $2 \mathrm{~mm}$ (Tadross et al., 2007), was recorded. Farmers' practices recorded by the field technicians included actual planting and weeding dates, the number of ridges and their spacing, the number of rows sown per ridge and the number of plants counted on two selected ridges in each plot at 3 WAP. Weed pressure was scored visually from $1(<10 \%$ of the plot surface covered with weeds) to 5 ( $>90 \%$ of the plot surface covered with weeds) at 5,8 and 11 WAP. Pest and disease incidence was scored visually on leaves at half the plant height at 3, 7 and 11 WAP before spraying. Leaf damage was scored as the average percentage of leaf area defoliated and leaf rust incidence as the percentage of leaf area covered by rust lesions.

At mid pod-filling stage (R5.5) three sub-samples of biomass were taken in each plot by harvesting $0.5 \mathrm{~m}$ of a ridge at a randomly selected spot. Sub-samples were combined and fresh weight was determined in the field. Samples were oven-dried at $70^{\circ} \mathrm{C}$ until constant weight to determine dry matter concentration. Nodulation was assessed by uprooting six sampled plants and scoring on a scale of $1-5$ with 1 being no nodulation and 5 abundant nodules observed.

At crop maturity, plots were harvested excluding the outer ridges and the $1.5 \mathrm{~m}$ ridge-length from which the biomass sub-samples were collected. Harvested plants were threshed and weighed, and a sub-sample of the grain was taken from each plot to assess moisture concentration and 100 seed weight. Yields were adjusted to $13 \%$ grain moisture concentration. 


\subsubsection{Partial gross margin analysis}

Partial gross margins in the NM trials were calculated for the various input combinations in T2-T5 relative to the farmers practice (T1). In the CM trials the margins were calculated for increased plant population (T4) and spraying (T5). Variety Nasoko (T2) and weed management (T3) were excluded since these treatments did not enhance yields relative to T1. Therefore $\mathrm{T} 3$ was considered as a base case in the analysis.

Marginal revenues were calculated by multiplying the marginal grain yields with the average farm-gate price farmers received from vendors in the months May to July following harvest $\left(0.67 \mathrm{USD} \mathrm{kg}^{-1}\right)$. The marginal costs include variable and fixed marginal costs (Table 2.1) where the variable costs represent the (post-) harvest costs that result from increased yields and the fixed costs represent the procurement, transport and application costs of the inputs. Labour costs are those of hired labour commonly used in the study areas based on information from local informants. Costs and benefits were calculated in USD at the official exchange rate of $150 \mathrm{MWK}$ per USD at the time the field work was conducted. The incremental value to cost ratio (VCR) was calculated for each technology by dividing the marginal revenue by the marginal production costs. We calculated the percentage of farms with a VCR $>2$ for each technology since this is often considered to be a sufficient economic incentive for adoption by smallholder farmers (Kelly, 2006).

\subsubsection{Technology evaluations and ranking}

In each region, field days were organized each season when the crop was around the midpod filling stage. After a visit to a block of the NM and the CM trial, group discussions were held. Early planting was not a treatment in the trials but was included in the evaluations because farmers considered it to be an important factor determining yield. Each farmer evaluated the technologies early planting, optimal weed management, spraying against pests and diseases, planting two lines per ridge, variety choice, inoculation, fertilizer application and compost manure by noting their advantages and disadvantages. This was followed by a pair wise technology ranking exercise where each farmer selected the preferred technology out of a set of two technologies until all eight technologies were compared with each other. Grain yields and their implications for technology adoption were discussed in meetings with participating farmers after each growing season. 
Table 2.1: Marginal costs of technologies.

\begin{tabular}{lc}
\hline Variable marginal costs* & $\mathrm{USD} \mathrm{kg}^{-1}$ \\
\hline Labour for harvesting and threshing & 0.053 \\
Harvest bags & 0.010 \\
Transport produce to homestead & 0.017 \\
\hline Total & 0.080 \\
& \\
Fixed marginal costs & $\mathrm{USD} \mathrm{ha}^{-1}$ \\
\hline Inoculation & 2.00 \\
Procurement inoculants & 6.00 \\
Transport to nearest supplier & 8.00
\end{tabular}

Fertilizer $1\left(100 \mathrm{~kg} \mathrm{ha}^{-1}\right)$

Super D fertilizer 2 bags

Transport

Labour fertilizer application

13.33

Total

117.33

Fertilizer $2\left(300 \mathrm{~kg} \mathrm{ha}^{-1}\right)$

Super D fertilizer 6 bags $\quad 280.00$

Transport $\quad 16.00$

Labour fertilizer application $\quad 13.33$

Total 309.33

Compost manure $\left(6 \mathrm{tha}^{-1}\right)$

Labour for making manure $\quad 26.67$

Transport of manure to the field $\quad 10.67$

Labour manure application in the field $\quad 20.00$

Total 57.33

Improved variety

Procurement logistics/transport $\quad 10.67$

Additional costs $80 \mathrm{~kg}$ certified seed $\quad 80.00$

\begin{tabular}{ll}
\hline Total & 90.67
\end{tabular}

Increase plant population

$20 \mathrm{~kg}$ certified seed

Additional labour planting two lines per ridge $\quad 24.00$

Total 57.33

Pest and disease control

Costs of Cypermethrin

13.33 


\begin{tabular}{lc}
\hline Costs of Folicur & 18.00 \\
Transport to town & 8.00 \\
Labour chemical application & 6.67 \\
Rent of sprayer & 6.67 \\
\hline Total & 52.67 \\
\hline
\end{tabular}

\subsubsection{Data analysis}

Statistical analyses were conducted in Genstat 12.2 VSN International Ltd. Average yields of blocks (average of T1-T5), wealth indicators and soil characteristics were subjected to general analysis of variance (ANOVA) to identify differences between regions and to test for region $\mathrm{x}$ year interactions. The treatment effects on yield, crop components, pest and disease incidence and first weeding date were tested in both trials for the whole data set (there was no blocking effect of region or season). We also evaluated whether the treatment responses were different for the regions or years by testing for interactions. Pair wise ranking data were analysed by adding a score of 1-7 to each technology for each farmer based on the number of times the technology was preferred over other technologies. General ANOVA was used to identify differences in scores for technologies across regions and years. The advantages and disadvantages of technologies were analysed using frequency tables.

\subsection{Results}

\subsubsection{Households, soils and rainfall in the study regions}

The three regions varied in wealth, soil characteristics and rainfall distribution (Table 2.2 and Fig. 2.1). In Mchinji the planting rains started about a month earlier than in the other regions. Total rainfall was sufficient for soybean production, but the distribution was uneven in Salima in 2010 (Fig. 2.1). Farmers in Mchinji owned more assets such as a house with an iron sheet roof, a television, radio, phone, irrigation pump or bicycle. In Dowa most hou ses were constructed of mud with a grass roof and farmers owned only few assets. On the other hand, soils in Dowa contained more SOC, N and clay than the other regions (Table 2.2). Soil available $\mathrm{P}$ and exchangeable $\mathrm{K}$ were expected to be limiting $\left(\mathrm{P}<10 \mathrm{mg} \mathrm{kg}^{-1}\right.$ and $\mathrm{K}<0.02$ $\mathrm{cmol} \mathrm{kg}^{-1}$ ) in $76 \%$ and $16 \%$ of the fields in Dowa, $71 \%$ and $47 \%$ in Mchinji and $77 \%$ and $0 \%$ in Salima respectively. Soil $\mathrm{pH}$ was generally not limiting because $96 \%$ of the fields fell within the range $\left(4.2-7.5\left(\mathrm{CaCl}_{2}\right)\right)$ considered suitable for soybean production.

\subsubsection{Trial performance and yields}

Yields averaged $1.22 \mathrm{t} \mathrm{ha}^{-1}$ in the NM trials and $1.09 \mathrm{t} \mathrm{ha}^{-1}$ in the CM trials (Table 2.3). Yields in Salima in 2010 were significantly less than in Mchinji and Dowa, and also less than in Salima in 2011. Poor yields in Salima in 2010 can be explained by drought stress after planting and water logging in the middle of the growing season (Fig. 2.1), grasshoppers 
attacking emerging plants, and a small number of weeding operations per block. No other significant differences in yield performance between regions or years were observed. The trials were planted on average 21 (3-44) days after the first planting rains, on ridges spaced 77 (59-100) cm apart.

The yield responses to treatments (Table 2.4) were consistent across regions and years. However, the boxplots in Fig. 2.2 show wide variation in yields achieved across the replicate blocks within each region and year in both trials.

Table 2.2: Wealth indicators and soil characteristics in three districts in central Malawi.

\begin{tabular}{|c|c|c|c|c|c|}
\hline & Dowa & Mchinji & Salima & Mean & $\mathrm{LSD}^{1}$ \\
\hline Wealth indicators & $(n=47)$ & $(n=31)$ & $(n=42)$ & $(n=120)$ & \\
\hline Arable land (ha) & $1.5(0.8)^{1}$ & $2.6(2.0)$ & $2.9(3.3)$ & $2.3(2.3)$ & $1.0^{*}$ \\
\hline Household labour (ME) & $4.4(2.2)$ & $4.0(1.8)$ & $3.1(1.5)$ & $3.9(1.9)$ & $0.9^{* *}$ \\
\hline Value of assets (USD) & $87(126)$ & $286(326)$ & $206(384)$ & $180(300)$ & $134^{*}$ \\
\hline Housing quality (0-3) & $0.3(0.6)$ & $1.9(1.0)$ & $0.8(0.6)$ & $0.9(1.0)$ & $0.3^{* * *}$ \\
\hline Soils & $(n=41)$ & $(n=45)$ & $(n=37)$ & $(n=123)$ & \\
\hline $\mathrm{pH}(\mathrm{CaCl})$ & $4.9(0.5)$ & $4.6 \quad(0.3)$ & $5.5(0.9)$ & $5.0 \quad(0.7)$ & $0.25 * * *$ \\
\hline $\operatorname{SOC}(\%)$ & $1.6(0.6)$ & $0.9 \quad(0.5)$ & $0.9 \quad(0.8)$ & $1.12(0.6)$ & $0.22 * * *$ \\
\hline $\operatorname{SOM}(\%)$ & $2.4(0.8)$ & $1.6(0.8)$ & $1.5(0.9)$ & $1.81(0.9)$ & $0.33 * * *$ \\
\hline $\mathrm{N}(\%)$ & $0.08(0.03)$ & $0.05(0.02)$ & $0.04(0.04)$ & $0.06(0.031)$ & $0.01 * * *$ \\
\hline $\mathrm{P}\left(\mathrm{mg} \mathrm{kg}^{-1}\right)$ & $8.1 \quad(9.3)$ & $8.3(6.5)$ & $10.4(10.9)$ & $8.8 \quad(10.8)$ & ns \\
\hline $\mathrm{K}(\mathrm{cmol} / \mathrm{kg})$ & $0.57(0.42)$ & $0.23(0.18)$ & $0.51(0.36)$ & $0.42(0.32)$ & $0.12 * * *$ \\
\hline Clay $(\%)$ & $41.5(10.4)$ & $27.6(11.7)$ & $29.8(11.5)$ & $32.9(12.8)$ & $3.31 * * *$ \\
\hline Silt (\%) & $14.3(4.0)$ & $12.7(6.9)$ & $14.9(8.1)$ & $14.0(6.6)$ & ns \\
\hline Sand $(\%)$ & $44.2(10.4)$ & $59.8(17.5)$ & $55.4(17.8)$ & $53.2(17.0)$ & $4.11 * * *$ \\
\hline
\end{tabular}


Table 2.3: Mean soybean yields observed in each region and year.

\begin{tabular}{|c|c|c|c|c|c|c|c|c|}
\hline & Dowa & & Mchinji & & Salima & & Mean & LSD \\
\hline & $\begin{array}{c}\text { Yield } \\
\left(\mathrm{t} \mathrm{ha}^{-1}\right)\end{array}$ & $n^{1}$ & $\begin{array}{c}\text { Yield } \\
\left(\mathrm{t} \mathrm{ha}^{-1}\right)\end{array}$ & $n$ & $\begin{array}{c}\text { Yield } \\
\left(\mathrm{t} \mathrm{ha}^{-1}\right)\end{array}$ & $n$ & & \\
\hline \multicolumn{9}{|l|}{$\mathrm{NM}$ trial } \\
\hline 2010 & 1.44 & 11 & 1.00 & 10 & 0.43 & 10 & 0.95 & $0.46 * * *$ \\
\hline 2011 & 1.38 & 11 & 1.40 & 12 & 1.63 & 10 & 1.47 & ns \\
\hline mean & 1.39 & 22 & 1.22 & 22 & 1.03 & 20 & 1.22 & \\
\hline $\mathrm{LSD}^{2}$ & ns & & ns & & $0.52 * * *$ & & & \\
\hline \multicolumn{9}{|l|}{$\mathrm{CM}$ trial } \\
\hline 2010 & 0.88 & 10 & 0.96 & 11 & 0.37 & 10 & 0.74 & $0.37 * *$ \\
\hline 2011 & 1.38 & 9 & 1.23 & 12 & 1.70 & 11 & 1.43 & ns \\
\hline mean & 1.11 & 19 & 1.10 & 23 & 1.06 & 21 & 1.09 & \\
\hline LSD & ns & & ns & & $0.40 * * *$ & & & \\
\hline
\end{tabular}

${ }^{1} \mathrm{~N}=$ number of replicate blocks ${ }^{2} \mathrm{LSD}=$ Least significant difference between means, significant at * $P<0.05$, ** $P<0.01$, *** $P<0.001$, ns $=$ not significant. 

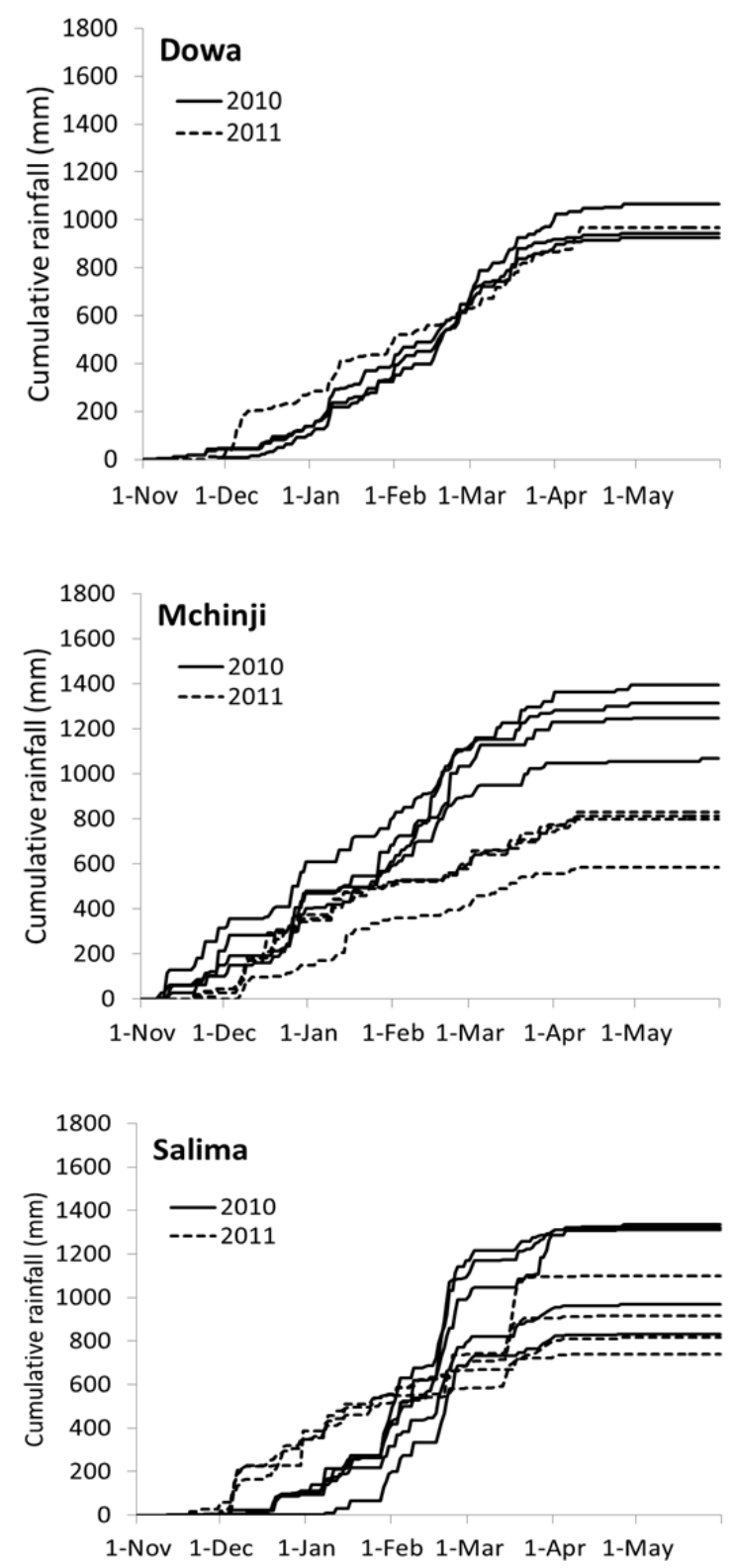

Fig. 2.1: Cumulative rainfall data collected by four farmers in each region in 2010 and 2011. Each line represents the data from a single farmer. 


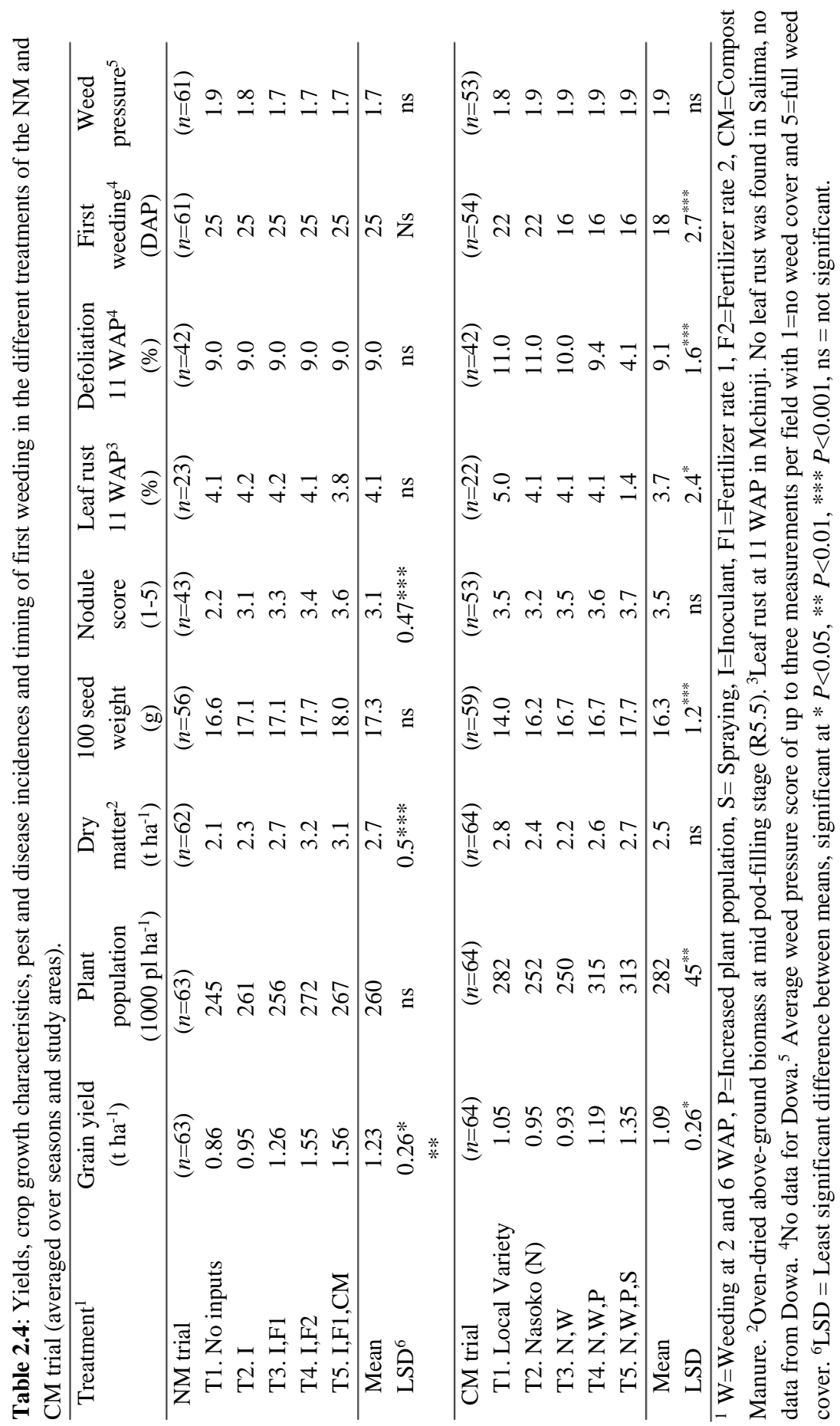


The NM trial yields ranged from $0.43 \mathrm{t} \mathrm{ha}^{-1}$ in Salima 2010 to $1.63 \mathrm{t} \mathrm{ha}^{-1}$ in Salima 2011 (Table 2.3). Yields increased from $0.86 \mathrm{t} \mathrm{ha}^{-1}$ in the control to $1.56 \mathrm{t} \mathrm{ha}^{-1}$ with a combination of inoculation, $100 \mathrm{~kg} \mathrm{ha}^{-1}$ fertilizer and $6 \mathrm{t} \mathrm{ha}^{-1}$ compost manure (Table 2.4). Of this yield increase of $0.70 \mathrm{t} \mathrm{ha}^{-1}, 0.09 \mathrm{t} \mathrm{ha}^{-1}$ could be attributed to inoculation (T2-T1), $0.31 \mathrm{t} \mathrm{ha}^{-1}$ to fertilizer application (T3-T2) and $0.30 \mathrm{t} \mathrm{ha}^{-1}$ to compost manure application (T5-T3). Increasing the fertilizer rate from 100 (T3) to $300 \mathrm{~kg} \mathrm{ha}^{-1}$ (T4) enhanced yields by 0.29 $\mathrm{t} \mathrm{ha}^{-1}$. Compost manure (average $252 \mathrm{~kg} \mathrm{ha}^{-1} \mathrm{OC}, 12.6 \mathrm{~kg} \mathrm{ha}^{-1} \mathrm{~N}, 0.8 \mathrm{~kg} \mathrm{ha}^{-1} \mathrm{P}$ ) had roughly the same effect on the yield as the additional $200 \mathrm{~kg} \mathrm{ha}^{-1}$ inorganic fertilizer $\left(20 \mathrm{~kg} \mathrm{ha}^{-1} \mathrm{~N}, 16\right.$ $\mathrm{kg} \mathrm{ha}^{-1} \mathrm{P}, 40 \mathrm{~kg} \mathrm{ha}^{-1} \mathrm{~K}$ ). Inoculation resulted in better nodulation scores. Increased nutrient inputs resulted in more dry matter accumulation at R5.5 (Table 2.4). The yields for the various nutrient management treatments varied considerably across replicate blocks (Fig. 2.2), but differences between treatments were significant in each region and year except in Salima in 2010.

Soybean yields in the CM trial ranged from $0.37 \mathrm{t} \mathrm{ha}^{-1}$ in Salima in 2010 to $1.70 \mathrm{t} \mathrm{ha}^{-1}$ in Salima in 2011 (Table 2.3). The variety Nasoko (T2) did not give better yields than the local varieties (T1) but Nasoko had a larger grain size (Table 2.4). The 'improved' weeding treatment (T3) did not result in better yields than the farmers' weeding practice (T2) since the average weed pressure scores and the number of weedings recorded in T3 were similar to the farmers' practice. Farmers' first weeding in T1 and T2 was done on average six days later, though still three days earlier than farmers' practice in the NM trials (Table 2.4). It was observed that $40 \%$ of the farmers followed exactly the first weeding date of the field technicians. The increased plant population treatment (T4) resulted in an average yield increase of $0.25 \mathrm{t} \mathrm{ha}^{-1}$. However, an increased plant stand was observed in only $74 \%$ of the sites. In $32 \%$ of the sites, farmers planted 2 lines per ridge in both T3 and T4. Despite this, a yield increase was observed in $82 \%$ of the replicate blocks, while the average plant population increased from 250,000 to 315,000 plants ha $^{-1}$ (Table 2.4). This was less than the intended 400,000 plants per ha-1 due to poor germination, grasshopper damage to emerging plants in Salima, termite damage, and birds removing seeds after planting. Application of Folicure and Cypermethrin (T5) increased yields on average by $0.16 \mathrm{t} \mathrm{ha}^{-1}$. In Salima leaf rust was not observed and spraying was not effective (Fig. 2.2). In Mchinji leaf rust scores were significantly reduced by spraying (Table 2.4). The highest leaf rust incidence was observed in Mchinji in 2010 with an average incidence of $8.0 \%$ at 11 WAP $(n=11)$ and spraying increased yields from 0.86 to $1.47 \mathrm{t} \mathrm{ha}^{-1}$. Though there was some caterpillar damage in all sites and seasons, the percentage of defoliation was unlikely to result in economic loss. 


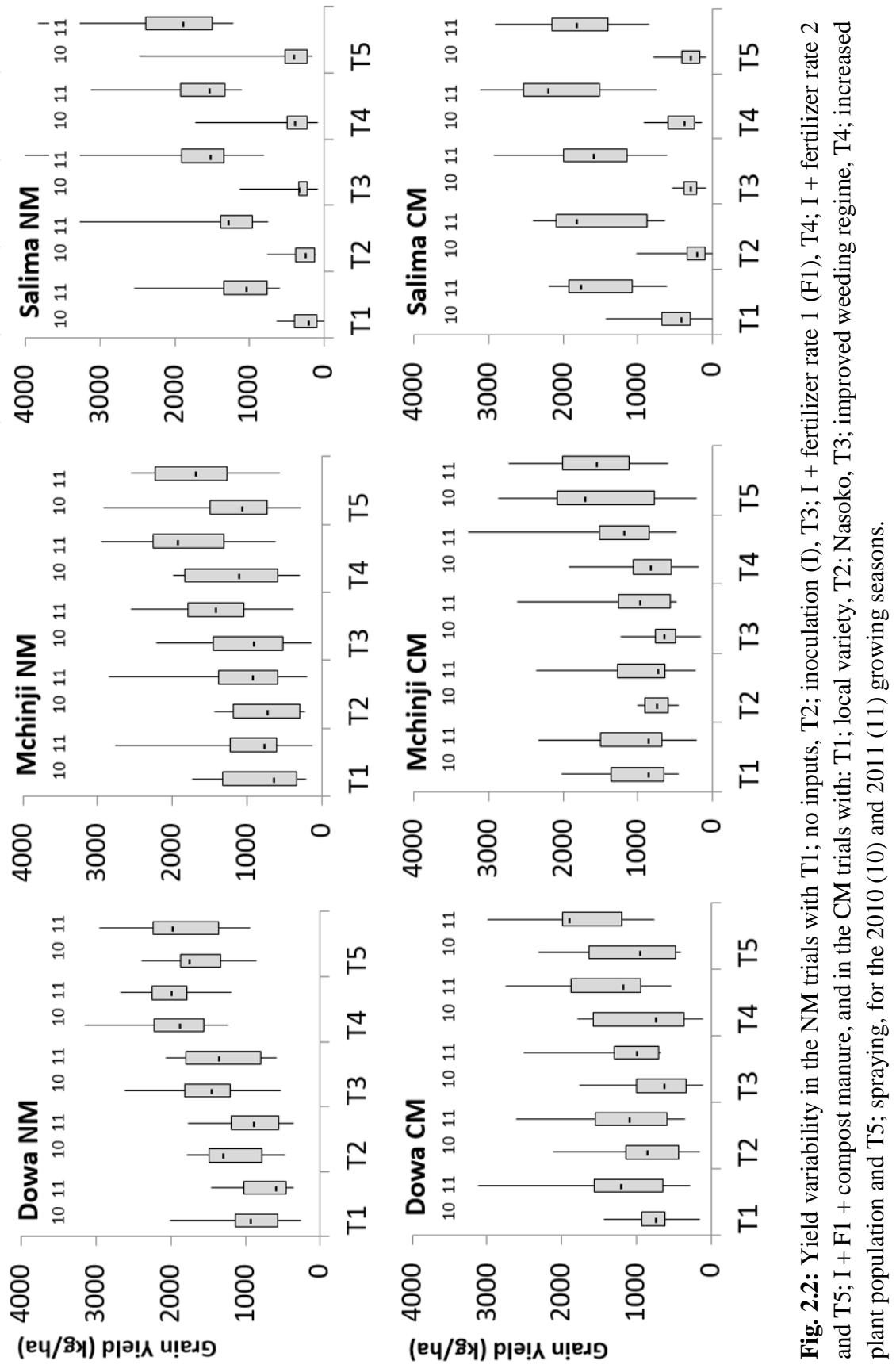




\subsubsection{Partial gross margin analysis}

The investment costs and economic benefits of the technologies tested in the trials varied considerably (Table 2.5). Inoculation was the cheapest technology requiring an investment of only $23 \mathrm{USD} \mathrm{ha}^{-1}$ including transport to the nearest city for procurement. It was profitable with an average VCR $>2$ in both years, though the marginal yields were low resulting in relatively low absolute profits. Fertilizer application was the most expensive technology but resulted in relatively high marginal revenues (Table 2.5). The low VCR for the high fertilizer dose shows that large fertilizer applications are unlikely to be attractive to farmers. The low fertilizer rate $\left(100 \mathrm{~kg} \mathrm{ha}^{-1}\right)$ combined with inoculation was attractive in 2011 (VCR 2.1) but less so in 2010 (VCR 1.3). Yields in 2010 were smaller than in 2011 which also affected the marginal yields and revenues resulting from fertilizer application. The most profitable package in the NM trial was the combination of inoculation, fertilizer rate 1 and compost manure (T5) with a profit of $100 \mathrm{USD} \mathrm{ha}^{-1}$ in 2010 and $339 \mathrm{USD}^{-1}$ in 2011 and a mean

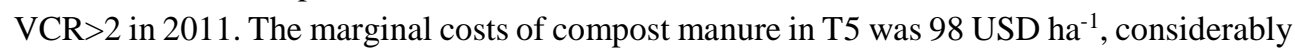
less than the full fertiliser application rate in $\mathrm{T} 4$.

Increasing the plant population resulted in an average VCR $>2$ in all regions and on $40 \%$ of the farmers' fields. The economic benefit was stronger in 2011 (VCR 2.5) than in 2010 (VCR 1.6). Spraying resulted in average VCR $>2$ in Dowa and Mchinji but resulted in economic loss in Salima due to the absence of leaf rust. The largest revenue in the CM trial was obtained in Mchinji in 2010 by spraying with a VCR>2 on $73 \%$ of the fields and a marginal revenue

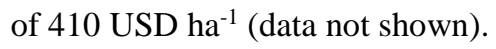

\subsubsection{Farmers' perceptions}

The farmers ranked early planting as the most preferred technology (Table 2.6), even though it was not a treatment in the trials. However, they also recognized that planting too early increases risks of dry spells at the start of the season and fungal infections of the crop at the end of the season when rains continue (Table 2.7).

Technologies tested in the NM trials were ranked relatively low (Table 2.6). Inoculant is not easily available to the farmers, inorganic fertilizer is considered very expensive, and applying compost manure involves high investments in labour and transport in an oxcart (Table 2.7). In Dowa, inoculation was ranked higher than in Mchinji and Salima and even higher than early planting. This may be related to the higher marginal yields and VCR for inoculant compared to the other regions (Table 2.5). Farmers in Mchinji preferred compost manure over inoculant and inorganic fertiliser (Table 2.6). 
Table 2.5: Partial gross margin analysis for the input treatments in the NM trial and increased plant population and spraying in the $\mathrm{CM}$ trial by location and year.

\begin{tabular}{|c|c|c|c|c|c|c|}
\hline & $n$ & $\begin{array}{l}\text { Marginal yield } \\
\left(\mathrm{t} \mathrm{ha}^{-1}\right)\end{array}$ & $\begin{array}{c}\text { Marginal costs } \\
\left(\text { USD ha }^{-1}\right)\end{array}$ & $\begin{array}{l}\text { Marginal revenue } \\
\left(\text { USD ha }^{-1}\right)\end{array}$ & $\mathrm{VCR}^{1}$ & $\begin{array}{c}\text { Sites with } \\
\text { VCR>2 (\%) }\end{array}$ \\
\hline \multicolumn{7}{|c|}{ Nutrient Management (NM) trial } \\
\hline \multicolumn{7}{|c|}{ T2 Inoculant (I) } \\
\hline Dowa & 22 & 0.22 & 28 & 148 & 5.3 & 68 \\
\hline Mchinji & 22 & 0.00 & 20 & -3 & -0.1 & 46 \\
\hline Salima & 20 & 0.13 & 22 & 87 & 4.0 & 65 \\
\hline 2010 & 31 & 0.07 & 21 & 48 & 2.3 & 58 \\
\hline 2011 & 33 & 0.16 & 26 & 105 & 4.1 & 61 \\
\hline Grand total & 64 & 0.12 & 23 & 77 & 3.3 & 59 \\
\hline \multicolumn{7}{|c|}{$\mathrm{T} 3 \mathrm{I}+$ Fertilizer $1\left(100 \mathrm{~kg} \mathrm{ha}^{-1}\right)$} \\
\hline Dowa & 22 & 0.37 & 151 & 248 & 1.6 & 46 \\
\hline Mchinji & 22 & 0.30 & 144 & 200 & 1.4 & 27 \\
\hline Salima & 20 & 0.26 & 139 & 174 & 1.2 & 30 \\
\hline 2010 & 31 & 0.30 & 156 & 198 & 1.3 & 32 \\
\hline 2011 & 33 & 0.55 & 173 & 368 & 2.1 & 52 \\
\hline Grand total & 64 & 0.43 & 165 & 286 & 1.7 & 42 \\
\hline \multicolumn{7}{|c|}{$\mathrm{T} 4 \mathrm{I}+$ Fertilizer $2\left(300 \mathrm{~kg} \mathrm{ha}^{-1}\right)$} \\
\hline Dowa & 22 & 0.93 & 384 & 624 & 1.6 & 27 \\
\hline Mchinji & 22 & 0.55 & 357 & 370 & 1.0 & 14 \\
\hline Salima & 20 & 0.32 & 339 & 212 & 0.6 & 5 \\
\hline 2010 & 31 & 0.57 & 367 & 380 & 1.0 & 10 \\
\hline 2011 & 33 & 0.87 & 391 & 583 & 1.5 & 27 \\
\hline Grand total & 64 & 0.72 & 379 & 485 & 1.3 & 19 \\
\hline \multicolumn{7}{|c|}{ T5 I + F1 + Compost Manure $\left(6 \mathrm{tha}^{-1}\right)$} \\
\hline Dowa & 22 & 0.90 & 257 & 604 & 2.3 & 64 \\
\hline Mchinji & 22 & 0.55 & 234 & 368 & 1.6 & 41 \\
\hline Salima & 20 & 0.63 & 236 & 420 & 1.8 & 40 \\
\hline 2010 & 31 & 0.49 & 226 & 326 & 1.4 & 29 \\
\hline 2011 & 33 & 0.89 & 258 & 597 & 2.3 & 67 \\
\hline Grand total & 64 & 0.70 & 243 & 465 & 1.9 & 48 \\
\hline \multicolumn{7}{|c|}{ Crop Management (CM) trial } \\
\hline \multicolumn{7}{|c|}{ T4 Plant population (relative to T3) } \\
\hline Dowa & 19 & 0.23 & 79 & 157 & 2.0 & 42 \\
\hline Mchinji & 23 & 0.25 & 81 & 169 & 2.1 & 35 \\
\hline Salima & 21 & 0.27 & 81 & 182 & 2.2 & 43 \\
\hline 2010 & 31 & 0.17 & 71 & 112 & 1.6 & 26 \\
\hline 2011 & 32 & 0.34 & 89 & 226 & 2.5 & 53 \\
\hline Grand total & 63 & 0.25 & 80 & 170 & 2.1 & 40 \\
\hline \multicolumn{7}{|c|}{ T5 Spraying (relative to T4) } \\
\hline Dowa & 19 & 0.25 & 73 & 165 & 2.3 & 53 \\
\hline Mchinji & 23 & 0.38 & 89 & 252 & 2.8 & 61 \\
\hline Salima & 21 & -0.15 & 57 & -98 & -1.7 & 14 \\
\hline 2010 & 31 & 0.25 & 76 & 169 & 2.2 & 39 \\
\hline 2011 & 32 & 0.08 & 71 & 51 & 0.7 & 47 \\
\hline Grand total & 63 & 0.16 & 73 & 109 & 1.5 & 43 \\
\hline
\end{tabular}

${ }^{1}$ Value Cost Ratio 


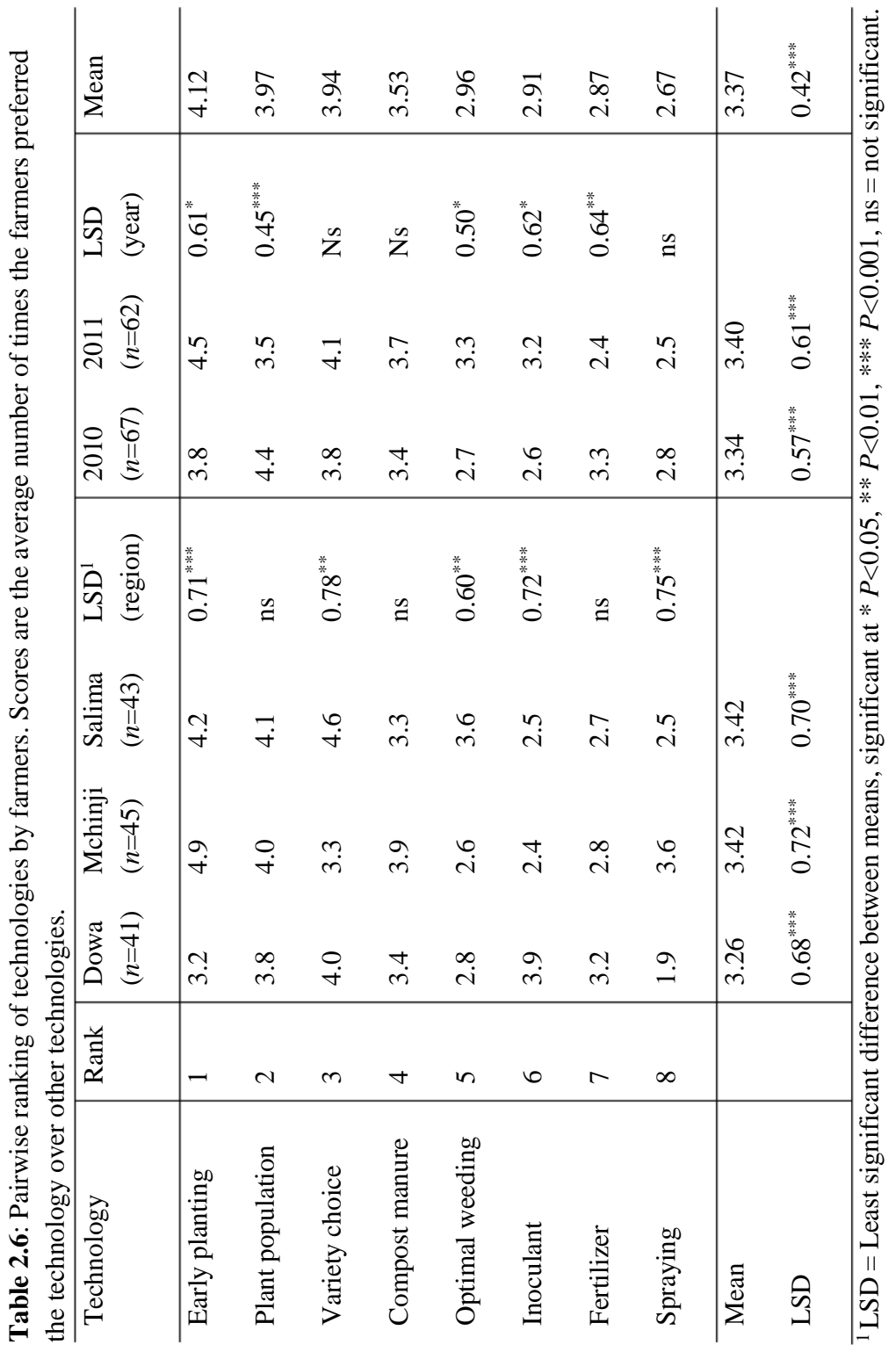


Table 2.7: Advantages and disadvantages of technologies identified by farmers.

\begin{tabular}{|c|c|c|c|c|c|}
\hline Technology & Rank & Advantages & $n^{1}$ & Disadvantages & $n$ \\
\hline \multirow{5}{*}{$\begin{array}{l}\text { Planting } \\
\text { with the first } \\
\text { rains }\end{array}$} & 1 & Good growth & 61 & $\begin{array}{l}\text { Crop can rot at the end of the } \\
\text { season }\end{array}$ & 14 \\
\hline & 2 & High yields & 34 & $\begin{array}{l}\text { Poor germination in case of dry } \\
\text { spell }\end{array}$ & 12 \\
\hline & 3 & Good germination & 22 & Dry spells during early growth & 11 \\
\hline & 4 & The crop is able to mature & 17 & $\begin{array}{l}\text { Grasshoppers eat the emerging } \\
\text { plants }\end{array}$ & 8 \\
\hline & 5 & $\begin{array}{l}\text { The crop can escape } \\
\text { drought }\end{array}$ & 4 & $\begin{array}{l}\text { Farmers are busy planting other } \\
\text { crops }\end{array}$ & 3 \\
\hline \multirow[t]{5}{*}{ Inoculant } & 1 & Ensures good germination & 39 & It is not easily available & 12 \\
\hline & 2 & Good growth & 36 & It requires money & 7 \\
\hline & 3 & Adds nitrogen or fertility & 16 & Poor germination & 4 \\
\hline & 4 & $\begin{array}{l}\text { Crops or seeds not eaten } \\
\text { by insects }\end{array}$ & 15 & $\begin{array}{l}\text { Need to plant the day that you } \\
\text { apply it }\end{array}$ & 3 \\
\hline & 5 & $\begin{array}{l}\text { Crop will not get (root) } \\
\text { diseases }\end{array}$ & 8 & Seed coats get removed & 3 \\
\hline \multirow[t]{4}{*}{ Fertilizer } & 1 & High yield & 59 & It is expensive & 23 \\
\hline & 2 & Good growth & 56 & It damages the soil & 13 \\
\hline & 3 & Good pod set & 11 & It is not easily available & 9 \\
\hline & 4 & The crop grows healthy & 9 & $\begin{array}{l}\text { It does not work during a dry } \\
\text { spell }\end{array}$ & 1 \\
\hline \multirow[t]{6}{*}{$\begin{array}{l}\text { Compost } \\
\text { manure }\end{array}$} & 1 & $\begin{array}{l}\text { Crop grows tall and } \\
\text { healthy }\end{array}$ & 46 & Oxcart expensive or unavailable & 14 \\
\hline & 2 & Adds fertility to the soil & 23 & It can bring insects and weeds & 10 \\
\hline & 3 & Improves soil structure & 14 & Requires much labour & 8 \\
\hline & 4 & Higher yields & 14 & Manure does not perform well & 3 \\
\hline & 5 & Keeps moisture in the soil & 11 & There is a shortage of manure & 3 \\
\hline & 6 & Prevents soil depletion & 5 & & \\
\hline \multirow[t]{7}{*}{$\begin{array}{l}\text { Variety } \\
\text { choice }\end{array}$} & 1 & High yield & 29 & $\begin{array}{l}\text { Lack of knowledge of suitable } \\
\text { variety }\end{array}$ & 6 \\
\hline & 2 & Good germination & 24 & $\begin{array}{l}\text { Needs good management, } \\
\text { inputs, rain }\end{array}$ & 5 \\
\hline & 3 & Good growth & 15 & It is expensive or not profitable & 4 \\
\hline & 4 & $\begin{array}{l}\text { Profitable or easy to } \\
\text { market }\end{array}$ & 12 & It is difficult to find the seed & 3 \\
\hline & 5 & Early maturity & 8 & & \\
\hline & 6 & Good pod set & 8 & & \\
\hline & 7 & $\begin{array}{l}\text { Variety suits the } \\
\text { environment }\end{array}$ & 6 & & \\
\hline
\end{tabular}




\begin{tabular}{|c|c|c|c|c|c|}
\hline Technology & Rank & Advantages & $n^{1}$ & Disadvantages & $n$ \\
\hline \multirow{4}{*}{$\begin{array}{l}\text { Weeding at } \\
2 \text { and } 6 \\
\text { weeks after } \\
\text { planting }\end{array}$} & 1 & Good and healthy growth & 75 & High weed pressure at harvest & 10 \\
\hline & 2 & Clean fields & 15 & High labour requirements & 8 \\
\hline & 3 & Good yield & 11 & $\begin{array}{l}\text { Termite damage in dry } \\
\text { conditions }\end{array}$ & 2 \\
\hline & 4 & No nutrient competition & 5 & Weeding can damage the crop & 1 \\
\hline \multirow{7}{*}{$\begin{array}{l}\text { Planting } 2 \\
\text { lines per } \\
\text { ridge }\end{array}$} & 1 & $\begin{array}{l}\text { High yields from a small } \\
\text { area }\end{array}$ & 99 & Plants don't grow well & 17 \\
\hline & 2 & Higher plant population & 5 & Wind and sun light competition & 15 \\
\hline & 3 & Good pod setting & 2 & Low yields & 10 \\
\hline & 4 & Diseases don't enter easily & 1 & The plants are too close together & 9 \\
\hline & 5 & Easy fertilizer application & 1 & More work during planting & 7 \\
\hline & 6 & & & Weeding is more difficult & 4 \\
\hline & 7 & & & Nutrient competition & 4 \\
\hline \multirow[t]{4}{*}{ Spraying } & 1 & $\begin{array}{l}\text { Crop is protected against } \\
\text { insects and diseases }\end{array}$ & 82 & Chemicals are hard to find & 13 \\
\hline & 2 & Good and healthy growth & 33 & $\begin{array}{l}\text { Chemicals can damage the crop } \\
\text { or soil }\end{array}$ & 9 \\
\hline & 3 & High yields & 7 & The activity requires money & 6 \\
\hline & 4 & The leafs don't drop & 2 & Chemicals are expensive & 6 \\
\hline
\end{tabular}

${ }^{1} \mathrm{n}=$ the number of times the advantage or disadvantage is mentioned 
Increasing the plant population received the highest ranking after early planting (Table 2.6), though farmers mentioned higher labour requirements and competition for water and nutrients as constraints (Table 2.7). Variety choice in general was ranked highly, though not specifically in favour of the variety Nasoko. Disadvantages are the high costs, limited access to certified seeds and limited knowledge of suitable varieties (Table 2.7). Optimal weed management was considered significantly more important in Salima than in the other regions. This agreed with our observed high frequency of weeding in Salima in 2011. Spraying was the least favoured technology due to difficult access to chemicals and high costs (Table 2.7). Only in Mchinji, where leaf rust incidence was high, farmers considered spraying as an important option (Table 2.6).

\subsection{Discussion}

\subsubsection{Trial design and implementation}

The treatments were chosen to increase management or input intensity in a stepwise fashion, and this proved to be a suitable method to test and evaluate a set of technologies in a limited number of treatments together with farmers. The small number of treatments allowed a large number of farmer replications, which was needed to capture a representative sample of the highly variable conditions in farmers' fields. A limitation of this trial design, however, is that some of the technologies are only tested in combination with others, and not as stand-alone treatments that can be compared directly with farmers practice. For example, in T3 in the $\mathrm{NM}$ trial, the combined inoculum and fertilizer application may have given synergistic effects, as increased availability of $\mathrm{P}$ can stimulate nitrogen fixation and the response to inoculation. The yield response to fertilizer without inoculants may be weaker. Similarly, the impact of fungicide spraying (T5) in the CM trial may be weaker with lower plant populations. Further, interactions between crop management and nutrient management treatments in the two trials could not be assessed with the current design.

\subsubsection{Soybean performance across regions and years}

The average farmers' practice yield for variety Nasoko was $0.86 \mathrm{t} \mathrm{ha}^{-1}$ (Table 2.4) which is comparable to the national average of $0.88 \mathrm{t} \mathrm{ha}^{-1}$ in 2003-2014 (FAO, 2016). Current global soybean yields are about $2.5 \mathrm{t} \mathrm{ha}^{-1}$ (Ray et al., 2013) and are predicted to increase to about $3.0 \mathrm{t} \mathrm{ha}^{-1}$. Observed average yields in the most intense treatment of the NM trial (T5: inoculant, fertiliser and compost manure) and the CM trial (increased plant population and spraying treatment) equalled 1.6 and $1.4 \mathrm{t} \mathrm{ha}^{-1}$, far less than the global averages. Combining the treatments from the NM and CM trials may have resulted in higher yields. Moreover, multiple production constraints likely interact to determine yields on smallholder farmers' fields (Fermont et al., 2009). This is evident from the large variability in yield among farmers' replicate blocks (Fig. 2.2). Some blocks achieved yields of over $3 \mathrm{t} \mathrm{ha} \mathrm{h}^{-1}$ 
demonstrating the potential for smallholders to achieve high yields when constraints are addressed simultaneously.

Soybean productivity was influenced by factors that varied among regions and years. Better soil fertility perhaps gave farmers in Dowa an advantage over the other regions (Table 2.2), but delays in planting probably caused yield reductions. In Salima, erratic rainfall distribution, grasshopper attacks and fast growth of weeds suppressed yields in the first season. Because of these unfavourable growing conditions, none of the technologies were economically interesting in Salima in 2010. In the second season, more motivated farmers, better weed control and equal rainfall distribution resulted in relatively large yields (Table 2.3), despite the poorer soil fertility in Salima compared with Dowa. Mchinji experienced better rainfall in the first season (Fig. 2.1) but yields were suppressed by leaf rust. In the second season, leaf rust pressure was less, resulting in better yields despite the lower rainfall. In short, a combination of soil characteristics, rainfall distribution, time of planting, time and frequency of weeding, leaf rust incidence, grasshopper damage, and the experience and motivation of farmers and technicians all influenced soybean productivity, though the exact contributions of each of these factors cannot be quantified.

\subsubsection{Evaluation of technologies}

A combination of inoculation, inorganic fertiliser application and compost manure resulted in significant yield increases (Table 2.4) and was profitable (Table 2.5). The yield responses to these inputs would most likely be even higher if the choice of weed management, seed rate, planting date and pest and disease control were not left to farmers' preferences. Inoculation is a cheap and generally profitable technology (Table 2.5), yet farmers do not know where it can be procured and they struggle to grasp the concept of biological nitrogen fixation. These may be reasons for the low ranking of inoculant by farmers (Table 2.6). Private sector involvement in the development, registration and marketing of high quality inoculants may improve opportunities for uptake of this technology in the future. An alternative approach to ensure effective $\mathrm{N}_{2}$-fixation is to grow promiscuous soybean genotypes that nodulate with indigenous bacteria in the soil (Mpepereki et al., 2000), though also these genotypes may still benefit from inoculation (Pule-Meulenberg et al., 2011).

Farmers prefer not to apply fertilizer to soybean, despite the observed yield response. This seems justified given the high investment costs, low VCR (Table 2.5), and preference of farmers to allocate resources to maize and cash crops such as cotton and tobacco. A study in Kasungu District (Kamanga et al., 2010b) showed a soybean yield response of $0.5 \mathrm{tha}^{-1}$ as a result of $20 \mathrm{~kg} \mathrm{P} \mathrm{ha}^{-1}$ applied as triple super phosphate (TSP), indicating that P-based fertiliser applications in soybean can be profitable. Research in north east Zimbabwe showed that on more fertile soils the economic potential of targeting manure and $\mathrm{P}$ fertilizer to soybean is larger than targeting it to maize in the rotation (Zingore et al., 2008). An alternative strategy 
to improve soil $\mathrm{P}$ status could include the use of local rock phosphate (Wendt and Jones, 1997). In the past, uptake of technologies such as fertilizer and hybrid maize seeds in Malawi depended strongly on subsidies, since these inputs are otherwise not affordable to most rural households (Carr, 1997; Chirwa, 2005).

Compost manure was preferred over inorganic fertiliser by farmers (Table 2.6) since it can be made on-farm with main costs being household labour and transport of manure to the field. However, the quantity of manure that can be produced in-situ is limited and there are often alternative, competing uses of crop residues, e.g. for animal feed or mulching (Giller $e t$ $a l ., 2009)$. Soybean residues are more likely to be used for compost since soybean is threshed at the household, whereas maize residues usually remain in the field. The nutrient concentrations in the compost used in this study $(4.2 \% \mathrm{C}, 0.21 \% \mathrm{~N}$ and $0.013 \% \mathrm{P}$ ) were low though typical of the farmers' situation. Despite the fact that the additional $200 \mathrm{~kg} \mathrm{ha}^{-1}$ mineral fertiliser (NM-T4) contained more NPK than the $6 \mathrm{t} \mathrm{ha}^{-1}$ compost manure (NM-T5), the yield response was comparable. Compost manure probably gave additional benefits such as impacts on the crop water balance or nutrients other than NPK (Steiner et al., 2007). Breeding efforts have significantly increased soybean yield potential over the last decades in sub-Saharan Africa (Tefera et al., 2009). Farmers perceived variety choice as an important production factor, despite the fact that Nasoko did not outperform the local varieties (Table $2.4 \&$ 2.6). Farmers evaluating the CM trial were aware of the importance of weeding (Table $2.6 \& 2.7$ ) and their weed management practices were quite similar to the proposed improved weeding regime. Precise recommendations on weeding dates and frequencies may not be suitable since the optimum timing of weeding is determined by various factors such as weed pressure, rainfall, termites, fertilizer use and labour supply (Kamanga et al., 2013; Orr et al., 2002; Dimes et al., 2001). Research in western Kenya showed that one instead of two weeding operations reduced soybean yields with $5 \%$, while reducing total labour costs for production by 36\% (Vandeplas et al., 2010) indicating there is more to consider than yields only. Increasing the plant population improved yields and resulted in economic benefits (Table $2.4 \& 2.5$ ), while the additional costs were small (Table 2.1). Since farmers prefer to maintain the $90 \mathrm{~cm}$ ridge spacing used in maize in the rotation, sowing two lines on each ridge is a better approach to increase plant population than reducing ridge spacing. Soybean leaf rust is a serious threat to the future of soybean farming in sub-Saharan Africa (Kawuki et al., 2003). The yield response to spraying Folicur (tebuconazole) at 7 and 11 WAP in Mchinji and Dowa where leaf rust was present is a significant finding, especially in case the leaf rust epidemic will spread further. In this study leaf defoliation by insects was low, and we can assume the yield response to spraying was mainly due to leaf rust control.

Early planting, despite not being a treatment in the trials, was ranked by farmers as the most important practice to ensure good yields (Table 2.6) by reducing the risk of drought stress at 
flowering and pod filling (Doss et al., 1974; Dogan et al., 2007). However, farmers usually plant crops such as maize, tobacco and cotton first, resulting in delayed planting of soybean.

\subsection{Conclusions}

Through farmer participatory research, we could identify economically viable and farmer acceptable methods to increase soybean productivity. While variability in yield within treatments among farmers was high, some plots gave yields of more than $3 \mathrm{t} \mathrm{ha}^{-1}$. This confirms that a wide gap exists between farmers' current yields in Malawi $\left(0.88 \mathrm{t} \mathrm{ha}^{-1}\right)$ and what is attainable if limiting constraints are addressed. While the application of mineral fertilizer helped to increase yield, farmers preferred to apply compost manure, due to the high investment costs and low VCR of mineral fertilizer, and farmers' preference to allocate resources to maize and cash crops. Inoculation of soybean seeds led to modest yield increases, but was the cheapest and most cost-effective technology with a VCR > 2 on 59\% of the farms. Its adoption is limited by the poor availability of quality inoculants. Increasing plant population was a relatively cheap and effective way to increase yields, without the use of fertiliser inputs, and was highly ranked by farmers. Fungicide spraying was found to be a cost effective technology to increase yield under smallholders' conditions when leaf rust was present. Limited purchasing power, awareness of farmers, access to inputs, the role of soybean in the cropping system, labour availability and risks associated with variability in yield responses to technology are important factors emerging from the participatory research approach that should be considered in the development of crop management recommendations.

\section{Acknowledgements}

The lead author thanks the Dutch Ministry of Foreign Affairs for funding his position at the International Institute of Tropical Agriculture (IITA) during which the research was conducted. Thanks to IITA for operational funds and to HAS University of Applied Sciences for providing time to write up this paper. This research would not be possible without all the feedback from the participating farmers in Dowa, Mchinji and Salima and the assistance of the field technicians. 


\section{Chapter 3}

Understanding variability in the benefits of $\mathrm{N}_{2}$-fixation in soybeanmaize rotations on smallholder farmers' fields in Malawi

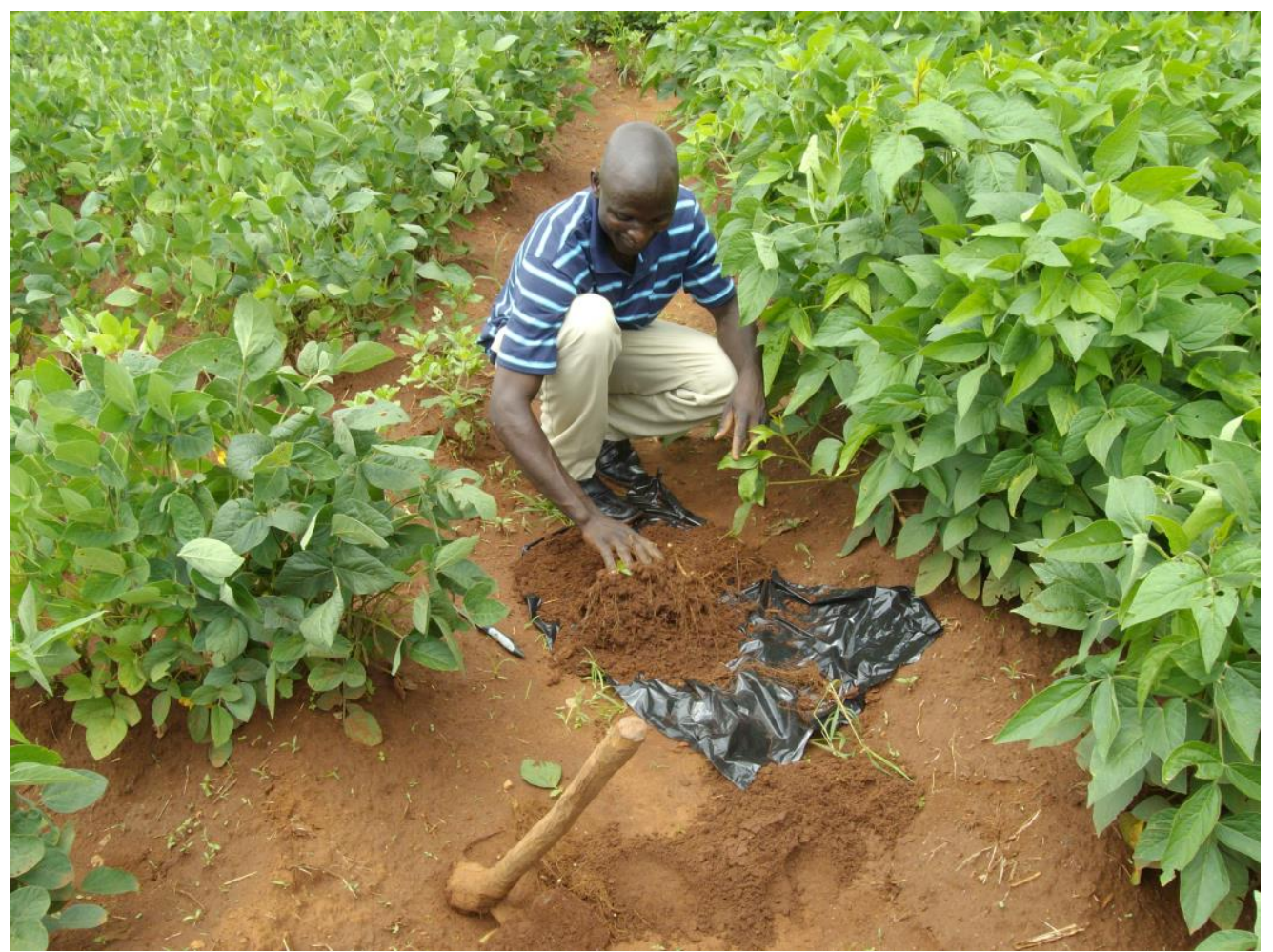

This chapter is published as:

Van Vugt, D., Franke, A.C., Giller, K.E., 2018, Understanding variability in the benefits of $\mathrm{N}_{2}$-fixation in soybean-maize rotations on smallholder farmers' fields in Malawi.

Agriculture, Ecosystems and Environment 261, 241-250. 


\begin{abstract}
Soybean production can contribute to the nitrogen economy of smallholder farming systems, but our understanding of factors explaining variability in nitrogen fixation and rotational benefits across farms and regions is limited. Biological nitrogen fixation (BNF) was quantified with the natural abundance method in 150 farmer-managed soybean plots under different varieties and inputs in Dowa, Mchinji and Salima districts of Malawi. Soybean yielded on average $1.2 \mathrm{t} \mathrm{ha}^{-1}$ grain and the above-ground biomass at mid pod filling (R5.5) was $2.8 \mathrm{t} \mathrm{ha}^{-1}$ and contained in total $63 \mathrm{~kg} \mathrm{ha}^{-1}$ nitrogen derived from the atmosphere (Ndfa). Locally sourced varieties obtained a larger $\% \mathrm{Ndfa}(65 \%)$ than the 'improved' variety Nasoko (53\%). The \%Ndfa was positively associated with soil sand content, sowing date, plant population and biomass accumulation, but it was not affected by inoculation with rhizobia or the combination of inoculation and NPK fertiliser application. Quantities of $\mathrm{N}_{2}$ fixed differed between regions and years, and was enhanced by applying inoculant and fertiliser together, leading to more biomass accumulation and larger grain yields. Soil available $\mathrm{P}$ and exchangeable $\mathrm{K}$ contents also increased the total amount of $\mathrm{N}_{2}$ fixed. In a related trial, continuous maize yields were compared with maize following soybean in 53 farmer-managed fields. Average yield in continuous maize was $2.5 \mathrm{t} \mathrm{ha}^{-1}$, while maize after soybean produced $3.5 \mathrm{t} \mathrm{ha}^{-1}$ (139\% of continuous maize). Farmers with higher maize yields, who applied external nutrient inputs, and with a larger value of household assets achieved greater yield responses to rotation with soybean. A relative yield increase of more than $10 \%$ was observed on 59, 90 and 77\% of the fields in Dowa, Mchinji and Salima respectively. We conclude that fields of soybean and maize that receive adequate nutrient inputs and good management to ensure good yields benefit most in terms of quantities of $\mathrm{N}_{2}$ fixed by the legume and the yield response of the following maize crop. The results suggest that the promotion of soybeanmaize rotations should be done through an integrated approach including the promotion of appropriate soil and crop management techniques. Furthermore, they suggest that wealthier households are more likely to apply adequate nutrient inputs and good crop management practices and are likely to receive larger maize yield responses to the incorporation of soybean.
\end{abstract}

Keywords: Natural abundance method, crop rotation, nitrogen fixation, soil fertility, yield variability 


\subsection{Introduction}

In southern Africa, maize is the most dominant crop and is produced on $47 \%$ of cultivated land (FAO, 2014). It is the main crop for smallholder farmers who constitute the majority of the rural population and depend mainly on rain fed agriculture for food and income generation. In 2011 the average smallholder landholding size in Malawi was 0.8 hectares and over $80 \%$ of this land was cultivated with maize (IFAD, 2011). Fertiliser use is highly variable among African smallholder farmers, but generally resource constrained farmers apply few external inputs, which leads to poor yields and nutrient depletion (Vanlauwe and Giller, 2006; Waddington et al., 2004). As a result nitrogen is widely limiting and farmers find themselves in a poverty trap where increasing nutrient and organic matter depletion may eventually result in non-responsive degraded soils (Tittonell and Giller, 2013). Increasing the share of legumes can contribute to sustainable intensification of maize-based cropping systems by enhancing the input of abundantly available atmospheric $\mathrm{N}_{2}$ through biological nitrogen fixation (BNF) (Mhango et al., 2013). Legumes fix on average 30-40 kg of $\mathrm{N}_{2}$ for every ton of shoot dry matter produced and can contribute to improved soil fertility and enhanced yields of a subsequent cereal crop (Peoples et al., 2009). Crop diversification with legumes can better meet caloric and protein needs of farm households if farmers adopt species that perform well under variable rainfall patterns (Snapp et al., 2014). Legumes also provide nutritional benefits through the addition of proteins to starch-based diets (Bezner Kerr et al., 2007). There is scope for enhancing productivity of edible and marketable grain legumes (Mhango et al., 2013) such as soybean (Glycine max (L.) Merril.) for the expanding market in southern Africa for livestock feeds, edible oils and human foods (Tichagwa and Rusike, 2009). Soybean fixes on average approximately 50-60\% of its nitrogen (Hardarson and Atkins, 2003; Salvagiotti et al., 2008) though ranges of 9 to $91 \%$ have been reported (Franke et al., 2018).

Challenges to increase the area under legumes in southern Africa include high labour costs associated with legume cultivation, poor yields (Waddington and Karigwindi, 2001; Franke et al., 2014) and poor access to quality seed, inputs and output markets (Mtambanengwe and Mapfumo, 2009; Snapp et al., 2002). Farmers usually prioritise maize above legumes as maize yields and returns to labour are often better. However, including soybean into the cropping system can become attractive when the rotational benefits to maize in terms of yield, food security and profitability are considered (Franke et al., 2014). This is especially the case if good productivity of the legume can be assured through good management practices such as the application of inoculants, inorganic fertiliser or compost manure (Hati et al., 2006; Ndakidemi et al., 2006; Van Vugt et al., 2017). The amounts of nitrogen fixed may vary across different agro-ecological zones (Ojiem et al., 2007). On poor degraded soils, manure application can enhance nitrogen fixation (Zingore et al., 2008). The percentage of nitrogen derived from the atmosphere $(\% \mathrm{Ndfa})$ can be reduced by nitrogen fertiliser application 
(Hardarson and Zapata, 1984; Salvagiotti et al., 2008) and soil water deficits (Sinclair et al., 2007). Self-nodulating promiscuous types of indeterminate soybean can fix more nitrogen than high harvest index grain type varieties (Snapp et al., 1998) due to their longer growing period and better ability to nodulate with indigenous Bradyrhizobium strains in the soil (Mpepereki et al., 2000). Therefore, when seeds are not inoculated, promiscuous soybean varieties tend to confer a larger residual benefit on the following maize crop than specific varieties (Kasasa et al., 1999). However, farmers often prefer shorter duration grain-type varieties as they give quicker returns on investments (Snapp and Silim, 2002; Adjei-Nsiah et al., 2008).

Nitrogen fixation, the yield performance of legumes and the residual benefits to a following cereal crop depend on a range of environmental and crop management factors which in turn are a reflection of farmers' socio-economic conditions. Smallholder farming systems are very heterogeneous in biophysical and socio-economical characteristics (Ojiem et al., 2006) and agronomic research is often not adapted to include this variability when identifying options to enhance productivity (Vanlauwe et al., 2016). While legumes are well known to fix $\mathrm{N}_{2}$ and improve yields of subsequent cereals in SSA, a high variability across smallholder farmers in socio-economic and biophysical conditions implies these benefits are also highly variable. We are unaware of studies in SSA that quantify and attempt to explain the variability in BNF by soybean and maize yield response to crop rotation across a wide range of smallholder farmers' fields. This is however crucial for improved tailoring of legume-based technologies to those farmers where impact is likely to be largest. Therefore, this study aims to quantify and understand the variability and factors behind BNF and rotational effects of including soybean in maize-based rotations, based on a large number of farmer-managed trials in central Malawi.

\subsection{Materials and methods}

\subsubsection{Trial lay-out and treatments}

On-farm experiments were conducted in Dowa, Mchinji and Salima districts (also referred to as regions) in central Malawi in the 2009/10 and 2010/11 growing seasons, in this study referred to as the 2010 and 2011 seasons respectively. Central Malawi has a uni-modal rainfall distribution with rains starting early December and continuing for four months. Long term precipitation averages are in the range of 900-950 mm per year (Hijmans et al., 2005). A nutrient management (NM) trial and a crop management (CM) trial was established with 12 treatment blocks for each trial in each region in each year giving a total of 72 blocks per trial. Farmers hosted a single replicate block of one of the trials with five non-randomly assigned treatments. In the NM trials inoculant, fertiliser and compost manure treatments were assigned to five plots of 10 by $10 \mathrm{~m}$. The CM trials consisted of five plots with variety, weed management, plant population, and pest and disease control treatments. In Dowa 
district, trials were established around Msakambewa trading centre $\left(13^{\circ} 33^{\prime} \mathrm{S}, 33^{\circ} 54^{\prime} \mathrm{E}\right)$ at 1200-1400 meters above sea level (masl), in Mchinji around Kachamba village $\left(13^{\circ} 44^{\prime} \mathrm{S}\right.$, $\left.33^{\circ} 20^{\prime} \mathrm{E}\right)$ at an altitude of 1050-1150 masl and in Salima around Chitala research station $\left(13^{\circ} 40^{\prime} \mathrm{S}, 34^{\circ} 15^{\prime} \mathrm{E}\right)$ at $550-650$ masl. The major soil types in Dowa and Mchinji are Chromic luvisols and in Salima Eutric cambisols. For a more detailed description of the NM and CM trials, see Chapter 2 .

In this study we use data collected from a subset of the treatments and farmers participating in the NM or CM trial. To assess BNF for different varieties and input levels, five blocks from the twelve replicate blocks per region per year were selected from each trial, resulting in a total of 60 blocks ( 5 blocks x 3 regions x 2 years x 2 type of trials; 30 blocks assessed in each trial), hosted by 56 farmers (four farmers in Mchinji hosted a trial block in both years). BNF data were collected from the following treatments:

- $\quad$ T1 $(n=30)$ inoculated soybean seed of unknown variety procured from local markets in each region

- $\quad$ T2 $(n=30)$ variety Nasoko without any inputs

- $\quad$ T3 $(n=60)$ variety Nasoko with inoculation

- $\quad$ T4 ( $n=30)$ variety Nasoko with inoculation and application of $300 \mathrm{~kg} \mathrm{ha}^{-1}$ compound fertiliser Super D containing 10\% N, $8 \%$ P and 20\% K.

Nasoko is a commonly grown, specifically-nodulating variety that, unlike more 'promiscuous' varieties that can effectively nodulate with a large diversity of indigenous rhizobia in the soil (Giller et al., 2011), needed to be inoculated. The applied inoculant was manufactured at the Soil Productivity Research Laboratory, Marondera, Zimbabwe and contained the Bradyrhizobium japonicum strain MAR 1491 (Giller et al., 2011). T1 was a treatment in the CM trials, T2 and T4 in the NM trials, and T3 in both trials. We refer to this set of treatments in which we assessed BNF as the 'BNF trial' and since we use a flexible linear mixed model (REML) tool for analysis we can still analyse this unbalanced design with treatments that were done at different farms. Apart from the described treatments, farmers were free to manage the trial plots according to their own preferences.

To assess the residual benefits of soybean on subsequent maize crop 53 farmers (17 in Dowa, 19 in Mchinji and 17 in Salima) participated in a crop rotation trial. These farmers all hosted a trial with a treatment plot 'Nasoko with inoculation' in 2010, but only 21 of these plots (7 in Dowa, 9 in Mchinji and 5 in Salima) were also part of the BNF trial. Soybean did not receive any external nutrient inputs. In 2010 farmers typically produced maize on a field near the soybean plot on a similar soil type. At the start of the 2011 season a plot of 10 by 10 meters was demarcated on this field previously cultivated with maize. All farmers subsequently sowed their own maize seeds on both plots, resulting in a soybean-maize 
rotation (SM) and a continuous maize (MM) treatment. Farmers were instructed to plant both maize plots on the same day and apply their common crop husbandry practices and inputs. This trial is referred to as 'rotation trial' in this study.

\subsubsection{Data collection}

Daily rainfall was collected by a field technician and three farmers in each region. Composite soil samples $(0-20 \mathrm{~cm})$ were collected in the BNF trial by taking five subsamples from each block. Samples were mixed, air-dried, crushed and sieved through a 2-mm sieve and analysed at IITA-Malawi and Chitedze Research Station for soil organic carbon (SOC) (WalkleyBlack), available $\mathrm{P}$ (Bray-1), soil $\mathrm{pH}\left(\mathrm{CaCl}_{2}\right)$, exchangeable $\mathrm{K}$ (Mehlich 3 method) and texture. In 2011 soil samples were collected from the two maize plots of the rotation trial and analysed for SOC, available $\mathrm{P}$ and soil $\mathrm{pH}$ following the same methods.

Farmers' practices in the BNF trial recorded by field technicians included actual sowing and weeding dates, the number of ridges and their spacing, the number of rows sown per ridge and the number of plants counted on two selected ridges in each plot at 3 weeks after sowing (WAS). Weed pressure was scored visually from 1 ( $<10 \%$ of the plot surface covered with weeds) to 5 ( $>90 \%$ of the plot surface covered with weeds) at 5, 8 and 11 WAS. Aboveground biomass samples of soybean were collected in the two seasons in all plots in the BNF trial at R5.5 (mid pod filling) growth stage. Sub-samples from three quadrants of $0.5 \times 0.5 \mathrm{~m}$ were combined into one composite biomass sample per plot. Broad-leaved weed species were sampled as reference plants from unfertilized un-weeded soybean plots or from border margins in case the plots were all weeded. The weed species sampled in Dowa were Ageratum conyzoides (11 fields) and Leucas martinicensis (7 fields), in Mchinji Bidens pilosa (all fields) and in Salima Bidens pilosa (13 fields), Bothriocline laxa (5 fields) and Leucas martinicensis (1 field). The 150 soybean and 60 broadleaved weed samples were oven-dried until constant weight and ground to powder with an electric mill. They were weighed at $7 \mathrm{mg}$ on a microbalance, stored in tin capsules, and analysed for nitrogen content (\%) and $\delta^{15} \mathrm{~N}$ at the UC Davis Stable Isotope Facility using a continuous flow isotope ratio mass spectrometer. The ${ }^{15} \mathrm{~N}$ natural abundance method was applied to estimate nitrogen fixation (Unkovich, 2008). The percentage of nitrogen derived from the atmosphere (\% Ndfa) was calculated using the formula $\% N d f a=\left(\left(\delta^{15} N_{r e f}-\delta^{15} N_{f i x}\right) /\left(\delta^{15} N_{r e f}-B\right)\right) \times 100$, where 'ref' are non-fixing and 'fix' are nitrogen fixing plants grown under the same conditions, and $B$ is the $\delta^{15} \mathrm{~N}$ of the $\mathrm{N}_{2}$-fixing plant grown with $\mathrm{N}_{2}$ as the sole external nitrogen source. The $B$ value for soybean used was -2.00 (Ojiem et al., 2007; Boddey et al., 2000). The formula $g N d f a=N$ yield $\times \% N d f a / 100$, was then used to calculate the amount of nitrogen fixed per ha based on the nitrogen content in the samples and the total dry biomass accumulated per ha at the time of sampling. The ${ }^{15} \mathrm{~N}$ natural abundance method only works if the $\delta^{15} \mathrm{~N}$ of the legume falls between the ' $B$ '-value and the $\delta^{15} \mathrm{~N}$ of the reference plant. Plots for which this 
condition was not met were excluded from further analysis. At crop maturity, plots were harvested excluding the outer ridges and the $1.5 \mathrm{~m}$ ridge-length from which the biomass subsamples were collected. Harvested plants were threshed and weighed, and a sub-sample of the grain was taken from each plot to assess moisture content. Yields were adjusted to $13 \%$ grain moisture content. Biomass is presented as above-ground dry matter weight. Socioeconomic characteristics including gender, age, arable land area (ha), available family labour (ME), value of assets (USD) and livestock ownership (LU) were collected through structured interviews with farmers participating in all soybean trials as explained in Chapter 2.

In the second season of the rotation trial (2011), structured questionnaires were conducted with all participating farmers to record input application and agronomic practices in the maize plots in the two seasons. The method of data collection in the 53 soybean plots in the first season was similar to the BNF trial, except that in the rotation trial oven-dried biomass samples were only analysed for nitrogen content $(\%)$ and $\delta^{15} \mathrm{~N}$ in the 21 plots that also formed part of the BNF trial. At maize maturity in 2011, both plots were entirely harvested and maize was dried, shelled and kept in $50 \mathrm{~kg}$ bags at the household until the technician came to weigh the grain. Therefore, this study presents maize yields measured under storage conditions with an estimated moisture content of 12 to $15.5 \%$.

\subsubsection{Data handling and analysis}

Linear mixed model (REML) analysis was used to test the effects of treatments in the BNF trials on $\delta^{15} \mathrm{~N}, \% \mathrm{Ndfa}$, total $\mathrm{N}_{2}$ fixed $\left(\mathrm{kg} \mathrm{ha}^{-1}\right)$ and grain yield $\left(\mathrm{t} \mathrm{ha}^{-1}\right)$, while testing for interactions between treatments, years and regions. Similar analysis was done to assess the effect of region on maize yields and the yield response to crop rotation with soybean. Since average values are not very informative due to large variability in responses across farms we presented data in cumulative frequency curves (Vanlauwe et al., 2016). The next step was to explore which factors contributed to the variability in the dependant variables $\% \mathrm{Ndfa}$, total $\mathrm{N}_{2}$ fixed, soybean yields, maize yields and yield responses. To avoid erratic model outputs due to collinearity, independent variables were associated with the dependant variables in separate analyses. REML is a flexible tool for analysis that can include unbalanced and categorical data and can be used to compensate for confounding factors and was used in similar studies to explain variability (Franke et al., 2016; Ronner et al., 2016). We included region and/or year as random factors in the model when they affected the dependant variable $(\mathrm{p}<0.05)$. Continuous independent variables in the fixed model included sowing date, first weeding date, weed pressure score (1-5), plant population density, biomass accumulation, plant height, soybean grain yield, soil texture, soil $\mathrm{OC}, \mathrm{P}, \mathrm{K}$ and $\mathrm{pH}$ and the socioeconomic characteristics arable land area, age of farmer, available family labour, value of assets and livestock ownership. Categorical factors included gender, external nutrient input (yes/no), improved maize variety (yes/no) and crop residue management (compost, incorporation in 
the soil, burnt). Input levels in maize were determined through questionnaires resulting in rough estimates of quantities of urea $(46 \% \mathrm{~N})$ and/or NPS $(23: 21+4 \mathrm{~S})$ applied per hectare. Since we could not assign reliable quantities of $\mathrm{N}$ and $\mathrm{P}$ to each field we included input level as a categorical factor (with or without inputs) in the REML. We used Spearman's Rank Correlations test to determine if the effect of a continuous independent variable on the dependent variable was positive or negative. In the 21 sites where the BNF and rotation trials overlapped, we also tested for correlations between soybean yield components and $\mathrm{N}_{2}$ fixation data and the following maize yields and yield responses to rotation. All statistical analysis were done using Genstat $18^{\text {th }}$ edition.

\subsection{Results}

\subsubsection{Socio-economic and biophysical characteristics of the farmers}

The 83 farmers who participated in the trials had different socio-economic and biophysical characteristics (Table 3.1). In Dowa a larger percentage of women hosted a trial and the households were poorer in terms of the value of assets, since field technicians in Dowa targeted vulnerable female farmers, while in the other districts a more random selection of farmers was made. In Salima participating farmers were relatively young and families had less labour available than in the other regions. Farmers in Mchinji kept more livestock. Soils in Dowa contained more OC, while in Salima soil $\mathrm{pH}$ was higher and more favourable for crop growth. There was a large variability in soil available $\mathrm{P}$ content within each region. Soil properties in soybean-maize plots were not different from the continuous maize plots in any of the three regions (data not shown). Rainfall was more than the 50-year average in both seasons except for Mchinji in 2011. In Salima in 2010 over $80 \%$ of the total rain fell in February. Daily rainfall data in the three regions during the trials are presented in Chapter 2.

\subsubsection{BNF trial}

\subsubsection{Farmers' practices and yields}

The BNF trial plots were established on average 20 days after the first effective sowing rains, though differences in the onset of the rains between years and regions, and in farmers' practices resulted in a wide range of sowing dates (Table 3.2). Fields in Dowa had larger plant populations compared with Mchinji and Salima. Mean soybean grain yields were 1.47 $\mathrm{t} \mathrm{ha}^{-1}$ in Dowa, $1.14 \mathrm{t} \mathrm{ha}^{-1}$ in Mchinji and $0.99 \mathrm{t} \mathrm{ha}^{-1}$ in Salima. The average yields did not differ much between regions and years in Dowa and Mchinji, but yields of $0.38 \mathrm{t} \mathrm{ha}^{-1}$ in Salima in 2010 were much smaller than $1.60 \mathrm{t} \mathrm{ha}^{-1}$ in 2011 (Table 3.2). This resulted in a strong region by year effect on both biomass and grain yields. The poor performance in Salima 2010 can be explained by the erratic rainfall distribution that resulted in dry spells after sowing. This was exacerbated by grasshoppers that damaged emerging plants. Strong weed pressure (Table 3.2) also contributed to poor yields in 2010. In 2011 rainfall was more evenly distributed and weed pressure was less. 
Table 3.1: Socio-economic and biophysical characteristics of participating farmers in three regions. Data in brackets represent standard deviations from the mean.

\begin{tabular}{|c|c|c|c|c|}
\hline & Dowa & Mchinji & Salima & Total / Fpr ${ }^{1}$ / Mean \\
\hline Participation in trials & & & & Total \\
\hline Only $\mathrm{BNF}^{2}$ trial $(n)$ & 13 & 6 & 11 & 30 \\
\hline Only rotation trial $(n)$ & 9 & 10 & 8 & 27 \\
\hline Both trials $(n)$ & 8 & 9 & 9 & 26 \\
\hline Socio-economic characteristics & & & & F pr \\
\hline Female participants $(\%)$ & 72 & 31 & 32 & \\
\hline Age of farmer & 51 & $47 \quad(14)$ & 32 (9) & $<0.001$ \\
\hline Arable land (ha) & $1.4(0.86)$ & $2.9(2.6)$ & $3.4(3.8)$ & 0.017 \\
\hline Available family labour $\left(\mathrm{ME}^{3}\right)$ & $4.4(2.4)$ & $4.1(1.8)$ & $3.1(1.3)$ & 0.041 \\
\hline Value of assets (USD) & $81(152)$ & $288(334)$ & $250(463)$ & n.s. \\
\hline Livestock ownership $\left(\mathrm{LU}^{4}\right)$ & $0.7(1.8)$ & $3.1(5.6)$ & $1.1(2.4)$ & 0.036 \\
\hline Soil data both trials & & & & F pr \\
\hline $\operatorname{SOC}^{5}\left(\mathrm{~g} \mathrm{~kg}^{-1}\right)$ & $15.3(4.1)$ & $8.3(2.4)$ & $8.8(4.1)$ & $<0.001$ \\
\hline $\mathrm{P}\left(\mathrm{mg} \mathrm{kg}^{-1}\right)$ & $7.2(9.7)$ & $9.8(5.8)$ & $8.6(13.7)$ & n.s. \\
\hline $\mathrm{pH}\left(\mathrm{CaCl}_{2}\right)$ & $4.8 \quad(0.4)$ & $4.6(0.3)$ & $5.4(0.6)$ & $<0.001$ \\
\hline Soil data BNF trials only & & & & F pr \\
\hline $\mathrm{K}(\mathrm{cmol} \mathrm{kg}-1)$ & $5.4(3.5)$ & $2.5(1.2)$ & $6.1(2.2)$ & $<0.001$ \\
\hline Clay $\left(\mathrm{g} \mathrm{kg}^{-1}\right)$ & $402(80)$ & $282(127)$ & $285(121)$ & $<0.001$ \\
\hline Silt $\left(\mathrm{g} \mathrm{kg}^{-1}\right)$ & $146(36)$ & $125(75)$ & $143(73)$ & n.s. \\
\hline Sand $\left(\mathrm{g} \mathrm{kg}^{-1}\right)$ & $452(89)$ & $594(188)$ & $572(183)$ & 0.002 \\
\hline Climatic data & & & & Mean \\
\hline Rainfall 2009/10 (mm) & 979 & 1257 & 1199 & 1145 \\
\hline Rainfall 2010/11 (mm) & 1278 & 756 & 1106 & 1047 \\
\hline Rainfall 50 years average 6 & 905 & 952 & 946 & 934 \\
\hline
\end{tabular}

${ }^{1} \mathrm{Fpr}=$ the probability of no difference between regions calculated through REML analysis. Fpr $>0.05$ means no significant difference (n.s.) between regions, ${ }^{2}$ Biological Nitrogen Fixation, ${ }^{3}$ Men Equivalent, ${ }^{4}$ Livestock Units, ${ }^{5}$ Soil Organic Carbon, ${ }^{6}$ Source: Hijmans et al. (2005).

\subsubsection{2 ${ }^{15} \mathrm{~N}$ natural abundance signatures in soybean and reference plants}

The average $\delta^{15} \mathrm{~N}$ values in the BNF trials were $+0.80 \%$ for soybean shoots and $+3.85 \%$ for broad leaved weeds species (Table 3.3). The $\delta^{15} \mathrm{~N}$ of the local soybean varieties $(-0.12 \%$ ) was smaller $(\mathrm{p}<0.01)$ than for Nasoko $(+0.91 \%)$ across the three sites. The soybean $\delta^{15} \mathrm{~N}$ was not affected by region or year but the $\delta^{15} \mathrm{~N}$ of broad-leaved weed species were smaller in Salima. A combination of inoculant and fertiliser application resulted in smaller $\delta^{15} \mathrm{~N}$ values compared with plots that received no inputs. 
Table 3.2: Farmers' crop management practices and soybean characteristics in the biological nitrogen fixation trial.

\begin{tabular}{|c|c|c|c|c|c|c|}
\hline & $n$ & Dowa & Mchinji & Salima & Mean & $\mathrm{SED}^{1}$ \\
\hline \multicolumn{7}{|l|}{ Date of sowing rains (SR) } \\
\hline 2010 & 75 & $15 \mathrm{Dec}$ & $11 \mathrm{Nov}$ & $21 \mathrm{Dec}$ & & \\
\hline 2011 & 75 & $5 \mathrm{Dec}$ & $24 \mathrm{Nov}$ & $2 \mathrm{Dec}$ & & \\
\hline Sowing date (days after SR) & & & & & & $\mathrm{Y}=0.99 * *$ \\
\hline 2010 & 75 & 26 & 22 & 8 & 19 & $\mathrm{R}=1.21 * * *$ \\
\hline 2011 & 75 & 28 & 24 & 13 & 22 & $\mathrm{R} \times \mathrm{Y}=1.71$ \\
\hline First weeding (DAP) & & & & & & $\mathrm{Y}=1,68 * * *$ \\
\hline 2010 & 63 & 12 & 22 & 21 & 19 & $\mathrm{R}=2.05 *$ \\
\hline 2011 & 67 & 30 & 30 & 25 & 28 & $\mathrm{R} \times \mathrm{Y}=2.89^{* *}$ \\
\hline Weed pressure (1-5) & & & & & & $\mathrm{Y}=0.09$ \\
\hline 2010 & 73 & 1.9 & 1.4 & 2.4 & 1.9 & $\mathrm{R}=0.12 * * *$ \\
\hline 2011 & 60 & 2.2 & 1.6 & 1.8 & 1.8 & $\mathrm{R} \times \mathrm{Y}=0.16^{* * *}$ \\
\hline Plant population $\left(1000 \mathrm{pl} \mathrm{ha}^{-1}\right)$ & & & & & & $\mathrm{Y}=17.5^{*}$ \\
\hline 2010 & 75 & 412 & 266 & 205 & 294 & $\mathrm{R}=21.4 * * *$ \\
\hline 2011 & 75 & 308 & 207 & 257 & 257 & $\mathrm{R} \times \mathrm{Y}=30.3^{* *}$ \\
\hline Plant height $(\mathrm{cm})$ & & & & & & $\mathrm{Y}=1.76$ \\
\hline 2010 & 75 & 47 & 53 & 40 & 47 & $\mathrm{R}=2.15^{* *}$ \\
\hline 2011 & 75 & 57 & 44 & 48 & 50 & $\mathrm{R} \times \mathrm{Y}=3.04 * * *$ \\
\hline Biomass dry weight $\left(\mathrm{t} \mathrm{ha}^{-1}\right)$ & & & & & & $\mathrm{Y}=0.23 * * *$ \\
\hline 2010 & 73 & 2.8 & 2.7 & 1.1 & 2.2 & $\mathrm{R}=0.28 * * *$ \\
\hline 2011 & 75 & 4.6 & 2.3 & 2.9 & 3.3 & $\mathrm{R} \times \mathrm{Y}=0.40^{* * *}$ \\
\hline Grain yield $\left(\mathrm{t} \mathrm{ha}^{-1}\right)$ & & & & & & $\mathrm{Y}=0.11 * * *$ \\
\hline 2010 & 75 & 1.4 & 1.1 & 0.4 & 1.0 & $\mathrm{R}=0.13 * *$ \\
\hline 2011 & 75 & 1.6 & 1.2 & 1.6 & 1.5 & $\mathrm{R} \times \mathrm{Y}=0.19 * * *$ \\
\hline
\end{tabular}




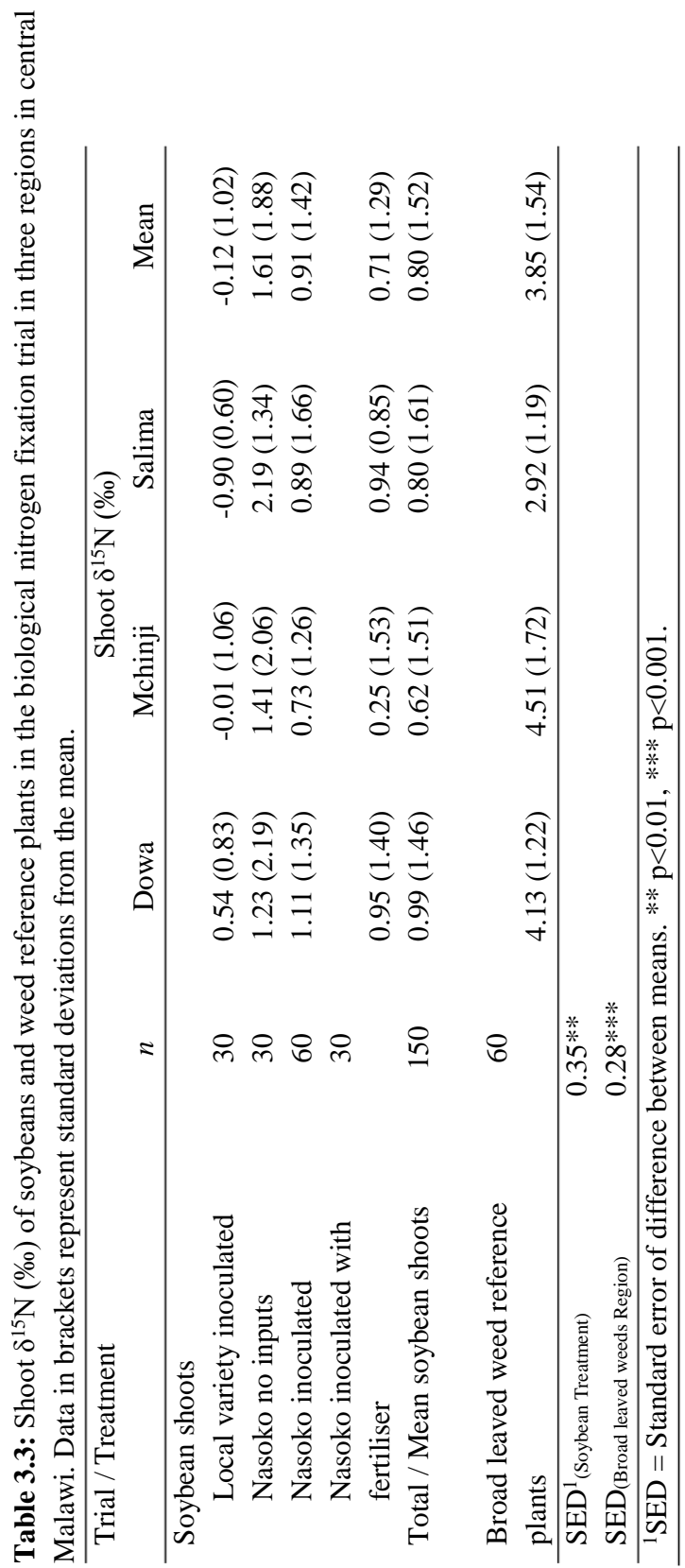




\subsubsection{Variability in \%Ndfa, total $N_{2}$ fixed and grain yields}

The average $\%$ Ndfa of soybean was $57 \%$ in Dowa, $58 \%$ in Mchinji and 54\% in Salima (n.s.) and did not differ between the years. The local varieties fixed a larger percentage of $\mathrm{N}_{2}$, while inoculation and fertiliser treatments did not affect $\%$ Ndfa (Table 3.4). There was a large variability in \%Ndfa across farms, also within treatments (Fig. 3.1a). Several factors contributing to this variability were identified in the REML analysis (Table 3.5). Plant population and biomass accumulation were positively associated with \%Ndfa. Delayed sowing also correlated with a larger $\% \mathrm{Ndfa}$. Clay content correlated negatively and sand positively with $\% \mathrm{Ndfa}$. Soybean plots hosted by male farmers $(n=93)$ fixed $61 \% \mathrm{~N}$ compared to $50 \%$ on female farmers' fields $(n=57)$. Male farmers' fields contained more sand $(580 \mathrm{~g}$ $\mathrm{kg}^{-1}$ versus $\left.470 \mathrm{~g} \mathrm{~kg}^{-1} ; \mathrm{p}=0.01\right)$ and less clay $\left(290 \mathrm{~g} \mathrm{~kg}^{-1}\right.$ versus $\left.390 \mathrm{~g} \mathrm{~kg}^{-1} ; \mathrm{p}<0.001\right)$ than female farmers' fields. The percentage of female farmers that participated in the BNF trial varied by region (57\% in Dowa, 20\% in Mchinji and 33\% in Salima) and soils in Dowa contained more clay than in Mchinji and Salima (Table 3.1). Despite this, there was no interaction between the variables gender and region $(\mathrm{p}=0.15)$, soil texture and region $(\mathrm{p}=0.8)$, or gender and soil texture $(\mathrm{p}=0.07)$ in the effect on $\% \mathrm{Ndfa}$.

The average total $\mathrm{N}_{2}$ fixed was $63 \mathrm{~kg} \mathrm{ha}^{-1}$ and there was an effect of region (Table 3.4) and year with for instance $21 \mathrm{~kg} \mathrm{ha}^{-1}$ fixed in Salima in 2010 and $107 \mathrm{~kg} \mathrm{ha}^{-1}$ in Dowa in 2011. Like the \%Ndfa, the local varieties also fixed larger quantities of $\mathrm{N}_{2}$ per ha, though this did not result in better grain yields (Table 3.4). Total $\mathrm{N}_{2}$ fixed increased with the combined application of inoculant and NPK fertiliser compared to the no input treatment (Table 3.4), though a considerable variability existed within all treatments (Fig. 3.1b). Total $\mathrm{N}_{2}$ fixed was strongly associated with plant growth traits such as grain yield, biomass yield and plant height and was positively affected by soil available $\mathrm{P}$ and exchangeable $\mathrm{K}$ (Table 3.5). Plants on soils containing more available $\mathrm{P}$ accumulated more biomass $(\mathrm{r}=0.32, \mathrm{p}<0.001)$ and had taller plants $(\mathrm{r}=0.19, \mathrm{p}=0.05)$.

Soybean grain yields were affected by year, region and input level (Table $3.2 \& 3.4$ ). Average grain yields without inputs were $1.02 \mathrm{t} \mathrm{ha}^{-1}$, with only inoculation $1.08 \mathrm{t} \mathrm{ha}^{-1}$ and with inoculation plus fertiliser $1.68 \mathrm{t} \mathrm{ha}^{-1}$. The combined application of fertiliser and inoculant enhanced both biomass and grain yields compared with application of only inoculant (Table 3.4). The REML analysis identified additional factors that may have contributed to the large variability in yields across farms (Fig. 3.1c). Fields with larger plant populations were associated with better yields, while high weed pressure was associated with lower yields. Male farmers and farmers with more assets tended to have better yields (Table 3.5). Female farmers' soybean grain yields were only $0.99 \mathrm{t} \mathrm{ha}^{-1}$ compared with $1.33 \mathrm{t} \mathrm{ha}^{-1}$ achieved by male farmers. Besides soil texture, we did not find any associations between other biophysical, crop management, or socio-economic variables and gender. 


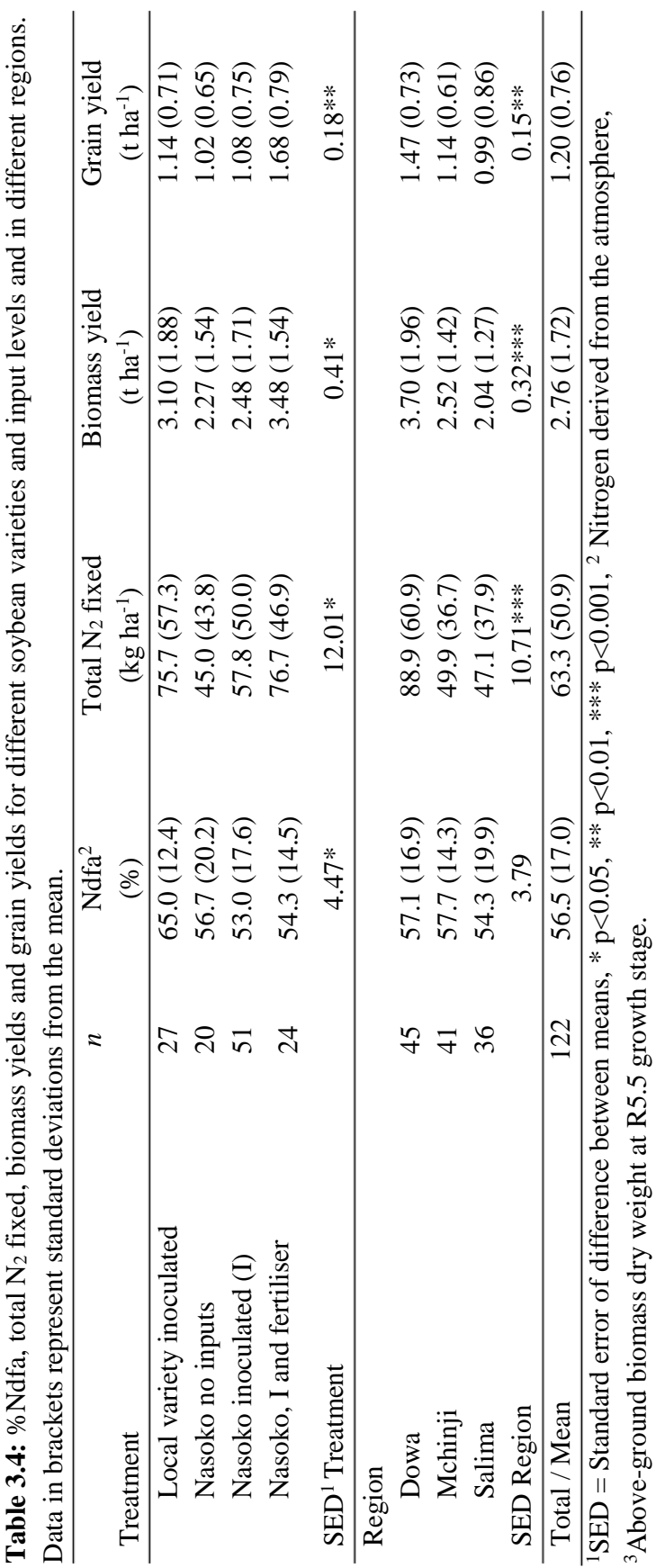


Chapter 3

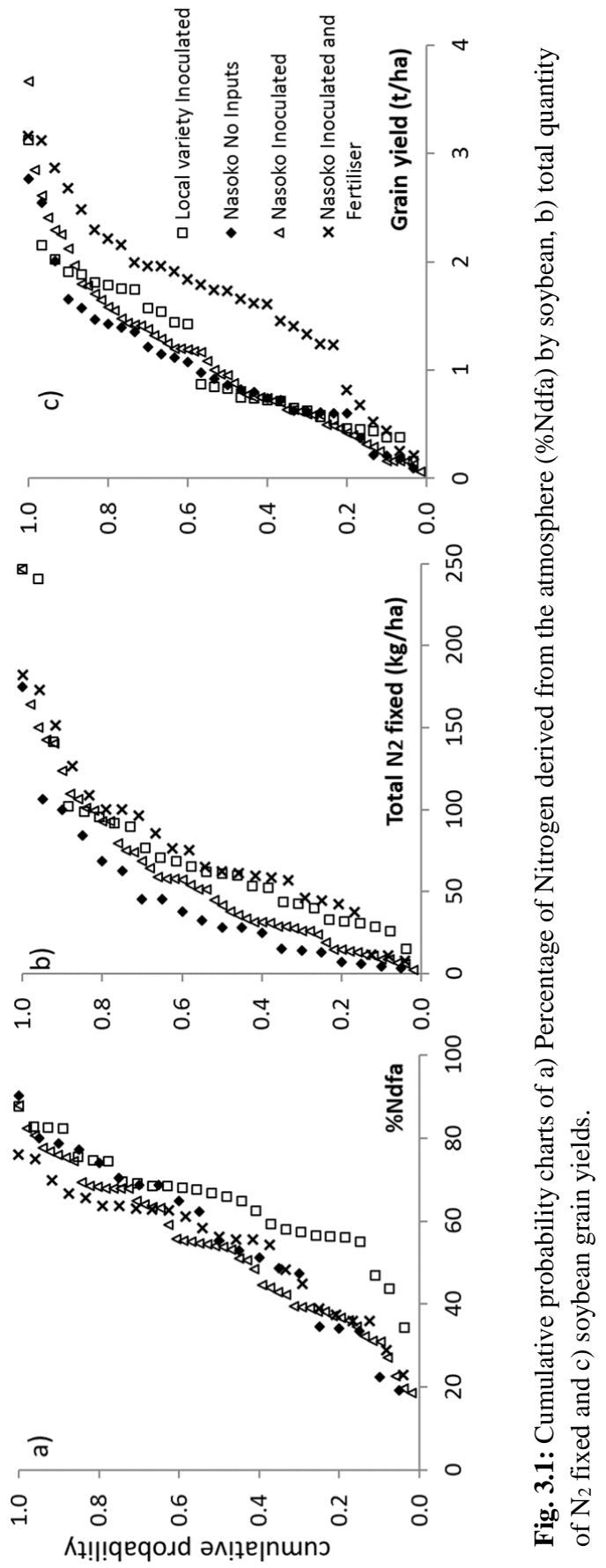


Table 3.5: Factors affecting \%Ndfa, quantities of $\mathrm{N}_{2}$ fixed and soybean grain yield.

\begin{tabular}{lcccc}
\hline $\begin{array}{c}\text { Dependent variable } \\
\text { Explanatory variables }\end{array}$ & Type of relation $^{\mathbf{1}}$ & $\boldsymbol{n}$ & Fpr & Random Factors $^{2}$ \\
\hline $\mathbf{\% N d f a}^{\mathbf{3}}$ & & & & \\
Technology treatment & $\mathrm{C}$ & 122 & 0.023 & - \\
Clay & - & 120 & 0.043 & $\mathrm{~T}$ \\
Sand & + & 120 & 0.039 & $\mathrm{~T}$ \\
Sowing date & + & 122 & 0.042 & $\mathrm{~T}$ \\
Plant population & + & 150 & 0.029 & - \\
Biomass yield & + & 148 & 0.049 & - \\
Gender & $\mathrm{C}$ & 150 & $<0.001$ & $\mathrm{~T}$ \\
Value of assets & - & 150 & 0.050 & $\mathrm{~T}$
\end{tabular}

\section{Total $\mathbf{N}_{2}$ fixed}

$\begin{array}{lcccc}\text { Region } & \text { C } & 120 & <0.001 & - \\ \text { Year } & \text { C } & 120 & 0.003 & - \\ \text { Technology treatment } & \text { C } & 120 & 0.043 & \text { R, Y } \\ \text { Available P } & + & 141 & <0.001 & \text { R, Y, T } \\ \text { Exchangeable K } & + & 111 & 0.015 & \text { R, Y, T } \\ \text { Grain yield } & + & 150 & <0.001 & \text { R, Y } \\ \text { Biomass yield } & + & 148 & <0.001 & \text { R, Y } \\ \text { Plant height } & + & 148 & 0.002 & \text { R, Y }\end{array}$

\section{Soybean grain yield}

\begin{tabular}{lcccc} 
Region & $\mathrm{C}$ & 150 & 0.005 & - \\
Year & $\mathrm{C}$ & 150 & $<0.001$ & - \\
Technology treatment & $\mathrm{C}$ & 150 & $<0.001$ & $\mathrm{R}, \mathrm{Y}$ \\
Plant height & + & 148 & $<0.001$ & $\mathrm{R}, \mathrm{Y}$ \\
Biomass yield & + & 148 & $<0.001$ & $\mathrm{R}, \mathrm{Y}$ \\
Plant population density & + & 150 & 0.013 & $\mathrm{R}, \mathrm{Y}$ \\
Weed score & - & 133 & 0.022 & $\mathrm{R}, \mathrm{Y}$ \\
Total N2 fixed & + & 120 & $<0.001$ & $\mathrm{R}, \mathrm{Y}$ \\
Net N benefit from BNF & - & 120 & $<0.001$ & $\mathrm{R}, \mathrm{Y}$ \\
Gender & $\mathrm{C}$ & 150 & 0.002 & $\mathrm{R}, \mathrm{Y}, \mathrm{T}$ \\
Value of assets & + & 150 & $<0.001$ & $\mathrm{R}, \mathrm{Y}, \mathrm{T}$ \\
\hline
\end{tabular}

${ }^{1}$ For continuous variables ' + ' indicates a positive and '-' a negative correlation with the dependent variable; Categorical factors are indicated with 'C'. ${ }^{2}$ Random factors included in the REML model: $\mathrm{R}=$ Region, $\mathrm{Y}=$ Year, $\mathrm{T}=$ Technology treatment. ${ }^{3}$ Percentage of nitrogen derived from the atmosphere. 


\subsubsection{Rotation trial}

\subsubsection{Farmers' practices and maize yields}

Most soybean plots cultivated in 2010 were preceded by cereal crops in 2009 whereas the maize plots were preceded by cereals (53\%), legumes (29\%) or other cash crops (Table 3.6). The soybean plots in Dowa accumulated most biomass and attained the largest yields followed by Mchinji and Salima. In the maize plots in 2010 most farmers in Mchinji applied a combination of 'NPS' $(23: 21+4 \mathrm{~S})$ and urea fertilisers at a rate of at $85 \mathrm{~kg} \mathrm{~N}, 11 \mathrm{~kg} \mathrm{P}$ and 5 $\mathrm{kg} \mathrm{S} \mathrm{ha}^{-1}$, but in Dowa unfertilised maize was most common. The use of animal manure was rare and only three farmers used chemicals for weed, pest or disease control. At the end of the season, maize residues were mainly incorporated into the soil or burnt. Soybean residues were taken to the homestead for threshing and residues were commonly used to make compost manure, but in Salima farmers burnt the residues or took them back to the field to incorporate them into the soil.

Most maize plots in the second season of the rotation trial were sown in December, though in Mchinji and Salima sowing was spread out over two months (Table 3.7). In Dowa only $36 \%$ of the plots received external nutrient inputs, compared to $89 \%$ in Mchinji and $65 \%$ in Salima. There was much variation in the date of first weeding ranging from 14 to 70 days after sowing. Improved varieties were used by $61 \%$ of the farmers whereas the rest of the farmers cultivated local varieties. There was large variability in number of sowing stations per hectare and number of seeds per station. The average sowing rate was 57,700 seeds ha- ${ }^{-1}$.

\subsubsection{Maize yields, yield responses and yield variability in the rotation trials}

Mean maize grain yield in 2011 was $3.98 \mathrm{t} \mathrm{ha}^{-1}$ and yields varied between regions (Table 3.8) with $1.63 \mathrm{t} \mathrm{ha}^{-1}$ in Dowa, $2.94 \mathrm{t} \mathrm{ha}^{-1}$ in Mchinji and $4.37 \mathrm{t} \mathrm{ha}^{-1}$ in Salima $(\mathrm{p}<0.001)$. Maize yields achieved by farmers were highly variable between and within regions with $90 \%$ of the fields having yields in the range of 0.9 to $3.4 \mathrm{t} \mathrm{ha}^{-1}$ in Dowa, 1.5 to $5.3 \mathrm{t} \mathrm{ha}^{-1}$ in Mchinji and 1.8 to $7.5 \mathrm{t} \mathrm{ha}^{-1}$ in Salima. The REML analysis identified the region and the previous crop (maize or soybean) as factors affecting maize yields (Table 3.9). Farmers that cultivated improved maize varieties also benefitted from better yields in plots that were proceeded by soybean, and input application enhanced maize yields in both treatments (Table 3.8). We did not find a relationship between soil characteristics, sowing date, sowing rate or socioeconomic characteristics of the households and maize yields. 
Table 3.6: History and characteristics of plots used in the rotation trial.

\begin{tabular}{|c|c|c|c|c|}
\hline \multicolumn{5}{|l|}{ Plot history before rotation trial (2009) } \\
\hline Crop $^{1}$ before soybean ( $\%$ of plots) & $\begin{array}{c}\text { Dowa } \\
(n=16)\end{array}$ & $\begin{array}{l}\text { Mchinji } \\
(n=19)\end{array}$ & $\begin{array}{l}\text { Salima } \\
(n=17)\end{array}$ & Mean \\
\hline Cereals & 81 & 84 & 71 & 79 \\
\hline Legumes & 0 & 5 & 0 & 2 \\
\hline Other cash crops & 6 & 0 & 24 & 10 \\
\hline Fallow & 13 & 11 & 6 & 10 \\
\hline Crop before maize (\% of plots) & $\begin{array}{l}\text { Dowa } \\
(n=6)\end{array}$ & $\begin{array}{c}\text { Mchinji } \\
(n=16)\end{array}$ & $\begin{array}{l}\text { Salima } \\
(n=16)\end{array}$ & Mean \\
\hline Cereals & 83 & 25 & 50 & 53 \\
\hline Legumes & 17 & 44 & 25 & 29 \\
\hline Other cash crops & 0 & 31 & 25 & 19 \\
\hline Fallow & 0 & 0 & 0 & 0 \\
\hline \multicolumn{5}{|l|}{ Plot characteristics trial season 1 (2010) } \\
\hline External inputs in maize plots ${ }^{2}$ & $\begin{array}{c}\text { Dowa } \\
(n=11)\end{array}$ & $\begin{array}{l}\text { Mchinji } \\
(n=18)\end{array}$ & $\begin{array}{l}\text { Salima } \\
(n=17)\end{array}$ & Mean \\
\hline NPS and Urea (\%) & 27 & 83 & 47 & 57 \\
\hline Animal manure $(\%)$ & 9 & 6 & 12 & 9 \\
\hline \multirow[t]{2}{*}{ External inputs in soybean plots } & 0 & 0 & 0 & 0 \\
\hline & $\begin{array}{c}\text { Dowa } \\
(n=15)\end{array}$ & $\begin{array}{l}\text { Mchinji } \\
(n=17)\end{array}$ & $\begin{array}{l}\text { Salima } \\
(n=15)\end{array}$ & Mean \\
\hline Yields in soybean plots $\left(\mathrm{t} \mathrm{ha}^{-1}\right)$ & 1.13 & 0.76 & 0.33 & 0.74 \\
\hline Soybean dry biomass at R5.5 ( $\left.\mathrm{t} \mathrm{ha}^{-1}\right)$ & 2.49 & 1.94 & 1.00 & 1.83 \\
\hline Use of maize residues after harvest & $\begin{array}{l}\text { Dowa } \\
(n=8)\end{array}$ & $\begin{array}{l}\text { Mchinji } \\
(n=18)\end{array}$ & $\begin{array}{l}\text { Salima } \\
(n=17)\end{array}$ & Mean \\
\hline Make compost manure $(\%)$ & 13 & 6 & 6 & 7 \\
\hline Incorporate into the soil (\%) & 50 & 67 & 53 & 58 \\
\hline Burn $(\%)$ & 38 & 28 & 41 & 35 \\
\hline Use of soybean residues after harvest & $\begin{array}{c}\text { Dowa } \\
(n=11)\end{array}$ & $\begin{array}{l}\text { Mchinji } \\
(n=17)\end{array}$ & $\begin{array}{l}\text { Salima } \\
(n=17)\end{array}$ & Mean \\
\hline Make compost manure (\%) & 91 & 94 & 6 & 60 \\
\hline Incorporate into the soil (\%) & 0 & 0 & 53 & 20 \\
\hline Burn $(\%)$ & 9 & 6 & 41 & 20 \\
\hline
\end{tabular}

${ }^{1}$ Cereals are maize (53) and in Salima sorghum (5); Legumes include groundnuts (8) and soybean (6); Cash crops include in Mchinji tobacco (5), in Salima cotton (8) and in Dowa sweet potatoes (1). ${ }^{2}$ Percentage of farmers applying these inputs. NPS (23:21+4S) and urea (46:0:0) were commonly applied at $125 \mathrm{~kg} \mathrm{ha}^{-1}$ each. 
Table 3.7: Maize management in the second year (2011) of the rotation trial.

\begin{tabular}{|c|c|c|c|c|}
\hline External inputs in trial plots (\% of trials) & $\begin{array}{l}\text { Dowa } \\
(n=11)\end{array}$ & $\begin{array}{c}\text { Mchinji } \\
(n=18)\end{array}$ & $\begin{array}{l}\text { Salima } \\
(n=17)\end{array}$ & Mean \\
\hline NPS $^{1}$, Urea and Manure & 0.0 & 16.7 & 5.9 & 7.5 \\
\hline NPS and Urea & 36.4 & 61.1 & 41.2 & 46.2 \\
\hline Urea or $\mathrm{CAN}^{2}$ only & 0.0 & 11.1 & 11.8 & 7.6 \\
\hline NPS only & 0.0 & 0.0 & 5.9 & 2.0 \\
\hline No inputs & 63.6 & 11.1 & 35.3 & 36.7 \\
\hline Other crop management practices & $\begin{array}{c}\text { Dowa } \\
(n=8)\end{array}$ & $\begin{array}{c}\text { Mchinji } \\
(n=18)\end{array}$ & $\begin{array}{l}\text { Salima } \\
(n=17)\end{array}$ & Mean \\
\hline \multicolumn{5}{|l|}{ Sowing date } \\
\hline First & - & $27 \mathrm{Nov}$ & $11 \mathrm{Nov}$ & \\
\hline Median & - & $12 \mathrm{Dec}$ & $6 \mathrm{Dec}$ & \\
\hline Last & - & $28 \mathrm{Jan}$ & 15 Jan & \\
\hline First weeding date (DAP) & - & $30(16-54)^{3}$ & $22(14-70)$ & \\
\hline Second weeding date (DAP) & - & $58(43-75)$ & $40(27-58)$ & \\
\hline Improved variety ${ }^{4}$ ( $\%$ of farmers) & 50 & 68 & 65 & 61 \\
\hline Row spacing $(\mathrm{cm})$ & 75 & $84(75-90)$ & $77(75-90)$ & 79 \\
\hline \multicolumn{5}{|l|}{ Plant spacing (\%) } \\
\hline $20-25 \mathrm{~cm} ; 1$ seed per station & 25 & 5 & 29 & 20 \\
\hline $40-50 \mathrm{~cm} ; 2-3$ seeds per station & 50 & 95 & 6 & 50 \\
\hline $60-90 \mathrm{~cm} ; 3-4$ seeds per station & 25 & 0 & 65 & 30 \\
\hline Sowing rate (1000 seeds ha $\left.{ }^{-1}\right)$ & 60.4 & 57.2 & 56.8 & 57.7 \\
\hline
\end{tabular}

${ }^{1}$ NPS $(23: 21+2 \mathrm{~S}) .{ }^{2} \mathrm{CAN}$ is Calcium ammonium nitrate $(27 \% \mathrm{~N}, 8 \% \mathrm{Ca}) .{ }^{3}$ Data in brackets are minimum and maximum observes values. ${ }^{4}$ Includes hybrid and open pollinated maize varieties.

On most farms, maize following soybean outperformed continuous maize (Fig. 3.2). The average yield increase of maize after soybean relative to continuous maize was $0.32 \mathrm{t} \mathrm{ha}^{-1}$ in Dowa, $1.29 \mathrm{t} \mathrm{ha}^{-1}$ in Mchinji and $1.23 \mathrm{t} \mathrm{ha}^{-1}$ in Salima (Table 3.8). The maize yield response was highly variable (Fig. 3.2a) with an overall probability of a positive response of $85 \%$, and a $40 \%$ probability of a response above $1.0 \mathrm{tha}^{-1}$. There was variation across regions with 60 , 100 and $85 \%$ of fields showing a positive response in Dowa, Mchinji and Salima respectively. Farmers that applied nutrient inputs $(n=32)$ had mean yield responses to rotation of $1.32 \mathrm{t} \mathrm{ha}^{-1}$ compared with $0.47 \mathrm{t} \mathrm{ha}^{-1}$ without input application $(n=15)$. The average site yield (average yield of the two maize plots) was strongly correlated with the absolute yield response $(\mathrm{r}=0.52, \mathrm{p}<0.001)$ indicating that more productive farmers benefited from larger absolute yield increases. The value of assets at the household was also associated with larger yield responses $(\mathrm{r}=0.37, \mathrm{p}=0.006)$. 
Table 3.8: Effect of region, maize variety and input application on maize yields and yield response to rotation. Data in brackets represent standard deviations from the mean.

\begin{tabular}{|c|c|c|c|c|}
\hline & $n$ & M-M ${ }^{1}$ plot $\left(\mathrm{t} \mathrm{ha}^{-1}\right)$ & S-M ${ }^{2}$ plot $\left(\mathrm{t} \mathrm{ha}^{-1}\right)$ & Yield response $\left(\mathrm{t} \mathrm{ha}^{-1}\right)$ \\
\hline \multicolumn{5}{|l|}{ Region } \\
\hline Dowa & 17 & $1.47(0.59)$ & $1.79(1.12)$ & $0.32(0.92)$ \\
\hline Mchinji & 19 & $2.30(1.37)$ & $3.59(1.56)$ & $1.29(0.87)$ \\
\hline Salima & 17 & $3.75(1.75)$ & $4.98(2.29)$ & $1.23(1.09)$ \\
\hline $\mathrm{SED}^{3}$ & & $0.45^{* * *}$ & $0.58 * * *$ & $0.32 * *$ \\
\hline \multicolumn{5}{|l|}{ Variety class } \\
\hline Improved $^{4}$ & 27 & $2.98(1.65)$ & $4.01(2.14)$ & $1.23(1.06)$ \\
\hline Local & 18 & $2.23(1.57)$ & $2.88(1.87)$ & $0.69(0.97)$ \\
\hline SED & & n.s. & $0.80 *$ & n.s. \\
\hline \multicolumn{5}{|l|}{ Input class } \\
\hline No inputs & 15 & $1.66(0.93)$ & $2.19(1.24)$ & $0.49(0.96)$ \\
\hline With inputs ${ }^{5}$ & 32 & $3.06(1.72)$ & $4.28(2.10)$ & $1.28(1.00)$ \\
\hline SED & & $0.60 * *$ & $0.55 * * *$ & $0.32 *$ \\
\hline
\end{tabular}

Table 3.9: Factors affecting maize yields and absolute and relative response of maize yield to crop rotation.

\begin{tabular}{|c|c|c|c|c|}
\hline $\begin{array}{l}\text { Dependent variable } \\
\text { Explanatory variables }\end{array}$ & Type of relation ${ }^{1}$ & $n$ & Fpr & $\begin{array}{l}\text { Random } \\
\text { Factors }^{2}\end{array}$ \\
\hline \multicolumn{5}{|l|}{ Maize yield $\left(\mathrm{t} \mathrm{ha}^{-1}\right)$} \\
\hline Region & $\mathrm{C}$ & 106 & $<0.001$ & - \\
\hline Treatment (soya or maize in 2010) & $\mathrm{C}$ & 106 & 0.002 & $\mathrm{R}$ \\
\hline Variety (local or improved) & $\mathrm{C}$ & 70 & 0.02 & $\mathrm{R}, \mathrm{T}$ \\
\hline Input application (yes or no) & $\mathrm{C}$ & 92 & $<0.001$ & $\mathrm{R}, \mathrm{T}$ \\
\hline \multicolumn{5}{|l|}{ Absolute response to rotation $\left(\mathrm{tha}^{-1}\right)$} \\
\hline Region & $\mathrm{C}$ & 53 & 0.007 & - \\
\hline Inputs applied to maize plots (yes or no) & $\mathrm{C}$ & 47 & 0.018 & $\mathrm{R}$ \\
\hline Mean site maize yield & + & 53 & $<0.001$ & $\mathrm{R}$ \\
\hline Value of assets (USD) & + & 53 & 0.029 & $\mathrm{R}$ \\
\hline \multicolumn{5}{|l|}{ Relative response to rotation $(\%)$} \\
\hline Region & $\mathrm{C}$ & 53 & 0.03 & \\
\hline Maize yield in control plot & - & 53 & 0.019 & $\mathrm{R}$ \\
\hline
\end{tabular}

${ }^{1}$ For continuous variables ' + ' indicates a positive and '-' a negative correlation with the dependent variable; Categorical factors are indicated with 'C'. ${ }^{2}$ Random factors included in the REML model: $\mathrm{R}=$ Region, $\mathrm{Y}=$ Year, $\mathrm{T}=$ Technology treatment. 
Soybean as a previous crop increased maize yield on average by $39 \%$. This relative response was affected by region with average yield increases of 22, 56 and 33\% in Dowa, Mchinji and Salima respectively (Table 3.7). An increase of more than $10 \%$ (considered a minimum increase to be noticeable by farmers) was observed on 59, 90 and $77 \%$ of fields in Dowa, Mchinji and Salima respectively. A yield response of more than $100 \%$ was observed on $15 \%$ of the fields (Fig. 3.2b). Unlike the absolute yield response, the relative yield response was less in fields with a larger continuous maize yield (Table 3.9). There was no correlation between soybean grain yield, biomass, $\% \mathrm{Ndfa}$ or total $\mathrm{N}_{2}$ fixed and the following maize yield or yield response to rotation in the 21 fields where both BNF and rotation data were collected.

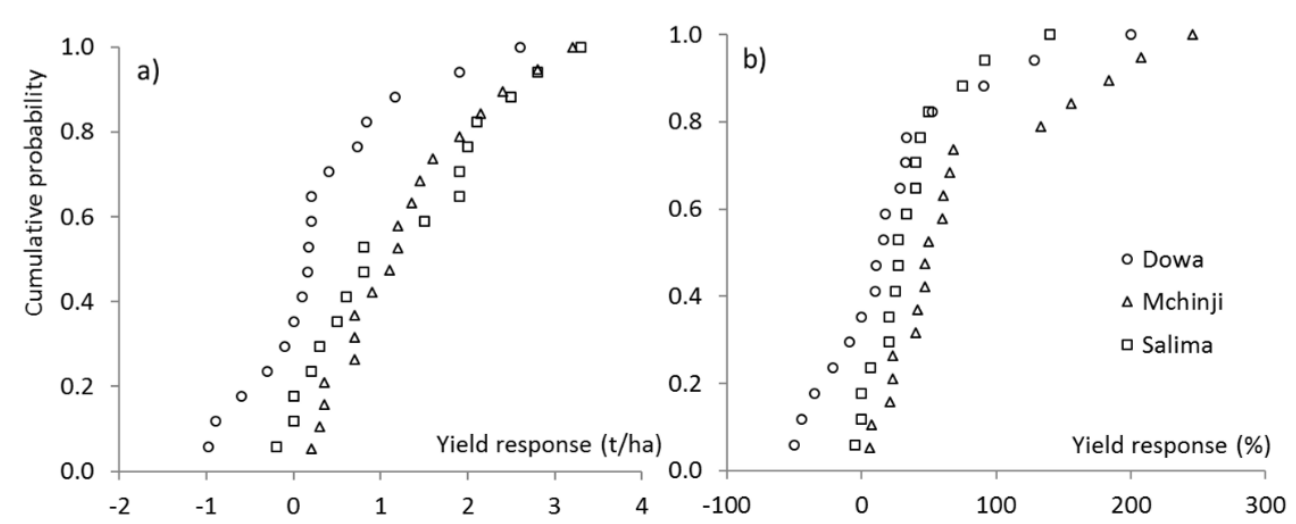

Fig. 3.2: Cumulative probability of the absolute (a) and relative (b) maize yield response to crop rotation following soybean instead of continuous maize production in three regions in central Malawi.

\subsection{Discussion}

\subsubsection{Methodological considerations}

The farmers and fields included in the estimation of $\mathrm{N}_{2}$-fixation and rotational benefits represented a wide range of environmental and socio-economic conditions and crop management practices in central Malawi. This offered a valuable opportunity to quantify and analyse the large variability in maize and soybean yields, $\mathrm{N}_{2}$-fixation parameters and residual effects of soybean. This type of experimentation, often conducted as part of an agricultural dissemination programme with goals other than scientific research, can easily lead to challenges with unbalanced treatment designs and confounded co-variables, which reduces statistical power and the ability to explain variability. Moreover, multiple interacting constraints typically affect crop productivity which also complicates the analyses (Ronner $e t$ al., 2016; Fermont et al., 2009). Therefore, we identified those factors that are associated with the dependant variables, but did not attempt to quantify the relative importance of each 
variable in explaining the overall variability. Some potentially relevant factors that could contribute to explaining variability such as daily rainfall at field level, pest and disease incidence and severity, livestock damage, and crop theft were not captured.

\subsubsection{Factors affecting $\mathrm{N}_{2}$-fixation and soybean and maize yields}

Our results show that a combination of genetic, environmental, management (GxExM) and socio-economic variables affect $\mathrm{N}_{2}$-fixation and soybean and maize yields (Table 3.5, 3.8 \& 3.9). Locally procured, undefined varieties had a larger $\% \mathrm{Ndfa}(65 \%)$ than variety Nasoko $(53 \%)$ receiving inoculation, while observed values were within the range reported in literature (Salvagiotti et al., 2008). The \%Ndfa was not affected by region and year (Table 3.5). While research in Kenya showed that differences between agro-ecological zones in terms of soil fertility and rainfall can affect the \% Ndfa (Ojiem et al., 2007), in our study the regions may not have been sufficiently distinct to affect $\%$ Ndfa. However, within regions a larger percentage of $\mathrm{N}_{2}$ was fixed on soils with a relatively high sand content (Table 3.5). A possible explanation for this could be that clay soils can store more organic $\mathrm{N}$ suppressing $\mathrm{N}_{2}$ fixation (Schipanski et al., 2010; Giller et al., 1997). The \%Ndfa was not affected by inoculation or fertiliser application (Table 3.4 and Fig. 1a). Chapter 2 showed that the same inoculant applied in a larger number of farmers' fields $(n=63)$ did not enhance grain yields, which could indicate that the inoculant was not very effective. Reported yield responses to inoculant application on smallholder farmers' fields are highly variable and there can be an additive effect of inoculant and $P$ fertiliser application on yield (Ronner et al., 2016). In our study, different nutrients in the applied fertiliser blend may have had contrasting impacts on the \%Ndfa. While the $\mathrm{N}$ input from fertiliser may have suppressed $\mathrm{N}_{2}$-fixation (Salvagiotti et al., 2008), the additional P may have enhanced the \%Ndfa (Pule-Meulenberg et al., 2011).

The total amount of $\mathrm{N}_{2}$ fixed was strongly affected by crop productivity components such as grain yield, biomass accumulation and plant height (Table 3.5). Unlike the $\% \mathrm{Nfda}$, total $\mathrm{N}_{2}$ fixation and soybean yields varied considerably between regions and years, probably due to different interacting production constraints (Fermont et al., 2009) such as soil characteristics, rainfall distribution, weed management, pest and disease incidence and time of sowing (Chapter 2). The combined application of fertiliser and inoculant increased the quantity of $\mathrm{N}_{2}$ fixed, biomass and grain yields (Table 3.4). This is in line with our findings that the amount of $\mathrm{N}_{2}$ fixed was associated with soil available $\mathrm{P}$ content (Table 3.5). Since soil exchangeable $\mathrm{K}$ content did not appear to be limiting (Table 3.1), the positive effect of $\mathrm{K}$ on $\mathrm{N}_{2}$-fixation (Table 3.5) may be due to a correlation between soil available $\mathrm{P}$ and exchangeable $\mathrm{K}(\mathrm{r}=0.35, \mathrm{p}<0.001)$. The effect of grain yield on total $\mathrm{N}_{2}$ fixation and vice versa (Table 3.5) suggests that adoption of yield improving crop management practices such as the correct sowing rate to achieve a good plant population $\left(200,000-500,000\right.$ plants ha $\left.{ }^{-1}\right)$ and appropriate weed control (Table 3.5) will also result in larger quantities of $\mathrm{N}_{2}$ fixation. 
Therefore, our results suggest that farmers whose soybean crops are likely to fix large quantities of $\mathrm{N}_{2}$ are those who achieve good soybean yields, apply $\mathrm{P}$ fertiliser or have soils that are rich in available $\mathrm{P}$, and adopt crop management practices that enhance biomass accumulation and grain yields. This is in line with several studies that have shown that including soybean in a maize-based system is a better investment if $\mathrm{P}$ fertiliser is applied to soybean (Ogoke et al., 2003; Kihara et al., 2010), since application of P fertiliser is known to enhance $\mathrm{N}$ accumulation by soybean (Jemo et al., 2006).

Soybean as a preceding crop improved maize grain yields, but this yield benefit was not affected by the soybean grain yields or biomass accumulation in 2010 (Table 3.9). Due to the limited number of plots included in the BNF trial in 2010, we also could not find correlations between the $2010 \mathrm{~N}_{2}$-fixation data and the rotational benefits of soybean to maize in 2011. A review of several studies in sub-Saharan Africa shows that a cereal crop preceded by soybean takes up an additional 10-77 $\mathrm{kg} \mathrm{N} \mathrm{ha}^{-1}$ (Franke et al., 2018). This effect could be less in our study since the majority of farmers burnt or removed above-ground biomass from the field at harvest (Table 3.6), though there may have been a contribution of the below-ground biomass to the $\mathrm{N}$ economy (Wichern et al., 2008). The field $\mathrm{N}$ balance of soybean after grain removal is often negative (Salvagiotti et al., 2008; Vanlauwe and Giller, 2006; Mastrodomenico and Purcell, 2012) but it is usually still larger than in continuous maize without adequate $\mathrm{N}$ inputs (Peoples et al., 1995; Sanginga, 2003). In our study we did not measure $\mathrm{N}$ uptake by maize and the yield increase is likely to be a combination of $\mathrm{N}$ and non$\mathrm{N}$ factors (Franke et al., 2018). Non-N rotational benefits could have included increased availability of $\mathrm{P}$ to maize following legumes (Carsky et al., 1997), suppression of root nematodes (Bagayoko et al., 2000) or other benefits (Franke et al., 2018). Non-N benefits may explain why yield increases of maize preceded by soybean were stronger in more productive fields where $\mathrm{N}$ was applied to maize (Table $3.8,3.9$ ).

\subsubsection{Which farmers benefit most from $\mathrm{N}_{2}$-fixation and crop rotation?}

For sustainable intensification to be acceptable to smallholder farmers, promoted technologies should be aligned to the local heterogeneous conditions and should result in immediate benefits for farmers (Vanlauwe et al., 2014). Surprisingly, gender strongly affected the $\% \mathrm{Ndfa}$, though this may be confounded with soil type since most participating female farmers were based in Dowa where soils were less sandy. Though interaction between soil texture and gender was not significant $(\mathrm{p}=0.07)$, there is still a $93 \%$ likelihood that this was not by coincidence. Moreover, male farmers achieved better soybean grain yields (Table 3.5). This is in line with findings by Kilic et al. (2015) that female-managed plots in Malawi are $25 \%$ less productive than male-managed plots. Gender of the farmer was not related to any of the household socio-economic characteristics, which suggests that female farmers did not belong to poorer households than male farmers. Possibly, female farmers had less access 
to resources within the household, as was the case with climbing bean producers in Rwanda (Franke et al., 2016). Poor female farmers in Malawi are more likely to diversify into offfarm casual labour (ganyu) on wealthier farmers' fields in exchange for basic food supplies (Bryceson, 2006; Simtowe, 2010). Time spent on off-farm activities may have negatively affected crop management and yields on female farmers' fields. Men tend to allocate their time to high-value crops resulting in limited male labour inputs in female-managed fields (Kilic et al., 2015). Our results show that wealth of the household in terms of value of assets is positively associated with soybean grain yields (Table 3.5) and the absolute maize yield response to soybean (Table 3.9), probably because wealthier farmers have more fertile soils and can afford better management (Franke et al., 2014). These farmers may be in a better position to invest in nutrient inputs. The low value to cost ratio of fertiliser application to soybean and farmers' perceptions that soybean does not require additional nutrients may hamper the adoption of inorganic fertiliser application in legumes (Kamanga et al., 2010b; Van Vugt et al., 2017). However, our observation that the response to nutrient inputs to maize is enhanced by soybean as a previous crop implies that soybean cultivation can make fertiliser application to maize economically more attractive. Poor farmers who cannot afford improved varieties and fertiliser inputs may benefit less from including soybean in the crop rotation than wealthier farmers who can invest in improved inputs.

The results from both trials suggest that an improved integrated management including variety choice, external nutrient input application and other yield enhancing crop management practices, is associated with greater $\mathrm{N}_{2}$-fixation and residual effects of soybean on a subsequent maize crop. Thus, promoting the cultivation of soybean should be part of a wider Integrated Soil Fertility Management strategy (Vanlauwe et al., 2010). Farmers that have the means to invest in yield-enhancing technologies in both maize and soybean are likely to achieve the greatest benefits from incorporating soybean in maize-based rotations. Simply distributing soybean seed to support resource-poor smallholder farmers without further support is unlikely to be an effective development strategy.

\section{Acknowledgements}

This work was supported by the Directorate for Development Cooperation of the Netherlands Ministry of Foreign affairs (DGIS) through funding of the first author's position at IITA. Operational research costs were provided by IITA. We thank the Bill \& Melinda Gates Foundation for funding through a grant to Wageningen University to support the project N2Africa: Putting Nitrogen Fixation to Work for Smallholder Farmers in Africa (www.N2Africa.org). We acknowledge the field technicians and farmers in Dowa, Mchinji and Salima who helped to collect data and participated in this study. 
Chapter 3 


\section{Chapter 4}

Exploring the yield gap of orange-fleshed sweet potato varieties on smallholder farmers' fields in Malawi

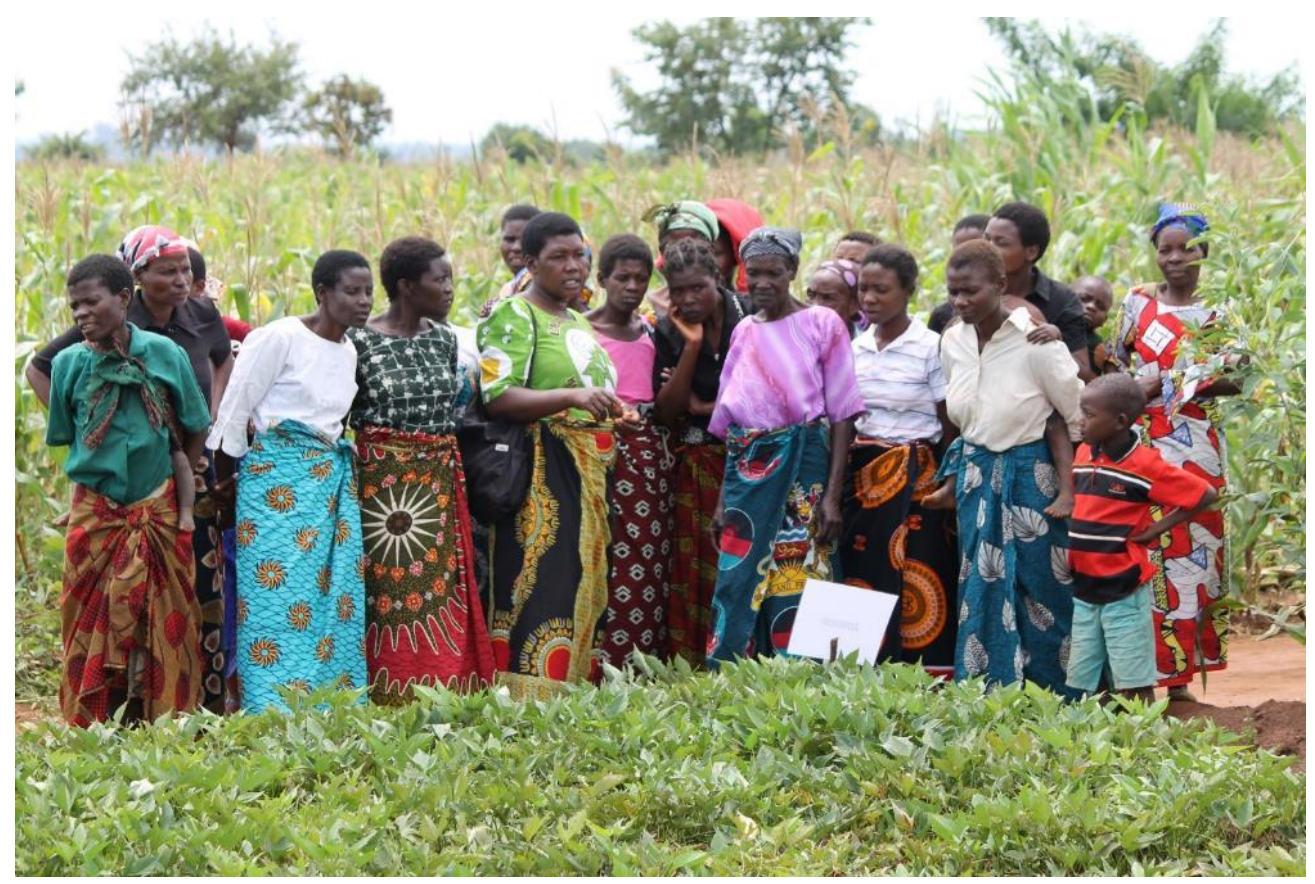

This chapter is published as:

Van Vugt, D., Franke, A.C., 2018, Exploring the yield gap of orange-fleshed sweet potato varieties on smallholder farmers' fields in Malawi. Field Crops Research 221, 245-256. 


\begin{abstract}
Orange-fleshed sweet potato (OFSP) can contribute to combating vitamin A deficiency and establishing more resilient cropping systems in sub-Saharan Africa. There is limited understanding of the factors that affect yield and quality of OFSP on smallholder farmers' fields. This study aimed to assess the performance of six OFSP varieties, identify factors limiting productivity and explore options to close the gap between actual and attainable OFSP yields on fields of smallholder farmers. Data were collected in the 2015/16 growing season from 221 on-farm variety demonstrations in seven districts in central and southern Malawi. Dependent variables of interest included crop establishment, vine yields, storage root formation, root yields, percentage of marketable root yield, and weevil infestation. Using linear mixed models, a range of biophysical, climatic, management and socio-economic factors and variables was used to identify associations with these dependent variables. The root yield gap was explored using a multivariate boundary line model to identify the most yield limiting factors. Results show a large variability across farmers' fields and a wide range of interacting factors affecting the variables of interest. Varieties Chipika and Kadyaubwerere attained good yields and were preferred by farmers in terms of taste. Varieties Zondeni and Anaakwanire gave a poor root yield, but a good vine yield. Timely planting is crucial to attain good root yields by making better use of the available rainfall. There was a varietal effect on weevil infestation and Kaphulira was most affected. Weevil control is required for market-oriented producers to enhance the percentage of marketable roots. The average attainable fresh root yield ranged from $18 \mathrm{t} \mathrm{ha}^{-1}$ for Zondeni to $32 \mathrm{t} \mathrm{ha} \mathrm{h}^{-1}$ for Mathuthu, against actual yields of 5 to $9 \mathrm{t} \mathrm{ha}^{-1}$. Elevation, planting date, rainfall and crop establishment could explain only 28 percent of the average yield gap, while 49 percent was explained for Mathuthu. Other factors that may explain the yield gap, but were not included in the model are: tillage methods and soil nutrient limitations. Male host farmers received better quality cuttings and planted in better soil moisture conditions, resulting in better establishment and vine yields. OFSP productivity can be enhanced through gender-sensitive extension, by ensuring male and female farmers can plant clean planting material of a suitable variety early in the rainy season. This requires additional efforts in vine multiplication of the required variety prior to the onset of the rains.
\end{abstract}

Keywords: Boundary line analysis, production constraints, sweet potato yield, weevils, planting material 


\subsection{Introduction}

The population in sub-Saharan Africa is expected to increase 2.5-fold and the demand for cereals to triple by 2050, indicating a pressing need to close yield gaps and increase cropping intensity to reduce future dependence on food imports (Van Ittersum et al., 2016). At the same time food systems should not only feed the population, but also provide affordable nutritious diets (Haddad et al., 2016). Micronutrient deficiencies are a major health concern in sub-Saharan Africa caused by a lack of crop diversity, limited access to markets with nutritious food and consequently limited dietary diversity (Luckett et al., 2015).

Sweet potato (Ipomoea batatas [L.] Lam) fits well in this context, since it is widely produced and rich in carbohydrates, protein, calcium, iron, potassium, carotenoids, dietary fiber, and vitamins (especially $\mathrm{C}$, folate, and $\mathrm{B}_{6}$ ), and very low in fat and sodium (Bovell-Benjamin, 2007). Sweet potato production in Africa has doubled from 1.0 to 2.0 million tons between 2002 and 2012 (FAO, 2017). Predominantly white or yellow fleshed varieties are cultivated, while orange-fleshed sweet potato (OFSP) is rich in beta-carotene which is converted into vitamin A in the human body (Low et al., 2017). Vitamin A is an essential nutrient that prevents blindness in children and pregnant women. It is deficient among people in most subSaharan African countries, which results in increased risks of severe infections and even death from common diseases such as diarrhea and measles (WHO, 2017). Promotion of OFSP has proven to be an effective food based approach to increase vitamin A intake and serum retinol concentrations in young children in rural Mozambique (Low et al., 2007). As a result of a growing evidence base on the effectiveness of OFSP to improve nutritional status (Tanumihardjo et al., 2017), to date 42 OFSP varieties have been bred in Africa (Low et al., 2017). Sweet potato in Africa is perceived as a drought-tolerant food security crop (Motsa et $a l ., 2015)$. Mass relief distributions of planting material to drought-, flood- or conflictaffected households are common (Kapinga et al., 2005). There is limited awareness on the potential of sweet potato as a viable cash crop. Consumers that were well informed about the nutritional benefits were willing to pay $51 \%$ more for OFSP than for white-fleshed sweet potato in Mozambique (Naico and Lusk, 2010) and 25\% more in Uganda (Chowdhury et al., 2011), while without prior nutritional information this is not the case. This corresponds with results of a meta-analysis of 23 studies that shows consumers are willing to pay $21 \%$ more for biofortified crops (De Steur et al., 2017).

Better OFSP yields will enable smallholder farmers to harvest more beta-carotene per ha for home consumption or market sales to the wider rural and urban population. Breeding programs continue releasing new OFSP varieties in Africa (Andrade et al., 2016). Besides good potential yields, traits of particular importance include storability, sweet and dry taste, early maturity, drought tolerance and high beta-carotene content (Laurie et al., 2004). The actual yields of sweet potato in southern Africa are estimated to be as low as $3 \mathrm{t}$ fresh root 
$\mathrm{ha}^{-1}$ in the period 2010-2014 (FAO, 2017) compared with attainable yields of $27 \mathrm{t} \mathrm{ha}^{-1}$ reported in Mozambique (Andrade et al., 2016) and $35 \mathrm{t} \mathrm{ha}^{-1}$ in Malawi (Chipungu, 2015). This shows that despite breeding efforts, smallholder farmers are often unable to benefit from yield gains from genetic improvement (Tittonell and Giller, 2013) due to other yield reducing factors.

Despite the relative drought tolerance of sweet potato compared to cereal crops (Motsa et al., 2015), water limitations greatly affect crop development. Root formation on freshly planted cuttings is optimal at a soil water content of $80 \%$ of field capacity, though even at $40 \%$ of field capacity considerable root formation still occurs (Belehu, 2003). Crop water use of sweet potato under full irrigation in Mozambique was $800 \mathrm{~mm}$ with root yields of $33 \mathrm{tha}^{-1}$ compared to $360 \mathrm{~mm}$ and $15 \mathrm{t} \mathrm{ha}^{-1}$ in the same site under rain fed production (Gomes and Carr, 2001; Gomes and Carr, 2003). Other studies confirmed that irrigation can enhance yields (Ghuman and Lal, 1983) and total nitrogen concentration, but can reduce dry matter concentration in the roots (Ekanayake and Collins, 2004). Despite common low-input cultivation practices, sweet potato shows a large yield response to nutrient input application via fertilizer and manure (Agbede, 2010). Potassium enhances root yields and quality by increasing the root: top ratio, dry matter concentration and beta-carotene and anthocyanin contents (George et al., 2002). Phosphorus and nitrogen application also enhance yields (Dumbuya et al., 2016; Ankumah et al., 2003). Tillage benefits root yield by reducing the bulk density of the soil (Agbede, 2010), while production on ridges may result in better yields than production on mounds (Dumbuya et al., 2016).

The most serious sweet potato disease in Africa is the sweet potato virus disease (SPVD) which is caused by combined infection with sweet potato chlorotic stunt virus by whiteflies and sweet potato feathery mottle virus by aphids (Gibson et al., 2004; Karyeija et al., 1998). Sweet potato weevil (C. formicarius complex) is worldwide considered the biggest pest attacking both cultivated and stored sweet potatoes (Allemann et al., 2004; Chalfant et al., 1990). Severity of weevil infestation depends on variety (Stathers et al., 2003b) and increases with delaying the harvest of mature roots (Smit, 1997). Both SPVD and weevils can infect new fields via planting material. Timely access by farmers to sufficient quantities of clean planting material is a challenge in areas with a long dry season due to limited knowledge of technologies to conserve vines (Okello et al., 2015). A final challenge affecting smallholder sweet potato producers is poor storability of roots compared to grain crops (Abidin et al., 2016).

Low crop yields are usually caused by a multitude of interacting biophysical, socio-economic and management constraints that determine final production on farmers' fields (Fermont et al., 2009). Production ecology concepts (Van Ittersum and Rabbinge, 1997) are often used to quantify the yield gaps between potential, water- or nutrient-limited and actual yields. The 
extent to which biotic stresses such as pests, diseases and weeds or abiotic stresses such as nutrient deficiencies and drought affect the yield gap can vary across regions (Wairegi et al., 2010). To target interventions that aim to improve OFSP productivity on smallholder farmers' fields we need to identify the main factors contributing to the yield gap. This study reports on data collected in on-farm variety demonstration plots in seven districts in central and southern Malawi in the 2015/16 rainy season. We aimed to (i) assess the performance of six released OFSP varieties on a large number of farmers' fields in different agro-ecological conditions; (ii) identify important varietal, abiotic, biotic and crop management factors limiting smallholder OFSP production; (iii) discuss opportunities to enhance OFSP productivity for smallholder farmers, and; (v) draw lessons on the conditions under which OFSP planting material distributions to smallholder farmers will be most beneficial.

\subsection{Materials and methods}

\subsubsection{Location and approach of the study}

The study was conducted under the project 'Feed the Future Malawi Improved Seed Systems and Technologies' which aims to scale out seed and other crop technologies of various crops to >280,000 rural households in seven districts (Mchinji, Lilongwe, Dedza, Ntcheu, Balaka, Machinga and Mangochi) in central and southern Malawi. This target area represents three agro-ecological zones (AEZ) as defined in Malawi (Saka et al., 2006): AEZ 1 represents the lake shore, middle and upper Shire at an elevation of 200-760 meters above sea level (masl), AEZ 2 the mid-elevation upland plateau at 760-1300 masl, and AEZ 3 the highlands at $>1300$ masl (Fig. 4.1).

Malawi has a unimodal rainfall distribution with rains from December to April, followed by a long dry season. Long term average total rainfall in the research sites ranges from 801-1000 mm with 1001-1200 mm in the higher elevation areas of Dedza and Ntcheu (METMALAWI, 2017). On farm demonstrations were established in 390 sites in the 2015/16 rainy season. Eleven project partners including government and NGO's were responsible for implementation of the field activities and data collection. Each demonstration site consisted of six plots each planted with a different OFSP variety. Zondeni is a local variety that was recommended by the Department of Agricultural Research Services (DARS) in 2008 for scaling out, because there were no released OFSP varieties in Malawi yet. It matures late in 5-6 months and has a yield potential of only $16 \mathrm{t} \mathrm{ha}^{-1}$. Five other varieties were released by DARS in 2011 (Chipungu, 2015). These are Anaakwanire with a 5-6 months maturity period and yield potential of $25 \mathrm{t} \mathrm{ha}^{-1}$, Chipika and Kadyaubwerere with a medium maturity period of 4-5 months and $35 \mathrm{t} \mathrm{ha}^{-1}$, Mathuthu with 4-5 months and $25 \mathrm{t} \mathrm{ha}^{-1}$ and Kaphulira which is the earliest maturing variety with a growing period of 3-4 months and a potential yield of 35 $\mathrm{t} \mathrm{ha}^{-1}$. Each demonstration served as a learning site for fifty farmers who also received one bundle of planting material to plant in their own fields to apply what they learnt. 


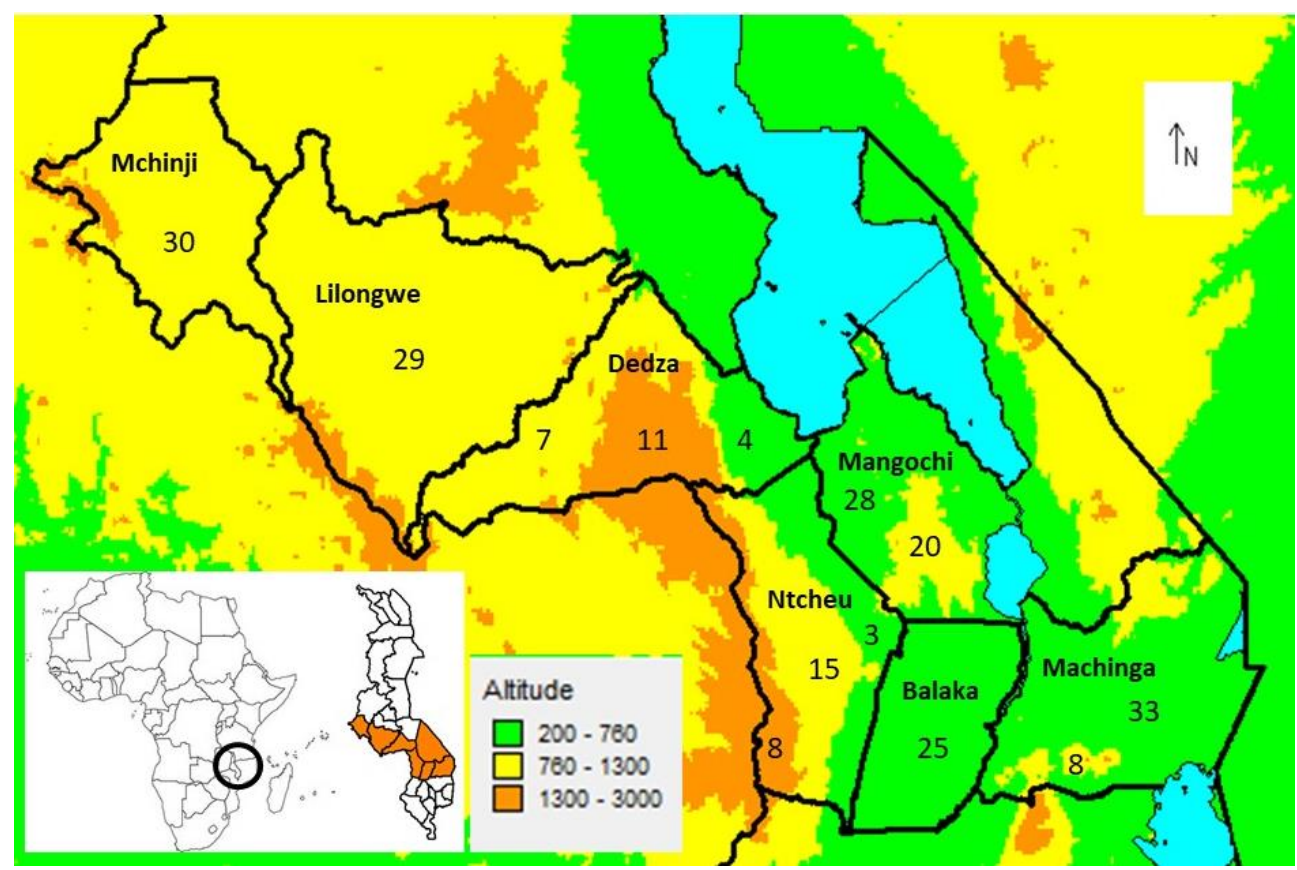

Fig. 4.1: Location and number of OFSP Mother Baby Trials in seven districts in three agro-ecological zones in Central and Southern Malawi.

\subsubsection{Trial design and data collection}

The field study was considered as a variety trial with 390 blocks that we refer to as 'demonstration sites'. Each site was a replication and contained six plots. The demonstration sites were established jointly by research, extension and farmers to ensure uniformity amongst treatments allowing for visual comparison and the collection of quantitative data. Each of the six varieties was planted in a plot of $5.4 \mathrm{~m}$ by $3.75 \mathrm{~m}\left(20.25 \mathrm{~m}^{2}\right)$. The plots consisted of five ridges of $5.4 \mathrm{~m}$ length with a spacing of $0.75 \mathrm{~cm}$ between ridges. The plants on each ridge were spaced at $32 \mathrm{~cm}$ resulting in 17 planting stations per ridge and 85 per plot, which equals 41,975 plants per ha. The sites were planted from December 26 to March 3 in AEZ 1, December 22 to February 23 in AEZ 2 and December 30 to January 23 in AEZ 3. This resulted in the five planting date classes: 16-31 December $(n=41), 1-15$ January $(n=$ $24), 16-31$ January $(n=90), 1-15$ February $(n=58)$ and $>16$ February $(n=8)$. The boundaries of the planting date classes were set at approximately two-week intervals starting at the beginning or the middle of a month to ensure that a representative sample was included in each class and planting date recommendations can be derived. No fertilizer, manure or chemicals to control pests and diseases were applied at any stage during the season. 
Within the first month after planting (MAP), composite soil samples $(0-20 \mathrm{~cm})$ were collected in 70 sites (10 per district) by taking six subsamples in each site. Subsamples were taken at the flank of the ridge in the middle of each plot, mixed, air-dried, crushed and sieved through a 2-mm sieve. They were analyzed at SGS in South Africa for soil $\mathrm{pH}(1 \mathrm{M} \mathrm{KCl})$, available P (Bray-1), K, Ca, Mg (Amm Acetate), $\mathrm{Cu}, \mathrm{Zn}, \mathrm{Mn}, \mathrm{Fe}(0.1 \mathrm{M} \mathrm{HCl}), \mathrm{B}\left(\mathrm{H}_{2} \mathrm{O}\right), \mathrm{S}$ (Am Ac), texture (hydrometer), soil organic carbon (Walkley-Black) and organic matter. Each district is divided in 5 to 6 administrative units called extension planning areas (EPAs). Monthly accumulated rainfall data $(\mathrm{mm})$ and the number of rainy days per month were provided by government for each EPA following regular district level data collection. These data were used to estimate the total rainfall received in the season (November to May) for each demonstration site. The last month with rainfall was defined as the last month in the growing season with more than $20 \mathrm{~mm}$ rainfall (in most cases March or April). The last date with effective rainfall was estimated by dividing the total rainfall received in the last month with rainfall by a daily evapotranspiration rate of $4 \mathrm{~mm}$. The number of days between planting the site and the estimated last available rainfall date was calculated to estimate the period over which each site received rainfall, also referred to as rainfall exposure period.

Data collected at planting included gender of the host farmer of the demonstration site, planting date, GPS coordinates and elevation. The quality of the cuttings was categorized as poor, just fine, or healthy and soil moisture content as dry, moist or wet. In most demonstration sites, field facilitators and the 50 satellite farmers counted the number of plants that established out of the 85 cuttings in each plot between one and two months after planting. Weeding dates were not recorded, but prior to or during participatory vine establishment all fields were cleared of weeds. At the time of participatory harvest an area of 4.20 by 2.25 meter was demarcated as the 'net plot' for each variety excluding the two border ridges and two planting stations on each end of the three middle ridges. First, the vines and roots from these border plants were harvested, labelled and removed from the field. After this, the net plot with a maximum on 39 plants was harvested. Data collected included the total number of plants harvested, the number of plants that had storage roots, and the fresh weight of the vines from the net plot. Roots were harvested and separated into marketable (>100 g) and non-marketable ( $<100 \mathrm{~g})$ sizes. Besides root size, the marketability was determined based on farmers' assessment whether they would be able to sell the roots on the local fresh root market or not. The number of roots and total weight of marketable and non-marketable roots was recorded separately. The total number of weevil infested roots was recorded in each plot. Weevil infestation was identified by dark scarred spots on the root surface where weevils penetrated to feed on the roots (Stathers et al., 2003a).

Data on sensory evaluation of the six OFSP varieties were recorded in 94 sites (50 in AEZ 1, 41 in AEZ 2, and 3 in AEZ 3) with the farmers that participated in the harvest. Groups in each site consisted of about 40-60 people including men, women and children in different 
ratios depending on the site. A group of women boiled the roots harvested from the border ridges in six pots up to the point a fork could enter the root without it breaking. The roots were cut in pieces and presented on six plates without mention of the name of the variety. All participants could see and taste a sample of each variety. Thereafter they were asked to stand in a line behind the plate of their most preferred variety and the number of people in each line were counted. The varieties were subsequently ranked from 1 (most preferred) to 6 (least preferred).

\subsubsection{Data handling and statistical analysis}

Sites with yield data on less than four out of the six plots were excluded from analysis, resulting in a data set of 221 sites with soil data available for 63 of these sites. To explore variability in the dependent variables (establishment percentage, vine yield, total root yield, percentage of marketable root yield and percentage of weevil infested roots), these were presented by variety in cumulative probability curves (Vanlauwe et al., 2016). Linear mixed model (REML) analysis in Genstat $18^{\text {th }}$ edition was used to test which categorical factors were significantly associated with the dependent variables. Categorical factors included AEZ, variety, planting date class, gender, condition of cuttings and soil moisture at planting. A linear mixed model was also used to test for significant associations between continuous independent variables on the same dependent variables of interest, while adding relevant categorical factors as random factors in the model. The continuous variables included elevation, planting date, rainfall exposure days, total rainfall, harvest date, growing period and all soil parameters. Spearman's Rank Correlation coefficients were calculated to determine the strength and the direction of the association. Correlation analysis was also done to assess associations between the dependent variables: percentage establishment, vine yield, percentage of plants harvested with roots, total root yield, percentage of root yield that is marketable and percentage weevil infested roots. The sum of preference rank scores was calculated for each variety. Differences in sensory preference for the varieties were analysed using critical values for the differences between rank sums $(\mathrm{p}<0.05)$. The critical values were derived from expanded tables for multiple comparison of ranked data (Newell and MacFarlane, 1988). This was done for all sites $(n=94)$ and by AEZ. Due to the small number of data points $(n=3)$ in AEZ 3, these were merged with AEZ 2.

\subsubsection{Root yield gap analysis}

We assessed correlations between root yield and continuous variables with Spearman's test for non-parametric data and explored functional relationships in scatter graphs. Variables with a correlation coefficient $>0.3$ (Van Asten et al., 2003), a significant correlation $(\mathrm{p}<0.05)$, or where the upper points in the scatter plot with yield suggested a functional relationship (Wairegi et al., 2010) were included in the boundary line analysis. Plots with missing data for one or more variables were removed from the analysis and 1057 plots from 191 trials were included. Several methods have been reported to fit boundary lines through 
the upper boundary points of the data clouds. Simple methods include drawing the lines by hand (Chambers et al., 1985) or manually selecting upper points and fitting a linear, logarithmic or polynomial regression line (Van Asten et al., 2003). In this study we explored two more advanced methods. Firstly, we split data sets into 8-10 equidistant groups on the $\mathrm{X}$-axis followed by calculating the boundary points as the upper confidence interval (Schmidt et al., 2000; Casanova et al., 1999). We selected 'mean + 3 x STDEV' as boundary points. In the second method, we applied the model $y_{l}=\frac{y_{\max }}{1+K^{-R x}}$ where $\mathrm{y}_{\max }$ is the observed attainable yield level, $\mathrm{x}$ is the independent variable, and $\mathrm{K}$ and $\mathrm{R}$ are constants (Wairegi et al., 2010; Fermont et al., 2009). In both methods the best boundary line model was obtained by minimizing the root mean squared error (RMSE) between the fitted boundary line ( $\left.\mathrm{y}_{1}\right)$ and the boundary points. In case of a negative correlation between the two variables we fitted a linear or polynomial boundary line through the boundary points. After visual assessment of the boundary lines resulting from both methods, the upper confidence interval method was selected for further analysis. We combined the boundary lines for each variable in a multivariate model and predicted the yield for each individual plot by identifying the most limiting factor following von Liebig's law of the minimum (Shatar and McBratney, 2004; Von Liebig, 1863). We ranked the most limiting constraints for each variety by counting the frequency that each variable is responsible for the lowest predicted yield. To evaluate this multivariate model we plotted the predicted yields for each plot against actual yields in scatter graphs. The difference between the attainable yield (Yatt) and the minimum yield predicted by the model (Ymin) was defined as the explainable yield gap. We quantified Yatt for each variety as the mean $+3 \mathrm{x}$ STDEV of the total root yield. The difference between Ymin and the actual yield (Yact) was defined as the unexplained yield gap. When the unexplained yield gap is large this means that not all important variables have been included in the analysis (Van Asten et al., 2003). Yield gaps have been quantified in similar way for cereals (Casanova et al., 1999), cassava (Fermont et al., 2009) and East African highland bananas (Wairegi et al., 2010).

\subsection{Results}

\subsubsection{Biophysical and climatic conditions of the trial sites}

Among farmers hosting a demonstration, 33\% were female. Planting took place between December 22, 2015 and March 3, 2016. A mismatch between time of distribution of perishable planting materials and distribution of rainfall resulted in planting demonstrations under dry soil conditions in $6 \%$ of the sites and poor quality planting material was planted in $2 \%$ of the sites (Table 4.1 ). 
Table 4.1: Biophysical conditions, crop management components and gender participation in three agro-ecological zones (AEZ), mean and standard deviations from mean between brackets.

\begin{tabular}{|c|c|c|c|c|c|}
\hline & $\begin{array}{l}\text { AEZ 1 } \\
(n=92) \\
\end{array}$ & $\begin{array}{l}\text { AEZ 2 } \\
(n=110)\end{array}$ & $\begin{array}{l}\text { AEZ 3 } \\
(n=19) \\
\end{array}$ & $\begin{array}{l}\text { Mean } \\
(n=221)\end{array}$ & SED $^{1}$ \\
\hline \multicolumn{6}{|l|}{ Continuous } \\
\hline Elevation $^{2}$ & $585(107)$ & $1036(141)$ & $1465(102)$ & $885(306)$ & $27 * * *$ \\
\hline Planting date ${ }^{3}$ & $35(13)$ & $26(17)$ & $15(8.8)$ & $29(16)$ & $3.2 * * *$ \\
\hline Harvest date ${ }^{4}$ & $38(16)$ & $31(13)$ & $28(11)$ & $34(14)$ & $1.2 * * *$ \\
\hline Growing period (days) & $135(16)$ & $137(16)$ & $144(13)$ & $137(16)$ & n.s. \\
\hline Total rainfall & $513(181)$ & $635(169)$ & $780(131)$ & 597 (189) & $15 * * *$ \\
\hline Rainfall exposure $^{5}$ (days) & $78(16)$ & $89(24)$ & $105(14)$ & $86(22)$ & $4.4 * * *$ \\
\hline $\begin{array}{l}\text { Plant population }(1000 \mathrm{pl} \\
\left.\mathrm{ha}^{-1}\right)\end{array}$ & $30(17)$ & $33(9)$ & $28(11)$ & $32(10)$ & $1.1 * * *$ \\
\hline \multicolumn{6}{|l|}{ Categorical } \\
\hline $\begin{array}{l}\text { Female host farmers ( } \% \\
\text { of farmers) }\end{array}$ & 26 & 36 & 47 & 33 & \\
\hline \multicolumn{6}{|l|}{ Soil moisture at planting } \\
\hline (\% of sites) & 7 & 6 & 11 & 6 & \\
\hline Moist (\% of sites) & 68 & 25 & 73 & 48 & \\
\hline Wet (\% of sites) & 25 & 69 & 16 & 46 & \\
\hline \multicolumn{6}{|l|}{$\begin{array}{l}\text { Condition of cuttings at } \\
\text { planting }\end{array}$} \\
\hline (\% of sites) & 0 & 2 & 11 & 2 & \\
\hline Just fine $(\%$ of sites $)$ & 33 & 19 & 21 & 25 & \\
\hline Healthy (\% of sites) & 67 & 79 & 68 & 73 & \\
\hline
\end{tabular}

${ }^{1}$ Standard Error of Differences, ${ }^{*} \mathrm{p}<0.05, * * \mathrm{p}<0.01,{ }^{* * *} \mathrm{p}<0.001,{ }^{2}$ meters above sea level, ${ }^{3}$ expressed as the number of days after the first trial was established, ${ }^{4}$ number of days after the first trial was harvested, ${ }^{5}$ number of days from planting to the last effective rainfall event.

The average plant stand 1-2 months after planting was 32,000 plants ha ${ }^{-1}$ out of a planting density of 41,975 cuttings ha ${ }^{-1}$. Harvesting took place in the period May 2 to July 22 in AEZ 1, May 12 to July 10 in AEZ 2 and May 19 to June 27 in AEZ 3. The average growing period from planting to harvest was 137 days (Table 4.1). The demonstrations were established in a season that was considered poor in rainfall, with especially AEZ 1 and AEZ 2 receiving on average only 513 and $635 \mathrm{~mm}$. Due to the wide range in planting dates, demonstration sites in these AEZs did not equally benefit from the available rainfall. The average rainfall exposure period ranged from 78 days in AEZ 1 to 105 days in AEZ 3 (Table 4.1). After the last effective rainfall event the sweet potato roots stayed in the soil for an average of 51 days before harvesting. The relatively low soil OM content (Table 4.2) indicates that nitrogen (not measured) may be limiting OFSP yields. Available P appears less limiting but the large variability shows it may limit yields in several sites, especially in AEZ 1 and 2. The soils do not show severe signs of $\mathrm{K}$ deficiency, though the large crop requirement for $\mathrm{K}$ may result in 
yield limitations. The average soil $\mathrm{pH}$ was in the range of 4.7-4.9 (in $\mathrm{KCl}$ ) and the smallest $\mathrm{pH}$ of 4.3 was unlikely to limit yields. Soils in AEZ 1 and 2 contained more sand than in AEZ 3.

Table 4.2: Soil characteristics in selected trial sites, mean and standard deviations from the mean between brackets

\begin{tabular}{|c|c|c|c|c|c|c|c|c|}
\hline \multicolumn{2}{|c|}{ Soil parameter } & \multicolumn{2}{|c|}{$\begin{array}{l}\text { AEZ 1 } \\
(n=23)\end{array}$} & \multicolumn{2}{|c|}{$\begin{array}{l}\text { AEZ 2 } \\
(n=32)\end{array}$} & \multicolumn{2}{|c|}{$\begin{array}{c}\text { AEZ 3 } \\
(n=8)\end{array}$} & \multirow{2}{*}{$\begin{array}{l}\text { SED }^{1} \\
0.22\end{array}$} \\
\hline $\mathrm{pH}^{2}$ & $(\mathrm{KCl})$ & 4.9 & & 4.9 & & 4.7 & & \\
\hline Carbon & $\left(\mathrm{g} \mathrm{kg}^{-1}\right)$ & 12 & (4.6) & 12 & (5.6) & 12 & (3.5) & 0.7 \\
\hline $\mathrm{OM}$ & $\left(\mathrm{g} \mathrm{kg}^{-1}\right)$ & 21 & (7.9) & 21 & (9.7) & 20 & (6.0) & 1.3 \\
\hline Available P & $\left(\mathrm{mg} \mathrm{kg}^{-1}\right)$ & 27 & (18.7) & 18 & (14.6) & 40 & (14.8) & $2.4 * * *$ \\
\hline CEC & $\left(\mathrm{cmol} \mathrm{kg}^{-1}\right)$ & 6.80 & $(4.20)$ & 5.84 & $(3.06)$ & 6.35 & $(3.57)$ & 0.53 \\
\hline Exch. $\mathrm{K}^{+}$ & $\left(\mathrm{cmol} \mathrm{kg}^{-1}\right)$ & 0.43 & $(0.20)$ & 0.33 & $(0.18)$ & 0.40 & $(0.16)$ & $0.03 * * *$ \\
\hline Exch. $\mathrm{Ca}^{2+}$ & $\left(\mathrm{cmol} \mathrm{kg}^{-1}\right)$ & 4.53 & $(2.51)$ & 4.29 & $(2.13)$ & 4.32 & $(2.47)$ & 0.34 \\
\hline Exch. $\mathrm{Mg}^{2+}$ & $\left(\mathrm{cmol} \mathrm{kg}^{-1}\right)$ & 1.55 & $(0.93)$ & 1.21 & $(0.88)$ & 1.62 & (1.06) & $0.14 * * *$ \\
\hline Exch. $\mathrm{Na}^{+}$ & $\left(\mathrm{cmol} \mathrm{kg}^{-1}\right)$ & 0.05 & $(0.02)$ & 0.05 & $(0.02)$ & 0.05 & $(0.01)$ & $0.00 * *$ \\
\hline $\mathrm{Cu}$ & $\left(\mathrm{mg} \mathrm{kg}^{-1}\right)$ & 0.7 & $(0.22)$ & 1.1 & $(0.45)$ & 1.4 & $(0.76)$ & $0.07 * * *$ \\
\hline $\mathrm{Zn}$ & $\left(\mathrm{mg} \mathrm{kg}^{-1}\right)$ & 2.9 & $(2.27)$ & 1.8 & (1.63) & 2.4 & $(1.90)$ & $0.28 * * *$ \\
\hline $\mathrm{Mn}$ & $\left(\mathrm{mg} \mathrm{kg}^{-1}\right)$ & 28 & (10.2) & 26 & (16.1) & 28 & (7.66) & 2.0 \\
\hline B & $\left(\mathrm{mg} \mathrm{kg}^{-1}\right)$ & 0.35 & $(0.14)$ & 0.26 & $(0.16)$ & 0.28 & $(0.12)$ & $0.02 * * *$ \\
\hline S & $\left(\mathrm{mg} \mathrm{kg}^{-1}\right)$ & 12 & (7.4) & 11 & $(4.8)$ & 11 & (5.6) & 0.9 \\
\hline Clay & $\left(\mathrm{g} \mathrm{kg}^{-1}\right)$ & 107 & (50) & 150 & (56) & 168 & (85) & $8.6^{* * *}$ \\
\hline Silt & $\left(\mathrm{g} \mathrm{kg}^{-1}\right)$ & 134 & (49) & 126 & (46) & 158 & (33) & $6.7 * * *$ \\
\hline Sand & $\left(\mathrm{g} \mathrm{kg}^{-1}\right)$ & 759 & (84) & 724 & (91) & 675 & (99) & $13.1 * * *$ \\
\hline
\end{tabular}

${ }^{1}$ Standard Error of Differences, $* \mathrm{p}<0.05, * * \mathrm{p}<0.01, * * * \mathrm{p}<0.001,{ }^{2} \mathrm{pH}$ data were back-log transformed before calculating the means and therefore standard deviation are not provided; $\mathrm{pH}$ values ranged from 4.3 to 6.4 .

\subsubsection{Exploring variability in establishment, vine yield, total and marketable root yield, and weevil infestation.}

The effects of variety, AEZ and planting date class (Table 4.3) and the cumulative probability charts (Fig. 4.2) demonstrate the variability in establishment, vine yield, root yield, percentage of root yield that is marketable and the percentage of roots affected by weevils. The percentage establishment was associated with total root yield $(r=0.18 ; \mathrm{p}<0.001)$. Vine yield correlated with root yield $(r=0.41 ; p<0.001)$ and percentage marketable yield $(r=0.14$; $\mathrm{p}<0.001)$. Root yield correlated with the number of plants with roots harvested per ha $(\mathrm{r}=0.42$; $\mathrm{p}<0.001)$ and percentage marketable yield $(\mathrm{r}=0.18 ; \mathrm{p}<0.001)$. Marketable root yield $(\%)$ was negatively associated with percentage of roots affected by weevils $(\mathrm{r}=-0.27 ; \mathrm{p}<0.001)$. 


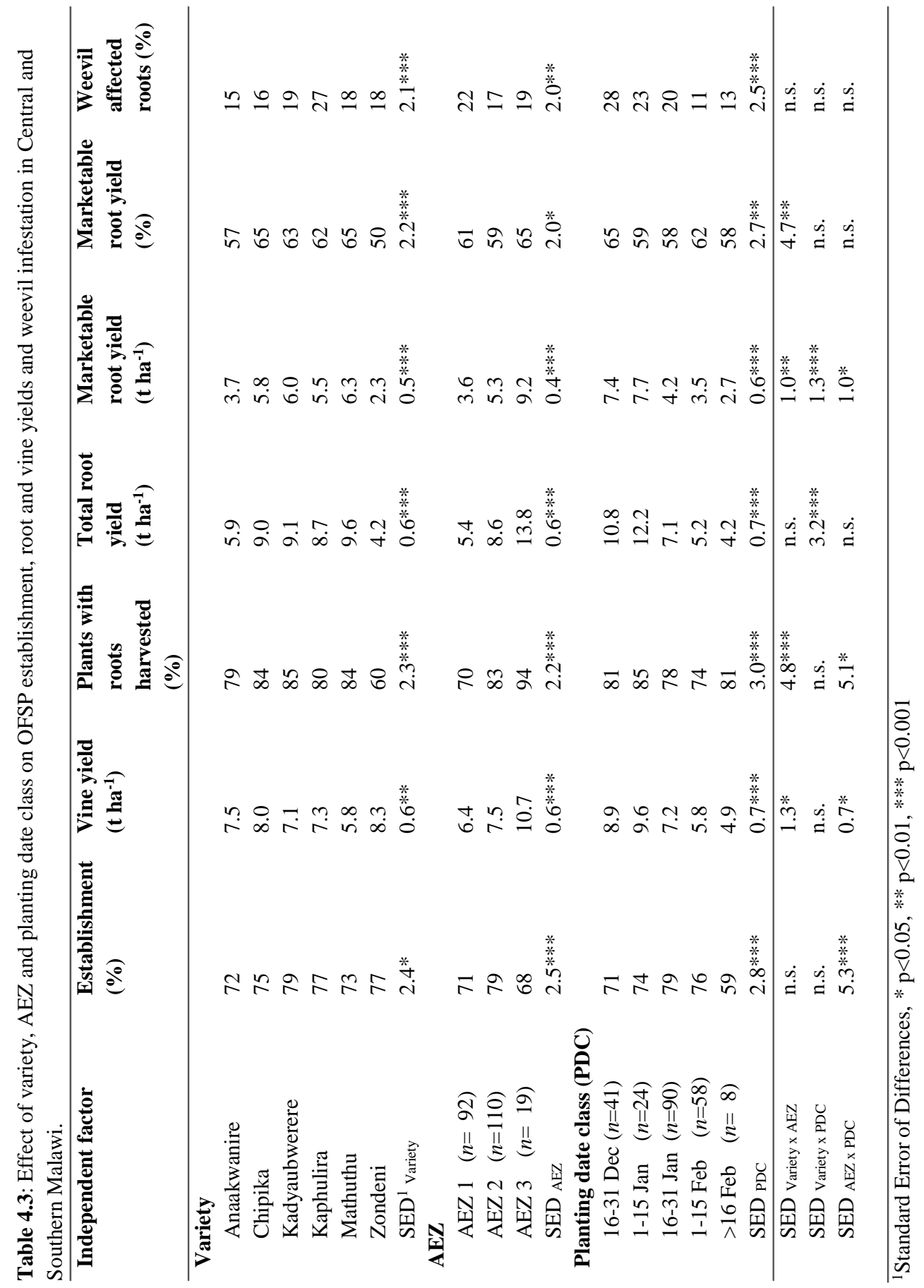



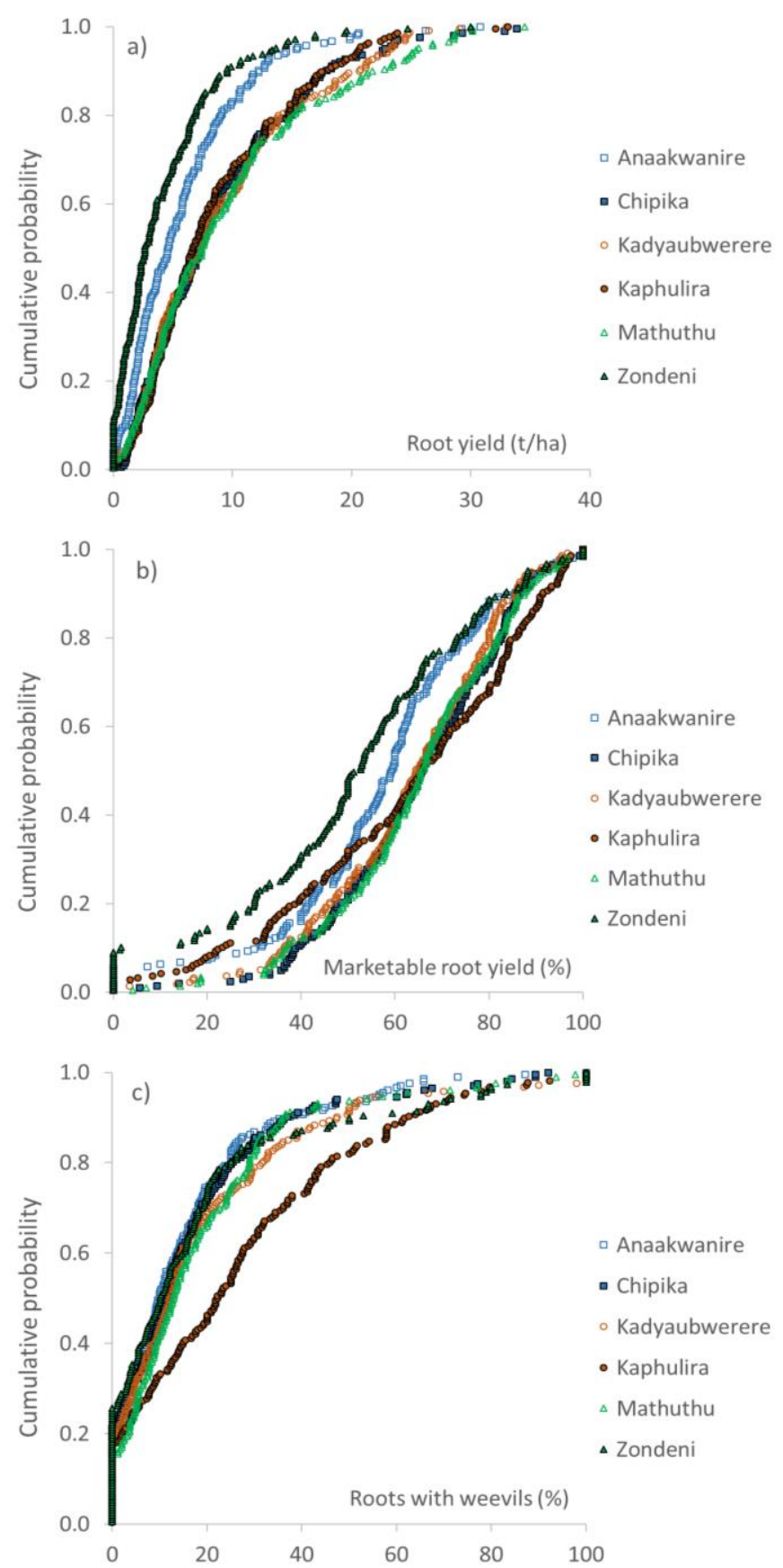

Fig. 4.2: Cumulative probability charts for six OFSP varieties of a) root yield, b) marketable root yield ( $\%$ of root weight) and c) percentage of roots infested with weevils. 
The REML resulted in additional categorical and continuous variables that are significantly associated with the dependent variables of interest (Table 4.4).

On average 31,718 out of the 41,975 cuttings ha ${ }^{-1}$ (76\%) established well. Kadyubwerere established better than Anaakwanire. AEZ and planting date class also affected establishment with the best establishment observed in AEZ 2, and in sites planted between 16 and 31 January (Table 4.3). Good establishment of more than $80 \%$ was achieved in $50 \%$ of the sites for Anaakwanire and $61 \%$ of the sites for Kadyaubwerere. Poor establishment of less than $50 \%$ ranged from $12 \%$ of the sites for Kadyaubwerere to $22 \%$ for Anaakwanire. Healthy cuttings resulted in better establishment (72\% establishment) than cuttings of fine $(69 \%)$ or poor $(64 \%)$ quality. Soil moisture conditions at planting also affected establishment with $76 \%$ achieved in wet soils compared to $69 \%$ in moist and $67 \%$ in dry soil conditions. Plants in male host farmers' fields established better (72\%) than in female farmers' fields $(67 \%)$. Gender interacted with both quality of cuttings $(\mathrm{p}=0.007)$ and soil moisture condition at planting $(\mathrm{p}<0.001)$ which suggests female farmers received poorer quality planting material at a time with less soil moisture content than male host farmers.

Mathuthu had a slightly smaller vine yield at harvest though overall vine yield did not differ much between varieties (Table 4.3). Vine yields were better in AEZ 3 and in sites planted before January 16 (Table 4.3). Fresh vine yield of over $10 \mathrm{t} \mathrm{ha}^{-1}$ was achieved in $15 \%$ of the sites for Mathuthu to $27 \%$ for Zondeni. Male farmers had better vine yields of $8.2 \mathrm{t} \mathrm{ha}^{-1}$ than female farmers with $7.1 \mathrm{t} \mathrm{ha}^{-1}$. Plots planted with healthy or medium quality cuttings yielded more vines ( 8.3 and $\left.8.0 \mathrm{t} \mathrm{ha}^{-1}\right)$ than with poor quality cuttings $\left(3.3 \mathrm{t} \mathrm{ha}^{-1}\right)$. There was an interaction between gender and quality of cuttings $(\mathrm{p}=0.034)$. Soil moisture conditions at planting also affected vine yields with $9.0 \mathrm{t} \mathrm{ha}^{-1}$ achieved in wet soils compared to $7.6 \mathrm{t} \mathrm{ha}^{-1}$ in moist and $5.9 \mathrm{t} \mathrm{ha}^{-1}$ in dry soil conditions. Vine yield correlated $(\mathrm{r}>0.2$ or $<-0.2)$ with the continuous variables elevation $(r=0.20 ; \mathrm{p}<0.001)$, root yield $(r=0.40 ; \mathrm{p}<0.001)$, clay content $(\mathrm{r}=0.24 ; \mathrm{p}<0.001)$ and sand content $(\mathrm{r}=-0.24 ; \mathrm{p}<0.001)$.

At harvest on average 30,490 plants ha $^{-1}$ (96\% of established plants) were uprooted. An average of $79 \%$ of these had storage roots. Root set for Zondeni and Anaakwanire was only $40 \%$ and $67 \%$ in AEZ 1 while it was $90 \%$ and $94 \%$ in AEZ 3. AEZ also affected the root set of other varieties but not to the same extent (Table 4.3). Soil texture affected root set (Table $4.4)$, as larger clay concentration correlated with more $(\mathrm{r}=0.23 ; \mathrm{p}<0.01)$, and larger sand concentration with less $(r=-0.22 ; \mathrm{p}<0.01)$ plants with roots. The percentage of plants with roots was also associated with total root yield $(\mathrm{r}=0.33 ; \mathrm{p}<0.001)$ and the percentage marketable yield $(\mathrm{r}=0.17 ; \mathrm{p}<0.01)$. 
Table 4.4: Factors affecting plant establishment, vine yield, root yield, percentage marketable root yield and percentage of weevil affected roots. The values are the F-probabilities generated by the REML analysis with the direction of the association given in brackets for the continuous variables.

\begin{tabular}{|c|c|c|c|c|c|c|c|}
\hline $\begin{array}{l}\text { Explanatory } \\
\text { variables }\end{array}$ & $\begin{array}{l}\text { Establish } \\
\text { ment }\end{array}$ & $\begin{array}{l}\text { Vine } \\
\text { yield }\end{array}$ & $\begin{array}{l}\text { Plants } \\
\text { with } \\
\text { roots } \\
\text { harvested } \\
(\%)\end{array}$ & $\begin{array}{l}\text { Root } \\
\text { yield }\end{array}$ & $\begin{array}{l}\text { Marketa- } \\
\text { ble root } \\
\text { yield }(\%)\end{array}$ & $\begin{array}{l}\text { Weevil } \\
\text { infested } \\
\text { roots }(\%)\end{array}$ & $\begin{array}{l}\text { Random } \\
\text { Factors }^{1}\end{array}$ \\
\hline $\begin{array}{l}\text { Categorical } \\
\text { factors }\end{array}$ & $\left(n^{2}=139\right)$ & $(n=221)$ & $(n=221)$ & $(n=221)$ & $(n=221)$ & $(n=221)$ & \\
\hline $\begin{array}{l}\text { Agro-ecological } \\
\text { zone }\end{array}$ & $<0.001$ & $<0.001$ & $<0.001$ & $<0.001$ & 0.017 & $<0.001$ & $\mathrm{~V}, \mathrm{P}$ \\
\hline Variety & 0.020 & $<0.001$ & $<0.001$ & $<0.001$ & $<0.001$ & $<0.001$ & $\mathrm{~A}, \mathrm{P}$ \\
\hline $\begin{array}{l}\text { Planting date } \\
\text { class }\end{array}$ & $<0.001$ & $<0.001$ & 0.042 & $<0.001$ & 0.002 & $<0.001$ & $\mathrm{~A}, \mathrm{~V}$ \\
\hline Gender & $<0.001$ & 0.004 & 0.561 & 0.177 & 0.468 & 0.017 & $\mathrm{~A}, \mathrm{~V}, \mathrm{P}$ \\
\hline $\begin{array}{l}\text { Condition of } \\
\text { cutting }\end{array}$ & 0.047 & $<0.001$ & 0.229 & 0.058 & 0.015 & 0.027 & $\mathrm{~A}, \mathrm{~V}, \mathrm{P}$ \\
\hline $\begin{array}{l}\text { Soil moisture at } \\
\text { planting }\end{array}$ & $<0.001$ & $<0.001$ & 0.395 & $<0.001$ & 0.642 & 0.138 & $\mathrm{~A}, \mathrm{~V}, \mathrm{P}$ \\
\hline $\begin{array}{l}\text { Continuous } \\
\text { variables }\end{array}$ & $(n=139)$ & $(n=221)$ & $(n=221)$ & $(n=221)$ & $(n=221)$ & $(n=221)$ & \\
\hline Elevation & $0.004(+)$ & $0.005(+)$ & $0.003(+)$ & $0.003(+)$ & $0.107(+)$ & $0.007(-)$ & $\mathrm{A}, \mathrm{V}, \mathrm{P}$ \\
\hline Planting date & $0.819(+)$ & $<0.001(-)$ & $0.384(-)$ & $0.009(-)$ & $0.592(-)$ & $<0.001(-)$ & $\mathrm{A}, \mathrm{V}, \mathrm{P}$ \\
\hline $\begin{array}{l}\text { Rainfall exposure } \\
\text { days }\end{array}$ & $0.165(-)$ & $0.107(+)$ & $0.405(+)$ & $<0.001(+)$ & $0.255(+)$ & $<0.001(+)$ & $\mathrm{A}, \mathrm{V}, \mathrm{P}$ \\
\hline Total rainfall & $0.021(-)$ & $0.005(+)$ & $0.054(+)$ & $<0.001(+)$ & $<0.001(+)$ & $0.008(-)$ & $\mathrm{A}, \mathrm{V}, \mathrm{P}$ \\
\hline Harvest date & $X$ & $<0.001(-)$ & $<0.001(-)$ & $0.059(-)$ & $0.024(+)$ & $0.143(-)$ & $\mathrm{A}, \mathrm{V}, \mathrm{P}$ \\
\hline Growing period & $\mathrm{X}$ & $<0.001(+)$ & $<0.001(-)$ & $0.238(-+)$ & $0.065(+)$ & $0.006(+)$ & $\mathrm{A}, \mathrm{V}, \mathrm{P}$ \\
\hline Soil parameters ${ }^{3}$ & $(n=55)$ & $(n=61)$ & $(n=61)$ & $(n=61)$ & $(n=61)$ & $(n=61)$ & \\
\hline $\mathrm{pH}$ & $0.015(-)$ & $0.007(+)$ & $0.431(-)$ & $0.134(-)$ & $0.009(+)$ & $0.003(-)$ & $\mathrm{A}, \mathrm{V}, \mathrm{P}$ \\
\hline $\mathrm{P}$ & $0.803(+)$ & $0.176(+)$ & $0.129(+)$ & $<0.001(+)$ & $0.954(-)$ & $0.982(+)$ & $\mathrm{A}, \mathrm{V}, \mathrm{P}$ \\
\hline CEC & $0.554(+)$ & $0.016(+)$ & $0.037(+)$ & $0.036(+)$ & $0.001(+)$ & $0.175(-)$ & $\mathrm{A}, \mathrm{V}, \mathrm{P}$ \\
\hline K & $0.247(+)$ & $<0.001(+)$ & $0.801(-)$ & $0.361(-)$ & $0.105(+)$ & $0.101(-)$ & $\mathrm{A}, \mathrm{V}, \mathrm{P}$ \\
\hline $\mathrm{Ca}$ & $0.686(+)$ & $0.140(+)$ & $0.142(+)$ & $0.132(+)$ & $0.014(+)$ & $0.159(-)$ & $\mathrm{A}, \mathrm{V}, \mathrm{P}$ \\
\hline $\mathrm{Mg}$ & $0.954(-)$ & $0.062(+)$ & $0.113(+)$ & $0.105(+)$ & $0.007(+)$ & $0.093(-)$ & $\mathrm{A}, \mathrm{V}, \mathrm{P}$ \\
\hline $\mathrm{Na}$ & $0.075(-)$ & $0.124(+)$ & $0.471(-)$ & $0.119(-)$ & $0.003(+)$ & $0.011(-)$ & $\mathrm{A}, \mathrm{V}, \mathrm{P}$ \\
\hline $\mathrm{Zn}$ & $0.452(+)$ & $0.131(-)$ & $0.482(-)$ & $0.104(-)$ & $0.755(-)$ & $0.017(+)$ & $\mathrm{A}, \mathrm{V}, \mathrm{P}$ \\
\hline $\mathrm{Mn}$ & $0.344(+)$ & $0.590(-)$ & $0.795(-)$ & $0.533(-)$ & $0.026(+)$ & $0.685(+)$ & $\mathrm{A}, \mathrm{V}, \mathrm{P}$ \\
\hline B & $0.942(+)$ & $0.043(-)$ & $0.603(-)$ & $0.889(-)$ & $0.854(-)$ & $0.002(+)$ & $\mathrm{A}, \mathrm{V}, \mathrm{P}$ \\
\hline S & $0.772(+)$ & $0.101(+)$ & $0.067(+)$ & $0.153(+)$ & $0.017(+)$ & $0.221(-)$ & $\mathrm{A}, \mathrm{V}, \mathrm{P}$ \\
\hline Clay & $0.289(-)$ & $0.003(+)$ & $0.035(+)$ & $0.300(+)$ & $0.615(+)$ & $0.139(+)$ & $\mathrm{A}, \mathrm{V}, \mathrm{P}$ \\
\hline Silt & $0.064(+)$ & $0.009(+)$ & $0.021(+)$ & $0.033(+)$ & $0.862(+)$ & $0.016(+)$ & $\mathrm{A}, \mathrm{V}, \mathrm{P}$ \\
\hline Sand & $0.668(-)$ & $<0.001(-)$ & $0.011(-)$ & $0.079(-)$ & $0.827(-)$ & $0.028(-)$ & $\mathrm{A}, \mathrm{V}, \mathrm{P}$ \\
\hline
\end{tabular}

${ }^{1}$ Random factors included in the REML model: $\mathrm{A}=$ Agro-ecological zone, $\mathrm{V}=$ Variety, $\mathrm{P}=$ Planting date class. ${ }^{2} n=$ the number of trials with data to include in the model. ${ }^{3} \mathrm{Carbon}, \mathrm{OM}$ and $\mathrm{Cu}$ were not associated with any of the dependent variables. 
Fresh root yields differed by variety with Zondeni and Anaakwanire achieving much smaller root yields than the other varieties (Table 4.3, Fig. 4.2a). Yields over $5 \mathrm{t} \mathrm{ha}^{-1}$ were achieved on $30 \%$ of sites for Zondeni, $46 \%$ for Anaakwanire, and $62-63 \%$ of sites for the other varieties. Yields over $20 \mathrm{t} \mathrm{ha}^{-1}$ were achieved on less than $2 \%$ of sites for Zondeni and Anaakwanire, and 6-12\% of the sites for the other varieties. Sites in AEZ 3 achieved the best average root yields of $14 \mathrm{t} \mathrm{ha}^{-1}$. This was $60 \%$ more than in AEZ 2 and even $156 \%$ more than in AEZ 1 (Table 4.3). Root yield was strongly affected by planting date with sites planted between 16-31 January (Class 3) achieving only 58\% of the yields of sites planted in the first half of January (Class 2) with further yield reductions observed in sites planted in February. Root yield was affected by soil moisture conditions at planting with $9.9 \mathrm{t} \mathrm{ha}^{-1}$ achieved when planted in wet soils compared to $8.5 \mathrm{t} \mathrm{ha}^{-1}$ in moist and $6.5 \mathrm{t} \mathrm{ha}^{-1}$ in dry soil conditions. Root yield was associated with the continuous variables elevation $(r=0.38 ; \mathrm{p}<0.001)$, planting date $(\mathrm{r}=-0.33 ; \mathrm{p}<0.001)$, rainfall exposure days $(\mathrm{r}=0.33 ; \mathrm{p}<0.001)$, total rainfall $(\mathrm{r}=0.31 ; \mathrm{p}<0.001)$ and vine yield $(\mathrm{r}=0.40 ; \mathrm{p}<0.001)$.

The percentage of the total root yield considered as marketable was best in AEZ 3, though still only 65\% (Table 4.3). It was smallest for Zondeni and Anaakwanire (Table 4.3) and highly variable across sites (Fig. 4.2b). Less than $50 \%$ of root yield was marketable in $44 \%$ of the sites for Zondeni, 30\% for Kaphulira, 28\% for Anaakwanire and 21-23\% of the sites for Chipika, Mathuthu and Kadyaubwerere. Plots planted with healthy or medium quality cuttings had a larger percentage of marketable root yield (63 and 61\%) than plots planted with poor quality cuttings $(50 \%)$. Marketable root yield was also associated with percentage weevil infested roots $(r=-0.26 ; \mathrm{p}<0.001)$.

Fields in AEZ 1 had the largest percentage of roots infested with weevils (Table 4.3). It was also observed that sites that were planted early were more affected by weevils than those planted in February or March. Kaphulira was more affected by weevils than the five other varieties at harvest (Fig. 4.2c). The percentage of sites without weevil infestation ranged from $15 \%$ for Mathuthu to $26 \%$ for Zondeni. On female farmers' fields $20 \%$ of the roots were infested with weevils compared to $17 \%$ on male farmers' fields. There was an interaction between the condition of the cuttings at planting and gender $(\mathrm{p}=0.01)$ on weevil infestation. The percentage of infested roots correlated with planting date $(r=-0.27 ; p<0.001)$, rainfall exposure days $(r=0.25 ; \mathrm{p}<0.001)$, growing period $(\mathrm{r}=0.20 ; \mathrm{p}<0.001)$ and $\%$ marketable root yield $(\mathrm{r}=-0.27 ; \mathrm{p}<0.001)$.

\subsubsection{Interactions between variety, environment and management affecting total root yield}

There was a strong interaction observed between the effects of variety and categorical planting date class $(\mathrm{p}<0.001)$ and planting date as continuous variable $(\mathrm{p}<0.001)$ on root yield. Delaying planting from the first to the second half of January resulted in $6.1-7.0$ 
$\mathrm{t} \mathrm{ha}^{-1}$ yield reduction for the better yielding varieties Chipika, Kadyaubwerere, Kaphulira and Mathuthu (Fig. 4.3). This reduction was only $0.7 \mathrm{t} \mathrm{ha}^{-1}$ for Anakwanire and $2.9 \mathrm{t} \mathrm{ha}^{-1}$ for Zondeni. Variety also interacted with continuous variables harvest date $(p=0.02)$, rainfall exposure days $(\mathrm{p}<0.001)$ and total rainfall $(\mathrm{p}=0.026)$. Planting date correlated strongly $(\mathrm{p}<0.001)$ with all these variables and especially with rainfall exposure days $(r=-0.86)$. Varieties did not differ in yield response to elevation or soil properties.

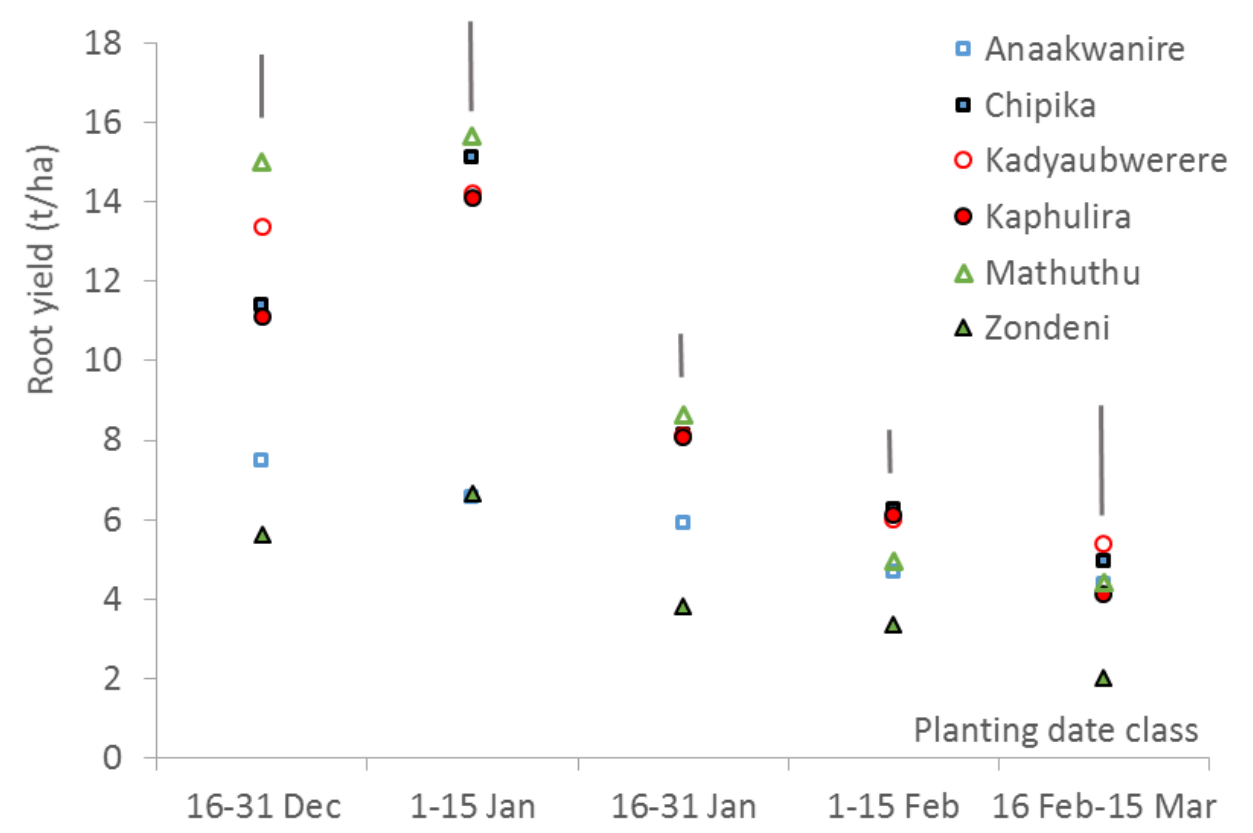

Fig. 4.3: Average OFSP root yields for six varieties by planting date class. The vertical lines represent the standard error of differences between means.

\subsubsection{Yield gap analysis}

From the continuous variables that are significantly associated with root yield (Table 4.4), the correlations between soil parameters and yield were weak $(\mathrm{r}=0.12$ for soil available $\mathrm{P}$ and $\mathrm{r}=0.13$ for silt). The variables elevation, planting date, rainfall exposure days and total rainfall correlated more strongly with root yield $(r=>0.3$ or $<-0.3)$ and were therefore included in the boundary line analysis. Out of these, only elevation and total rainfall strongly interacted $(\mathrm{p}<0.001)$ in the association with root yield because the highlands in Dedza and Ntcheu received more rainfall than the southern districts. The percentage establishment had a weak correlation with yield $(\mathrm{r}=0.18 ; \mathrm{p}<0.001)$, but was included in the model because the scatter graph showed a clear association. Boundary regression lines were therefore conducted using the factors elevation, planting date, rainfall exposure days, total rainfall and percentage 
establishment (Fig. 4.4). Out of these, total rainfall was the most limiting factor in $30 \%$ of all plots, followed by elevation (23\%), planting date (21\%), percentage establishment (18\%) and rainfall exposure period $(8 \%)$. There was little difference between varieties in the percentage of fields in which each variable is most limiting (Fig. 4.5).
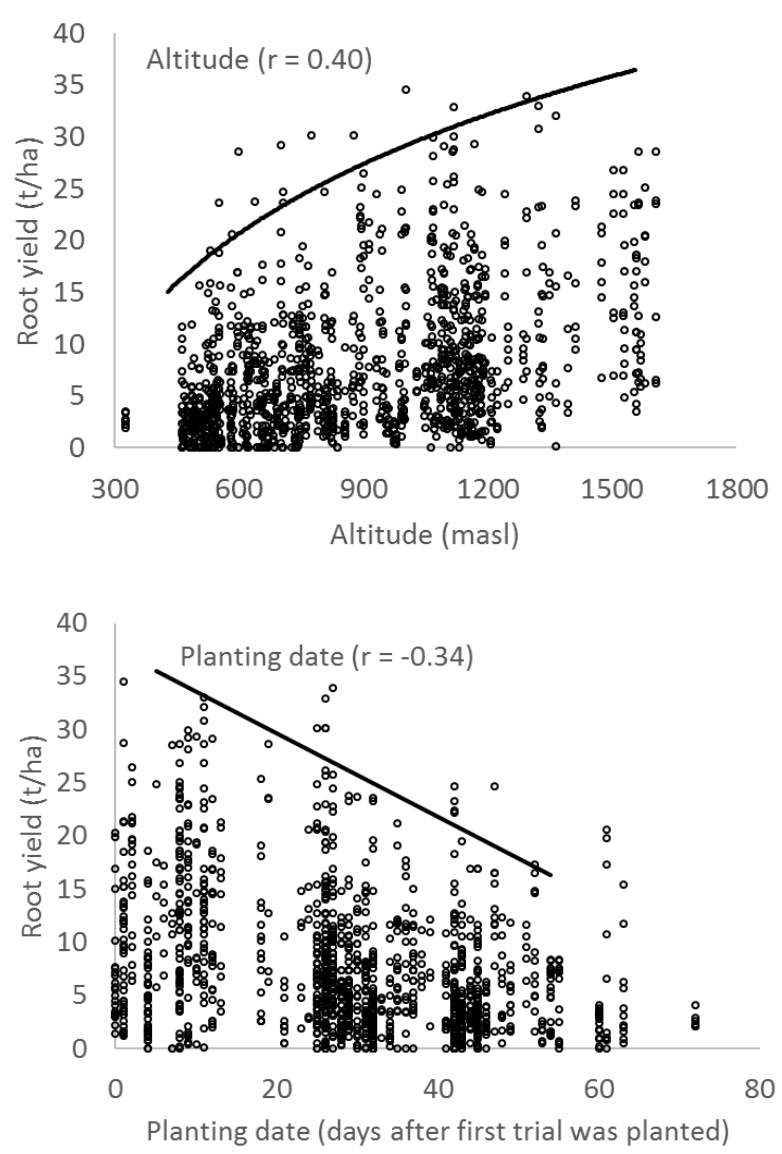

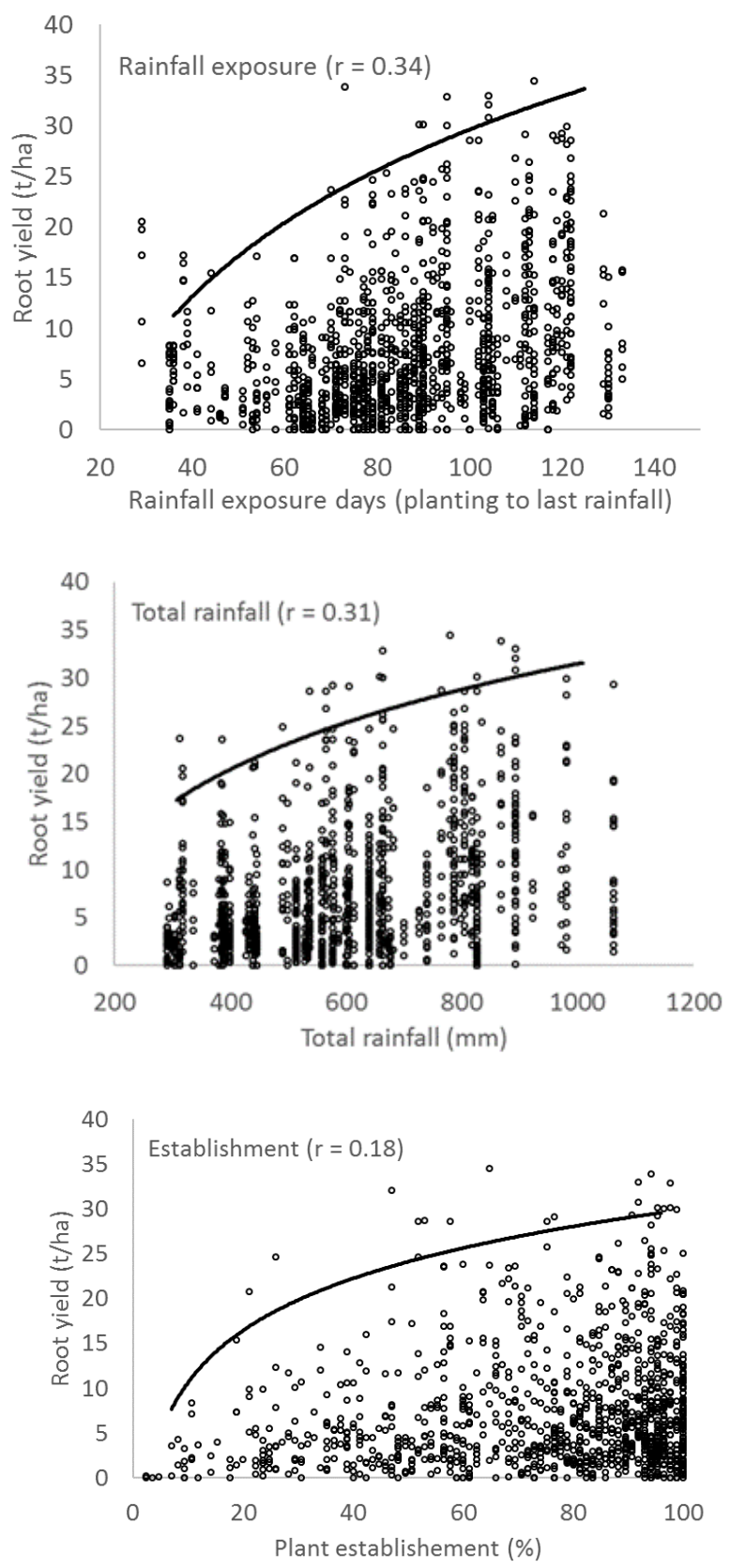

Fig. 4.4: Boundary lines for sweet potato yields. ' $r$ ' represents the correlation coefficient between the two variables. 


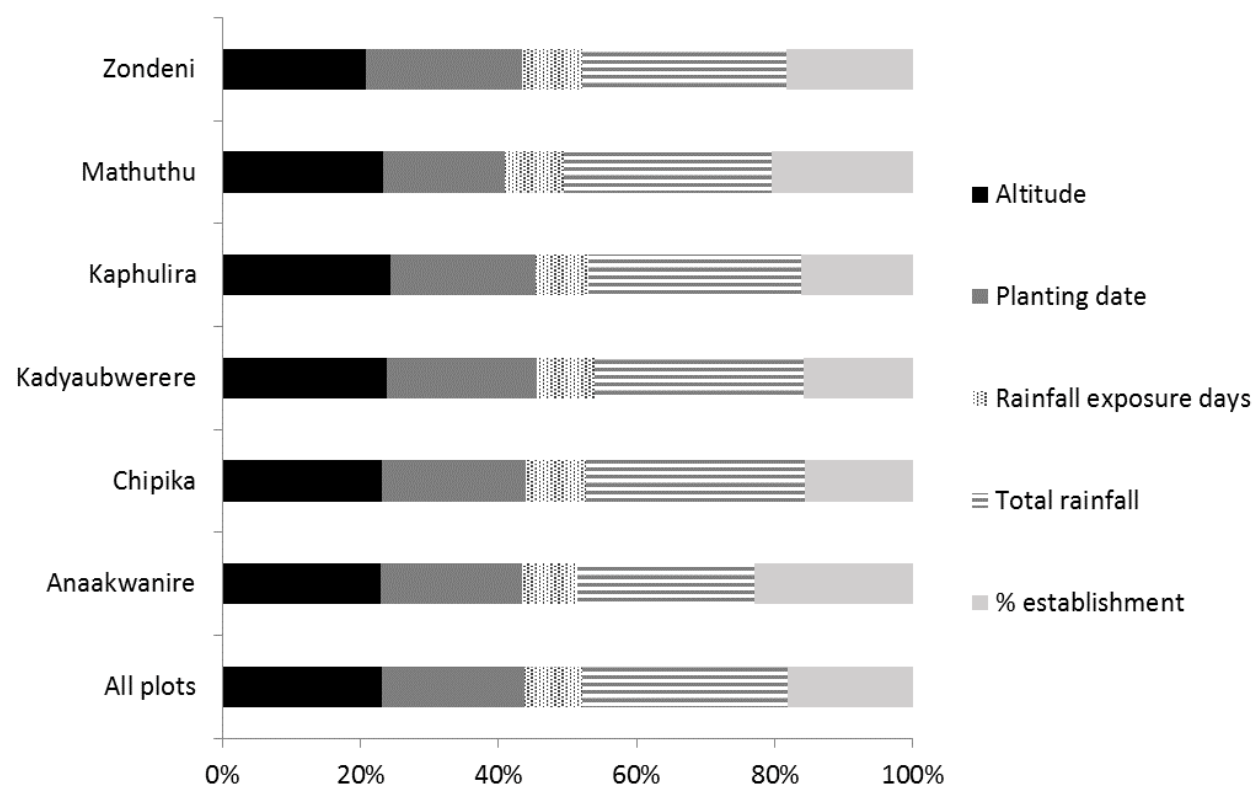

Fig. 4.5: The most limiting factors identified using the boundary line approach and the corresponding proportion of plots $(\%)$ in which these factors were most limiting by variety and for all plots.

The attainable yield ranged from $17.6 \mathrm{t} \mathrm{ha}^{-1}$ for Zondeni to $32.0 \mathrm{t} \mathrm{ha}^{-1}$ for Mathuthu (Table 4.5), while actual yields of these varieties were only 4.5 and $9.3 \mathrm{t} \mathrm{ha}^{-1}$. Across varieties, average root yields were only $29 \%$ of the attainable yield and the average yield gap was 18.6 $\mathrm{t} \mathrm{ha}^{-1}$. The factors included in the multivariate boundary line model could explain $31 \%$ of the yield gap. The explainable yield gap for the low yielding varieties Anaakwanire $\left(2.5 \mathrm{t} \mathrm{ha}^{-1}\right)$ and Zondeni $\left(0.8 \mathrm{t} \mathrm{ha}^{-1}\right)$ was small compared to that of the four better yielding varieties $(6.1$ - $11.2 \mathrm{t} \mathrm{ha}^{-1}$ ). Mathuthu had the largest explainable yield gap (Fig. 4.6), but $48 \%$ was nevertheless unexplainable. It is therefore not surprising that the multivariate model did not serve well to predict yields based on the most limiting factor (Fig. 4.7). The predicted root yields were much larger than the actual yields and the $\mathrm{R}^{2}$ of the regression line was only 0.16 . When testing the model with data for individual varieties the graphs looked similar (not presented) and $\mathrm{R}^{2}$ ranged from 0.11 for Anaakwanire to 0.22 for Mathuthu. 
Table 4.5: Explained and unexplained average root yield gap using the multivariate boundary line model.

\begin{tabular}{lcccccc}
\hline Variety & $\boldsymbol{n}$ & $\begin{array}{c}\text { Attainable } \\
\text { yield } \\
\left(\mathbf{t ~ h a}^{-\mathbf{1}}\right)\end{array}$ & $\begin{array}{c}\text { Actual } \\
\mathbf{y i e l d} \\
\left(\mathbf{t ~ h a}^{-\mathbf{1}}\right)\end{array}$ & $\begin{array}{c}\text { Total } \\
\mathbf{y i e l d ~ g a p} \\
\left(\mathbf{t ~ h a}^{-\mathbf{1}}\right)\end{array}$ & $\begin{array}{c}\text { Explainable } \\
\text { yield gap } \\
\left(\mathbf{t ~ h a}^{-\mathbf{1}}\right)\end{array}$ & $\begin{array}{c}\text { Unexplainable } \\
\text { yield gap } \\
\left(\mathbf{t ~ h a}^{-\mathbf{1}} \mathbf{)}\right.\end{array}$ \\
\hline Anaakwanire & 175 & 21.6 & 5.8 & 15.7 & 2.5 & 13.3 \\
Chipika & 173 & 28.4 & 8.5 & 20.0 & 7.5 & 12.5 \\
Kadyaubwerere & 189 & 29.0 & 8.7 & 20.3 & 7.9 & 12.5 \\
Kaphulira & 185 & 27.2 & 8.4 & 18.9 & 6.1 & 12.8 \\
Mathuthu & 176 & 32.0 & 9.3 & 22.7 & 11.2 & 11.4 \\
Zondeni & 159 & 17.6 & 4.5 & 13.0 & 0.8 & 12.2 \\
All data & 1057 & 26.1 & 7.6 & 18.6 & 6.1 & 12.5 \\
\hline
\end{tabular}

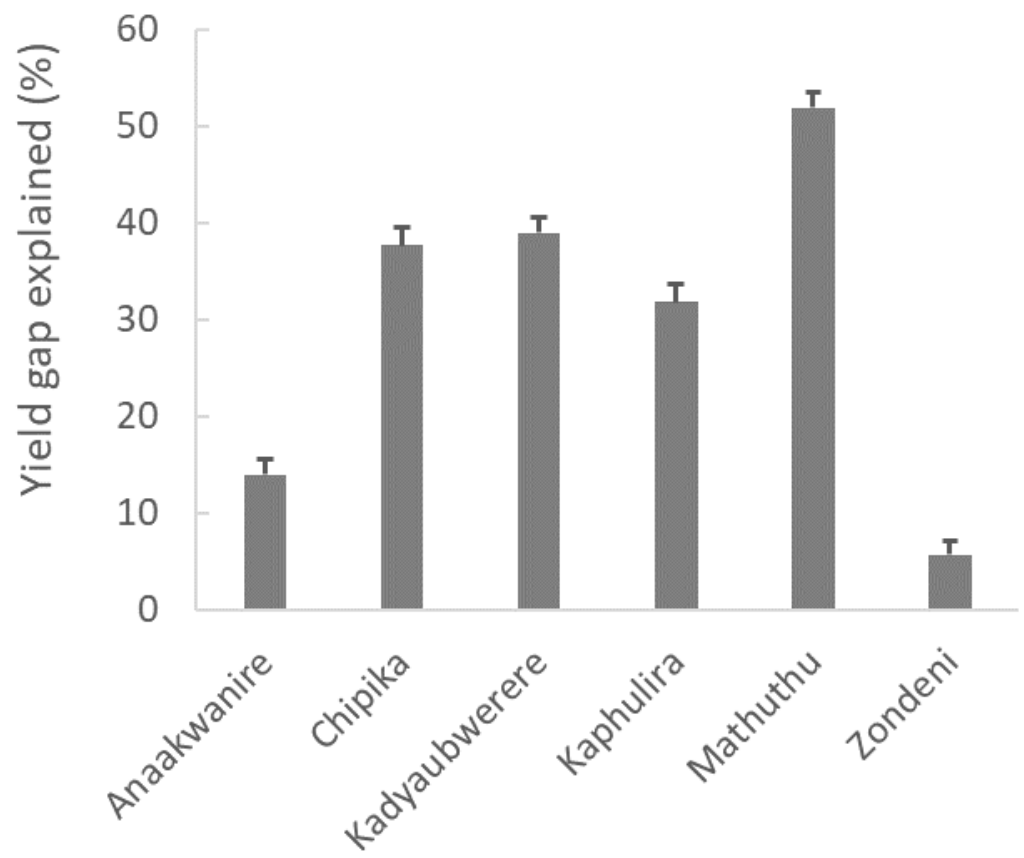

Fig. 4.6: The percentage of the sweet potato yield gap that could be explained by the model for six varieties. Whiskers indicate standard errors. The standard error of differences between means is 2.4 


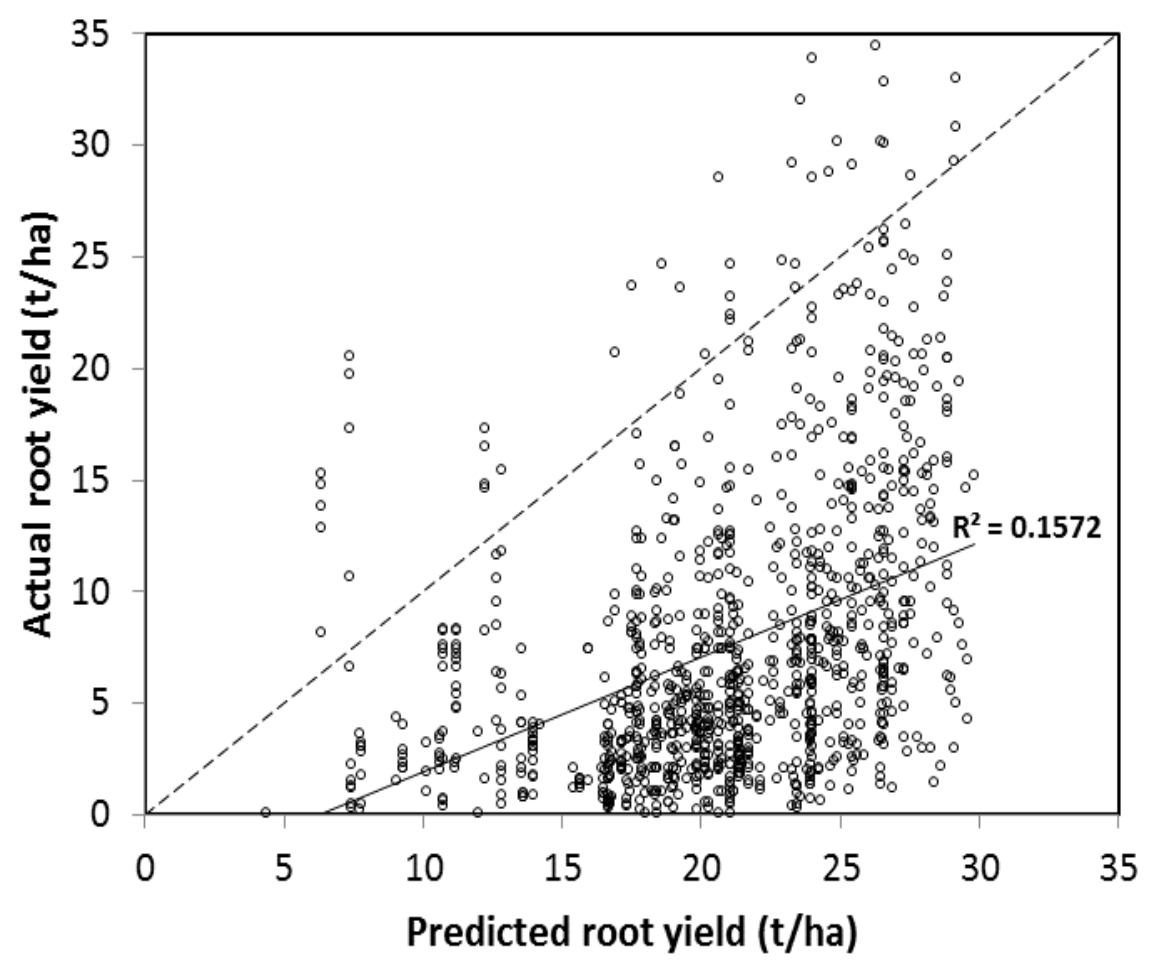

Fig. 4.7: Actual and predicted yield from the multivariate boundary line model. The dotted diagonal line depicts the relationship $\mathrm{y}=\mathrm{x}$ and the solid line is the linear regression line. 


\subsubsection{Sensory evaluations}

Kadyaubwerere and Chipika were the most preferred varieties in terms of consumption of boiled roots (Table 4.6). Zondeni was ranked third and was preferred over the varieties Anaakwanire, Mathuthu and Kaphulira. Preferences differed slightly between AEZs since Zondeni was ranked significantly lower than Chipika in lower areas but not in higher elevations. Overall, the top three most preferred varieties were the same in all AEZs.

Table 4.6: Sensory evaluations of six OFSP varieties in three agro-ecological zones (AEZ) in Central and Southern Malawi

\begin{tabular}{lcccc}
\hline Variety & $\begin{array}{c}\text { Sum of preference rank scores } \\
\text { Rank }^{2}\end{array}$ & $\begin{array}{c}\text { All sites } \\
(n=94)\end{array}$ & $\begin{array}{c}\text { AEZ 1 } \\
\text { 200-760 masl }{ }^{3}(n=50)\end{array}$ & $\begin{array}{c}\text { AEZ 2\&3 } \\
>760-1300 \text { masl }(n=44)\end{array}$ \\
\hline Kadyaubwerere & 1 & 220 & 116 & 104 \\
Chipika & 2 & 239 & 120 & 119 \\
Zondeni & 3 & 300 & 179 & 121 \\
Anaakwanire & 4 & 380 & 209 & 171 \\
Mathuthu & 5 & 399 & 198 & 201 \\
Kaphulira & 6 & 423 & 225 & 198 \\
\hline Critical value & & 74 & 54 & 51 \\
\hline${ }^{1}$ Ranking from 1 = most preferred to 6 = least preferred, ${ }^{2}$ Each variety received a rank score $(1=$ most \\
preferred to 6 = least preferred) in each of the 94 sites. The data represent the sum of the rank scores \\
given to each variety. ${ }^{3}$ Meters above sea level, ${ }^{4}$ According to expanded tables for comparison of ranked \\
data (Newell and MacFarlane, 1988$)$, this critical value is the least significant difference (p<0.05) in \\
the sum of preference ranks between varieties.
\end{tabular}

\subsection{Discussion}

\subsubsection{Methodological considerations}

The large number of sites allowed for a good quantification of the variability in performance of the six OFSP varieties, exploration of yield limiting factors and identification of opportunities to enhance productivity. The demonstration sites did not fully reflect farmers' practices since land preparation and plant and row spacing were pre-defined. Planting material was sourced from the formal market and diseased plants were removed during and after establishment as part of the training of farmers, which probably reduced incidences of SPVD and weevils compared to farmers' practices and using locally sourced planting material. On the other hand, local sourcing could have resulted in fresher planting material by cutting out transport and distribution time. Since varieties have different maturity periods, yield assessment may have been better by harvesting each variety at the optimal harvest time. However, in that case the participatory harvest evaluations and sensory evaluations with the satellite farmers would not have been possible. The type of information provided before tasting could have affected the sensory evaluations (Lagerkvist et al., 2016), for example 
understanding that darker orange flesh-colour corresponds with higher beta-carotene content may lead to preference for Kadyaubwerere. While lining up for the preferred variety, peer pressure may have affected independence of the ranking between individual evaluators. The taste and sweetness of sweet potato change when stored for a couple of days after harvest, though differences in sensory preferences are mainly determined by texture which is not much affected by storage (Van Oirschot et al., 2003).

\subsubsection{Performance of six OFSP varieties}

Suitability of a variety depends on the characteristics a farmer is looking for and can included vine production, total and marketable root yield, resistance to pests, storability and sensory characteristics (Ndolo et al., 2001). While vine yield may have been affected by theft and roaming livestock, it still largely correlated with total root yields. Anaakwanire and Zondeni had better vine to root ratios than the other varieties (Table 4.3). These varieties may not be recommended since they consistently underperform in terms of root yield even when planted early in the season (Fig. 4.3). The poor attainable yields of $22 \mathrm{t} \mathrm{ha}^{-1}$ (Anaakwanire) and $18 \mathrm{t}$ $\mathrm{ha}^{-1}$ (Zondeni) compared to 27 to $32 \mathrm{tha}^{-1}$ for the other varieties (Table 4.5) indicate a limited genetic potential of these varieties. Probably due to small root size, also the percentage of marketable root yield of these two varieties is poor (Table 4.3), limiting options for commercialized market-oriented production. Our data did not show any interactive effect on root yield between variety and AEZ indicating there is no need to recommend certain varieties for specific environmental conditions. Timely planting (which strongly correlates with the number of days a site is exposed to rainfall) will mostly benefit the better yielding varieties Chipika, Kadyaubwerere, Kaphulira and Mathuthu (Fig. 4.3). While Kaphulira achieved good yields, the large percentage of roots infected with weevils (Table 4.3) may limit its marketability. Weevils were encountered on $74 \%-85 \%$ of sites depending on variety. The correlation between weevil infestation and planting date $(r=-0.27)$ and growing period $(r=0.20)$ suggest farmers can reduce weevil infestation by earlier harvesting. Studies in Cameroon (Parr et al., 2014) and Uganda (Smit, 1997) confirm that delayed harvesting increases weevil infestation. Since industrial processing of OFSP for human consumption is gaining momentum in Malawi and weevils are not tolerated, additional measures are needed to control weevils. These can include hilling up twice at 4 and 6 weeks after planting (Pardales Jr and Cerna, 1987), filling cracks in the soil with loose soil when roots expand, or piece-meal harvesting as soon as cracks form (Ebregt et al., 2007). Besides high weevil infestation, Kaphulira also scored low on sensory preferences (Table 4.6). Similar to Mathuthu, this may affect willingness to adopt the variety for household consumption. Kadyaubwerere and Chipika stand out as promising varieties that receive the best sensory preference score (Table 4.5), are preferred by industrial processors (UIL, 2017), achieve good root yields (Table 4.3) especially when planted early (Fig. 4.3) and are less susceptible to weevil infestation than Kaphulira. 


\subsubsection{Important factors limiting smallholder OFSP production}

Besides variety choice several other factors affected total root yield. The final yield of any crop is a product of interacting genetic, environmental, management and socio-economic factors (Tittonell and Giller, 2013). Using fresh planting material and planting in wet soil positively affected the crop establishment (Table 4.4), while poor establishment was the most root yield limiting factor in $18 \%$ of the sites (Fig. 4.4). This suggests that timely access to fresh planting material will benefit final productivity. Once established, the percentage of plants that will form storage roots can be enhanced by choosing the right variety for the AEZ (no Zondeni in AEZ 1) and avoiding soils that are too sandy (Table 4.4). The strong effect of AEZ on root formation suggests farmers may benefit from larger planting densities in AEZ 1 to compensate for the reduced root set, which strongly correlates with total root yield $(\mathrm{r}=0.33)$. Our results show that the importance of timely planting to make optimal use of available rainfall cannot be overemphasized to achieve good yields (Table 4.4, Fig. 4.3, Fig. 4.4) The strong correlations between planting date and rainfall exposure days $(r=-0.86$, $\mathrm{p}<0.001$; most limiting on $8 \%$ of sites) and total rainfall (most limiting on $30 \%$ of sites) indicates that these factors may be confounded in the yield gap analysis. The strong effect of AEZ on yield may also partly be explained by the correlation between elevation and rainfall exposure days $(r=0.34, p<0.001)$ and the fact that sites in AEZ 3 were planted earlier and AEZ 3 received more rain (Table 4.1).

The large unexplainable yield gap (Table 4.5) and the systematic over-estimation of yields (Fig. 4.6) suggest there are several other yield limiting factors unaccounted for by the model. The poor yield predictions for Anaakwanire and Zondeni (Table 4.5) may be due to the overriding constraint of poor genetic yield potential. Addressing the constraining factors included in the boundary line model may result in yield increases of 6.1 to $11.2 \mathrm{t} \mathrm{ha}^{-1}$ for the other four varieties, leaving an unexplainable yield gap of 11.4 to $12.8 \mathrm{t} \mathrm{ha}^{-1}$ (Table 4.6). Soil fertility constraints were not captured in the model due to the small sample size $(n=61)$ and small correlations with root yield. Soil nitrogen content was not measured, but a positive association between soil available P, CEC and root yield was found and texture may have had some effect (Table 4.4). Soil fertility may become a constraint to achieve attainable yields, since for each ton of root yield, an estimated $10 \mathrm{~kg} \mathrm{~N}, 2 \mathrm{~kg} \mathrm{P}$ and $17 \mathrm{~kg} \mathrm{~K}$ is removed from the soil (IPNI, 2017). Improved tillage and nutrient input applications (Agbede, 2010) could have made a significant contribution to closing the yield gap. Yield reducing factors such as weeds, pests and diseases were assumed negligible due to the controlled nature of the demonstrations. Weeds, viruses-infested plants and plants with other disease symptoms were uprooted and removed from the field during farmer trainings, and weevil infestation only affected marketability but not the total root yield. The yield reductions caused by viral disease in smallholder sweet potato crops needs more research and more technology transfer efforts. Most farmers in our study could not recognize a plant virus, while these can lead to large yield reductions or complete crop failure (Adikini et al., 2016). Male host farmers' fields had 
better crop establishment, better vine yields and less weevil infestation, but there was no effect of gender on root yield (Table 4.4). The interactions between gender and the quality of cuttings and soil moisture condition at planting, suggest that when planting material arrived in an area to establish several demonstration sites, male farmers could have been prioritized by extension agents resulting in fresher planting material and timely planting in male host farmers' fields.

\subsubsection{Recommendations to enhance OFSP productivity on smallholder farms}

Sweet potato development objectives in sub-Saharan Africa include emergency relief distributions of planting material to vulnerable households, reducing Vitamin A deficiency with nutritious OFSP, and product development and commercialization. Enhanced productivity will benefit all these objectives and should first include promotion of the better yielding varieties Chipika, Kadyaubwerere, Kaphulira and Mathuthu. Emergency distributions of sweet potato planting material as a drought tolerant crop in case it is too late to plant maize is probably not a good strategy to promote its cultivation and use, because delayed planting will result in poor root yields (Fig. 4.3). Transportation time and distances result in farmers receiving poor quality cuttings and risks planting in soils without adequate moisture content. This will affect establishment and yield (Table 4.4). The nutritional and commercialization objectives require awareness efforts to change the farmers' and consumers' mindset that sweet potato is a 'poor men's crop'. The varieties Kadyaubwerere and Chipika may be prioritized as they are both highly ranked in sensory evaluations (Table 4.6) and suitable for processing. Market-oriented producers will benefit from adopting measures to control weevils to reduce the percentage of unmarketable yield. Farmers often do not have access to sufficient planting material at the onset of the rains and therefore plant later in the season by cutting and transplanting material that sprouted in the early weeks of the rainy season. More training on the importance of early planting (Table 4.3, 4.4, Fig. 4.3) should therefore be combined with initiatives that ensure availability of quality planting material of the most preferred varieties at the right time. This can be achieved by promoting rapid vine multiplication techniques under irrigation in the dry season either for own use or as a business opportunity to sell to others (McEwan et al., 2017), though sustainable vine multiplication business can only be achieved where there is sufficient demand (Rao and Huggins, 2017). Promotion of OFSP in combination with training on vine conservation has proven to enhance conservation practices by farmers (Okello et al., 2015). There should be special emphasis on gender in extension programs to ensure both men and women benefit equality from timely access to quality planting material. 


\section{Acknowledgements}

This work was supported by the United States Agency for International Development under the Feed the Future Malawi Improved Seed Systems and Technologies project [grant number AID-BFS-G-11-00002]; The authors thank Arthur Chibwana, Brian Kachisa and Denis Kathabwalika for contributions to development of protocols, trainings of partner staff and oversight during implementation and data collection; Research technicians Stanley Mbewe, David Mthobwa, Thokozani Mvula, Pearson Phiri, Benjamin Muhalu, Khalaniphe Kamuonjola and Patison Mamboya for working closely with project partners at district level. All staff from partner organizations that implemented the field work and provided data: Department of Agricultural Extension Services, We Effect, Concern Worldwide, Farmers Union of Malawi, Catholic Development Commission Dedza Diocese, Zomba Diocese Research and Development Department, Tetra Tech (PERFORM project), Development Alternatives Incorporated (INVC project), Project Concern International (NJIRA project), National Association of Smallholder Farmers in Malawi and Total Land Care. 
Chapter 4 


\section{Chapter 5}

Exploring fertilizer use with maize, legumes and sweet potato to intensify and diversify cropping systems in Malawi

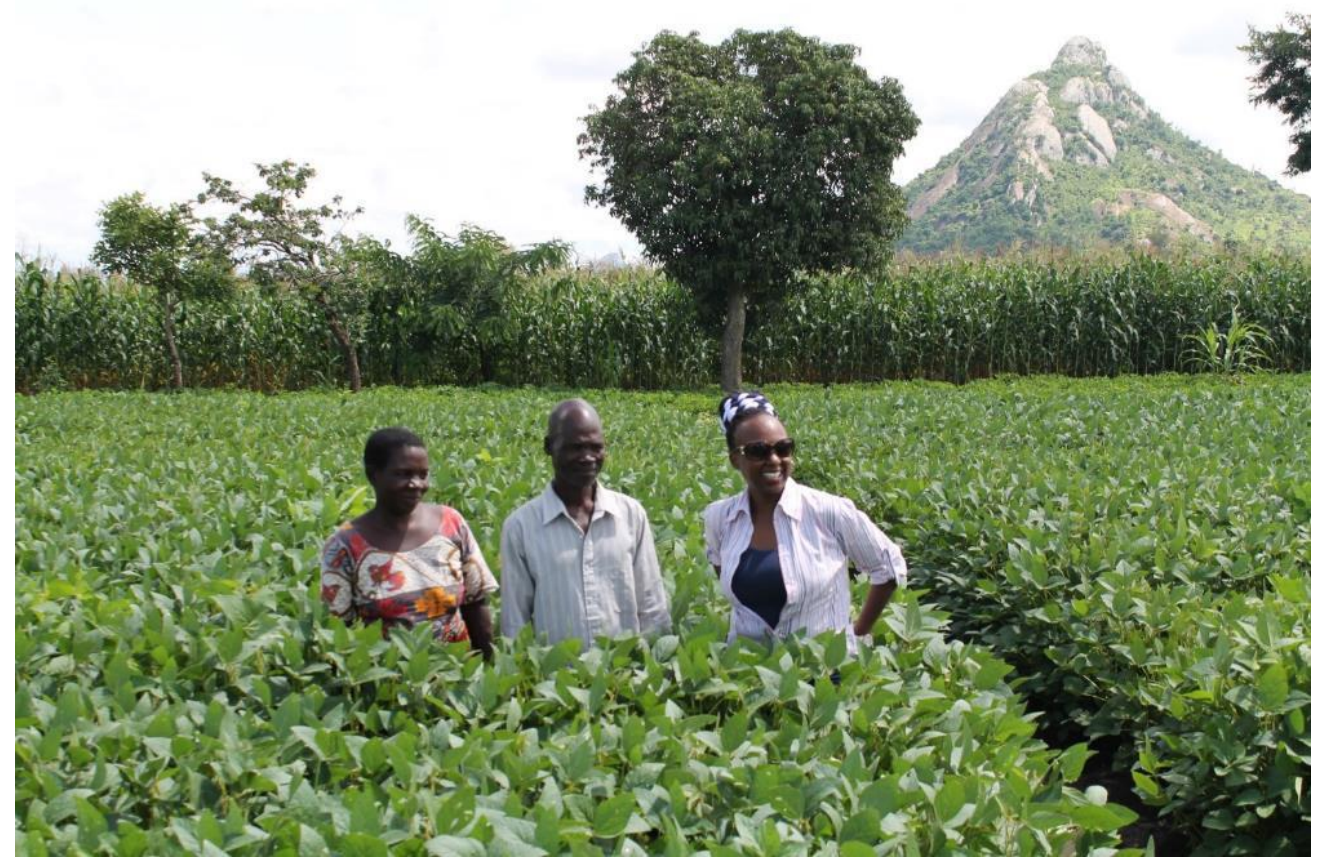

This chapter is submitted to Experimental Agriculture as:

Van Vugt, D., Jones, N., Giller, K.E., Franke, A.C. (under review), Exploring fertilizer use with maize, legumes and sweet potato to intensify and diversify cropping systems in Malawi. Experimental Agriculture. 


\begin{abstract}
Maize, the main staple food of smallholder farmers in southern Africa, is cultivated on a large share of the agricultural land. Limited nutrient input results in soil nutrient depletion over time. There is need for productive farming systems that are better adapted to a changing climate, and that produce more diverse food to achieve both food and nutrition security. We explored options for crop intensification and diversification in central Malawi by combining yield responses to inputs in 50 maize, 28 soybean, 24 groundnut and 26 sweet potato on-farm trials with economic analysis and focus group discussions. Due to proper crop management and the use of good varieties in a season with above-average rainfall, excellent mean trial yields of $5.0 \mathrm{t} \mathrm{ha}^{-1}$ for maize, $3.4 \mathrm{t} \mathrm{ha}^{-1}$ for soybean, $2.5 \mathrm{t} \mathrm{ha}^{-1}$ for groundnuts and $13.2 \mathrm{t} \mathrm{ha}^{-1}$ for sweet potato were achieved. Responses to combinations of inorganic fertilizer and lime were highly variable, although yields of all crops were enhanced. Although maize production and response to fertilizer were not as profitable as the other crops, fertilizer application to maize gave the best returns of food per amount of money invested. Yield responses and value cost ratios showed that investments in fertiliser and lime on soybean was more worthwhile than on groundnut, although the relative differences were somewhat hidden by high groundnut prices. While there is potential to derive better financial returns from diversification and intensification with legumes and sweet potato, farmers prioritize maize in terms of land area and resource allocation. Policies to enhance crop diversification and intensification should address the main constraints of lack of awareness of the agronomic and financial benefits of nutrient application to legumes and sweet potato, unstable markets, access to credit and access to improved seed.
\end{abstract}

Keywords: Sustainable intensification, soil fertility, yield variability, crop diversification, fertilizer 


\subsection{Introduction}

Food security remains a major concern in southern Africa where eight percent of the population is undernourished, while in Malawi this is even 26 percent of the population (FAO et al., 2017). The agricultural sector in Malawi is constrained by low productivity, poor management of water and soils and susceptibility to climatic shocks (MAIWD, 2016a). There is little mechanization or irrigation and almost no use of credit to procure agricultural inputs (Sheahan and Barrett, 2017). The population has grown rapidly over the past two decades, increasing pressure on farming systems, while new market opportunities emerge following urbanisation and economic growth (Binswanger-Mkhize and Savastano, 2017). Farming systems need to intensify in a sustainable manner by maintaining healthy soils and increasing resilience to climatic and other shocks (Vanlauwe et al., 2014). Maize is the main staple crop in Malawi, produced on over $70 \%$ of the fields (NSO, 2012). Average maize yields of smallholder farmers in Malawi are only about $2 \mathrm{t} \mathrm{ha}^{-1}$ whilst currently cultivated varieties can yield 6 to $10 \mathrm{t} \mathrm{ha}^{-1}$ (Mutegi et al., 2015). Fallow areas have largely disappeared but cropping intensities remain low and the process of intensification has been weak in terms of organic fertilizer and agro-chemical use (Binswanger-Mkhize and Savastano, 2017). Although it is estimated that 408000 ha, out of a total arable land area of $3.8 \mathrm{M}$ ha, is potentially suitable for irrigation, only a quarter of this area is currently irrigated (MAIWD, 2016b). Inorganic fertilizer is applied on 61 percent and organic fertilizer on 12 percent of fields in Malawi (NSO, 2012). While insufficient to prevent soil nutrient depletion, an increase in inorganic fertilizer use was observed from $31 \mathrm{~kg}$ per arable hectare in 2003 to $43 \mathrm{~kg} \mathrm{ha}^{-1}$ in 2015 (Nalivata et al., 2017) alongside adoption of improved seeds (Binswanger-Mkhize and Savastano, 2017). Inorganic fertilizer is mainly applied to maize and tobacco and not to legumes by the majority of farmers in central Malawi, while only 20 to 40 percent of farmers apply organic manure or compost to any field (Mungai et al., 2016). Continued maize cultivation without adequate nutrient and organic matter inputs may in the long term lead to extensive soil degradation (Tittonell and Giller, 2013).

Crop diversification can benefit the farming system productivity, food and nutrition security, and resilience to climate change (Bezner Kerr et al., 2007; Kankwamba et al., 2012) and features prominently in the National Agricultural Policy (2016-2020) of Malawi (MAIWD, 2016a). A key benefit of including or expanding the contribution of legumes in the farming systems is their ability to fix freely-available atmospheric nitrogen (Giller, 2001). Legumes positively affect the following cereal crops with average yield increases of 42 percent, relative to continuous cereal cultivation, in the savannas of southern Africa (Franke et al., 2018). Especially soybean and maize fields that receive adequate nutrient inputs and good management benefit from $\mathrm{N}_{2}$ fixation by the legume and increased yield of the following maize crop (Chapter 3). Incorporating grain legumes in the cropping system can be especially promising in areas with good soils and rainfall (Ojiem et al., 2014), while resource poor 
farmers that cannot invest in inputs such as P-fertilizer and inoculant may not be able to achieve food self-sufficiency through legume adoption (Franke et al., 2014). Intercropping maize with pigeon pea strongly increased the likelihood to produce sufficient calories for smallholder households in northern Malawi compared to sole maize cropping (Snapp et al., 2014). Legumes can also supplement cereal-based diets with essential amino-acids (Jones and Divine, 1944). Current diets are lacking important vitamins and minerals and there is an urgent need for more nutritious food systems (Haddad et al., 2016). Sweet potato is commonly perceived as a crop that can enhance food security in the face of challenges such as drought or climate change (Motsa et al., 2015). There is scope for its expansion, especially since production and consumption of orange-fleshed varieties are a promising approach to reduce Vitamin A deficiency in breastfeeding mothers and children under the age of five (Low et al., 2017; Tanumihardjo et al., 2017). There is large potential to enhance sweet potato productivity as yields in unfertilized fields in Malawi are only $29 \%$ of the attainable yields leaving a yield gap of 18.6 tons per ha (Chapter 4 ).

The Ministry of Agriculture Irrigation and Water Development in Malawi has long recommended application of NPS 23:9:4 basal fertilizer and top dressing with urea at a recommended rate of $92 \mathrm{~kg} \mathrm{ha}^{-1} \mathrm{~N}, 18 \mathrm{~kg} \mathrm{ha}^{-1} \mathrm{P}$ and $8 \mathrm{~kg} \mathrm{ha}^{-1} \mathrm{~S}$ as the standard for maize (MAFS, 2012). One 50-kg bag of each of these fertilizers is included in the governments targeted agricultural input subsidy program since 2005 (Dorward and Chirwa, 2011) to benefit resource-constrained smallholder farmers. Over time many fertilizer recommendations have been developed for different crops in the country of which some specifically target $\mathrm{K}$ and $\mathrm{Zn}$ deficiencies and soil acidity (Nalivata et al., 2017). More recently, based on previous work in the country, soil fertility maps for Malawi have been developed and fertilizer recommendations have been derived for maize by Extension Planning Area (a subdivision of District). Depending on the soil status of N, P, K, S, Zn and the soil acidity, different combinations of the available fertilizers NPKSZn 23:4:4:6:1, NPKS 10:11:17:7, NPS 23:9:4, urea, sulphate of ammonia and calcium ammonium nitrate (CAN) are recommended (Mutegi et al., 2015). For new fertilizer blends to be used effectively there is need to understand the responses of different crops to fertilizer, farmers' land allocation to crops, fertilizer costs and the expected value of the commodities (Nalivata et al., 2017). It is also of crucial importance to look beyond average responses and consider the wide range of responses that occur due to the heterogeneity of smallholder farmers practices (Vanlauwe et al., 2016). Finally, the farmers' needs, perceptions and evaluations of the new technologies should be in the forefront to assess the potential for adoption (Snapp and Silim, 2002; Van Vugt et al., 2017).

In the research reported here, we (i) evaluate the effectiveness and profitability of fertilizer and lime application to maize, soybean, groundnut and sweet potato; (ii) identify factors affecting the yield and yield responses; (iii) explore farmer perceptions on intensification 
with fertilizers, and (iv) discuss the implications for intensification and crop diversification with soybean, groundnuts and sweet potato in central Malawi.

\subsection{Materials and methods}

\subsubsection{Study sites and approach}

On farm trials with maize, soybean, groundnut and sweet potato were established by Farmers World Ltd in the 2016/17 growing season in eight districts in central Malawi (Fig. 5.1). Most trials were established on the mid-elevation upland plateau at 760-1300 m above sea level (masl) and in the highlands above 1300 masl. Central Malawi has a single rainy season from December to April with a long term annual rainfall between 801 and $1000 \mathrm{~mm}$ on the plateau and 1001 to $1200 \mathrm{~mm}$ in the highlands (METMALAWI, 2017). Farmers World Ltd imports and distributes a range of products including agricultural inputs such as fertilizer, seed and chemicals through their network of retail stores. The company aims to enhance farmers' productivity by providing access to tailor-made fertilizer and extension services. A dedicated extension officer (agronaut) in each store provides advice, conducts farmer trainings, establishes trial plots, collects data and organizes field days. Based on soil properties in the catchment areas around 30 stores, the company produces crop-specific fertilizer blends for maize (NPKSZnB 15:23:16:6:0.5:3 basal; NK 30:16 top dressing), soybean and groundnut (NPK 6:20:24) and sweet potato (NPKS 10:20:20:6), and developed liming recommendations (FW, 2016). Two farmers' fields were identified around each of the 30 stores to test the effectiveness of the application of lime and the fertilizer blends. Each host farmer managed two or three crops, with only one legume planted per trial site: soybean or groundnut. Maize trials were established on 50, soybean on 28, groundnuts on 24, and sweet potato on 26 sites. 


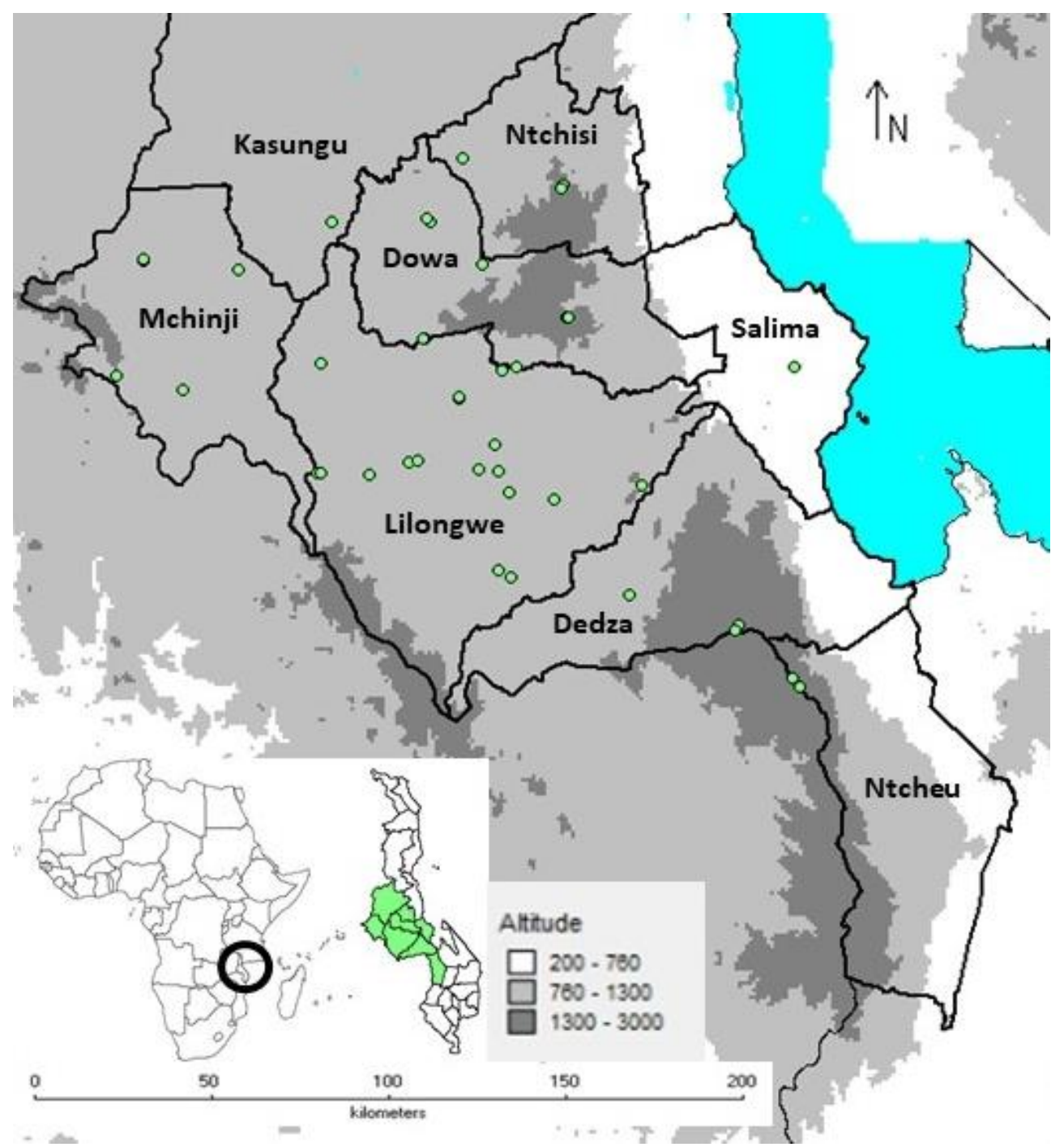

Fig 5.1: Location of Farmers World Ltd demo sites in eight districts of central Malawi.

\subsubsection{Trial design and data collection}

The maize trials consisted of four plots of $7.5 \mathrm{~m}$ by $8.0 \mathrm{~m}$ each. Ridge spacing was $0.75 \mathrm{~m}$ and each plot had 10 rows of $8 \mathrm{~m}$ length with $0.25 \mathrm{~m}$ spacing between plants. One seed was sown per planting station. Maize variety MH26, a hybrid, drought tolerant, medium duration (about 110 days) variety was planted in all sites. The soybean and groundnut trials both consisted of four plots of $8.0 \mathrm{~m}$ by $8.1 \mathrm{~m}$. Each plot had 16 ridges spaced $0.5 \mathrm{~m}$ apart. On each ridge two rows were sown with one seed per planting station every $0.25 \mathrm{~m}$. Soybean 
variety Tikolore was selected because it is an early maturing self-nodulating variety that is resistant to leaf rust. Soybean seeds were not inoculated before sowing. Groundnut variety CG7 was chosen because it is a popular high yielding variety with high oil content. The sweet potato trials consisted of twelve plots of $5.4 \mathrm{~m}$ by $3.75 \mathrm{~m}$. Each plot had five ridges spaced $0.75 \mathrm{~m}$ apart with $32 \mathrm{~cm}$ between planting stations on each ridge. In each site a block of six sweet potato plots received fertilizer, while the other six control plots did not receive inputs. Six varieties were planted: the five orange-fleshed varieties Anaakwanire, Mathuthu, Kaphulira, Kadyaubwerere and Chipika (Chapter 4) and a local white- or yellow-fleshed variety. Each variety featured two times in each trial: once in the fertilized block, and once in the control block. Table 5.1 presents the fertilizer and lime treatments in the maize, soybean, groundnut and sweet potato trials. Basal fertilizer was applied after germination for all crops. Top dressing was applied only to maize on average 28 days after planting. The lime (chemical composition $96 \% \mathrm{CaCO}_{3}, 1.5 \% \mathrm{MgCO}_{3}, 0.7 \% \mathrm{SiO}_{2}$ and $0.6 \% \mathrm{MnO}_{2}$ ) was incorporated in the ridges two weeks before planting. In case of poor emergence, gaps in the maize and groundnut trials were filled with new seed. This was not needed in the soybean trials where germination was excellent in all sites. Host farmers kept the fields weed-free by manual weeding throughout the season. Where pests were observed, cypermethrin was applied as a biocide.

To avoid border effects, net plots were harvested in each plot, leaving the outer row on each side of the plot, and the last two plants on both sides of each row. Maize plants in the net harvest area of $6 \mathrm{~m}$ by $7 \mathrm{~m}\left(42 \mathrm{~m}^{2}\right)$ were cut from the base. Cobs were removed, counted and placed on drying bags for three to five weeks. The stover was removed from the cobs, the cobs were shelled and the grain weight recorded. The net harvest area of each soybean and groundnut plot was $6.0 \mathrm{~m}$ by $6.9 \mathrm{~m}\left(41.4 \mathrm{~m}^{2}\right)$. The soybean plants were harvested when the first plants started shattering. The plants were uprooted and left indoors to dry for three to four weeks. After this the soybean was threshed and grain weight recorded. At maturity, groundnuts were uprooted and left in the field for three to four weeks to dry. Then the pods were removed and shelled and grain weight was recorded. Sweet potato roots were harvested from a net area of $4.2 \mathrm{~m}$ by $2.25 \mathrm{~m}$ that contained a maximum of 39 plants. The fresh weight of the storage roots and the vines were recorded separately at the day of harvest. 
Table 5.1: Input treatments in the maize, soybean, groundnut and sweet potato plots.

\begin{tabular}{|c|c|c|c|c|}
\hline Plot & Fertilizer type & $\begin{array}{l}\text { Fertilizer } \\
\text { applied } \\
\left(\mathrm{kg} \mathrm{ha}^{-1}\right)\end{array}$ & $\begin{array}{l}\text { Nutrients applied in } \\
\text { fertilizer } \\
\left(\mathrm{kg} \mathrm{ha}^{-1}\right)\end{array}$ & $\begin{array}{l}\text { Lime } \\
\text { application } \\
\left(\mathbf{k g ~ h a}^{-1}\right)\end{array}$ \\
\hline \multicolumn{5}{|l|}{ Maize $^{1}$} \\
\hline $\mathrm{T} 1$ & No & 0 & 0 & 0 \\
\hline $\mathrm{T} 2^{2}$ & $\begin{array}{ll}\text { NPS } & 23: 9: 4 \\
\text { N Urea } & 46\end{array}$ & $\begin{array}{l}150 \\
100\end{array}$ & $81 \mathrm{~N}, 14 \mathrm{P}, 6 \mathrm{~S}$ & 0 \\
\hline $\mathrm{T} 3$ & $\begin{array}{ll}\text { NPKSZnB } & 15: 10: 13: 6: 0.5: 3 \\
\text { NK } & 30: 13\end{array}$ & $\begin{array}{l}175 \\
150\end{array}$ & $\begin{array}{l}71 \mathrm{~N}, 18 \mathrm{P}, 42 \mathrm{~K}, 11 \mathrm{~S} \\
1 \mathrm{Zn}, 5 \mathrm{~B}\end{array}$ & 1000 \\
\hline $\mathrm{T} 4$ & $\begin{array}{ll}\text { NPKSZnB } & 15: 10: 13: 6: 0.5: 3 \\
\text { NK } & 30: 13\end{array}$ & $\begin{array}{l}350 \\
300\end{array}$ & $\begin{array}{l}143 \mathrm{~N}, 35 \mathrm{P}, 85 \mathrm{~K}, 21 \mathrm{~S}, \\
2 \mathrm{Zn}, 11 \mathrm{~B}\end{array}$ & 1000 \\
\hline
\end{tabular}

\section{Soybean}

T1 No

T2 NPK 6:9:20

T3 NPK 6:9:20

T4 NPK 6:9:20
0

150

150

250
0

9N, 14P, 30K

$9 \mathrm{~N}, 14 \mathrm{P}, 30 \mathrm{~K}$

$15 \mathrm{~N}, 23 \mathrm{P}, 50 \mathrm{~K}$
0

0

1000

1000

\section{Groundnut}

T1 No

T2 NPK 6:9:20

T3 NPK 6:9:20

T4 NPK 6:9:20
0

200

200

300
0

$12 \mathrm{~N}, 18 \mathrm{P}, 40 \mathrm{~K}$

$12 \mathrm{~N}, 18 \mathrm{P}, 40 \mathrm{~K}$

$18 \mathrm{~N}, 27 \mathrm{P}, 60 \mathrm{~K}$

\section{0}

0

1000

1000

\section{Sweet potato ${ }^{3}$}

T1 No

0

0

0

T2 NPKS 10:9:17:6

250

25N, 23P, 43K, 15S

1000

${ }^{1}$ In maize T2-4, the first fertilizer type is applied as basal and the second type as top dressing. ${ }^{2}$ National fertilizer recommendation using commonly available fertilizers. ${ }^{3}$ Observations in sweet potato treatments represent the average of the 6 varieties planted.

Soil texture was determined in each site by obtaining a soil sample of $0-15 \mathrm{~cm}$ depth, moistening a handful of soil and shaping the soil into a ball and forming a ribbon with the soil with the thumb (Weil, 2015). Four texture classes were defined as 1) Coarse; very gritty, the ball falls apart when poked, no ribbon (loamy sand, fine sand), 2) Moderately coarse; gritty, forms soft ball, weak ribbon $<2.5 \mathrm{~cm}$ (fine sandy loam, loam), 3) Medium; grittiness slight to none, ribbons dull and 2.5 to $5 \mathrm{~cm}$ (loam, silt loam, sandy clay loam) and 4) Fine; grittiness none, ribbons shiny, $>5 \mathrm{~cm}$ (clay, clay loam, silty clay loam). The terrain slope was classified as steep slope, gentle slope or flat. Other data collected for each site included the elevation of the site and the GPS coordinates, the previous crop planted on the site, and 
the gender of the host farmer and the agronaut. Rainfall data were not collected in the trial sites but total rainfall for the growing season in each site was estimated from data collected by government in each extension planning area (EPA; the eight districts are divided in 4-20 administrative units) where a trial was established.

\subsubsection{Returns on investment in input application}

Returns to investment in fertilizer and lime were calculated for each treatment and crop. The average farm-gate prices for maize, soybean and groundnut were collected by the department of Planning in the Ministry of Agriculture. An average farm-gate price for the period May to August 2017 was used for maize, soybean and groundnuts. To estimate the farm gate price for sweet potato, the average market price in the same period in 22 markets in the eight districts was reduced by a 66.5 percent marketing margin for local traders (CIP, 2016). Applying an exchange rate of $726 \mathrm{MWK} \mathrm{USD}^{-1}$ resulted in farm gate prices of $0.09 \mathrm{USD} \mathrm{kg}^{-}$ ${ }^{1}$ for maize, $0.41 \mathrm{USD} \mathrm{kg}^{-1}$ for groundnuts, $0.20 \mathrm{USD} \mathrm{kg}^{-1}$ for soybean and $0.12 \mathrm{USD} \mathrm{kg}^{-1}$ for sweet potato. The costs of fertilizer and lime inputs were calculated per hectare using Farmers World Ltd retail prices or price estimates (in case of new fertilizer blends not yet on the market) at the time of planting (December 2016). Partial gross margins were calculated per hectare as the farm-gate value of produce minus the costs of fertilizer and lime. The valuecost ratio (VCR) for each treatment and crop was calculated as the value of additional produce per dollar invested in inputs. A VCR $>2$ is often considered to be a minimum for technology adoption by smallholder farmers (Kelly, 2006) and therefore we calculated the percentage of fields with $\mathrm{VCR}>2$ for each treatment. A sensitivity analysis was done to compare the effect of other farm gate price scenarios on the VCRs. In the first scenario we accounted for price fluctuations between years by comparing the 2017 May-August prices with the 10-year average of 2005-2105 for the same months. In the second scenario we accounted for price fluctuations within years by estimating the price increase farmers would get when postponing sales to the month with the best market price. In absence of long-term farm gate prices, we used national monthly retail market prices for maize, soybean and groundnut collected in 75 markets in the period 2005 - 2014 (MAIWD, 2017). To estimate the farm gate prices for the two scenarios, we applied the proportional difference in retail prices to the 2017 farm gate prices.

\subsubsection{Focus group discussions}

A focus group discussion with eight female and seven male lead farmers supported by Farmers World Ltd was organized in Lumbadzi, Lilongwe District. The objective was to understand farmer perceptions on crop diversification and intensification. Pairwise ranking was used to identify eight priority crops and collect qualitative data about the importance of each crop. Men and women separately indicated on a scale of 1-5 whether each crop was produced (1) for home consumption only, (2) mainly for consumption but some for sales, (3) equally for consumption and sales, (4) some for consumption but mostly for sales, or (5) for 
market sales only. The group was then asked to describe current common nutrient input practices and quantities applied for each crop. Reasons that underlie decisions to allocate land to certain crops, and willingness to make changes in land allocation were explored in the group discussion. The group was provided with a scenario of a 1.6-hectare (four acres) field with 0.4 hectare (one acre) each allocated to maize, groundnut, soybean and sweet potato. To identify priority crops for fertilizer application, the group was asked to discuss and agree how to allocate six bags of $50 \mathrm{~kg}$ fertilizer to this field. After presenting the basic yield results of the fertilizer trials to the group, this exercise was repeated.

\subsubsection{Data analysis}

Descriptive statistics were used to present the main environmental and socio-economic characteristics of the trial sites that were used in inferential statistics. The mean yield of the six sweet potato varieties was calculated to arrive at one value for no-input and one for the fertilized treatment in each site. Linear mixed model (MERL) analysis was used to analyse differences in yields between the input treatments in the four crops. Yield variability was presented in boxplots that show the minimum, first quartile, medium, third quartile and maximum yields for each treatment. A mean site yield was calculated for each crop as the average yield of all nutrient treatments in each site. MERL analysis was used to test which continuous variables (elevation, planting date and rainfall) and categorical factors (agroecological zone, district, soil texture class, terrain slope, previous crop, gender of the farmer and gender of the agronaut) were significantly associated with the dependent variables 'noinput yield (T1)' and 'mean site yield'. The absolute yield response ( $\left.\mathrm{t} \mathrm{ha}{ }^{-1}\right)$ was calculated as the difference between each treatment yield and the no-input treatment (T1). Variability in yield responses across sites was presented in cumulative probability charts for each crop. For each crop and treatment, MERL analysis was used to test which continuous variables and categorical factors were significantly associated with the yield responses. District and agroecological zone were added as random factors in the MERL model. After MERL analysis, Spearman's Rank Correlation coefficients were calculated to determine the strength and the direction of the association between the continuous and the dependent variables. All statistical analyses were conducted in Genstat $18^{\text {th }}$ edition.

\subsection{Results}

\subsubsection{Environmental conditions and management of the trial sites}

Most (>80\%) trial sites were located on the plateau between 760 and 1300 masl. Maize trials were planted from 7 December to 23 January, groundnuts from 7 December to 10 January and soybean from 7 December to 30 January and sweet potato between December 25 and January 31. The season had an exceptionally high total amount of rainfall (Table 5.2) and a uniform rainfall distribution (no data). There was an equal gender balance in the agronauts supporting the trials, while about $28 \%$ of the trials was hosted by female farmers. Relatively 
more men were selected to host sweet potato trials. The number of sites planted on flat land was similar to the number of sites with a gentle slope, while trials were rarely planted on steep slopes. Most sites had a moderately coarse (fine sandy loam, loam), or medium (loam, silt loam, sandy clay loam) soil texture with few exceptions of either coarse sandy, or fine clay soils (Table 5.2). Seventy percent of trials were preceded by a maize crop in the previous season, 16 percent by a legume and 12 percent by tobacco.

Table 5.2: Environmental and socio-economic characteristics of the trial sites. Characteristics of continuous variables are indicated as the average followed by the standard deviation between brackets.

\begin{tabular}{|c|c|c|c|c|}
\hline & $\begin{array}{l}\text { Maize } \\
(n=50)\end{array}$ & $\begin{array}{l}\text { Soybean } \\
(n=28)\end{array}$ & $\begin{array}{l}\text { Groundnuts } \\
(n=24)\end{array}$ & $\begin{array}{l}\text { Sweet potato } \\
(n=26)\end{array}$ \\
\hline \multicolumn{5}{|l|}{ Continuous } \\
\hline Elevation (masl) & $1183(114)$ & $1201(136)$ & $1137(86)$ & $1182(133)$ \\
\hline Planting date ${ }^{1}$ & $8.0(9.2)$ & $13.3(14.7)$ & $9.2(9.6)$ & $18-55^{2}$ \\
\hline Total rainfall (mm) & $1034(227)$ & $1034(220)$ & $982(235)$ & $1052(217)$ \\
\hline \multicolumn{5}{|l|}{ Categorical } \\
\hline $\begin{array}{l}\text { Female host farmers (\% of } \\
\text { farmers) }\end{array}$ & 32 & 36 & 25 & 15 \\
\hline Female agronauts ( $\%$ of agronauts) & 50 & 46 & 54 & 46 \\
\hline \multicolumn{5}{|l|}{ Agro-ecological zone (\% of sites) } \\
\hline$<760$ masl & 2 & 0 & 8 & 0 \\
\hline 760-1300 masl & 82 & 79 & 84 & 85 \\
\hline$>1300$ masl & 16 & 21 & 8 & 15 \\
\hline \multicolumn{5}{|l|}{ Terrain Slope (\% of sites) } \\
\hline Flat & 42 & 39 & 42 & 35 \\
\hline Gentle slope & 56 & 50 & 54 & 57 \\
\hline Steep slope & 2 & 4 & 0 & 0 \\
\hline No data & 0 & 7 & 4 & 8 \\
\hline \multicolumn{5}{|l|}{ Soil texture (\% of sites) } \\
\hline Coarse & 8 & 7 & 0 & 11 \\
\hline Moderately Coarse & 50 & 39 & 58 & 50 \\
\hline Medium & 34 & 39 & 30 & 31 \\
\hline Fine & 8 & 7 & 8 & 0 \\
\hline No data & 0 & 7 & 4 & 8 \\
\hline \multicolumn{5}{|l|}{ Previous crop (\% of sites) } \\
\hline Maize & 72 & 68 & 83 & 58 \\
\hline Soybean or groundnut & 14 & 18 & 17 & 15 \\
\hline Tobacco & 10 & 14 & 0 & 23 \\
\hline Sunflower or fallow & 4 & 0 & 0 & 4 \\
\hline
\end{tabular}

${ }^{1}$ The number of days from $7^{\text {th }}$ December $2016 .{ }^{2}$ No planting dates were collected; the trials were established in this period. 


\subsubsection{Trial performance and yield variability of maize, soybean, groundnuts and sweet potato}

The average no-input (T1) and mean site yields were 2.5 and $5.0 \mathrm{t} \mathrm{ha}^{-1}$ for maize, 2.3 and 3.4 $\mathrm{t} \mathrm{ha}^{-1}$ for soybean, 2.0 and $2.5 \mathrm{t} \mathrm{ha}^{-1}$ for groundnuts and 11.8 and $13.2 \mathrm{t} \mathrm{ha}^{-1}$ for sweet potato respectively. Yield responses to fertilizer and lime were evident in each crop, while there was a large variability in yield between sites within each treatment (Fig. 5.2). Elevation, planting date, rainfall, AEZ, district, terrain slope, soil texture, previous crop, gender of farmer and gender of agronaut could not explain variability in maize yields (Table 5.3). Groundnut yields (mean site yield and the no input yield) were strongly negatively associated with elevation ( $\mathrm{p}<0.001$ and $\mathrm{p}=0.003$ ). Groundnut yields were thus generally higher at lower elevation. Mean site yields of sweet potato were positively associated with elevation $(\mathrm{r}=0.40 ; \mathrm{p}=$ 0.048 ) with average yields of $18.4 \mathrm{t} \mathrm{ha}^{-1}$ in the highlands (AEZ 3) and $12.2 \mathrm{t} \mathrm{ha}^{-1}$ on the plateau (AEZ 2). Soybean trials were established later than maize (Table 5.2) and planting date was negatively associated with mean site soybean yields $(\mathrm{r}=-0.62 ; \mathrm{p}<0.001)$. Total rainfall positively affected soybean $\mathrm{T} 1$ yields $(\mathrm{r}=0.45 ; \mathrm{p}=0.017)$ and mean site yields $(\mathrm{r}=$ 0.50; $\mathrm{p}=0.007$ ). Farmers in Lilongwe, Mchinji and Ntcheu Districts achieved exceptionally good mean site soybean yields of $4.0-4.4 \mathrm{t} \mathrm{ha}^{-1}$ compared to $2.6-2.9 \mathrm{t} \mathrm{ha}^{-1}$ in Dedza, Dowa and Kasungu. 

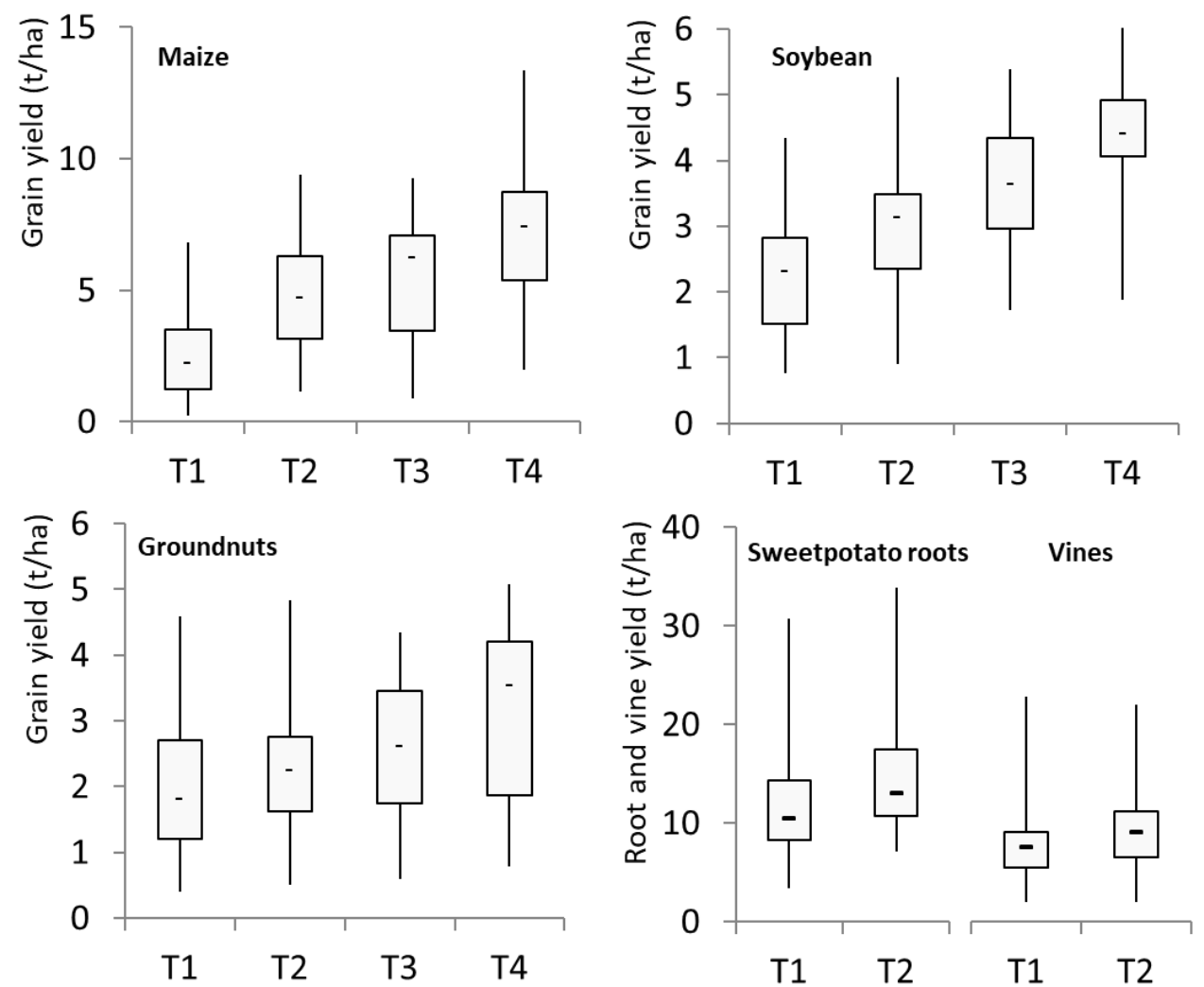

Fig. 5.2: Variability in yield of maize $(n=50)$, soybean $(n=28)$, groundnuts $(n=24)$ and sweet potato $(n=26)$ under different input treatments (treatment details are presented in Table 5.1). Boxplots present the minimum, $1^{\text {st }}$ quartile, medium, $3^{\text {rd }}$ quartile and maximum yields for each treatment. 
Table 5.3: Factors affecting yields in no-input treatments and mean site yields in maize, soybean, groundnuts and sweet potato in the central region of Malawi. The values are the F-probabilities generated by the REML analysis with the direction of the association given in brackets for the continuous variables in case $\mathrm{F}_{\mathrm{pr}}<0.1$.

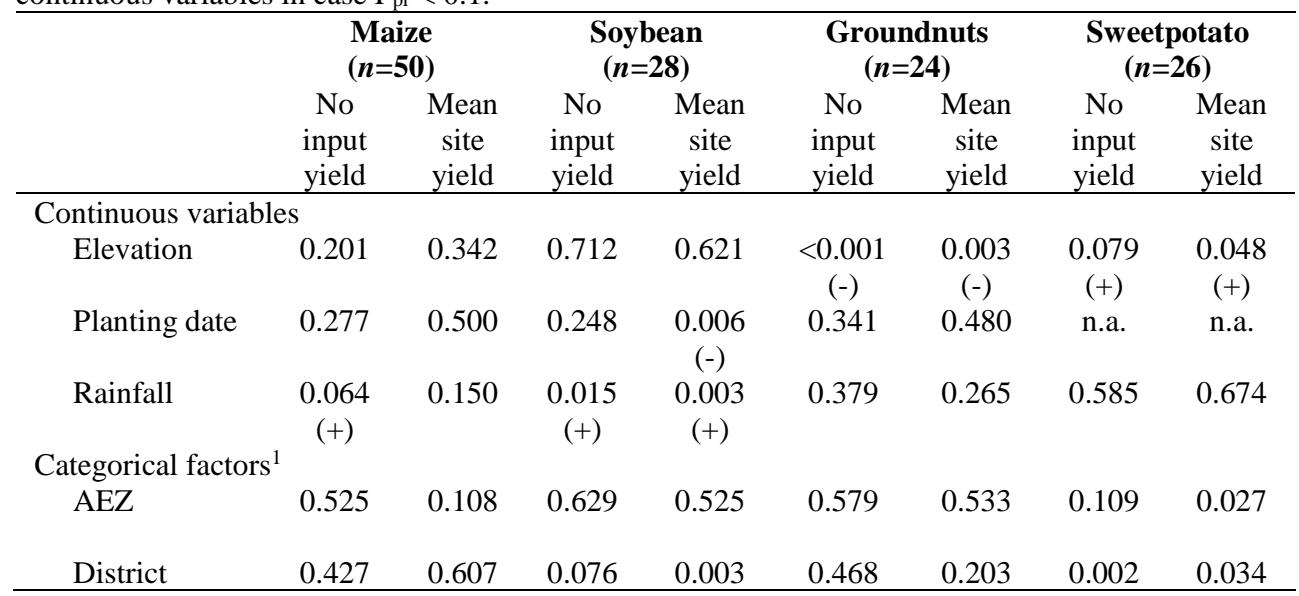

${ }^{1}$ Gender of the farmer, gender of the agronaut, terrain slope, soil texture and previous crop were not associated with any of the dependent variables.

\subsubsection{Yield responses to inputs}

Significant yield responses to inputs were observed in all four crops (Table 5.5). The commonly recommended fertilizer rate in maize in Malawi (T2: 81N, 14P, 6S) almost doubled yields from 2.5 to $4.8 \mathrm{tha}^{-1}$ compared to the no-input (T1) treatment. The combined application of the special blended fertilizer and lime (T3: 71N, 18P, 42K, 11S, 1Zn, 5B, lime) also more than doubled the yield compared with the control (T1), but it was not significantly better than T2. Increasing the quantity of special blended fertilizers combined with lime (T4: $143 \mathrm{~N}, 35 \mathrm{P}, 85 \mathrm{~K}, 21 \mathrm{~S}, 2 \mathrm{Zn}, 11 \mathrm{~B}$, lime) resulted in very good maize yields of $7.2 \mathrm{t} \mathrm{ha}^{-1}$; an increase of $1.6 \mathrm{t} \mathrm{ha}^{-1}$ compared to $\mathrm{T} 3$. Soybean also responded well to the special fertilizer blends and lime. Treatment 2 (9N, 14P and 30K) increased soybean yields to $3.1 \mathrm{tha}^{-1}(135 \%$ of $\mathrm{T} 1$ yields). The lime added in $\mathrm{T} 3$ significantly enhanced yields further by $0.6 \mathrm{t} \mathrm{ha} \mathrm{h}^{-1}$. Increasing the fertilizer dose further (T4: $15 \mathrm{~N}, 23 \mathrm{P}, 50 \mathrm{~K}$, lime) also proved to benefit soybean productivity up to exceptional yields of $4.5 \mathrm{t} \mathrm{ha}^{-1}$. The effect of fertilizer and lime application on groundnut was only significant in the highest input treatment (T4: 18N, 27P, 60K, lime) which resulted in yields of $3.1 \mathrm{t} \mathrm{ha}^{-1}$ (155\% of $\mathrm{T} 1$ yields). Unlike for soybean, there was no significant increase of groundnut yield after adding lime in $\mathrm{T} 3$ to the low-fertilizer input treatment (T2). Sweet potato yields increased from 11.8 to $14.5 \mathrm{t} \mathrm{ha}^{-1}$ in response to application of inputs (T2: $25 \mathrm{~N}, 22.5 \mathrm{P}, 42.5 \mathrm{~K}, 15 \mathrm{~S}$, lime). 


\subsubsection{Variability in yield responses}

There was considerable variability in yield responses to the input treatments in each crop (Fig. 5.3). Almost all maize and soybean plots showed a positive response to inputs. This was not the case for groundnut and sweet potato where no response or even a negative yield response was observed on $15 \%$ and $23 \%$ of the plots respectively. The percentage of maize plots with a yield response of more than $3 \mathrm{t} \mathrm{ha}^{-1}$ relative to $\mathrm{T} 1$ increased with higher input levels from $28 \%$ of the sites in $\mathrm{T} 2(81 \mathrm{~N}, 14 \mathrm{P}, 6 \mathrm{~S})$ to $52 \%$ in $\mathrm{T} 3(71 \mathrm{~N}, 18 \mathrm{P}, 42 \mathrm{~K}, 11 \mathrm{~S}, 1 \mathrm{Zn}$, $5 \mathrm{~B}$, lime) and even $84 \%$ of fields in T4 (143N, 35P, 85K, 21S, 2Zn, 11B, lime). Soybean gave more frequently yield responses of more than $1 \mathrm{t} \mathrm{ha}^{-1}$ than groundnut. For example, in the low input treatments (T2: $9 \mathrm{~N}, 14 \mathrm{P}, 30 \mathrm{~K}$ for soybean and $12 \mathrm{~N}, 18 \mathrm{P}, 40 \mathrm{~K}$ for groundnut) such a response was observed on $21 \%$ of the soybean sites, compared to none of the groundnut sites. At the highest input rates (T4: 15N, 23P, $50 \mathrm{~K}$ and lime for soybean and $18 \mathrm{~N}$, $27 \mathrm{P}, 60 \mathrm{~K}$ and lime for groundnut) a response of more than $1 \mathrm{t} \mathrm{ha}^{-1}$ was observed on $93 \%$ and $54 \%$ of the sites for soybean and groundnut respectively. A positive sweet potato yield response of more than $5 \mathrm{tha}^{-1}$ was achieved on $23 \%$ of the sites.

Several continuous variables were associated with the yield responses in the different crops (Table 5.4). Higher elevation was associated with smaller yield responses in groundnuts $\left(\mathrm{r}_{\mathrm{T} 2}\right.$ $\left.=-0.42 ; \mathrm{p}=0.025, \mathrm{r}_{\mathrm{T} 4}=-0.45 ; \mathrm{p}=0.036\right)$. In the soybean trials, a later planting date was negatively associated with the yield response in $\mathrm{T} 3\left(\mathrm{r}_{\mathrm{T} 3}=-0.39 ; \mathrm{p}=0.044\right)$. Better control plot (T1) yields were associated with smaller yield responses in some of the soybean $\left(\mathrm{r}_{\mathrm{T} 3}=\right.$ $\left.-0.328 ; \mathrm{p}=0.088, \mathrm{r}_{\mathrm{T} 4}=-0.43 ; \mathrm{p}=0.024\right)$, groundnut $\left(\mathrm{r}_{\mathrm{T} 2}=-0.401 ; \mathrm{p}=0.052\right)$ and sweet potato $\left(\mathrm{r}_{\mathrm{T} 2}=-0.40 ; \mathrm{p}<0.041\right)$ treatments. With maize on the other hand, the mean site yields were strongly positively associated with yield responses $\left(\mathrm{r}_{\mathrm{T} 3}=0.47 ; \mathrm{p}<0.001, \mathrm{r}_{\mathrm{T} 4}=0.57\right.$; $\mathrm{p}<0.001)$. Categorical factors that affected some of the yield responses included AEZ, district, soil texture and the gender of the agronaut (Table 5.4). At higher elevations (AEZ 3) the maize yield responses were slightly better in T2 $(81 \mathrm{~N}, 14 \mathrm{P}, 6 \mathrm{~S})$ and $\mathrm{T} 3(71 \mathrm{~N}, 18 \mathrm{P}, 42 \mathrm{~K}$, $11 \mathrm{~S}, 1 \mathrm{Zn}, 5 \mathrm{~B}$, lime). Sweet potato yield responses were affected by district with high responses of $16 \mathrm{t} \mathrm{ha}^{-1}$ in Ntcheu. Soil texture did not affect the yield responses except in the low input treatment (T2) of the soybean trials where yield responses averaged $1.2 \mathrm{t} \mathrm{ha}^{-1}$ in fine, $0.9 \mathrm{t} \mathrm{ha}^{-1}$ in medium, $0.5 \mathrm{t} \mathrm{ha}^{-1}$ in moderately coarse, and $0.7 \mathrm{t} \mathrm{ha}^{-1}$ in coarse textured soils. In fields supported by female agronauts the yield response of groundnut was $0.3 \mathrm{tha}^{-1}$ in $\mathrm{T} 3\left(12 \mathrm{~N}, 18 \mathrm{P}, 40 \mathrm{~K}\right.$, lime) and $0.7 \mathrm{t} \mathrm{ha}^{-1}$ in $\mathrm{T} 4(18 \mathrm{~N}, 27 \mathrm{P}, 60 \mathrm{~K}$, lime $)$, compared to 1.1 and $1.7 \mathrm{t} \mathrm{ha}^{-1}$ in fields supported by male agronauts. 

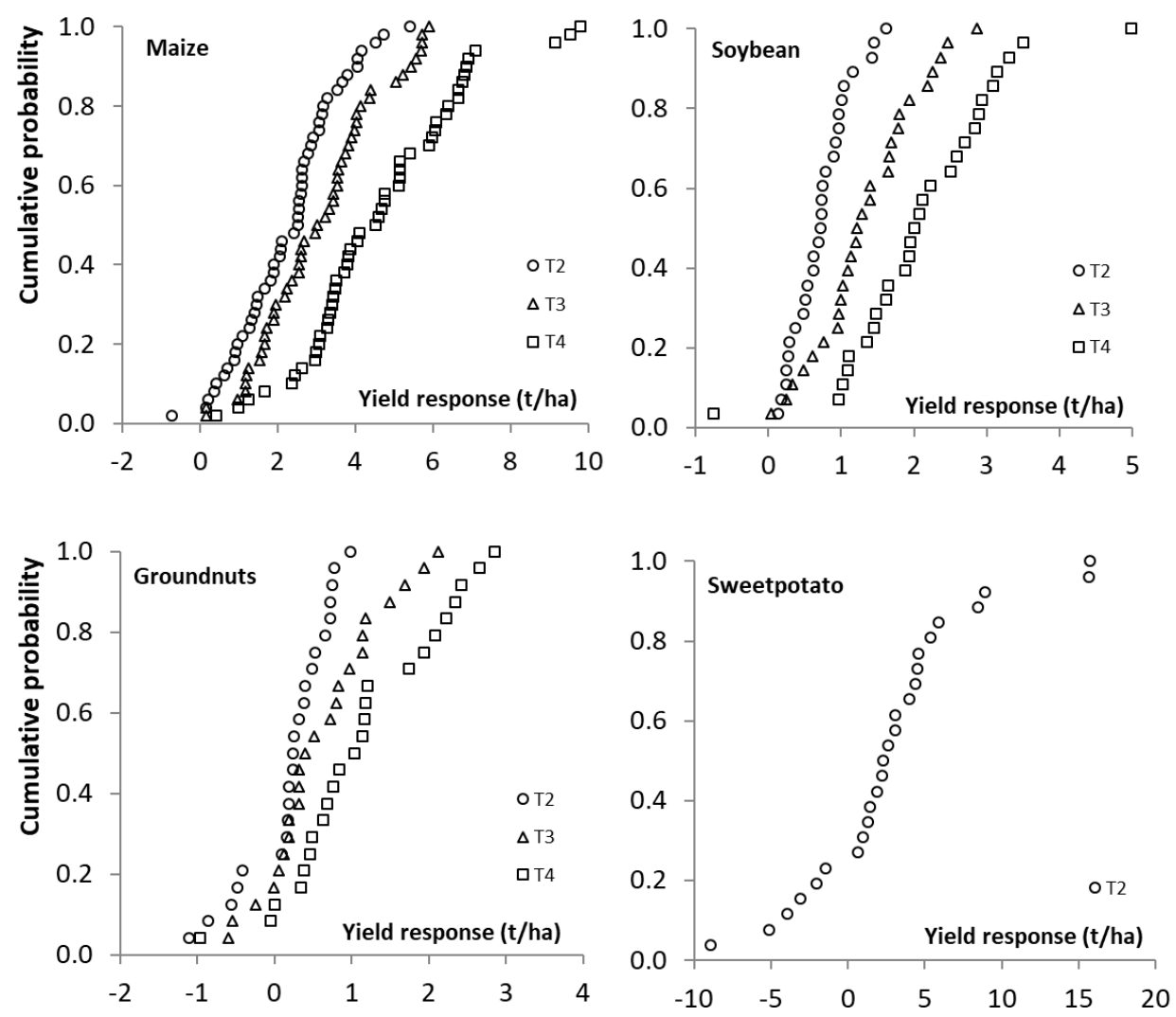

Fig. 5.3: Cumulative probability charts for the absolute yield responses to the input treatments, relative to $\mathrm{T} 1$, in maize, soybean, groundnut and sweet potato trials. 
Table 5.4: Factors ${ }^{1}$ affecting the absolute yield responses, relative to $\mathrm{T} 1$, to the input treatments in maize, soybean, groundnut and sweet potato. The values are the F-probabilities generated by the REML analysis with the direction of the association given in brackets for the continuous variables in case $\underline{\mathrm{F}_{\mathrm{pr}}}<0.1$.

\begin{tabular}{|c|c|c|c|c|}
\hline & $\begin{array}{l}\text { Maize } \\
(n=50)\end{array}$ & $\begin{array}{l}\text { Soybean } \\
(n=28)\end{array}$ & $\begin{array}{l}\text { Groundnuts } \\
(n=24)\end{array}$ & $\begin{array}{l}\text { Sweet potato } \\
(n=26)\end{array}$ \\
\hline \multicolumn{5}{|c|}{ Elevation } \\
\hline $\mathrm{T} 2$ & $0.080(+)$ & 0.610 & $0.017(-)$ & \multirow{3}{*}{0.740} \\
\hline $\mathrm{T} 3$ & 0.913 & 0.838 & 0.180 & \\
\hline $\mathrm{T} 4$ & 0.104 & 0.625 & $0.039(-)$ & \\
\hline \multicolumn{5}{|c|}{ Planting date } \\
\hline $\mathrm{T} 2$ & 0.103 & $0.057(-)$ & 0.513 & \multirow[t]{3}{*}{ No data } \\
\hline $\mathrm{T} 3$ & 0.641 & $0.021(-)$ & 0.337 & \\
\hline $\mathrm{T} 4$ & 0.963 & $0.096(-)$ & 0.444 & \\
\hline \multicolumn{5}{|c|}{ No input yield } \\
\hline $\mathrm{T} 2$ & 0.321 & 0.398 & $0.043(-)$ & $0.027(-)$ \\
\hline $\mathrm{T} 3$ & 0.824 & $0.020(-)$ & 0.484 & \\
\hline $\mathrm{T} 4$ & 0.879 & $<0.001(-)$ & 0.549 & \\
\hline \multicolumn{5}{|c|}{ Mean site yield } \\
\hline $\mathrm{T} 2$ & $0.053(+)$ & 0.132 & 0.791 & \multirow[t]{3}{*}{0.184} \\
\hline $\mathrm{T} 3$ & $0.001(+)$ & 0.432 & 0.150 & \\
\hline $\mathrm{T} 4$ & $<0.001(+)$ & 0.592 & 0.137 & \\
\hline \multicolumn{5}{|l|}{ AEZ } \\
\hline $\mathrm{T} 2$ & 0.046 & 0.224 & 0.409 & \multirow{3}{*}{0.906} \\
\hline $\mathrm{T} 3$ & 0.042 & 0.889 & 0.324 & \\
\hline $\mathrm{T} 4$ & 0.214 & 0.644 & 0.033 & \\
\hline \multicolumn{5}{|l|}{ District } \\
\hline $\mathrm{T} 2$ & 0.455 & 0.671 & 0.804 & \multirow[t]{3}{*}{0.028} \\
\hline $\mathrm{T} 3$ & 0.196 & 0.643 & 0.722 & \\
\hline $\mathrm{T} 4$ & 0.323 & 0.872 & 0.140 & \\
\hline \multicolumn{5}{|c|}{ Soil texture } \\
\hline $\mathrm{T} 2$ & 0.638 & 0.003 & 0.313 & \multirow[t]{3}{*}{0.115} \\
\hline $\mathrm{T} 3$ & 0.607 & 0.124 & 0.225 & \\
\hline $\mathrm{T} 4$ & 0.460 & 0.533 & 0.600 & \\
\hline \multicolumn{5}{|c|}{ Gender Agronaut } \\
\hline $\mathrm{T} 2$ & 0.509 & 0.299 & 0.395 & \multirow[t]{3}{*}{0.600} \\
\hline $\mathrm{T} 3$ & 0.203 & 0.325 & 0.012 & \\
\hline $\mathrm{T} 4$ & 0.598 & 0.620 & 0.007 & \\
\hline
\end{tabular}

${ }^{1}$ The continuous variable 'rainfall' and the categorical factors 'terrain slope', 'previous crop' and 'gender farmer' were not associated with any of the dependent variables. 


\subsubsection{Costs and benefits of investing in inputs}

The partial gross margins ranged from 230 to $315 \mathrm{USD}^{-1}$ for maize, 475 to $735 \mathrm{USD}^{-1}$ for soybean, 821 to 1092 USD ha $^{-1}$ for groundnut and 1380 to $1478 \mathrm{USD} \mathrm{ha}^{-1}$ for sweet potato (Table 5.5). Considering average returns on investment in inputs, all treatments were profitable for all crops with average VCR $>1$, while average VCR $>2$ was only achieved in $\mathrm{T} 3$ and $\mathrm{T} 4$ of soybean and in T4 of groundnuts. The quantity of farm produce in kg per USD invested in inputs was highest for maize followed by sweet potato, soybean and groundnuts, while the VCR for maize was below 2 in most fields. This indicates that investments in fertiliser application to maize gives high returns in terms of additional produce, but low monetary returns due to low maize outputs prices. On the contrary, fertiliser investments in groundnut provided relatively small returns in terms of additional produce, but the associated VCR values were at par with other crops due to high groundnut prices. VCR values associated with soybean were generally largest, indicating the good potential for investments in inputs for this crop as a source of income.

Farm gate prices from May to August 2017 were 0.09 USD kg-1 for maize, $0.20 \mathrm{USD} \mathrm{kg}^{-1}$ for soybean and $0.41 \mathrm{USD} \mathrm{kg}^{-1}$ for groundnuts. Retail prices from May to August 2017 as a percentage of the 10-year average (2005-2014) for the same months were $135 \%$ for maize, $74 \%$ for soybean and $93 \%$ for groundnuts. Adjustments of the 2017 farm gate prices with these percentages gave estimated long-term average farm gate prices of $0.067 \mathrm{USD} \mathrm{kg}^{-1}$ for maize, $0.276 \mathrm{USD} \mathrm{kg}^{-1}$ for soybean and $0.444 \mathrm{USD} \mathrm{kg}^{-1}$ for groundnut. In this price scenario, the VCR for input application in maize is even smaller than for the 2017 prices and less than eight percent of fields have a VCR >2 (Table 5.6). The VCR for input application to soybean increases, as the farm gate prices in 2017 were less than the long-term average. With an average price, depending on input level, 64 to 82 percent of fields would have a VCR $>2$. The 2017 groundnut prices were quite representative of the long-term average. The second price scenario considered prices in the best month. Depending on the year, retail prices in the period 2005-2014 were best in the period January to March for maize, December to March for soybean and February to April for groundnuts. Prices in the best month were on average $175 \%, 136 \%$, and $138 \%$ of average retail prices in May to August for maize, soybean and groundnuts respectively. Proportional adjustments of the farm gate prices resulted in estimated farm gate prices in the best month of $0.159 \mathrm{USD} \mathrm{kg}^{-1}$ for maize, $0.277 \mathrm{USD} \mathrm{kg}^{-1}$ for soybean and $0.570 \mathrm{USD} \mathrm{kg}^{-1}$ for groundnut. This enhanced especially the returns to investment in inputs for maize with VCR $>2$ on 52 to 66 percent of fields (Table 5.6). The proportion of groundnut fields with $\mathrm{VRC}>2$ increased, but relatively less than maize and soybean. 
Table 5.5: Mean grain and fresh root yields, costs and value of production for different input treatments in maize, soybean, groundnut and sweet potato in central Malawi. Standard deviations from the means are presented in brackets.

\begin{tabular}{|c|c|c|c|c|c|c|}
\hline & $\begin{array}{c}\text { Yield } \\
\left(\mathrm{t} \mathrm{ha}^{-1}\right)\end{array}$ & $\begin{array}{l}\text { Farm-gate } \\
\text { value of } \\
\text { produce } \\
\left(\mathrm{USD} \mathrm{ha}^{-1}\right)\end{array}$ & $\begin{array}{c}\text { Partial } \\
\text { gross } \\
\text { margin }^{1} \\
\left(\text { USD ha }^{-1}\right)\end{array}$ & $\begin{array}{l}\text { Additional } \\
\text { produce per } \\
\text { USD invested } \\
\text { in inputs } \\
\left(\mathrm{kg} \mathrm{USD}^{-1}\right)\end{array}$ & $\begin{array}{c}\mathrm{VCR}^{3} \\
(-)\end{array}$ & $\begin{array}{c}\text { VCR>2 } \\
\text { (\% of } \\
\text { fields) }\end{array}$ \\
\hline \multicolumn{7}{|c|}{ Maize $(n=50)$} \\
\hline $\mathrm{T} 1$ & $2.5(1.6)$ & $230(146)$ & 230 & & & \\
\hline $\mathrm{T} 2$ & $4.8(2.0)$ & $437(178)$ & 292 & $15.7(9.0)$ & $1.4(0.8)$ & 24 \\
\hline $\mathrm{T} 3$ & $5.6(2.2)$ & $510(196)$ & 315 & $15.9(7.8)$ & $1.4(0.7)$ & 20 \\
\hline $\mathrm{T} 4$ & $7.2(2.7)$ & $655(243)$ & 300 & $13.2(5.8)$ & $1.2(0.5)$ & 6 \\
\hline $\mathrm{SED}^{4}$ & $0.43 * * *$ & $38.8 * * *$ & & 1.53 n.s. & 0.14 n.s. & \\
\hline \multicolumn{7}{|c|}{ Soybean $(n=28)$} \\
\hline $\mathrm{T} 1$ & $2.3(0.9)$ & $475(191)$ & 475 & & & \\
\hline $\mathrm{T} 2$ & $3.1(1.0)$ & $623(194)$ & 539 & $8.6(4.7)$ & $1.8(0.6)$ & 36 \\
\hline $\mathrm{T} 3$ & $3.7(1.0)$ & $750(198)$ & 631 & $11.3(5.9)$ & $2.3(0.8)$ & 57 \\
\hline $\mathrm{T} 4$ & $4.5(1.1)$ & $910(220)$ & 735 & $12.2(6.1)$ & $2.5(0.8)$ & 64 \\
\hline SED & $0.26 * * *$ & $53.8 * * *$ & & $1.50 *$ & $0.31 *$ & \\
\hline \multicolumn{7}{|c|}{ Groundnut $(n=24)$} \\
\hline $\mathrm{T} 1$ & $2.0(1.1)$ & $821(450)$ & 821 & & & \\
\hline $\mathrm{T} 2$ & $2.2(1.0)$ & 905 (414) & 792 & $1.8(4.7)$ & $0.7(2.0)$ & 25 \\
\hline $\mathrm{T} 3$ & $2.6(1.2)$ & $1080(499)$ & 933 & $4.3(5.0)$ & $1.8(2.1)$ & 46 \\
\hline $\mathrm{T} 4$ & $3.1(1.4)$ & $1295(565)$ & 1092 & $5.6(4.7)$ & $2.3(2.0)$ & 54 \\
\hline SED & $0.34 * *$ & $140^{* *}$ & & $1.39 *$ & $0.57 *$ & \\
\hline \multicolumn{7}{|c|}{ Sweet potato $(n=26)$} \\
\hline $\mathrm{T} 1$ & $11.8(7.1)$ & $1380(834)$ & 1380 & & & \\
\hline $\mathrm{T} 2$ & $14.5(7.5)$ & $1701(877)$ & 1478 & $12.5(24.8)$ & $1.5(2.9)$ & 39 \\
\hline SED & $0.84 * *$ & $97.9 * *$ & & & & \\
\hline
\end{tabular}


Table 5.6: Returns on investments in inputs in maize, soybean and groundnut under three farm gate price scenarios.

\begin{tabular}{|c|c|c|c|c|c|c|}
\hline \multirow[t]{2}{*}{$\begin{array}{l}\text { Price } \\
\text { scenario: }\end{array}$} & \multicolumn{2}{|c|}{$\begin{array}{l}\text { Farm gate prices } 2017 \\
\text { (May-August) }^{1}\end{array}$} & \multicolumn{2}{|c|}{$\begin{array}{c}\text { Mean farm gate price } \\
\text { 2005-2014 } \\
\text { (May-August) }^{2} \\
\end{array}$} & \multicolumn{2}{|c|}{$\begin{array}{l}\text { Farm gate price in best } \\
\text { month } \\
{\text { (December-April })^{3}}^{\text {(Dember }}\end{array}$} \\
\hline & $\begin{array}{c}\text { VCR } \\
(-) \\
\end{array}$ & $\begin{array}{c}\text { VCR }>2 \\
(\% \text { of fields })\end{array}$ & $\begin{array}{c}\text { VCR } \\
(-) \\
\end{array}$ & $\begin{array}{c}\text { VCR }>2 \\
(\% \text { of fields })\end{array}$ & $\begin{array}{c}\text { VCR } \\
(-)\end{array}$ & $\begin{array}{c}\text { VCR }>2 \\
(\% \text { of fields })\end{array}$ \\
\hline \multicolumn{7}{|c|}{ Maize $(n=50)$} \\
\hline $\mathrm{T} 2$ & 1.4 & 24 & 1.1 & 6 & 2.5 & 66 \\
\hline $\mathrm{T} 3$ & 1.4 & 20 & 1.1 & 8 & 2.5 & 64 \\
\hline $\mathrm{T} 4$ & 1.2 & 6 & 0.9 & 0 & 2.1 & 52 \\
\hline \multicolumn{7}{|c|}{ Soybean $(n=28)$} \\
\hline $\mathrm{T} 2$ & 1.8 & 36 & 2.4 & 64 & 2.4 & 64 \\
\hline T3 & 2.3 & 57 & 3.1 & 79 & 3.1 & 79 \\
\hline $\mathrm{T} 4$ & 2.5 & 64 & 3.4 & 82 & 3.4 & 82 \\
\hline \multicolumn{7}{|c|}{ Groundnut $(n=24)$} \\
\hline $\mathrm{T} 2$ & 0.7 & 25 & 0.8 & 29 & 1.0 & 33 \\
\hline $\mathrm{T} 3$ & 1.8 & 46 & 1.9 & 46 & 2.4 & 50 \\
\hline $\mathrm{T} 4$ & 2.3 & 54 & 2.5 & 54 & 3.2 & 63 \\
\hline
\end{tabular}

${ }^{1}$ Actual data collected in the eight districts. ${ }^{2}$ Estimated farm gate price adjusted based on proportional differences in retail prices between 2017 and the mean of 2005-2014 in the period May to August. ${ }^{3}$ Estimated farm gate prices in the month when retail prices are best.

\subsubsection{Farmers perceptions on crop diversification and input allocation to different crops.}

The top eight priority crops produced by farmers who participated in the focus group discussion from most to least important were maize, groundnuts, soybean, common bean, sweet potato, potato, tomato and tobacco (Table 5.7). Maize is crucial for food security and all farmers agreed that an absolute minimum area of 0.4 hectare should be planted with maize. If funds for fertilizer are available and market prices are good, the area under maize could be expanded. After maize, farmers prioritized legumes because they believe they do not need fertilizer, can be stored relatively well, and have multiple uses for household utilization and income generation. Access to seed, land and labour costs were some of the reasons limiting the expansion of legumes, and marketing was considered more difficult for soybeans than for groundnuts. The farmers acknowledged the benefits of sweet potato and were interested in expanding its production, but experience problems accessing quality planting material and storing the roots after harvest. Potato was considered a more interesting cash crop than tobacco, because it can also be consumed in case there is a maize shortage. The advantage of root and tuber crops over tomato was that they are staple crops, whereas tomato is a cash crop or consumed as a side dish. The limitations of potato compared to legumes are the need to invest in fertilizer, poor storability, and the risk of pests and diseases. Farmers were generally happy with their current crop and fertilizer allocations to their available land. They 
did not show interest in reducing the area of land under maize, unless they were already producing beyond their household food requirements and maize market prices are low. An important reason for farmers to allocate land to legumes such as groundnut, soybean and common bean is their strong belief that these crops do not need fertilizer, coupled with their financial constraints to buy enough fertilizer for their whole arable land area. During the exercise to allocate six bags of $50 \mathrm{~kg}$ fertilizer to a 1.6-hectare field that was equally divided in maize, groundnut, soybean and sweet potato, all farmers strongly objected to the idea of applying any fertilizer to groundnut, soybean and sweet potato. They considered it a waste of money since extension workers had explained to them that legumes fix their own nitrogen and sweet potato is traditionally produced without inorganic fertilizer. They came up with alternatives such as finding more land to grow maize, keeping the fertilizer for next year, or giving the additional fertilizer away to friends. After seeing the fertilizer trial results, farmers reluctantly distributed two of the six bags of fertilizer to maize, one to soybean, one to groundnuts and two to the sweet potato field.

Table 5.7: Crop priorities, production objectives and farmer perceptions $(n=15 ; 8 \mathrm{~F}, 7 \mathrm{M})$ on input application in the cropping system.

\begin{tabular}{|c|c|c|c|c|c|}
\hline \multicolumn{2}{|c|}{ Priority crop } & \multicolumn{2}{|c|}{$\begin{array}{l}\text { Production } \\
\text { objective }^{1}\end{array}$} & \multirow{2}{*}{$\begin{array}{l}\text { Current fertilizer } \\
\text { application per } \\
\text { hectare }^{2}\end{array}$} & \multirow[t]{2}{*}{$\begin{array}{l}\text { Farmers perception on use of } \\
\text { inputs }\end{array}$} \\
\hline & & $\mathbf{M}$ & $\mathbf{F}$ & & \\
\hline 1 & Maize & 2 & 2 & $\begin{array}{l}123 \mathrm{~kg} \text { NPS 23:21:4; } \\
123 \mathrm{~kg} \text { urea N } 48\end{array}$ & $\begin{array}{l}\text { This is the recommended } \\
\text { application rate for maize that most } \\
\text { farmers follow. }\end{array}$ \\
\hline 2 & Groundnut & 3 & 2 & No inputs & $\begin{array}{l}\text { Extension workers explained that } \\
\text { legumes do not need fertilizer }\end{array}$ \\
\hline 3 & Soybean & 4 & 4 & No inputs & $\begin{array}{l}\text { because they fix nitrogen. Fertilizer } \\
\text { application to legumes would be }\end{array}$ \\
\hline 4 & Common bean & 3 & 3 & No inputs & wasting money. \\
\hline 5 & Sweet potato & 4 & 4 & No Inputs & $\begin{array}{l}\text { Traditional practice is to produce } \\
\text { sweet potato without fertilizer. }\end{array}$ \\
\hline 6 & Potato & 4 & 4 & $246 \mathrm{~kg}$ NPS $23: 21: 4^{3}$ & \\
\hline 7 & Tomato & 4 & 4 & $\begin{array}{l}123 \mathrm{~kg} \mathrm{CAN}^{4} \\
246 \mathrm{~kg} \text { NPS } 23: 21: 4 \\
123 \mathrm{~kg} \mathrm{CAN}\end{array}$ & $\begin{array}{l}\text { Farmers believe these are the } \\
\text { recommended fertilizer application } \\
\text { rates for potato, tomato and tobacco. }\end{array}$ \\
\hline 8 & Tobacco & 5 & 5 & $492 \mathrm{~kg}$ CAN & \\
\hline
\end{tabular}

${ }^{1}$ 1) for home consumption only, 2) primarily for home consumption and some for sale, 3 ) half for home consumption and half for sale, 4) some for home consumption but primarily for sale and 5) for sale only. ${ }^{2}$ Farmers expressed this in number of $50-\mathrm{kg}$ bags per acre. ${ }^{3} \mathrm{Or}$ another compound fertilizer. ${ }^{4} \mathrm{CAN}$ $=$ Calcium Ammonium Nitrate. 


\subsection{Discussion}

\subsubsection{Study design, implementation and analysis}

We analysed results of a private sector intervention to compare the effects of different intensity of input application to different crops in the farming system. The maize trial would have been more informative if a direct comparison between the currently recommended fertilizer blends (T2) and the special blended fertilizer (T3) would have been possible without confounding of nutrient application treatments with lime treatments (Table 5.1). The effect of lime alone could only be tested for soybean and groundnuts. The MERL analysis is used in different studies to explore variability in yields and yield responses to technologies (Franke et al., 2016; Ronner et al., 2016) since it can include balanced and unbalanced continuous and categorical data to compensate for confounding factors. A risk of testing the associations of many variables and factors on multiple dependent variables is that some of the associations could be significant by chance. For example, we cannot think of an explanation for better yield responses to high input treatments in groundnuts on fields supported by male agronauts (Table 5.5). A limited number of associations between biophysical and socio-economic characteristics and yields of the four crops were found. This suggests that we did not measure key variables that explain a large part of the variability in yield across farmers' fields. The collection of data on soil characteristics, on-site rainfall, weed pressure and pests and diseases may have resulted in better explanations of the variability in yields and yield responses across sites. However, even studies that include such variables also report a large unexplained variability in yields on smallholder farms (Ronner et al., 2016; Fermont et al., 2009). Nevertheless, the trial results provided an excellent opportunity to quantify variability in yields and responses to fertiliser and lime application, to evaluate the effectiveness and profitability of these applications to maize, soybean, groundnut and sweet potato at many sites, to identify factors affecting the yield and yield responses, and to explore farmer perceptions on intensification and diversification.

\subsubsection{Yield and economic performance across crops}

The average mean site yields of $5.0 \mathrm{t} \mathrm{ha}^{-1}$ for maize, $3.4 \mathrm{tha}^{-1}$ for soybean, $2.5 \mathrm{t} \mathrm{ha}^{-1}$ for groundnuts and $13.2 \mathrm{t} \mathrm{ha}^{-1}$ for sweet potato were exceptionally good for smallholder farmers' fields. The national average yields between 2000 and 2016 were only $2.0 \mathrm{tha}^{-1}$ for maize, 1.0 $\mathrm{t} \mathrm{ha}^{-1}$ for soybean and $1.0 \mathrm{t} \mathrm{ha}^{-1}$ for groundnuts (FAO, 2018), while mean sweet potato yields in farmer managed demonstration sites in 2017 ranged from 4.2 to $9.6 \mathrm{t} \mathrm{ha}^{-1}$ depending on variety (Chapter 4). The good yields even in the control plots (T1) are due to the use of improved varieties, high amounts of well-distributed rainfall in the season, and the timely establishment of the trials (Table 5.2). The close supervision of only two trial sites per agronaut and biocide application further contributed to good crop management. All four crops strongly responded to the application of inputs (Table 5.5). All input treatments in the four crops were on average more profitable than the control $(\mathrm{VCR}>1)$ but the variations in 
percentage of fields with $\mathrm{VCR}>2$ between treatments and crops indicate that profit margins may be too variable to encourage all farmers to adopt (Table 5.5). Price fluctuations within and between years also affect the financial returns to investment in inputs (Table 5.6). The average VCR would rise to over 2 in almost all treatments if farmers could wait with sales until the month with the best price, indicating farmers derive more benefits from investing in input application if they can store produce for later sales. The good yield responses in all crops raises the question if this would also be the case in years of poor rainfall. Other studies have shown that fertilizer application can still be profitable in sites with soybean control yields of only $0.9 \mathrm{t} \mathrm{ha}^{-1}$ (Chapter 2 ) or maize control yields of only $0.5-0.8 \mathrm{t} \mathrm{ha}^{-1}$ (Kamanga et al., 2013). Gender of the farmer did not affect yields or yield responses to inputs in our trials, although it has been reported that fields managed by women are on average $25 \%$ less productive than plots managed by men in Malawi (Kilic et al., 2015). This lack of gender effects could be due to host farmer selection criteria, equal access to all required inputs, and close supervision of the demos.

Yield response to inputs in maize was positively associated with mean site yields which is in line with other findings that more productive maize fields respond better to nutrient inputs (Chapter 3). While investments in nutrient inputs in maize gave the greatest return of additional grain, the VCR of input application in maize was lower than for investments in inputs in the other crops (Table 5.5). Using long-term average farm-gate prices in the analysis improved VCRs in soybean, while it reduced the benefits in maize even further (Table 5.6). This implies it is risky to base investment recommendations on a single season. Although a comparison of the results of the partial budgeting between crops should be done with caution as input costs not accounted for in the analyses may differ between crops, the large differences in partial budgets between crops suggest that soybean, groundnuts and sweet potato are more profitable per cultivated land area than maize (Table 5.5). Detailed farm characterizations in central Malawi also indicated that legume cultivation is more profitable than continuous maize, even though labour requirements are higher for groundnuts than for maize and soybean (Franke et al., 2014).

The importance of good agronomic management and rainfall was emphasized by the associations of planting date and rainfall with soybean yields (Table 5.3) and yield responses (Table 5.4). Better control plot yields for soybean and groundnut were associated with smaller responses to inputs in some treatments (Table 5.4). While no soil analysis was conducted, the smaller response in more productive sites was probably caused by better soil nutrient availability leading to higher yields in the control plot and smaller responses to nutrient applications. Nutrient application rates in soybean were generally lower than in groundnut (Table 5.1), but soybean nevertheless showed higher responses to nutrient inputs than groundnut. The effect of liming on yield was significant in soybeans but not in groundnuts, which suggests that lime application in soybean is more worthwhile. Despite the 
higher yield responses to inputs in soybean, the partial margins for groundnut were better than for soybean because of the greater farm gate price of groundnut. However, the higher VCR values associated with the input treatments in soybean suggest that fertiliser and lime application is more worthwhile in soybean than in groundnut. Some $15 \%$ of groundnut plots gave no or a negative yield response to inputs (Fig. 5.3) implying that investment in inputs in groundnuts is riskier than in soybean. Intensification of legumes with fertilizer and lime can be financially attractive since the higher input treatments of soybean and groundnut resulted in better profit margins and VCR than the lower input treatments (Table 5.5). In addition, this will provide residual benefits to the following maize crop in the rotation (Franke et al., 2018; Van Vugt et al., 2018). High-input legume production may be more suitable for commercially oriented farmers who have the financial resources to invest in fertilizer, since resource-poor farmers are reluctant to apply inorganic fertilizers to legumes (Chapter 2).

While input application to sweet potato increased yields and had a VCR of 1.5 (Table 5.5), $23 \%$ of sweet potato plots gave no or a negative response to inputs (Fig. 5.3). This implies there is more risk in input application in sweet potato compared to maize and soybean. Sweet potato is often considered a poor man's or food security crop and had a market price of 0.12 $\mathrm{USD} \mathrm{kg}^{-1}$; far below the $0.41 \mathrm{USD} \mathrm{kg}^{-1}$ for groundnuts and $0.20 \mathrm{USD} \mathrm{kg}^{-1}$ for soybean. This could be attributed to the relatively high average moisture content of sweet potato of $69 \%$ compared to $10 \%$ for soybean and $7 \%$ for groundnut (Leung et al., 1969). Yet, the good yields of sweet potato without inputs resulted in better values of produce per hectare than any of the treatments in the maize, soybean or groundnut trials (Table 5.5). The fresh and dry yield potential of sweet potato ( $35 \mathrm{t}$ fresh tuber ha- ${ }^{-1}$ equal to approximately $10.8 \mathrm{t}$ dry tuber $\mathrm{ha}^{-1}$ ) (Chipungu, 2015) is much larger than that of legumes.

\subsubsection{Farmers perceptions on intensification and diversification}

Soybean and sweet potato are produced more for the market than groundnuts and maize (Table 5.6). Allocation of fertilizer to either soybean or groundnut may depend on whether the household prioritizes food production or income generation. Farmers prioritize input application to maize, which has a large return in terms of grain yield per USD invested in inputs (Table 5.5). The food security aspect of maize appears to be more important than the potential profits that can be derived from the other crops. Farmers want to allocate at least 0.4 ha of land to maize to be self-sufficient with their staple food. Since maize cultivation depletes most of their financial resources available for investment in fertilizer, they primarily want to grow additional crops such as legumes and sweet potato that do not need fertilizer in their perception. As a result, the Farm Input Subsidy Program in Malawi has stimulated farmers to plant more land with maize and tobacco and allocate less land to other crops such as groundnuts, soybeans, and dry beans (Chibwana and Fisher, 2012), which goes against the aim of developing more sustainable, diversified, climate resilient and nutrient-rich production systems. Farmers' reluctance to reduce the area under maize and to apply inputs 
in soybean, groundnut or sweet potato may be due to lack of knowledge, lack of credit or an aversion to the risks associated with investments beyond household food security needs. Risk aversion and adoption of technologies in Malawi are mainly influenced by credit constraints, farm size, labour availability and access to output markets (Simtowe, 2006). Farmers show interest in expanding the area under sweet potato and this may reduce some of the risks of food shortages due to maize crop failure. However, it is likely that the increase in area under sweet potato will be at the expense of legumes instead of maize resulting in reduced nitrogen fixation and soil fertility benefits.

\subsubsection{Enhancing crop diversification and intensification}

Farmers mentioned challenges to crop diversification and intensification such as the need for a minimum area under maize cultivation, poor markets for soybean, limited access to improved seed or quality planting material, insufficient land and labour, and storage challenges for sweet potato. Risk mitigation and access to quality extension services will be important for farmers to invest in sustainable intensification practices as they need to tradeoff benefits of enhanced production, profits and soil fertility (Snapp et al., 2018). Investments in inputs in soybean cultivation are profitable (Table $5.5 \& 5.6$ ), enhance nitrogen fixation (Chapter 3) and soybean has better profit margins than maize (Table 5.5). Its expansion and intensification is constrained by uncertain markets, limited household utilization and the perception that legumes do not need fertilizer. Stimulating private sector investment in processing legumes and favourable policies to enhance export may result in increased demand and more stable markets for legumes. Improved extension messages concerning the benefits of fertilizer application to soybean may persuade farmers to invest in this in future. Inoculants can also enhance soybean yields and the profitability of $\mathrm{P}$ fertilizer (Van Heerwaarden et al., 2018; Ronner et al., 2016). Farmers have limited resources to invest in fertiliser and often sell their produce soon after harvest to vendors at low prices. Unless farmers are integrated in value chains and gain access to credit or fertilizer loans, legume intensification through fertilizer application is unlikely to occur. Supporting farmers with post-harvest credit while waiting with sales for commodity prices to increase (such as warehouse receipt systems) could also be of great financial benefit (Table 5.6). Campaigns to promote root and tuber crops as part of a more diverse source of calories may in the long term reduce the over-dependency on maize as a primary source of calories while contributing to more profitable, resilient and diverse cropping systems. A national option to enhance intensification and diversification could be the inclusion of planting material and special fertilizer blends for a wider range of crops in the Farm Input Subsidy Program. 


\section{Acknowledgements}

The trial establishment and data collection took place by Farmers World Ltd under the Productivity Improvement Program for Smallholders (PIPS) supported by the African Fertilizer and Agribusiness Partnership (AFAP). Sweet potato protocols, training and planting material were supported by the United States Agency for International Development under the Feed the Future Malawi Improved Seed Systems and Technologies project [grant number AID-BFS-G-11-00002] implemented by the International Potato Center. This research was undertaken as part of the CGIAR Research Program on Roots, Tubers and Bananas (RTB). The authors sincerely thank the management of Farmers World Ltd, the coordinator of the Farm Services Unit Caitlin Shaw, the area managers Kumbukani Munthali and Friday Mlenga and all agronauts for coordinating the field activities and making the data available for this publication. 
Chapter 6

General discussion

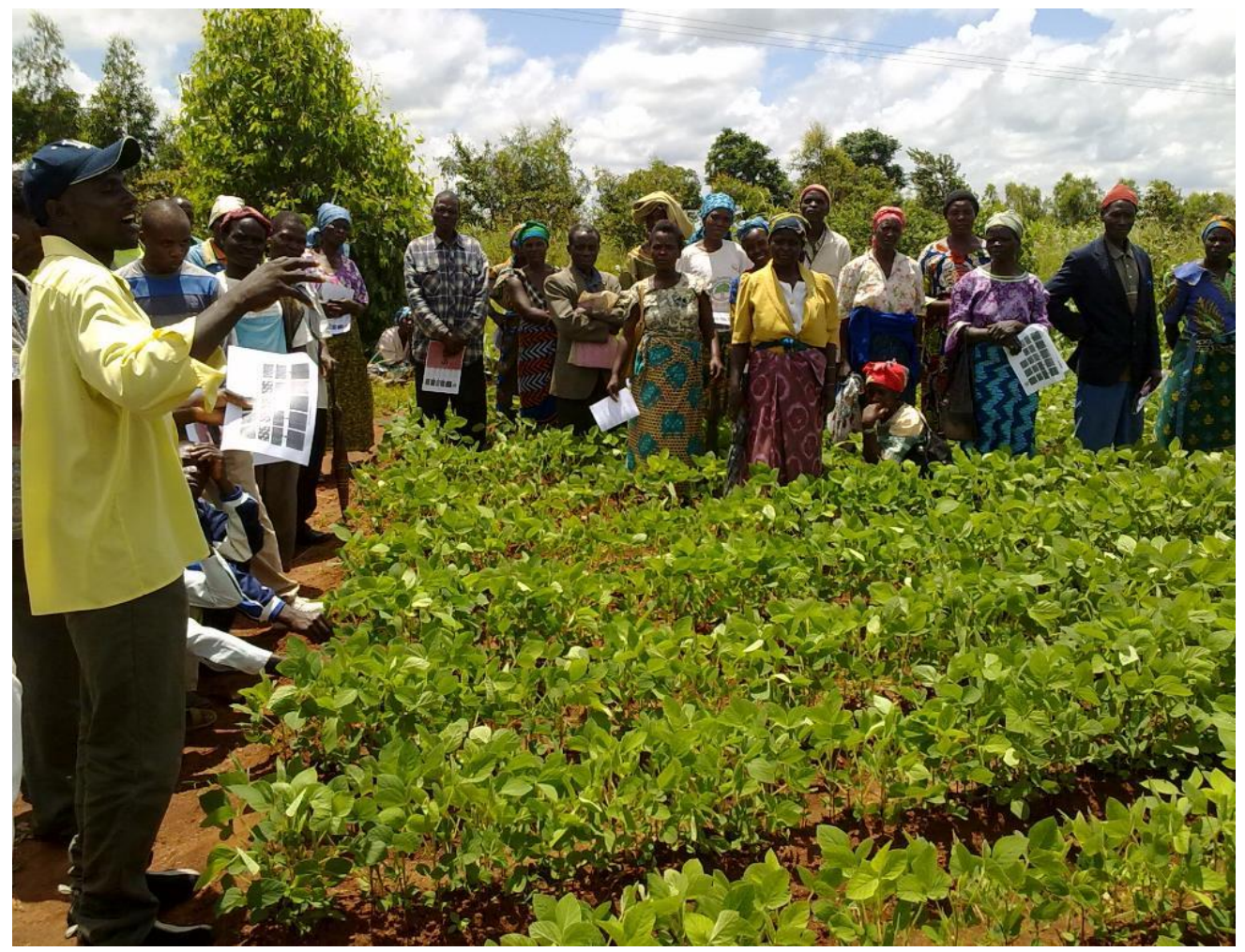




\subsection{Outline of discussion}

In this chapter I discuss the key findings (6.2) in relation to sustainable intensification (SI) of farming systems in central Malawi (6.3). I then discuss the implications of the large variability in yields and yield responses observed on smallholder farmers' fields (6.4). I will derive lessons from the participatory technology evaluations on the potential adoption (6.5) and discuss how SI can contribute to the Sustainable Development Goals (6.6). Finally, I will make recommendations on how to move from participatory research to 'partnerships for impact at scale' that can contribute to SI in a manner that acknowledges the realities and perceptions of smallholder farmers (6.7).

\subsection{Key findings}

The objective of this thesis was to assess whether smallholder farmers in central Malawi can increase their productivity and incomes through crop diversification with legumes and sweet potato and by application of improved agronomic practices and technologies. A wide range of treatments, biophysical conditions, crop management choices, and socio-economic variables affected maize, soybean, groundnut and sweet potato yields, $\mathrm{N}_{2}$ fixation and the rotational benefits of soybean on maize (Table 6.1).

In Chapter 2 I showed that nutrient management packages combining inoculants, inorganic fertilizer and compost manure can almost double smallholder farmers soybean yields, with value to cost ratios above 2 for about half of the farmers. Farmers prefer compost manure which is more accessible than inoculants and more affordable than fertilizer. Inoculants are an affordable option with an average value cost ratio of 3.3. Farmers ranked variety choice and early planting better than external inputs such as inoculant, fertilizer and biocides. Increasing the plant population was an acceptable and profitable option. Farmer preferences for soybean technologies were influenced by the costs and accessibility of the inputs.

Chapter 3 showed that $\mathrm{N}_{2}$-fixation by soybean is affected by a range of genetic, environmental, management and socio-economic factors. Yields of maize planted after soybean were on average $139 \%$ of continuous maize cultivation. Analysis of variability demonstrated that more productive and wealthier farmers who applied external nutrient inputs benefitted most from soybean-maize rotation.

In Chapter 4 I explored the sweet potato yield gap of $18.5 \mathrm{t} \mathrm{ha}^{-1}$ to explain why farmers achieved only about $30 \%$ of the attainable yields. Variety choice and timely planting of quality planting material enhanced sweet potato yields and weevil control is required to enhance the percentage of marketable roots. Elevation, planting date, rainfall and crop establishment affected yield but could explain only 28 percent of the yield gap. We 
discovered the importance of gender-sensitive extension to ensure timely access to planting material by women to avoid a gender-based yield gap.

Chapter 5 demonstrated that exceptionally good yields of maize, soybean and groundnut can be achieved under the right conditions of planting improved varieties, above-average rainfall and timely planting. The value of farm produce and financial returns to inputs in sweet potato, soybean and groundnuts were better than maize. This demonstrated the potential for crop diversification and intensification to enhance farmers' incomes, even though farmers prioritize maize in terms of land area and resource allocation as a risk aversion strategy to ensure food security at household level.

\subsection{Potential for sustainable intensification}

In this section I discuss whether farmers can sustainably increase their productivity through crop diversification and intensification. Sustainable intensification (SI) is broadly defined as the investment of inputs and capital to increase crop productivity over the long-term, while protecting the underlying resource base (Pretty et al., 2011). Sustainably intensified farming systems are often considered a useful future goal that will solve the issue of feeding a growing population, but without a clear pathway. Some scientists consider sustainable intensification an oxymoron and there is much variation in how intensification and sustainability are defined (Struik et al., 2014). The 'intensification' often refers to a set of yield enhancing technologies, where the 'sustainability' aspect focuses more on biological approaches (Petersen and Snapp, 2015). These include increased crop diversity with grain legumes, agroforestry, green manures, enhance nitrogen fixation, enhance organic nutrient inputs through incorporation of crop residues in the soil, minimize soil disturbance and erosion, onfarm water conservation, integrated pest management and irrigation (Ngwira et al., 2012; Bezner Kerr et al., 2007; Njira et al., 2013a; Droppelmann et al., 2017). Since poor soil fertility is a major cause of yield gaps in African smallholder agriculture (Tittonell and Giller, 2013) this section will focus on sustainability in terms of healthy soils that can serve future generations with adequate supplies of nutritious food. 


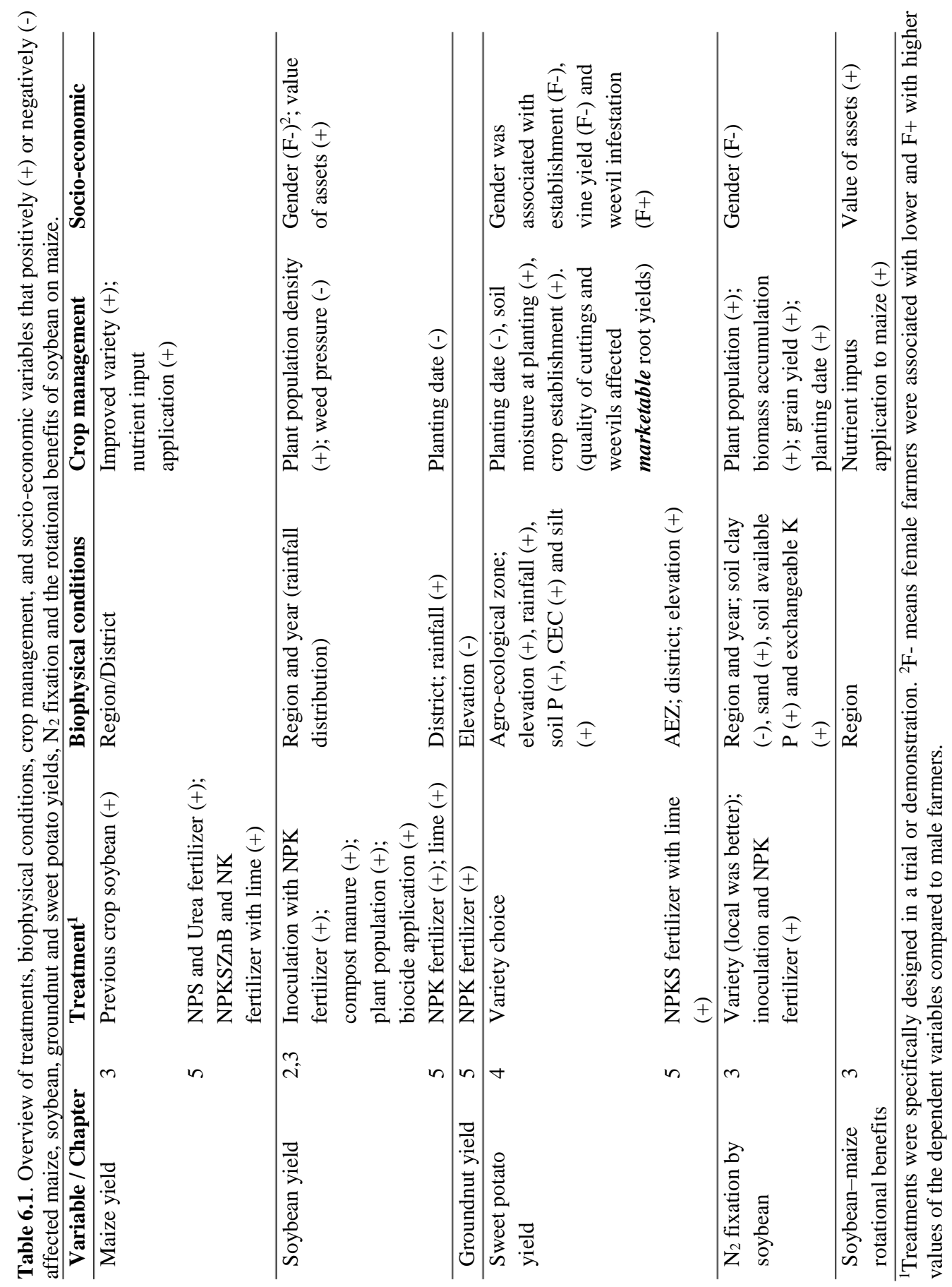




\subsubsection{Sustainability of the technologies}

In this research farmers experimented with different intensification options including improved varieties of maize, soybean, groundnuts and sweet potato, soybean-maize crop rotation, inoculation, compost manure, inorganic fertiliser, liming, biocide application, improved plant populations and optimal weeding. These could all form part of a SI package, but do these options contribute to improvement in soil fertility? While grain legumes benefit subsequent maize yields (Franke et al., 2018), varieties with high $\mathrm{N}$ harvest indices do not improve soil fertility (Vanlauwe and Giller, 2006) and inoculation enhances the need for soil P (Njira et al., 2013b). Enhancing yield with improved varieties and inorganic fertiliser can increase removal of micronutrients from the soil. An integrated soil fertility management (ISFM) approach combining both inorganic and organic nutrient inputs can result in better maize productivity and profits than relying on inorganic fertiliser only (Sauer and Tchale, 2009). Compost manure (Chapter 2) can therefore be considered a sustainable input, but especially for farmers without livestock, availability and quality of manure are factors limiting replenishment of soil organic matter and nutrients (Mafongoya et al., 2006). Therefore, while the technologies tested can contribute to intensification, they will only contribute to SI when coupled with adequate replenishment of both macro and micronutrients.

\subsubsection{Agronomic evaluation of the intensification options}

Production ecology concepts can be a helpful framework to evaluate the intensification options by looking at the genetic potential of the crop varieties, water and nutrient limitations and yield reducing factors such as pests and diseases (Van Ittersum and Rabbinge, 1997). Our results did not confirm the importance of selecting improved varieties for soybean and sweet potato. The improved soybean variety Nasoko did not outperform grain procured from local markets (Chapter 2). Chapter 4 showed a clear difference in yield between the six improved sweet potato varieties, but in Chapter 5 these did not outperform locally sourced varieties. However, there are other criteria for variety selection besides yield such as ability to fix nitrogen for legumes (Pule-Meulenberg et al., 2011) or pro-vitamin A content in the case of orange-fleshed sweet potato (Low et al., 2017). Maize producing farmers achieved better yields with improved (hybrid or open pollinated) varieties than with local varieties (Chapter 3). In average seasons and under full farmer management the benefits of selecting an improved variety may be overruled by other yield limiting and reducing factors (Chapter 2,4 and Tittonell and Giller (2013). However, it seems unlikely that the excellent maize, soybean and groundnut yields achieved in a good season (Chapter 5) would have been possible with local or unimproved varieties.

In terms of nutrient management, we discovered a range of options to enhance yields including compost manure, soybean inoculant, lime, inorganic fertilizer and integrating soybean into the crop rotation to benefit the following maize crop (Chapters 2,3,5). The 
observed yield increases confirm the importance of nutrient management to reduce soil fertility decline of Malawian soils (Mutegi et al., 2015). While soil samples were not conducted in all trials, clear associations were found between soil properties and $\mathrm{N}_{2}$ fixation (Chapter 3) and sweet potato yields (Chapter 4). Chapter 5 also confirms that, despite farmer perceptions, inorganic fertiliser application can enhance productivity of sweet potato (Mukhtar et al., 2010; Agbede, 2010). The rotational effects of soybean on maize (Chapter 3) suggests this can, besides non- $\mathrm{N}$ effects, also reduce mining of $\mathrm{N}$ from the soils resulting in better maize yields (Franke et al., 2018). These benefits can be further enhanced by optimizing phosphorus and manure application in the cropping system (Zingore and Giller, 2012; Kihara et al., 2010). Besides N and P, Farmers World Ltd identified S, Zn and B limitations in soils and included these in special blended fertilizers (FW, 2016). Addressing the soil nutrient limitations is crucial to enhance productivity of all four crops (Chapter 5).

All the trials were established under rain-fed conditions and therefore water limitations affected yields. The high yields of maize, soybean and groundnuts in a season of good rainfall (Chapter 5) suggests that water was probably a significant yield reduced factor in trials in other seasons (Chapter 2,3,4). Erratic distribution of rainfall resulted in annual differences in soybean yields in Salima (Chapter 2) which makes planting date recommendations a challenge. Timely planting and total rainfall were positively associated with sweet potato (Chapter 4) and soybean yields (Chapter 5) and early planting was ranked as the most important management option by soybean farmers (Chapter 2). While sweet potato is normally considered a drought tolerant crop (Motsa et al., 2015), these findings confirm that both on-farm nutrient and water management through timely planting can contribute substantially to closing yield gaps (Mueller et al., 2012).

The main pests and diseases encountered in the trials were leaf rust and caterpillars in soybean (Chapter 2), and weevils in sweet potato (Chapter 4). Leaf rust was most relevant in Mchinji district and can be prevented with fungicides, though biocide application is not favoured by smallholder farmers due to availability and cost implications (Chapter 2). Sweet potato weevils affected root quality more than root yield and become an important pest for market oriented producers. Breeding programs may focus on selecting varieties that show more resistance to weevils (Muyinza et al., 2012). While several other incidences of pests and diseases may have occurred, insufficient data was collected to make inferences about their effect on yields. General observations are that in most trials and fields, pests and diseases remained below the threshold to cause economic loss. 


\subsection{Assessment of variability in technology performance}

Our results show that there are indeed several options for smallholder farmers to increase their productivity through crop intensification and diversification with legumes and sweet potato. While this statement is based on average yields, not all farmers will benefit equally. In this section I reflect on the variability encountered, statistical methods used to explain variability, and the implications for targeting of technologies.

\subsubsection{Variability in yield, environmental, management and socio-economic conditions}

All chapters demonstrated that there is a large variability in yields and yield responses to technologies across farms. This is in line with other multi-locational trials on smallholder farmers' fields (Ronner et al., 2016; Franke et al., 2016). The final yield of a crop is a result of interactions between the genotype, environment and management (Tittonell and Giller, 2013; Fermont et al., 2009). Those in turn are a result of the socio-economic conditions and priorities of the household (Tittonell et al., 2010).

Region, district or agro-ecological zone affected yields of all crops, $\mathrm{N}_{2}$ fixation by soybean and the rotational benefits of soybean on maize (Table 6.1). The regional variability in $\mathrm{N}_{2}$ fixation is in line with other studies (Schipanski et al., 2010; Nyemba and Dakora, 2010). Soil parameters were also highly variable across farms (Table 2.2, Table 3.1, Table 4.2). While not measured in this research, a large variability in soil fertility within farms is often reported on smallholder farms (Tittonell et al., 2007). This implies that crop allocation to certain plots may have also affected nutrient uptake efficiencies and yields in plots with input treatments (Chikowo et al., 2010). Agro-ecological zone, elevation and rainfall were strongly correlated (Chapter 4) but rainfall conditions in each agro-ecology can vary between years (Chapter 2) and across farms. This implies that crop recommendations derived from one year on-farm data may not be suitable in other years (Ronner, 2018).

The variability in crop management was demonstrated in the wide range of planting dates and plant populations across farms (Table 3.7, Table 4.1). Fully farmer managed maize plots also showed diversity in terms of variety choice (improved versus local) and nutrient input levels (Table 3.7). Weed pressure varied considerably between soybean sites (Chapters 2 and 3) but was not measured in the other crops. Crop residue management practices of soybean and maize varied between incorporation in the soil, removal from the field for composting and burning (Table 3.6). We also encountered a diversity in soybean leaf rust incidence across districts and farms (Chapter 2) and sweet potato weevil infestation across varieties and farms (Chapter 4).

Households differed in wealth indicators arable land area, labour, assets and housing quality (Table 3.1). More assets were associated with better soybean yields and rotational benefits 
on maize (Chapter 3), and male farmers achieved better soybean yields and $\mathrm{N}_{2}$ fixation (Chapter 3). This confirms that socio-economic characteristics underlie the management practices that affect legume productivity (Franke et al., 2016; Chianu et al., 2011). The associations between socio-economic variables and yield may be better assessed under fully farmer managed conditions following farm characterization (Franke et al., 2016), instead of in researcher-designed trials that do not fully represent farmers practices. For example, in our trials farmer selection may have been biased towards those with better skills and positions in the community (Chapter 5), planting material of improved varieties was provided, and time of planting often depends on readiness of extension staff. These factors may also explain why the $25 \%$ lower productivity on female-managed plots in Malawi (Kilic et al., 2015) was not as clear in our on-farm research. Our finding that female host farmers receive poorer quality planting material for sweet potato (Chapter 4) is in line with gender research that shows that female farmers in central Malawi have less access to training and extension services (Netsayi et al., 2016).

\subsubsection{Scientific rigour and applicability of explaining variability}

While this variability in variety choice, biophysical conditions, crop management choices, wealth and gender can all contribute to the yield gap on smallholder farmers' fields, explanations of yield variability are often only partly successful (Ronner et al., 2016; Fermont et al., 2009; Wairegi et al., 2010). We used a multivariate boundary line model to explain the sweet potato yield gap (Chapter 4) and mixed model analysis (MERL) to identify factors that are associated with yields and yield responses in soybean, groundnut and maize (Chapter 3 and 5). We could not fully explain of the sweet potato yield gap, though the multivariate boundary line model was a useful tool to identify some of the most limiting factors. The method to determine outliers and draw the boundary lines (Casanova et al., 1999; Shatar and McBratney, 2004), the disregard for interactions between production constraints, and errors in data collection may limit the predictability of such a model. Boundary lines may only be useful if there is a wide range of values in the explanatory variable. For example, if all sites are highly deficient in soil available $\mathrm{P}$, the boundary line will have less power to predict yields compared to a line based on a wide range of observed $\mathrm{P}$ concentrations. This may also apply to associations between dependent and independent variables using MERL analysis. I therefore argue that while explaining variability with these methods provides useful insights in factors that affect yield, the scientific rigour to fully explain yield gaps is limited. Nevertheless, we identified many significant associations (Table 6.1), which provided more in-depth contributions to knowledge than focusing on averages only (Vanlauwe et al., 2016).

Explanation of yield variability helps identify yield limiting and reducing factors, but how can this understanding be applied? While the diversity in responses allows us to better understand the context in which technologies are introduced (Vanlauwe et al., 2016), most 
farmers will already know that suitable varieties need to be planted in time on good soils with adequate water and nutrient inputs following proper crop management. Strong associations between gender, wealth and yields will be informative only if we understand the underlying social dynamics. Association between late planting and poor soybean yields (Chapters 3 and 5) does not imply that early planting recommendations will be adopted. There may be other priority crops (Chapter 5) competing for scarce labour. Therefore, identifying key limiting factors may result in promoting specific interventions, but these will only be adopted if they fit in a socio-ecological niche (Ojiem et al., 2006). The large diversity in farmers biophysical and socio-economic conditions implies the need to foster innovation and adaptation rather than promoting one-size-fits-all solutions (Vanlauwe et al., 2014). This requires even closer engagement with farmers to explore the trade-offs behind the sub-optimal management, and to determine the adoption potential of yield-enhancing technologies and practices from a farming systems agronomy perspective (Giller et al., 2015).

\subsection{Potential for crop diversification and technology adoption}

The participatory technology ranking and focus group discussions (Chapters 2 and 5) proved useful for discussion on the potential adoption of crop diversification and SI technologies. While the Malawi Agricultural Policy aims to increase crop diversification (MAIWD, 2016a), there is limited strategic thinking about how it will be achieved and promoted among different types of farmers (Kankwamba et al., 2012). Two of the main shocks smallholder households face are high food prices and low crop yields due to droughts or floods (Chirwa et al., 2006). In this context investments in fertiliser and legume integration are more risky for resource poor farmers than for wealthier farmers (Kamanga et al., 2010a).

Farmers in our study emphasized on a minimum area under maize cultivation to ensure food security at household level, and prioritized maize in terms of input allocation (Chapter 5). While some studies link the input subsidy program to increased crop diversification (Snapp and Fisher, 2015), others show that subsidy beneficiaries increase their area under maize (Chibwana and Fisher, 2012), while achieving higher and more drought resilient yields (Arndt et al., 2016). Farmers in our study did not perceive reduction in maize area as an important need, and were interested to produce maize beyond household needs when assured of a good market price (Chapter 5). In case of depressed maize prices, they prefer investments in low-input crop diversification options as they struggled to access expensive fertiliser. While legume diversification can enhance environmental and food security (Snapp et al., 2010), Chapter 3 confirms this mainly applies to better-off households that can invest in nutrient inputs (Franke et al., 2014). However, farmers deliberately choose legumes as these are perceived to perform well without external inputs (Chapter 5). Despite limited interest in adoption of fertiliser in legumes, our results confirm that better crop management such as timely planting and optimal spacing (Chapter 2 and 4) are promising options that can 
contribute to closing the yield gaps even without nutrient inputs (Tittonell and Giller, 2013). Legumes and sweet potato are commonly planted later in the season after maize and cash crops such as tobacco are planted. Timeliness of planting depends on the availability of sufficient labour and planting material (especially for sweet potato) at the onset of the rains.

Farm size, capacity to bear risk, human capital, labour availability, credit constraint, tenure, and access to commodity markets are common factors affecting adoption of new agricultural technologies (Feder et al., 1985). However, even households with small farms that are not in a position to take risks can invest in crops such as tobacco and hybrid maize, as long as they have access to markets, extension services and credit (Zeller et al., 1998). While farmers are usually well aware of the climate variability in their areas, they often overestimate the risks (Coe and Stern, 2011). This provides opportunities for adoption of more drought tolerant root ant tuber crops such as sweet potato which, while constrained by limited access to planting material, is acceptable by farmers (Chapter 5).

The pairwise ranking exercise coupled with questions on the advantages and disadvantages of technologies gave good insights into farmers perceptions on a range of inputs and management options in soybean (Chapter 2). Exposure to such a 'basket of technologies' (Ronner, 2018) revealed that options that require procurement of external inputs were less preferred than other crop management options (Table 2.6). Farmer in central Malawi prefer maximizing legume production through investment in labour rather than fertilizer (Kamanga et al., 2010b). This is different for maize in which inorganic fertilizer is highly valued (Chapter 5). Adoption of external inputs targeted to legumes such as inoculant, chemicals and fertilizers is constrained by limited financial resources and limited availability near the smallholder farmer (Table 2.7). Extension services do not share information about the potential benefits of input application in legumes (Chapter 5). Variety choice was ranked highly by farmers (Table 2.6) but adoption may be constraint by lack of knowledge about suitable varieties, and high costs and access to seed (Table 2.7). Across crops over 68 percent of smallholder farmers in Malawi plant seed from informal sources, while 71 percent accessed a new variety in a five-year period; in 62 percent of the cases through free distributions by government or NGOs (McGuire and Sperling, 2016). Our participatory evaluation confirms that access to improved seed and other external inputs are still limiting technology adoption in Malawi. Addressing the multiple constraints of limited awareness of the agronomic and financial benefits of nutrient application to legumes and sweet potato, unstable markets, access to credit and access to improved seed may result in more diversified and intensified cropping systems. 


\subsection{Contribution of sustainable intensification to the SDGs}

The economic analysis (Chapters 2 and 5) showed that farmers can substantially increase their incomes through intensification and diversification. The Sustainable Development Goals (UN, 2018) aim by 2030 to end poverty in all its forms everywhere, and to end hunger, achieve food security and improved nutrition and promote sustainable agriculture. How can SI can contribute to achieving these goals? Ending poverty means nobody will live below the poverty line of USD 1.90 per capita per day by 2030. Intensification of soybean production enhanced incomes by an average over $400 \mathrm{USD} \mathrm{ha}^{-1}$ (Table 2.5). Fertilizer and lime input treatments increased partial gross margins by $85 \mathrm{USD} \mathrm{ha}^{-1}$ for maize, $260 \mathrm{USD} \mathrm{ha}^{-1}$ for soybean, $271 \mathrm{USD} \mathrm{ha}^{-1}$ for groundnuts and $89 \mathrm{USD} \mathrm{ha}^{-1}$ for sweet potato (Table 5.5). The substantially higher value of produce per ha of soybean, groundnut and sweet potato (Table 5.5) suggests crop diversification at the expense of maize can substantially enhance farmers' incomes. An increase in income in the range of 200-400 USD ha-1 would raise per capita income by $0.18-0.36$ USD per capita per day, assuming an average household size of 4.6 and cultivated land area of 1.5 ha in central Malawi (NSO, 2012).

Fifty-two percent of the rural households in Malawi experience food shortages, of which 43 percent due to lack of inputs and 11 percent due to small land sizes (NSO, 2012). This implies that most households living in poverty may not be able to invest in the required inputs that can push their incomes above the poverty line. For sub-Saharan Africa to feed a growing population will require large increases in yields, cropping intensity and irrigation (Van Ittersum et al., 2016). From 2017 to 2030 the population in Malawi is projected to increase by $43 \%$ from 18.6 to 26.6 million (UN, 2017), enhancing the challenge to achieve the SDG2 target of doubling the agricultural productivity and incomes of small-scale food producers. In our study, doubling of soybean yields only occurred under an input regime that combines inoculation with high fertilizer input rates (Chapter 2), a practice that is not favoured by farmers (Chapters 2 and 5). Doubling maize yields also required significant investments in fertilizer, whereas the fertilizer treatments in groundnut and sweet potato did not double yields (Chapter 5).

Targeting of SI interventions needs to consider the trade-offs farmers need to make between yields of maize and legumes and investments in soil fertility management (Snapp et al., 2018), while also considering dietary diversity (Haddad et al., 2016). The fact that the most preferred crops in the system are planted for both household consumption and the market (Chapter 5) confirms that crop production diversification can increase nutrition sensitivity in agriculture (Mazunda et al., 2018). Investments in integrated soil fertility management or micro-nutrient fertilisation can also enhance the nutritional quality of the food produced (De Valença et al., 2017). As discussed in previous sections, the large variability in yields and yield responses to inputs, and farmers perceptions on yield enhancing technologies, imply 
that not all farmers will benefit equally from SI. Better-off farmers with access to credit are less likely to diversify their livelihoods away from agriculture (Simtowe, 2010) and can derive more benefits from intensification (Chapter 3). Investment in wealthier farmers may result in enhanced opportunities for other members of the community to engage in casual labour, which is an important livelihood strategy for poor female-headed households with limited financial means to invest in their own fields (Simtowe, 2010; Takane, 2008). SI can therefore contribute to enhancing food and nutrition security but is unlikely to fully eradicate hunger and poverty by 2030. To achieve the SDG's, investments in agriculture may need to be targeted to the right farmers, but supplemented with creating opportunities for off-farm income generation and social protection interventions.

\subsection{From participatory research to 'partnering for impact at scale'.}

With more than 70 percent of agricultural GDP coming from smallholders (MAIWD, 2016a), these farmers have a crucial role to play in enhancing food and nutrition security in Malawi. Many stakeholders including policy makers, governmental agriculture research and extension departments, donors, international research for development organizations, NGOs and private sector are supporting this cause. The move towards sustainable intensification should be a process of societal negotiation resulting in agreed values, priorities and tradeoffs across stakeholders and institutional innovation (Struik and Kuyper, 2017).

What lessons can be learnt from the 'participatory approaches to diversification and intensification' and what are the implications for scaling? First, we have encountered a large variability in farmers biophysical and socio-economic conditions limiting the applicability of targeting technologies to pre-defined farm types (Ronner, 2018). Secondly, where on-farm research often targets a single commodity or practice (e.g. Chapter 2 and 4), farmers consider the whole cropping system (Chapter 5). Finally, we learnt that farmers are risk-averse when it comes to investments in external inputs in food crops other than maize (Chapter 5).

While participatory experiments can capture farmers preferences for technologies they do not necessarily answer why farmers adopt them or not (Pircher et al., 2012). Farmers in technology scaling projects are often considered 'beneficiaries' of technologies instead of development partners that engage in farming practices in response to their specific socioeconomic condition such as land tenure, gender and wealth status (Pircher et al., 2012). It is in this context that new participatory research should focus more on joint learning and experimentation with farmers on how technology packages or 'baskets of technologies' can be best adapted to ensure the innovation can work at farm level within a diversity of livelihood activities (Ronner, 2018). Technology packages could include combinations of crops and SI options, and ideally respond directly to farmers' expressed needs and constraints. 
Various projects in Africa have shown that sustainable agriculture can result in large increases in food production but scaling is a challenge (Pretty, 1999). A multi-sectoral approach including the health sector is needed if not only food but also nutrition security is to be achieved (Cole et al., 2016). With severe incidences of micro nutrient deficiencies in the human body (WHO, 2018) the importance of biofortification of food crops is growing (Tanumihardjo et al., 2017). OFSP varieties (Andrade et al., 2016) are an example of a successful approach to combat vitamin A deficiency. Similar options for yellow cassava, iron beans, protein-rich maize and orange-maize are gaining momentum. Important ingredients of food based approaches to improve nutrition are creating consumer awareness on healthy food and investment in healthy agriculture and food systems (Haddad et al., 2016), while mitigating the effects of climate variability and change (Jarvis et al., 2011). Climate variability and change increases the need for farmers to adapt and innovate with crops and practices that can reliably produce food under variable rainfall conditions (Snapp et al., 2014).

Addressing the multiple constraints of access to credit, inputs and markets that limit adoption requires innovative multi-stakeholder approaches. Therefore, adaptive on-farm integrated research to sustainably enhance food and nutrition security needs to be embedded in a 'partnerships for impact at scale' approach. Seed companies, agro-dealers and credit providers need to be engaged to ensure relevant inputs are accessible and affordable to farmers. At institutional level, improved coordination between government and private sector is needed to address the constraint of thin markets and ensure additional production can be absorbed by the market (Poulton et al., 2006). Adoption of soil fertility management technologies is market-driven as commodity sales provide opportunities to invest in inputs and in community-based savings and credit schemes (Vanlauwe et al., 2010). Governmental extension services and NGO's can facilitate knowledge transfer and scaling of best-bet technology packages to enhance nutrition, yields and incomes and facilitate market linkages.

\subsection{Concluding remarks and recommendations for further research}

I have shown that smallholder farmers in Malawi have several options to enhance yields and incomes from intensification and diversification of crop production. While maize is one of the least profitable and most input-intensive crops, farmers do not want to risk food insecurity in terms of maize production. This risk aversion may hamper adoption of more profitable and nutritious crops and technologies. This has implications for the government priority to enhance crop diversification and building of resilience to climate change in Malawi. There is a strong role for scientist to find solutions to the key constraints smallholder farmers face through integrated research. Table 6.2 proposes a set of research priorities to enhance sustainable intensification of smallholder farming systems. 
Table 6.2: Recommendation for integrated research to enhance sustainable intensification of farming systems in Malawi

\begin{tabular}{lll}
\hline \multicolumn{1}{c}{ Constraints } & Research questions \\
\hline $\begin{array}{l}\text { Access to } \\
\text { improved } \\
\text { varieties }\end{array}$ & $\bullet$ & $\begin{array}{l}\text { What variety characteristics is the market looking for and what are the } \\
\text { implications for breeding programs to develop varieties that can } \\
\text { enhance both farmer incomes and food and nutrition security? }\end{array}$ \\
& - $\begin{array}{l}\text { What mechanisms and partnership models are most suitable to } \\
\text { facilitate access by smallholder farmers to newly released crop } \\
\text { varieties? }\end{array}$ \\
& - $\begin{array}{l}\text { What seed system interventions are required to ensure equitable access } \\
\text { to clean seed and planting material? }\end{array}$ \\
\hline $\begin{array}{l}\text { Soil } \\
\text { degradation } \\
\text { and nutrient } \\
\text { depletion }\end{array}$ & $\begin{array}{l}\text { What are the best-bet farmer-acceptable options to enhance soil fertility } \\
\text { for different crops in the farming system (e.g. legume integration, } \\
\text { fertilizer trees, animal and compost manure, liming, inoculants, } \\
\text { inorganic fertilizer, mulching, minimal soil disturbance)? } \\
\text { How can integration of small livestock contribute to soil fertility } \\
\text { through enhanced application of manure? }\end{array}$
\end{tabular}

\begin{tabular}{lll}
\hline $\begin{array}{l}\text { Irrigation and } \\
\text { water }\end{array}$ & $\bullet$ & $\begin{array}{l}\text { What are the best farmer-acceptable options for small-scale irrigation } \\
\text { on smallholder farmers' fields? }\end{array}$ \\
management & $\bullet$ & $\begin{array}{l}\text { What on-farm water conservation and erosion prevention methods are } \\
\text { acceptable by farmers (e.g. boxed ridges, contour ridging, strip } \\
\text { cropping, intercropping, mulching)? }\end{array}$
\end{tabular}

\begin{tabular}{ll}
\hline $\begin{array}{l}\text { Climate } \\
\text { variability } \\
\text { and change }\end{array}$ & $\begin{array}{l}\text { What cropping patterns, agronomic practices and varieties can reduce } \\
\text { the impact of erratic rainfall distribution and climate change on the } \\
\text { farming system? }\end{array}$ \\
& $\begin{array}{l}\text { What is the comparative advantage of root and tuber crops and } \\
\text { vegetables in the context of climate change? }\end{array}$
\end{tabular}

\begin{tabular}{ll}
\hline $\begin{array}{l}\text { Pests and } \\
\text { diseases }\end{array}$ & $\begin{array}{l}\text { What are the best-bet integrated pest management strategies to control } \\
\text { the most pressing yield reducing pests and diseases (e.g. fall army } \\
\text { worm, cassava brown streak, potato bacterial wilt and late blight, } \\
\text { groundnut rosette virus, soybean leaf rust, etc.)? }\end{array}$
\end{tabular}

\begin{tabular}{ll}
\hline $\begin{array}{l}\text { Limited } \\
\text { diversification } \\
\text { of crops and } \\
\text { diets }\end{array}$ & $\begin{array}{l}\text { What are the most farmer acceptable options for adoption of nutrient } \\
\text { dense food commodities in Malawi (e.g. biofortified crops, legumes, } \\
\text { vegetables, fruits, nuts, small livestock, fish)? }\end{array}$ \\
& $\begin{array}{l}\text { What is the best farming system that would combine sustainable } \\
\text { production practices that assures nutrient adequacy of the family diet }\end{array}$ \\
& $\begin{array}{l}\text { year-round in different agro-ecologies? } \\
\text { What policies, institutional changes and mechanisms are needed to } \\
\text { ensure equitable access to nutrient dense commodities by rural and } \\
\text { urban consumers? }\end{array}$
\end{tabular}




\begin{tabular}{|c|c|}
\hline $\begin{array}{l}\text { Access to } \\
\text { extension } \\
\text { services }\end{array}$ & $\begin{array}{l}\text { - What extension model results in the best uptake of yield-enhancing } \\
\text { varieties, inputs and management practices (e.g. government extension, } \\
\text { NGOs, private sector extension)? }\end{array}$ \\
\hline $\begin{array}{l}\text { Access to } \\
\text { credit }\end{array}$ & $\begin{array}{l}\text { What are the best-bet options to provide credit to smallholder farmers } \\
\text { and how does access to credit contribute to enhanced productivity and } \\
\text { incomes? }\end{array}$ \\
\hline $\begin{array}{l}\text { Access to } \\
\text { inputs }\end{array}$ & $\begin{array}{l}\text { - What mechanisms and partnerships are most suitable to make seed, } \\
\text { planting material and other farm inputs accessible by smallholder } \\
\text { farmers? }\end{array}$ \\
\hline $\begin{array}{l}\text { Access to } \\
\text { markets }\end{array}$ & $\begin{array}{l}\text { - What mechanisms and partnerships are most suitable to integrate } \\
\text { farmers in value chains and enhance access to markets? } \\
\text { What policies or institutional changes are needed to stabilize market } \\
\text { prices and develop markets for commodities produced by smallholder } \\
\text { farmers? }\end{array}$ \\
\hline
\end{tabular}

Results from this research agenda could feed into evidence-based development programs implemented through multi-stakeholder 'partnerships for impact at scale'. Initiatives that reduce the risks associated with rainfed agriculture can put farmers in a stronger position to invest in SI options. These could include crop insurance, access to credit and input and output market development. Inputs should be accessible near the farmers and improved extension services are required to create awareness on fertiliser input options for crops such as legumes and sweet potato to enhance the financial benefits of these crops. Participatory research that addresses the multiple constraints faced by farmers in different agro-ecologies needs to be jointly designed, implemented and analysed in an integrated manner through intense collaboration between development partners. The design should focus on integrated packages that can be tested on-farm with smallholder farmers in multiple locations, recognizing that there are no 'silver bullets' and farmers may choose to use only parts of the entire package over time. Through such multi-stakeholder partnership approaches farmers can be empowered to substantially increase their productivity and incomes through crop diversification and intensification. 
General discussion 


\section{References}

Abidin, P. E., Kazembe, J., Atuna, R. A., Amagloh, F. K., Asare, K., Dery, E. K. \& Carey, E. E. (2016). Sand storage, extending the shelf-life of fresh sweetpotato roots for home consumption and market sales. Journal of Food Science and Engineering 6: 227-236.

Adhikari, U., Nejadhashemi, A. P. \& Woznicki, S. A. (2015). Climate change and eastern Africa: a review of impact on major crops. Food and Energy Security 4(2): 110132.

Adikini, S., Mukasa, S. B., Mwanga, R. O. M. \& Gibson, R. W. (2016). Effects of sweet potato feathery mottle virus and sweet potato chlorotic stunt virus on the yield of sweet potato in Uganda. Journal of Phytopathology 164: 242-254.

Adjei-Nsiah, S., Kuyper, T. W., Leeuwis, C., Abekoe, M. K., Cobbinah, J., Sakyi-Dawson, O. \& Giller, K. E. (2008). Farmers' agronomic and social evaluation of productivity, yield and $\mathrm{N}_{2}$-fixation in different cowpea varieties and their subsequent residual $\mathrm{N}$ effects on a succeeding maize crop. Nutrient Cycling in Agroecosystems 80: 199-209.

Agbede, T. M. (2010). Tillage and fertilizer effects on some soil properties, leaf nutrient concentrations, growth and sweet potato yield on an Alfisol in southwestern Nigeria. Soil \& Tillage Research 110: 25-32.

Alessi, J. \& Power, J. F. (1982). Effects of plant and row spacing on dryland soybean yield and water-use efficiency. Agronomy Journal 74: 851-854.

Allemann, J., Laurie, S. M., Thiart, S. \& Vorster, H. J. (2004). Sustainable production of root and tuber crops (potato, sweet potato, indigenous potato, cassava) in southern Africa. South African Journal of Botany 70(1): 60-66.

Andrade, M. I., Ricardo, J., Naico, A., Alvaro, A., Makunde, G. S., Low, J., Ortiz, R. \& Gruneberg, W. J. (2016). Release of orange-fleshed sweetpotato (Ipomoea batatas [1.] Lam.) cultivars in Mozambique through an accelerated breeding scheme. Journal of Agricultural Science 155(6): 919-929.

Ankumah, R. O., Khan, V., Mwamba, K. \& Kpomblekou-A, K. (2003). The influence of source and timing of nitrogen fertilizers on yield and nitrogen use efficiency of four sweet potato cultivars. Agriculture, Ecosystems and Environment 100: 201207.

Arndt, C., Pauw, K. \& Thurlow, J. (2016). The economy-wide impacts and risks of Malawi's farm input subsidy program. American Journal of Agricultural Economics 98(3): 962-980.

Bagayoko, M., Buerkert, A., Lung, G., Bationo, A. \& Römheld, V. (2000). Cereal/legume rotation effects on cereal growth in Sudano-Sahelian West Africa: soil mineral nitrogen, mycorrhizae and nematodes. Plant and Soil 218: 103-116. 
Belehu, T. (2003). Agronomical and physiological factors affecting growth, development and yield of sweet potato in Ethiopia. PhD thesis. 213p. Department of Plant Production and Soil Science In the Faculty of Natural and Agricultural Sciences: University of Pretoria.

Bezner Kerr, R., Snapp, S., Chirwa, M., Shumba, L. \& Msachi, R. (2007). Participatory research on legume diversification with Malawian smallholder farmers for improved human nutrition and soil fertility. Experimental Agriculture 43: 437453.

Binswanger-Mkhize, H. P. \& Savastano, S. (2017). Agricultural intensification: The status in six African countries. Food Policy 67: 26-40.

Bloem, J. F., Trytsman, G. \& Smith, H. J. (2009). Biological nitrogen fixation in resourcepoor agriculture in South Africa. Symbiosis 48: 18-24.

Boddey, R. M., Peoples, M. B., Palmer, B. \& Dart, P. J. (2000). Use of the ${ }^{15} \mathrm{~N}$ natural abundance technique to quantify biological nitrogen fixation by woody perennials. Nutrient Cycling in Agroecosystems 57: 235-270.

Bovell-Benjamin, A. C. (2007). Sweet potato: A review of its past, present, and future role in human nutrition. Advances in Food and Nutrition Research 52: 1-59.

Bryceson, D. F. (2006). Ganyu casual labour, famine and HIV/AIDS in rural Malawi: Causality and casualty. Journal of Modern African Studies 44: 173-202.

Carr, S. (1997). A green revolution frustrated: Lessons from the Malawi experience. African Crop Science Journal 5: 93-98.

Carsky, R. J., Abaidoo, R. C., Dashiell, K. E. \& Sanginga, N. (1997). Effect of soybean on subsequent maize grain yield in the guinea savanna zone of West Africa. African Crop Science Journal 5(1): 31-38.

Casanova, D., Goudriaan, J., Bouma, J. \& Epema, G. F. (1999). Yield gap analysis in relation to soil properties in direct-seeded flooded rice. Geoderma 91: 191-216.

Chalfant, R. B., Jansson, R. K. \& Seal, D. R. (1990). Ecology and management of sweet potato insects. Annual Review of Entomology 35: 157-180.

Chamango, A. M. Z. (2001). Improving grain yield of smallholder cropping systems: A farmer participatory research (FPR) approach with legumes for soil fertility improvement in central Malawi. In Seventh Eastern and Southern Africa Regional Maize Conference, 413-417.

Chambers, J. L., Hinckley, T. M., Cox, G. S., Metcalf, C. L. \& Aslin, R. G. (1985). Boundary-line analysis and models of leaf conductance for four oak-hickory forest species. Forest Science 31(2): 437-450.

Chianu, J. N., Nkonya, E. M., Mairura, F. S., Chianu, J. N. \& Akinnifesi, F. K. (2011). Biological nitrogen fixation and socioeconomic factors for legume production in sub-Saharan Africa: a review. Agronomy for Sustainable Development 31: 139154. 
Chibwana, C. \& Fisher, M. (2012). Cropland allocation effects of agricultural input subsidies in Malawi. World Development 40(1): 124-133.

Chikowo, R., Corbeels, M., Mapfumo, P., Tittonell, P., Vanlauwe, B. \& Giller, K. E. (2010). Nitrogen and phosphorus capture and recovery efficiencies, and crop responses to a range of soil fertility management strategies in sub-Saharan Africa. Nutrient Cycling in Agroecosystems 88: 59-77.

Chipungu, F. P. (2015). Orange-fleshed sweetpotato varieties for Malawi. International Potato Center.

Chirwa, E. W. (2005). Adoption of fertiliser and hybrid seeds by smallholder maize farmers in southern Malawi. Development Southern Africa 22: 1-12.

Chirwa, E. W., Kydd, J. \& Dorward, A. (2006). Future scenarios for agriculture in Malawi: Challenges and dilemmas. Future Agricultures Research Paper 003. March 2006. www.future-agricultures.org.

Chowdhury, S., Meenakshi, J. V. \& Owori, C. (2011). Are consumers in developing countries willing to pay more for micronutrient-dense biofortified foods? Evidence from a field experiment in Uganda. American Journal of Agricultural Economics 93: 83-97.

CIP (2016). Value chain analysis and marketing chain mapping for orange-fleshed sweet potato (OFSP) in Feed the Future Zone of Influence. 62p. Lilongwe:

Troppenwasser Consulting Firm.

Coe, R. \& Stern, R. D. (2011). Assessing and addressing climate-induced risk in subSaharan rainfed agriculture: lessons learned. Experimental Agriculture 47(2): 395410.

Cole, D. C., Levin, C., Loechl, C., Thiele, G., Grant, F., Girard, A. W., Sindi, K. \& Low, J. (2016). Planning an integrated agriculture and health program and designing its evaluation: experience from western Kenya. Evaluation and Program Planning 56: 11-22.

Davis, P. (1979). A Review of Soybean Research in Malawi. In GLR/RHIZ/SOY/4 Lilongwe: Microbiology Section. Chitedze Agricultural Research Station.

De Steur, H., Wesana, J., Blancquaert, D., Van Der Straeten, D. \& Gellynck, X. (2017). Methods matter: a meta-regression on the determinants of willingness-to-pay studies on biofortified foods. Annals of the New York Acadamy of Sciences 1390(1): 34-46.

De Valença, A. W., Bakeb, A., Brouwer, I. D. \& Giller, K. E. (2017). Agronomic biofortification of crops to fight hidden hunger in sub-Saharan Africa. Global Food Security 12: 8-14.

Dimes, J., Muza, L., Malunga, G. \& Snapp, S. (2001). Trade-offs between investments in nitrogen and weeding: on-farm experimentation and simulation analysis in Malawi and Zimbabwe. In Seventh Eastern and Southern Africa Regional Maize Conference, 452-456. 
Dogan, E., Kirnak, H. \& Copur, O. (2007). Deficit irrigations during soybean reproductive stages and CROPGRO-soybean simulations under semi-arid climatic conditions. Field Crops Research 103: 154-159.

Dorward, A. \& Chirwa, E. (2011). The Malawi agricultural input subsidy programme: 2005/06 to 2008/09. International Journal of Agricultural Sustainability 9: 232247.

Doss, B. D., Pearson, R. W. \& Rogers, H. T. (1974). Effect of soil water stress at various growth stages on soybean yield. Agronomy Journal 66: 297-299.

Droppelmann, K. J., Snapp, S. S. \& Waddington, S. R. (2017). Sustainable intensification options for smallholder maize-based farming systems in sub-Saharan Africa. Food Security 9: 133-150.

Dumbuya, G., Sarkodie-Addo, J., Daramy, M. A. \& Jalloh, M. (2016). Growth and yield response of sweet potato to different tillage methods and phosphorus fertilizer rates in Ghana. Journal of Experimental Biology and Agricultural Sciences 4(5): 476-483.

Ebregt, E., Struik, P. C., Odongo, B. \& Abidin, P. E. (2007). Piecemeal versus one-time harvesting of sweet potato in north-eastern Uganda with special reference to pest damage. NJAS - Wageningen Journal of Life Sciences 55(1): 75-92.

Ekanayake, I. J. \& Collins, W. (2004). Effect of irrigation on sweet potato root carbohydrates and nitrogenous compounds. Food, Agriculture \& Environment 2(1): 243-248.

FAO (2014). FAO statistical database. Rome: Food and Agricultural Organization of the United Nations (FAO).

FAO (2016). www.faostat.fao.org. Cited 26 March 2016.

FAO (2017). www.faostat.fao.org. Cited 16 September 2017.

FAO (2018). www.faostat.fao.org. Cited 23 February 2018.

FAO, IFAD, UNICEF, WFP \& WHO (2017). The state of food security and nutrition in the world 2017. Building resilience for peace and food security. 132p. Rome, FAO.

Feder, G., Just, R. E. \& Zilberman, D. (1985). Adoption of agricultural innovations in developing countries: A survey. Economic Development and Cultural Change 33(2): 255-298.

Fermont, A. M., van Asten, P. J. A., Tittonell, P., Van Wijk, M. T. \& Giller, K. E. (2009). Closing the cassava yield gap: An analysis from smallholder farms in East Africa. Field Crops Research 112: 24-36.

Franke, A. C., Baijukya, F., Kantengwa, S., Reckling, M., Vanlauwe, B. \& Giller, K. E. (2016). Poor farmers - poor yields: Socio-economic, soil fertility and crop management indicators affecting climbing bean productivity in northern Rwanda. Experimental Agriculture: 1-21. doi:10.1017/S0014479716000028. 
Franke, A. C., van den Brand, G. J. \& Giller, K. E. (2014). Which farmers benefit most from sustainable intensification? An ex-ante impact assessment of expanding grain legume production in Malawi. European Journal of Agronomy 58: 28-38.

Franke, A. C., Van den Brand, G. J., Vanlauwe, B. \& Giller, K. E. (2018). Sustainable intensification through rotations with grain legumes in sub-Saharan Africa: A review. Agriculture, Ecosystems and Environment 261: 172-185.

FW (2016). Guidelines to fertilizer recommendations for the central region of Malawi. 22p. Lilongwe, Malawi: Farmers World Ltd.

George, M. S., Lu, G. \& Zhou, W. (2002). Genotypic variation for potassium uptake and utilization efficiency in sweet potato (Ipomoea batatas L.). Field Crops Research 77: 7-15.

Ghuman, B. S. \& Lal, R. (1983). Mulch and irrigation effects on plant-water relations and performance of cassava and sweet potato. Field Crops Research 7: 13-29.

Gibson, R. W., Aritua, V., Byamukama, E., Mpembe, I. \& Kayongo, J. (2004). Control strategies for sweet potato virus disease in Africa. Virus Research 100: 115-122.

Giller, K. E. (2001). Nitrogen Fixation in Tropical Cropping Systems 2nd edition. CAB International.

Giller, K. E., Andersson, J. A., Corbeels, M., Kirkegaard, J., Mortensen, D., Erenstein, O. \& Vanlauwe, B. (2015). Beyond conservation agriculture. Frontiers in Plant Science 6(Article 870).

Giller, K. E., Cadisch, G., Ehaliotis, C., Adams, E., Sakala, W. D. \& Mafongoya, P. L. (1997). Building soil nitrogen capital in Africa. Pages 151-192 in R. J. Buresh, P. A. Sanchez, and F. Calhoun, editors. Replenishing soil fertility in Africa. ASA, CSSA, SSSA, Madison, Wisconsin.

Giller, K. E., Murwira, M. S., Dhliwayo, D. K. C., Mafongoya, P. L. \& Mpepereki, S. (2011). Soyabeans and sustainable agriculture in southern Africa. International Journal of Sustainable Agriculture 9(1): 50-58.

Giller, K. E., Witter, E., Corbeels, M. \& Tittonell, P. (2009). Conservation agriculture and smallholder farming in Africa: The heretics' view. Field Crops Research 114: 23 34.

Gomes, F. \& Carr, M. K. V. (2001). Effects of water availability and vine harvesting frequency on the productivity of sweet potato in southern Mozambique. I. Storage root and vine yields. Experimental Agriculture 37: 523-537.

Gomes, F. \& Carr, M. K. V. (2003). Effects of water availability and vine harvesting frequency on the productivity of sweet potato in southern Mozambique. II. Crop water use. Experimental Agriculture 39: 39-54.

Haddad, L., Hawkes, C., Webb, P., Thomas, S., Beddington, J., Waage, J. \& Flynn, D. (2016). A new global research agenda for food. Nature 540: 30-32. 
Haile, F. J., Higley, L. G. \& Specht, J. E. (1998). Integrated Pest Management. Soybean Cultivars and Insect Defoliation: Yield Loss and Economic Injury Levels. Agronomy Journal 90: 344-352.

Hardarson, G. \& Atkins, C. (2003). Optimising biological $\mathrm{N}_{2}$ fixation by legumes in farming systems. Plant and Soil 252: 41-54.

Hardarson, G. \& Zapata, F. (1984). Effect of plant genotype and nitrogen fertilizer on symbiotic nitrogen fixation by soybean cultivars. Plant and Soil 82: 397-405.

Hati, K. M., Mandal, K. G., Misra, A. K., Ghosh, P. K. \& Bandyopadhyay, K. K. (2006). Effect of inorganic fertilizer and farmyard manure on soil physical properties, root distribution, and water-use efficiency of soybean in Vertisols of central India. Bioresource Technology 97: 2182-2188.

Hijmans, R. J., Cameron, S. E., Parra, J. L., Jones, P. G. \& Jarvis, A. (2005). Very high resolution interpolated climate surfaces for global land areas. International Journal of Climatology 25: 1965-1978.

IFAD (2011). Republic of Malawi Sustainable Agricultural Production Programme: Programme Design Report. 124p. Rome: International Fund for Agricultural Development.

IFDC (2013). Malawi fertilizer assessment. In support of the African fertilizer and agribusiness partnership. 49p. Muscle Shoals, Alabama, USA: International Fertiliser Development Center.

IPNI (2017). Crop nutrient removal calculator. Georgia, USA: International Plant Nutrition Institute.

Jarvie, J. A. \& Shanahan, P. E. (2009). Assessing tolerance to soybean rust in selected genotypes. Field Crops Research 114: 419-425.

Jarvis, A., Lau, C., Cook, S., Wollenberg, E., Hansen, J., Bonilla, O. \& Challinor, A. (2011). An integrated adaptation and mitigation framework for developing agricultural research: synergies and trade-offs. Experimental Agriculture 47(2): 185-203.

Jemo, M., Abaidoo, R. C., Nolte, C., Tchienkoua, M., Sanginga, N. \& Horst, W. J. (2006). Phosphorus benefits from grain-legume crops to subsequent maize grown on acid soils of southern Cameroon. Plant and Soil 284: 385-397.

Jones, D. B. \& Divine, J. P. (1944). The protein nutritional value of soybean, peanut, and cottonseed flours and their value as supplements to wheat flour. Journal of Nutrition 28: 41-49.

Kabambe, V., Katunga, L., Kapewa, T. \& Ngwira, A. R. (2008). Screening legumes for integrated management of witchweeds (Alectra vogelii and Striga asiatica) in Malawi. African Journal of Agricultural Research 3(10): 708-715.

Kamanga, B. C. G., Waddington, S. R., Robertson, M. J. \& Giller, K. E. (2010a). Risk analysis of maize-legume crop combinations with smallholder farmers varying in resource endowment in central Malawi. Experimental Agriculture 46(1): 1-21. 
Kamanga, B. C. G., Waddington, S. R., Whitbread, A. M., Almekinders, C. J. M. \& Giller, K. E. (2013). Improving the efficiency of use of small amounts of nitrogen and phosphorus fertiliser on smallholder maize in central Malawi. Experimental Agriculture 50(2): 229-249.

Kamanga, B. C. G., Whitbread, A., Wall, P., Waddington, S. R., Almekinders, C. \& Giller, K. E. (2010b). Farmer evaluation of phosphorus fertilizer application to annual legumes in Chisepo, central Malawi. African Journal of Agricultural Research 5(8): 668-680.

Kankwamba, H., Mapila, M. A. T. J. \& Pauw, K. (2012). Determinants and spatiotemporal dimensions of crop diversification in Malawi. Project report produced under a cofinanced research agreement between Irish Aid, the United States Agency for International Development, and the Malawi Strategy Support Program (MaSSP) of the International Food Policy Research Institute (IFPRI). In Paper No. 2 of 4 , 37p.: IFPRI.

Kapinga, R., Andrade, M., Lemaga, B., Gani, A., Crissman, C. \& Mwanga, R. (2005). Role of orange-fleshed sweetpotato in disaster mitigation: Experiences from East and Southern Africa. In African Crop Science Conference, Vol. 7, 1321-1329 (Ed A. C. S. Society).

Karyeija, R. F., Gibson, R. W. \& Valkonen, J. P. T. (1998). The significance of sweet potato feathery mottle virus in subsistence sweet potato production in Africa. Plant Disease 82(1): 1-15.

Kasasa, P., Mpepereki, S., Musiyiwa, K., Makonese, F. \& Giller, K. E. (1999). Residual nitrogen benefits of promiscuous soybeans to maize under field conditions. African Crop Science Journal 7(4): 375-382.

Kawuki, R. S., Adipala, E., Lamo, J. \& Tukamuhabwa, P. (2003). Responding to the soybean rust epidemic in sub-Saharan Africa: A review. African Crop Science Journal 11(4): 301-318.

Kelly, V. A. (2006). Factors affecting demand for fertilizer in sub-Saharan Africa. Agriculture and rural development discussion paper 23. 89p. (Ed W. Bank). Washington DC.

Kihara, J., Vanlauwe, B., Waswa, B., Kimetu, J. M., Chianu, J. \& Bationo, A. (2010). Strategic posphorus application in legume-cereal rotations increases land productivity and profitability in western Kenya. Experimental Agriculture 46(1): 35-52.

Kilic, T., Palacios-Lopez, A. \& Goldstein, M. (2015). Caught in a productivity trap: A distributional perspective on gender differences in Malawian agriculture. World Development 70: 416-463.

Lagerkvist, C. J., Okello, J., Muoki, P., Heck, S. \& Prain, G. (2016). Nutrition promotion messages: The effect of information on consumer sensory expectations, 
experiences and emotions of vitamin A-biofortified sweet potato. Food Quality and Preference 52: 143-152.

Laurie, S. M., Van den Berg, A. A., Magoro, M. D. \& Kgonyane, M. C. (2004). Breeding of sweetpotato and evaluation of imported cultivars in South Africa. African Crop Science Journal 12(3): 189-196.

Leung, W.-T. W., Busson, F. \& Jardin, C. (1969). Food composition table for use in Africa. FAO, Rome, Italy. 306 p. http://www.fao.org/docrep/003/X6877E/X6877E00.htm\#TOC.

Levy, C. (2005). Epidemiology and chemical control of soybean rust in southern Africa. Plant Disease 89: 669-674.

Low, J. W., Arimond, M., Osman, N., Cunguara, B., Zano, F. \& Tschirley, D. (2007). A food-based approach introducing orange-fleshed sweet potatoes increased vitamin A intake and serum retinol concentrations in young children in rural Mozambique. Journal of Nutrition 137(5): 1320-1327.

Low, J. W., Mwanga, R. O. M., Andrade, M., Carey, E. \& Ball, A. (2017). Tackling vitamin A deficiency with biofortified sweetpotato in sub-Saharan Africa. Global Food Security 14: 23-30.

Luckett, B. G., DeClerck, F. A. J., Fanzo, J., Mundorf, A. R. \& Rose, D. (2015). Application of the Nutrition Functional Diversity indicator to assess food system contributions to dietary diversity and sustainable diets of Malawian households. Public Health Nutrition 18(13): 2479-2487.

Mafongoya, P. L., Bationo, A., Kihara, J. \& Waswa, B. S. (2006). Appropriate technologies to replenish soil fertility in southern Africa. Nutrient Cycling in Agroecosystems 76: $137-151$.

MAFS (2012). Ministry of Agriculture and Food Security (MAFS), 2012. Malawi Guide to Agriculture. Published by Agricultural Communication Branch. Government of Malawi, Lilongwe, Malawi.

MAIWD (2016a). National Agriculture Policy 2016. 132p.: Ministry of Agriculture, Irrigation and Water Development. Lilongwe, Malawi.

MAIWD (2016b). National Irrigation Policy. Ministry of Agriculture, Irrigation and Water Development (MAIWD). Department of Irrigation. September 2016: 44p.

MAIWD (2017). Ministry of Agriculture, Irrigation and Water Development (Malawi). Agro Economic Survey Department.

Mastrodomenico, A. T. \& Purcell, L. C. (2012). Soybean nitrogen fixation and nitrogen remobilization during reproductive development. Crop Science 52: 1281-1289.

Mazunda, J., Kankwamba, H. \& Pauw, K. (2018). Food and Nutrition Security Implications of Crop Diversification in Malawi's Farm Households. In Agriculture, Food Security and Nutrition in Malawi, 53-60 (Eds N. L. Aberman, J. Meerman and T. Benson). Washington, DC: International Food Policy Research Institute. 
McEwan, M. A., Lusheshanija, D., Shikuku, K. M. \& Sindi, K. (2017). Specialised sweetpotato vine multiplication in Lake Zone, Tanzania: What "sticks" and what changes? Open Agriculture 2: 64-69.

McGuire, S. \& Sperling, L. (2016). Seed systems smallholder farmers use. Food Security 8(1): 179-195.

METMALAWI (2017). Climate page - Malawi Meteorological Services. www.metmalawi.com/climate/climate.php.

Mhango, W. G., Snapp, S. \& Phiri, G. Y. K. (2013). Opportunities and constraints to legume diversification for sustainable maize production on smallholder farms in Malawi. Renewable Agriculture and Food Systems 28(3): 234-244.

Motsa, N. M., Modi, A. T. \& Mabhaudhi, T. (2015). Sweet potato (Ipomoea batatas L.) as a drought tolerant and food security crop. South African Journal of Science 111(11): 1-8.

Mpepereki, S., Javaheri, F., Davis, P. \& Giller, K. E. (2000). Soyabeans and sustainable agriculture. Promiscuous soyabeans in southern Africa. Field Crops Research 65: 137-149.

Mtambanengwe, F. \& Mapfumo, P. (2009). Combating food insecurity on sandy soils in Zimbabwe: The legume challenge. Symbiosis 48: 25-36.

Mueller, N. D., Gerber, J. S., Johnston, M., Ray, D. K., Ramankutty, N. \& Foley, J. A. (2012). Closing yield gaps through nutrient and water management. Nature 490: 254-257.

Mugwe, J., Mugendi, D., Kungu, J. \& Muna, M. (2009). Maize yields response to application of organic and inorganic input under on-station and on-farm experiments in central Kenya. Experimental Agriculture 45: 47-59.

Mukhtar, A. A., Tanimu, B., Arunah, U. L. \& Babaji, B. A. (2010). Evaluation of the agronomic characters of sweet potato varieties grown at varying levels of organic and inorganic fertilizer. World Journal of Agricultural Sciences 6(4): 370-373.

Mungai, L. M., Snapp, S., Messina, J. P., Chikowo, R., Smith, A., Anders, E., Richardson, R. B. \& Li, G. (2016). Smallholder farms and the potential for sustainable intensification. Frontiers in Plant Science 7(1720): 1-17. doi: 10.3389/fpls.2016.01720.

Mutegi, J., Kabambe, V., Zingore, S., Harawa, R. \& Wairegi, L. (2015). The fertilizer reccomendation issues in Malawi: Gaps, challenges, opportunities and guidelines: Soil Health Consortium of Malawi. 56p.

Muyinza, H., Talwana, H. L., Mwanga, R. O. M. \& Stevenson, P. C. (2012). Sweetpotato weevil (Cylas spp.) resistance in African sweetpotato germplasm. International Journal of Pest Management 58(1): 73-81.

Naico, A. T. A. \& Lusk, J. L. (2010). The value of a nutritionally enhanced staple crop: results from a choice experiment conducted with orange-fleshed sweet potatoes in Mozambique. Journal of African Economies 19: 536-558. 
Nalivata, P. C., Munthali, M. W., Makumba, W. I., Mbewe, E. \& Manase, H. (2017). Optimizing Fertilizer Use within the Context of Integrated Soil Fertility Management in Malawi. In: Fertilizer Use Optimization in Sub-Saharan Africa. Charles S. Wortmann and Keith Sones (eds). CAB International, Nairobi, Kenya, pp. 113-124.

Ndakidemi, P. A., Dakora, F. D., Nkonya, E. M., Ringo, D. \& Mansoor, H. (2006). Yield and economic benefits of common bean (Phaseolus vulgaris) and soybean (Glycine max) inoculation in northern Tanzania. Australian Journal of Experimental Agriculture 46: 571-577.

Ndolo, P. J., Mcharo, T., Carey, E. E., Gichuki, S. T., Ndinya, C. \& Maling'a, J. (2001). Participatory on-farm selection of sweetpotato varieties in western Kenya African Crop Science Journal 9(1): 41-48.

Netsayi, N. M., Chevoc, T., Nyekanyeka, T., Kapalasa, E. \& Demo, P. (2016). Gender norms and access to extension services and training among potato farmers in Dedza and Ntcheu in Malawi. The Journal of Agricultural Education and Extension 22(3): 291-305.

Newell, G. \& MacFarlane, J. (1988). Expanded tables for multiple comparison procedures in the analysis of ranked data. Journal of Food Science 52: 1721-1725.

Ngwira, A., Sleutel, S. \& De Neve, S. (2012). Soil carbon dynamics as influenced by tillage and crop residue management in loamy sand and sandy loam soils under smallholder farmers' conditions in Malawi. Nutrient Cycling in Agroecosystems 92: $315-328$.

Njira, K. O. W., Nalivata, P. C., Kanyama-Phiri, G. \& Lowole, M. W. (2013a). Effects of sole cropped, doubled-up legume residues and inorganic nitrogen fertilizer on maize yields in Kasungu, central Malawi. Agricultural Science Research Journals 3(3): 97-106.

Njira, K. O. W., Nalivata, P. C., Kanyama-Phiri, G. Y. \& Lowole, M. W. (2013b). An assessment for the need of soybean inoculation with Bradyrhizobium japonicum in some sites of Kasungu district, central Malawi. Agricultural Science Research Journals 2(8): 60-72.

NSO (2012). Integrated Household Survey 2010-2011. Household socio-economic characteristics report., 231p. Zomba, Malawi: National Statistical Office.

Nyemba, R. C. \& Dakora, F. D. (2010). Evaluating N2 fixation by food grain legumes in farmers' fields in three agro-ecological zones of Zambia, using $15 \mathrm{~N}$ natural abundance. Biology and Fertility of Soils 46: 461-470.

Odeleye, F. O., Odeleye, O. M. O. \& Dada, O. A. (2007). The performance of soybean (Glycine max (L.) Merrill) under varying weeding regimes in south western Nigeria. Notulae Botanicae Horti Agrobotanici Cluj-Napoca 35(1): 27-36. 
Ogoke, I. J., Carsky, R. J., Togun, A. O. \& Dashiell, K. (2003). Effect of P fertilizer application on $\mathrm{N}$ balance of soybean crop in the guinea savanna of Nigeria. Agriculture, Ecosystems and Environment 100: 153-159.

Ojiem, J. O., Franke, A. C., Vanlauwe, B., de Ridder, N. \& Giller, K. E. (2014). Benefits of legume-maize rotations: Assessing the impact of diversity on the productivity of smallholders in western Kenya. Field Crops Research 168: 75-85.

Ojiem, J. O., Ridder, N., Vanlauwe, B. \& Giller, K. E. (2006). Socio-ecological niche: A conceptual framework for integration of legumes in smallholder farming systems. International Journal of Agricultural Sustainability 4: 79-93.

Ojiem, J. O., Vanlauwe, B., De Ridder, N. \& Giller, K. E. (2007). Niche-based assessment of contributions of legumes to the nitrogen economy of western Kenya smallholder farms. Plant and Soil 292: 119-135.

Okello, J. J., Sindi, K., Shikuku, K., Low, J., McEwan, M., Nakazi, F., Namanda, S., Babu, A. \& Mafuru, J. (2015). Effect of technology awareness and access on the conservation of clean planting materials of vegetatively produced crops: The case of sweetpotato. Agroecology and Sustainable Food Systems 39(9): 955-977.

Orr, A., Mwale, B. \& Saiti, D. (2002). Modelling agricultural 'performance': smallholder weed management in southern Malawi. International Journal of Pest Management 48(4): 265-278.

Pardales Jr, J. R. \& Cerna, A. F. (1987). An agronomic approach to the control of sweetpotato weevil (Cylas formicarius elegantulus F.). Tropical Pest Management 33(1): 32-34.

Parker, M. B., Marchant, W. H. \& Mullinix, B. J. (1981). Date of planting and row spacing effects on four soybean cultivars. Agronomy Journal 73: 759-762.

Parr, M. C., Ntonifor, N. N. \& Jackai, L. E. (2014). Effect of planting dates on the population dynamics of Cylas puncticollis and sweet potato storage roots damage in South Western Cameroon. Journal of Biology, Agriculture and Healthcare 4(18): 41-48.

Peoples, M. B., Brockwell, J., Herridge, D., Rochester, I. J., Alves, B. J. R., Urquiaga, S., Boddey, R. M., Dakora, F. D., Bhattarai, S., Maskey, S. L., Sampet, C., Rerkasem, B., Khan, D. F., Hauggaard-Nielsen, H. \& Jensen, E. S. (2009). The contributions of nitrogen-fixing crop legumes to the productivity of agricultural systems. Review article. Symbiosis 48: 1-17.

Peoples, M. B., Ladha, J. K. \& Herridge, D. F. (1995). Enhancing legume $\mathrm{N}_{2}$ fixation through plant and soil management. Plant and Soil 174: 83-101.

Petersen, B. \& Snapp, S. (2015). What is sustainable intensification? Views from experts. Land Use Policy 46: 1-10.

Pircher, T., Almekinders, C. J. M. \& Kamanga, B. C. G. (2012). Participatory trials and farmers' social realities: understanding the adoption of legume technologies in a 
Malawian farmer community. International Journal of Agricultural Sustainability: 1-12.

Poulton, C., Kydd, J. \& Dorward, A. (2006). Overcoming market constraints on pro-poor agricultural growth in sub-Saharan Africa. Development Policy Review 24(3): 243277.

Pretty, J. (1999). Can sustainable agriculture feed Africa? New evidence on progress, processes and impacts. Environment, Development and Sustainability 1: 253-274.

Pretty, J., Toulmin, C. \& Williams, S. (2011). Sustainable intensification in African agriculture. International Journal of Agricultural Sustainability 9(1): 5-24.

Pule-Meulenberg, F., Gyogluu, C., Naab, J. \& Dakora, F. D. (2011). Symbiotic N nutrition, bradyrhizobial biodiversity and photosynthetic functioning of six inoculated promiscuous-nodulating soybean genotypes. Journal of Plant Physiology 168: 540-548.

Rao, S. \& Huggins, C. (2017). Sweet 'success': contesting biofortification strategies to address malnutrition in Tanzania. In Agronomy for development. The politics of knowledge in agricultural research, 192p (Ed J. Sumberg). Abingdon, Oxon: Routledge.

Ray, D. K., Mueller, N. D., West, P. C. \& Foley, J. A. (2013). Yield trends are insufficient to double global crop production by 2050. PLoS ONE 8(6): e66428 https://doi.org/66410.61371/journal.pone.0066428.

Ronner, E. (2018). From targeting to tailoring. Baskets of options for legume cultivation among African smallholders. PhD thesis. 181p. C.T. de Wit Graduate School of Production Ecology and Resource Conservation: Wageningen University.

Ronner, E., Franke, A. C., Vanlauwe, B., Dianda, M., Edeh, E., Ukem, B., Bala, A., van Heerwaarden, J. \& Giller, K. E. (2016). Understanding variability in soybean yield and response to P-fertilizer and rhizobium inoculants on farmers' fields in northern Nigeria. Field Crops Research 186: 133-145.

Saka, A. R., Mtukuso, A. P., Daudi, A. T., Banda, M. H. P. \& Phiri, I. M. G. (2006). Agricultural technologies released by the ministry of agriculture and food security2000-2005. 58p. Lilongwe: Department of Agricultural Research Services, Ministry of Agriculture and Food Security.

Salvagiotti, F., Cassman, K. G., Specht, J. E., Walters, D. T., Weiss, A. \& Dobermann, A. (2008). Nitrogen uptake, fixation and response to fertilizer $\mathrm{N}$ in soybeans: A review. Field Crops Research 108: 1-13.

Sanginga, N. (2003). Role of biological nitrogen fixation in legume based cropping systems; a case study of West Africa farming systems. Plant and Soil 252: 25-39.

Sastawa, B. M., Lawan, M. \& Maina, Y. T. (2004). Management of insect pests of soybean: effects of sowing date and intercropping on damage and grain yield in the Nigerian Sudan savanna. Crop Protection 23: 155-161. 
Sauer, J. \& Tchale, H. (2009). The economics of soil fertility management in Malawi. Review of Agricultural Economics 31: 535-560.

Schipanski, M. E., Drinkwater, L. E. \& Ruselle, M. P. (2010). Understanding the variability in soybean nitrogen fixation across agroecosystems. Plant and Soil 329: 379-397.

Schmidt, U., Thöni, H. \& Kaupenjohann, M. (2000). Using a boundary line approach to analyze $\mathrm{N}_{2} \mathrm{O}$ flux data from agricultural soils. Nutrient Cycling in Agroecosystems 57: 119-129.

Shatar, T. M. \& McBratney, A. B. (2004). Boundary-line analysis of field-scale yield response to soil properties. Journal of Agricultural Science 142: 553-560.

Sheahan, M. \& Barrett, C. B. (2017). Ten striking facts about agricultural input use in subSaharan Africa. Food Policy 67: 12-25.

Simtowe, F. (2006). Can risk-aversion towards fertilizer explain part of the non-adoption puzzle for hybrid maize? Empirical evidence from Malawi. Journal of Applied Sciences 6(7): 1490-1498.

Simtowe, F. P. (2010). Livelihoods diversification and gender in Malawi. African Journal of Agricultural Research 5(3): 204-216.

Sinclair, T. R., Purcell, L. C., King, C. A., Sneller, C. H., Chen, P. \& Vadez, V. (2007). Drought tolerance and yield increase of soybean resulting from improved symbiotic $\mathrm{N}_{2}$ fixation. Field Crops Research 101: 68-71.

Sisworo, W. H., Mitrosuhardjo, M. M., Rasjid, H. \& Myers, R. J. K. (1990). The relative roles of $\mathrm{N}$ fixation, fertilizer, crop residues and soil in supplying $\mathrm{N}$ in multiple cropping systems in a humid, tropical upland cropping system. Plant and Soil 121: 73-82.

Smit, N. E. J. M. (1997). The effect of the indigenous cultural practices of in-ground storage and piecemeal harvesting of sweetpotato on yield and quality losses caused by sweetpotato weevil in Uganda. Agriculture, Ecosystems and Environment 64: 191-200.

Snapp, S. \& Fisher, M. (2015). "Filling the maize basket" supports crop diversity and quality of household diet in Malawi. Food Security 7(1): 83-96.

Snapp, S., Kerr, R. B., Smith, A., Ollenburger, M., Mhango, W., Shumba, L., Gondwe, T. \& Kanyama-Phiri, G. (2014). Modeling and participatory, farmer-led approaches to food security in a changing world: a case study from Malawi. Science Planétaire - Sécheresse 24: 350-358.

Snapp, S. S., Blackie, M. J., Gilbert, R. A., Bezner-Kerr, R. \& Kanyama-Phiri, G. Y. (2010). Biodiversity can support a greener revolution in Africa. Proceedings of the National Academy of Sciences of the United States of America 107: 20840-20845.

Snapp, S. S., Grabowski, P., Chikowo, R., Smith, A., Anders, E., Sirrine, D., Chimonyo, V. \& Bekunda, M. (2018). Maize yield and profitability tradeoffs with social, human and environmental performance: Is sustainable intensification feasible? Agricultural Systems 162: 77-88. 
Snapp, S. S., Mafongoya, P. L. \& Waddington, S. (1998). Organic matter technologies for integrated nutrient management in smallholder cropping systems of southern Africa. Agriculture, Ecosystems and Environment 71: 185-200.

Snapp, S. S., Rohrbach, D. D., Simtowe, F. \& Freeman, H. A. (2002). Sustainable soil management options for Malawi: can smallholder farmers grow more legumes? Agriculture, Ecosystems and Environment 91: 159-174.

Snapp, S. S. \& Silim, S. N. (2002). Farmer preferences and legume intensification for low nutrient environments. Plant and Soil 245: 181-192.

Stathers, T. E., Rees, D., Kabi, S., Mbilinyi, L., Smit, N., Kiozya, H., Jeremiah, S., Nyango, A. \& Jeffries, D. (2003a). Sweetpotato infestation by Cylas spp. in East Africa. 1. Cultivar differences in field infestation and the role of plant factors. International Journal of Pest Management 49: 131-140.

Stathers, T. E., Rees, D., Nyango, A., Kiozya, H., Mbilinyi, L., Jeremiah, S., Kabi, S. \& Smit, N. (2003b). Sweetpotato infestation by Cylas spp. in East Africa: II. Investigating the role of root characteristics. International Journal of Pest Management 49(2): 141-146.

Steiner, C., Teixeira, W. G., Lehmann, J., Nehls, T., de Macêdo, J. L. V., Blum, W. E. H. \& Zech, W. (2007). Long term effects of manure, charcoal and mineral fertilization on crop production and fertility on a highly weathered central Amazonian upland soil. Plant and Soil 291(1): 275-290.

Struik, P. C. \& Kuyper, T. W. (2017). Sustainable intensification in agriculture: the richer shade of green. A review. Agronomy for Sustainable Development 37:39: https://doi.org/10.1007/s13593-13017-10445-13597.

Struik, P. C., Kuyper, T. W., Brussaard, L. \& Leeuwis, C. (2014). Deconstructing and unpacking scientific controversies in intensification and sustainability: why the tensions in concepts and values? Current Opinion in Environmental Sustainability 8(80-88).

Summerfield, R. J., Ellis, R. H. \& Craufurd, P. Q. (1996). Phenological adaptation to cropping environment. From evaluation descriptors of times to flowering to the genetic characterisation of flowering responses to photoperiod and temperature. Euphytica 92: 281-286.

Tadross, M., Suarez, P., Lotsch, A., Hachigonta, S., Mdoka, M., Unganai, L., Lucia, F., Kamdonyo, D. \& Mchinda, M. (2007). Changes in growing-season rainfall characteristics and downscaled scenarios of change over southern Africa: implications for growing maize. In IPCC regional Expert Meeting on Regional Impacts, Adaptation, Vulnerability, and Mitigation, 193-204 Nadi, Fiji.

Takane, T. (2008). Labor use in smallholder agriculture in Malawi: Six village case studies. African Study Monographs 29(4): 183-200. 
Tanumihardjo, S. A., Ball, A., Kaliwile, C. \& Pixley, K. V. (2017). The research and implementation continuum of biofortified sweet potato and maize in Africa. Annals of the New York Acadamy of Sciences 1390: 88-2017.

Taylor, H. M. (1980). Soybean growth and yield as affected by row spacing and by seasonal water supply. Agronomy Journal 72: 543-547.

Tefera, H., Kamara, A. Y., Asafo-Adjei, B. \& Dashiell, K. E. (2009). Improvement in grain and fodder yields of early-maturing promiscuous soybean varieties in the Guinea Savanna of Nigeria. Crop Science 49: 2037-2042.

Tichagwa, J. S. \& Rusike, J. (2009). Status of soybean production and utilization in southern Africa. In Developing a global soy blueprint for a safe security and sustainable supply. World Soybean Research Conference VIII Proceedings, 10-15 August, 2009, Beijing, China, 2009.

Tinsley, R. L. (2009).Value Chain Analysis for Soybeans in Malawi. 28p: Soils \& Crop Sciences Department Colorado State University.

Tittonell, P. \& Giller, K. E. (2013). When yield gaps are poverty traps: The paradigm of ecological intensification in African smallholder agriculture. Field Crops Research 143: 76-90.

Tittonell, P., Muriuki, A., Shepherd, K. D., Mugendi, D., Kaizzi, K. C., Okeyo, J., Verchot, L., Coe, R. \& Vanlauwe, B. (2010). The diversity of rural livelihoods and their influence on soil fertility in agricultural systems of East Africa - A typology of smallholder farms. Agricultural Systems 103(2): 83-97.

Tittonell, P., Zingore, S., van Wijk, M. T., Corbeels, M. \& Giller, K. E. (2007). Nutrient use efficiencies and crop responses to $\mathrm{N}, \mathrm{P}$ and manure applications in Zimbabwean soils: Exploring management strategies across soil fertility gradients. Field Crops Research 100: 348-368.

UIL (2017). Personal communication. Jean Pankuku, Food Technologist, Universal Industries Limited. Blantyre. Malawi.

UN (2017). United Nations, Department of Economic and Social Affairs, Population Division. World Population Prospects: The 2017 Revision, Key Findings and Advance Tables. Working Paper No. ESA/P/WP/248. .

UN (2018). http://www.un.org/sustainabledevelopment/hunger/.

Unkovich, M., Herridge, D., Peoples, M., Cadisch, G., Boddey, B., Giller, K.E. \& Alves, B. (2008). Measuring plant-associated $N_{2}$-fixation in agricultural systems. ACIAR, Canberra.

Van Asten, P. J. A., Wopereis, M. C. S., Heafele, S., Ould Isselmou, M. \& Kropff, M. J. (2003). Explaining yield gaps on farmer-identified degraded and non-degraded soils in a Sahelian irrigated rice scheme. NJAS - Wageningen Journal of Life Sciences 50: 277-296.

Van den Brand, G. (2011). Towards increased adoption of grain legumes among Malawian farmers - Exploring opportunities and constraints through detailed farm 
characterization. Master thesis Sustainable Development. 70p. Plant Production Systems Group, Wageningen: Utrecht University and Wageningen University.

Van Heerwaarden, J., Baijukya, F., Kyei-Boahen, S., Adjei-Nsiah, S., Ebanyat, P., Kamai, N., Wolde-meskel, E., Kanampiu, F., Vanlauwe, B. \& Giller, K. (2018). Soyabean response to rhizobium inoculation across sub-Saharan Africa: Patterns of variation and the role of promiscuity. Agriculture, Ecosystems and Environment 261: 211218.

Van Ittersum, M. K. \& Rabbinge, R. (1997). Concepts in production ecology for analysis and quantification of agricultural input-output combinations. Field Crops Research 52: 197-208.

Van Ittersum, M. K., van Bussel, L. G. J., Wolf, J., Grassini, P., van Wart, J., Guilpart, N., Claessens, L., de Groot, H., Wiebe, K., Mason-D’Croz, D., Yang, H., Boogaard, H., van Oort, P. A. J., van Loon, M. P., Saito, K., Adimo, O., Adjei-Nsiah, S., Agali, A., Bala, A., Chikowo, R., Kaizzi, K., Kouressy, M., Makoi, J. H. J. R., Ouattara, K., Tesfaye, K. \& Cassman, K. G. (2016). Can sub-Saharan Africa feed itself? Proceedings of the National Academy of Sciences of the United States of America 113(52): 14964-14969.

Van Oirschot, Q. E. A., Rees, D. \& Aked, J. (2003). Sensory characteristics of five sweet potato cultivars and their changes during storage under tropical conditions. Food Quality and Preference 14: 673-680.

Van Vugt, D., Franke, A. C. \& Giller, K. E. (2017). Participatory research to close the soybean yield gap on smallholder farms in Malawi. Experimental Agriculture 53(3): 396-415.

Van Vugt, D., Franke, A. C. \& Giller, K. E. (2018). Understanding variability in the benefits of $\mathrm{N}_{2}$-fixation in soybean-maize rotations on smallholder farmers' fields in Malawi. Agriculture, Ecosystems and Environment 261: 241-250.

Vandeplas, I., Vanlauwe, B., Driessens, L., Merckx, R. \& Deckers, J. (2010). Reducing labour and input costs in soybean production by smallholder farmers in southwestern Kenya. Field Crops Research 117: 70-80.

Vanlauwe, B., Chianu, J., Giller, K. E., Merckx, R., Mokwunye, U., Pypers, P., Shepherd, K., Smaling, E., Woomer, P. L. \& Sanginga, N. (2010). Integrated soil fertility management: operational definition and consequences for implementation and dissemination. Outlook on Agriculture 39: 17-24.

Vanlauwe, B., Coe, R. \& Giller, K. E. (2016). Beyond averages: New approaches to understand heterogeneity and risk of technology success or failure in smallholder farming. Experimental Agriculture: 1-23. doi:10.1017/S00144797160001931.

Vanlauwe, B., Coyne, D., Gockowski, J., Hauser, S., Huising, J., Masso, C., Nziguheba, G. \& Van Asten, P. (2014). Sustainable intensification and the smallholder African farmer. Current Opinions in Environmental Sustainability 8: 15-22. 
Vanlauwe, B. \& Giller, K. E. (2006). Popular myths around soil fertility management in sub-Saharan Africa. Agriculture, Ecosystems and Environment 116: 34-46.

Von Liebig, J. (1863). The Natural Laws of Husbandry. Walter and Maberly, London.

Waddington, S., Sakala, W. D. \& Mekuria, M. (2004). Progress in lifting soil fertility in southern Africa. In "New directions for a diverse planet". 4th International Crop Science Congress. Brisbane, Australia.

Waddington, S. R. \& Karigwindi, J. (2001). Productivity and profitability of maize + groundnut rotations compared with continuous maize on smallholder farms in Zimbabwe. Experimental Agriculture 37: 83-98.

Wairegi, L. W. I., Van Asten, P. J. A., Tenywa, M. M. \& Bekunda, M. A. (2010). Abiotic constraints override biotic constraints in East African highland banana systems. Field Crops Research 117: 146-153.

Weil, R. (2015). SoilDoc Kit Systems. BETA Version of SoilDoc Protocols. 75p: Agriculture and Food Security Center. Earth Institute. Columbia University.

Wendt, J. W. \& Jones, R. B. (1997). Evaluation of the efficacy of Malawi Tundulu phosphate rock for maize production. Nutrient Cycling in Agroecosystems 48: 161-170.

WHO (2017). World Health Organization. Nutrition topics. Micronutrient deficiencies. Vitamin A deficiency. www.who.int/nutrition/topics/vad/en (accessed 20/07/2017).

WHO (2018). World Health Organization. Nutrition topics. Micronutrient deficiencies. http://www.who.int/nutrition/topics/micronutrients/en/ (accessed 06/03/2018).

Wichern, Y., Eberhardt, E., Mayer, J., Joergensen, R. G. \& Müller, T. (2008). Nitrogen rhizodeposition in agricultural crops: Methods, estimates and future prospects. Soil Biology \& Biochemistry 40: 30-48.

Zeller, M., Diagne, A. \& Mataya, C. (1998). Market access by smallholder farmers in Malawi: implications for technology adoption, agricultural productivity and crop income. Agricultural Economics 19: 219-229.

Zingore, S. \& Giller, K. E. (2012). Optimizing phosphorus and manure application in maize-soybean rotations in Zimbabwe. Better Crops 96(2): 23-25.

Zingore, S., Murwira, H. K., Delve, R. J. \& Giller, K. E. (2008). Variable grain legume yields, responses to phosphorus and rotational effects on maize across soil fertility gradients on smallholder farms in Zimbabwe. Nutrient Cycling in Agroecosystems 80: 1-18. 


\section{Summary}

Crop production by smallholder farmers in southern Africa is characterized by cultivation of maize as a staple food on a large share of the agricultural land. Limited nutrient input results in soil nutrient depletion over time. To achieve the Sustainable Development Goals (SDGs) of zero hunger and poverty here is need for productive farming systems that are better adapted to a changing climate, and that produce more diverse food to achieve both food and nutrition security. The aim of this thesis was to explore options for sustainable intensification and diversification of maize-based farming systems in Central Malawi with legumes and sweet potato.

We tested crop and nutrient management practices in soybean through on-farm experimentation in 144 fields and participatory technology evaluation. The farmers ranked eight technologies in descending order of preference as 1 . Early planting 2. Plant population 3. Variety choice 4. Compost manure 5. Weeding 6. Inoculant 7. Fertilizer and 8. Spraying. A combination of inoculation, inorganic fertilizer $\left(10 \mathrm{~N}, 8 \mathrm{P}, 20 \mathrm{~K}\right.$ in kg ha-1), and $6 \mathrm{tha}^{-1}$ compost manure increased yields from $0.86 \mathrm{t} \mathrm{ha}^{-1}$ under farmers' practice to $1.56 \mathrm{t} \mathrm{ha}^{-1}$ and resulted in average profits of $222 \mathrm{USD} \mathrm{ha}^{-1}$. Increased plant populations and biocide spraying also resulted in substantial yield increases. All technologies except planting the improved variety Nasoko and weed management were profitable with a value to cost ratio (VCR) $>1$ but only inoculation and increased plant population resulted in an average VCR $>2$. Low investment costs make inoculants, compost manure and increased plant populations interesting options, whereas adoption of inorganic fertiliser application in soybean may be limited due to high costs and low VCR.

We explored the variability and factors behind the benefits of $\mathrm{N}_{2}$-fixation in soybean-maize rotations on smallholder farmers' fields. Locally sourced soybean varieties obtained a larger percentage of Nitrogen derived from the atmosphere (\%Ndfa; $65 \%)$ than the 'improved' variety Nasoko (53\%). The \%Ndfa was positively associated with soil sand content, sowing date, plant population and biomass accumulation, but it was not affected by inoculation with rhizobia or the combination of inoculation and NPK fertiliser application. Quantities of $\mathrm{N}_{2}$ fixed differed between regions and years, and was enhanced by applying inoculant and fertiliser together, leading to more biomass accumulation and larger grain yields. Soil available $\mathrm{P}$ and exchangeable $\mathrm{K}$ contents also increased the total amount of $\mathrm{N}_{2}$ fixed. Average yield in continuous maize was $2.5 \mathrm{tha}^{-1}$, while maize after soybean produced $3.5 \mathrm{t} \mathrm{ha}^{-1}(139 \%$ of continuous maize). Farmers with higher maize yields, who applied external nutrient inputs, and with a larger value of household assets achieved greater yield responses to rotation with soybean. We conclude that fields of soybean and maize that receive adequate nutrient inputs 
and good management to ensure good yields benefit most in terms of quantities of $\mathrm{N}_{2}$ fixed by the legume and the yield response of the following maize crop.

We assessed the performance of six orange-fleshed sweet potato (OFSP) varieties on 221 farmers' fields, identified factors limiting productivity and explored options to close the gap between actual and attainable OFSP yields on fields of smallholder farmers. Results show a large variability across farmers' fields and a wide range of interacting factors affecting the variables of interest. Varieties Chipika and Kadyaubwerere attained good yields and were preferred by farmers in terms of taste. Varieties Zondeni and Anaakwanire gave a poor root yield, but a good vine yield. Timely planting is crucial to attain good root yields by making better use of the available rainfall. There was a varietal effect on weevil infestation and Kaphulira was most affected. Weevil control is required for market-oriented producers to enhance the percentage of marketable roots. The average attainable fresh root yield ranged from $18 \mathrm{t} \mathrm{ha}^{-1}$ for variety Zondeni to $32 \mathrm{t} \mathrm{ha}^{-1}$ for Mathuthu, against actual yields of 5 to 9 $\mathrm{t} \mathrm{ha}^{-1}$. Elevation, planting date, rainfall and crop establishment could explain only 28 percent of the average yield gap, while 49 percent was explained for Mathuthu. Male host farmers received better quality cuttings and planted in better soil moisture conditions, resulting in better establishment and vine yields. OFSP productivity can be enhanced through gendersensitive extension, by ensuring male and female farmers can plant clean planting material of a suitable variety early in the rainy season. This requires additional efforts in vine multiplication of the required variety prior to the onset of the rains.

We than combined yield results of 50 maize, 28 soybean, 24 groundnut and 26 sweet potato on-farm input trials with economic analysis and focus group discussions to explore input options for crop intensification and diversification. Due to proper crop management and the use of good varieties in a season with above-average rainfall, excellent mean trial yields of $5.0 \mathrm{t} \mathrm{ha}^{-1}$ for maize, $3.4 \mathrm{t} \mathrm{ha}^{-1}$ for soybean, $2.5 \mathrm{t} \mathrm{ha}^{-1}$ for groundnuts and $13.2 \mathrm{t} \mathrm{ha}^{-1}$ for sweet potato were achieved. Responses to various combinations of inorganic fertilizer and lime were highly variable, but applications enhanced yields in all crops. Although maize production and investments in maize fertilizer were not as profitable as the other crops, fertilizer application to maize gave the best returns of food per amount of money invested. Better yield responses and value cost ratios showed that investments in fertiliser and lime in soybean was more worthwhile than in groundnut, though the financial benefits were somewhat hidden by high groundnut prices. While there is potential to derive better financial returns from diversification and intensification with legumes and sweet potato, farmers prioritize maize in terms of land area and resource allocation.

Our participatory research approach demonstrated that there is a wide range of technologies with different levels of human and financial investment costs that smallholder farmers can adopt to enhance their maize, soybean, groundnut and sweet potato yields and profits. A wide 
range of treatments, biophysical conditions, crop management choices, and socio-economic variables affected maize, soybean, groundnut and sweet potato yields, $\mathrm{N}_{2}$ fixation and the rotational benefits of soybean on maize. This led to large variability in yields and yield responses to technologies across farms. While the diversity in responses allows us to better understand the context in which technologies are introduced, associations between gender, wealth and yields will only be informative if we understand the underlying social dynamics. Considering this diversity, sustainable intensification can contribute to enhancing food and nutrition security but is unlikely to fully eradicate hunger and poverty by 2030 . Addressing the multiple constraints of poor extension services, unstable markets, access to credit and access to improved seed may result in more diversified and intensified cropping systems. To achieve this, investments in agriculture need to be targeted to better-off farmers in the form of technology packages that can be adapted to the local context. This should be complemented with investments in off-farm income generation and social protection. Adaptive on-farm integrated research to sustainably enhance food and nutrition security needs to be embedded in a multi-stakeholder 'partnerships for impact at scale' approach. This way farmers can be empowered to substantially increase their productivity and incomes through crop diversification and intensification. 
Summary

146 


\section{Acknowledgements}

This thesis is a result of many interesting and exciting interactions with farmers in the field, colleagues, project partners, promotors, friends and family. These interactions also contributed to the confidence and determination that was needed to complete the data analysis and writing of the thesis.

I would like to thank my promotor Ken Giller for believing in me and for helping me raise my level of thinking, and for the valuable input in the thesis. I owe very much to my copromotor Linus Franke who provided many critical suggestions and useful insights that helped me to improve the papers and sharpen my analytical and writing skills.

I thank Paul Demo, country manager at the International Potato Center (CIP) for motivating me to finish the $\mathrm{PhD}$, and for support in implementing the OFSP project. At CIP I learned the power of 'partnering for impact at scale' from Tom Remington and received good support from Simon Heck, Emily Mueller, Felistus Chipungu and Wells Kumwenda. I thank Arthur Chibwana, Brian Kachisa and Denis Kathabwalika for contributions to development of protocols, trainings of partner staff and oversight during implementation and data collection; research technicians Stanley Mbewe, David Mthobwa, Thokozani Mvula, Pearson Phiri, Benjamin Muhalu, Khalaniphe Kamuonjola and Patison Mamboya for working closely with project partners at district level, and all other CIP support staff for facilitating the work. Many partner staff were involved in the sweet potato scaling project that formed the basis of Chapter 4. I thank all staff from Departments of Agricultural Research and Extension Services, We Effect, Concern Worldwide, Farmers Union of Malawi, Catholic Development Commission Dedza Diocese, Zomba Diocese Research and Development Department, Tetra Tech (PERFORM project), Development Alternatives Incorporated (INVC project), Project Concern International (NJIRA project), National Association of Smallholder Farmers in Malawi and Total Land Care that have contributed to the successful implementation of the sweet potato mother-baby trial approach. I also thank Sheila Keino, Caitlin Shaw, Kumbukani Munthali, Friday Mlenga and all agronauts of Farmers World Ltd for designing and implementing all field work and making the data available, with special thanks to Nikhil Jones for support with organizing the data and his input in Chapter 5.

I also thank all my colleagues at the International Institute of Tropical Agriculture (IITA); country representatives Hailu Tefera and Arega Alene for encouraging me to pursue a PhD, and Julius Manda as fellow external PhD student for advice and support along the way. The field work on soybean and maize (Chapter 2,3) would not be possible without the hard and dedicated work of technicians Abel Mwale in Mchinji, Nepear Nkhwale in Salima and Mr Buno in Dowa district, and biomass sample preparations led by Felix Kaomba in Chitedze. 
I also thank HAS University of Applied Sciences for providing time to work on the thesis. I especially thank the great team of colleagues in the International Food and Agribusiness program. Balancing work as a new lecturer with making progress on the thesis was a challenge, but I thank my colleague Toon Keijsers for helping me keep my head cool with coaching and advise in this exciting job.

I am most grateful for the most important partners in development: The roughly 500 smallholder farmers that decided to participate in this research by offering their land and time for joint learning and experimentation. My interactions with many of these farmers have been some of the most enriching experiences of my life and opened my eyes to the realities, constraints and opportunities facing smallholder farmers in Malawi.

Many friends have motivated me along the way for which I am very grateful. A special word of thanks goes to my best friend for 14 years, Sjoerd Boekhoff (†March 2017), who has always been there for me. I cannot thank you enough for all your encouragements, acceptance and understanding that helped me reach this point. I also thank my parents, my brothers and sister and their families for moral support and especially my brother Marcel for always making me laugh whenever I need it most. What is life if you cannot laugh every day? This is probably the best lesson you can learn from living in Africa for almost 10 years, and I am thankful for the warmth, smiles and laughter I received from all Malawians in the warm heart of Africa. 


\section{About the author}

Daniel van Vugt was born on 13 July 1981 in Giessen, the Netherlands. After his secondary education at the Altena College in Sleeuwijk, he moved to Wageningen where he completed the first year of the Biology program in 2001. After a period of work and travel in Australia he returned to Wageningen and completed his BSc degree in International Land and Water Management in 2005. Following this, he enrolled in the MSc Plant Sciences at Wageningen University. During this time, he took part in a six-month exchange program on organic agriculture at the University of New England in Armidale, Australia. He conducted fieldwork for his thesis at Africa Rice Centre in Senegal to assess the adoption potential of water saving techniques in irrigated rice schemes in the Senegal River Valley.

From 2008 to 2013, Daniel worked as a Legume Agronomist and Systems Agronomist at the International Institute of Tropical Agriculture (IITA) in Malawi. His work included project management and design and implementation of participatory agronomic and variety trials on soybean, cowpea and legume-maize crop rotations in Malawi and Zambia. He also led the development of multi-stakeholder Innovation Platforms in the Eastern Province of Zambia as part of a sustainable intensification project. Following a brief experience as a founder and managing director of a small seed company in Malawi from 2013-2014, Daniel moved back to the Netherlands to work as a lecturer Crop Production Systems at the HAS University of Applied Sciences in the International Food and Agribusiness study program.

Since May 2015 Daniel is back in Malawi where he is currently working as country manager at the International Potato Center (CIP). He managed an 'Improved Seed Systems and Technologies' project that aimed to scale out orange-fleshed sweet potato technologies to thousands of households in Central and Southern Malawi. His work at IITA and CIP allowed him to register as an external $\mathrm{PhD}$ candidate at Wageningen University to combine project management with data collection, analysis and publication towards the $\mathrm{PhD}$. He is currently leading the contributions of seven International Research for Development Centres (CGIAR) to a Farmer Field School focused innovation systems project to enhance productivity of 400,000 farm households in partnership with GIZ, FAO, Government of Malawi and a consortium of NGOs. 
PE\&RC Training and Education Statement 


\section{PE\&RC Training and Education Statement}

With the training and education activities listed below the $\mathrm{PhD}$ candidate has complied with the requirements set by the C.T. de Wit Graduate School for Production Ecology and Resource Conservation (PE\&RC) which comprises of a minimum total of 32 ECTS (= 22 weeks of activities)

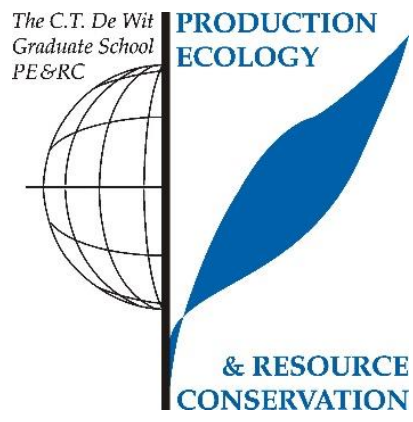

\section{Review of literature (4.5 ECTS)}

- Diversification and intensification of crop production with legumes and sweet potato on smallholder farms in Malawi

\section{Writing of project proposal (4.5 ECTS)}

- CGIAR contribution to KULIMA promoting farming in Malawi: improving the access to and use of agriculture research innovations by Malawian farmers.

\section{Post-graduate courses (5.6 ECTS)}

- Assessing crop production, nutrient management, climatic risk and environmental sustainability with simulation models; University of Georgia, Griffin, Georgia (2010)

- Engendered project planning, implementation, monitoring and evaluation; International Potato Center (CIP), Ukunda, Kenya (2016)

- Evaluating social programs; Massachusetts Institute of Technology (MIT) through edX. (2016)

\section{Invited review of (unpublished) journal manuscript (1 ECTS)}

- Experimental Agriculture: participatory variety selection: farmer criteria and rating of Vitamin A orange maize varieties in Northern Zambia (2017)

\section{Deficiency, refresh, brush-up courses (1.5 ECTS)}

- ArcGIS Training; International Institute of Tropical Agriculture (IITA), Chitedze, Malawi (2011)

\section{Competence strengthening / skills courses (3 ECTS)}

- $\quad$ Scientific writing and publishing course; Nairobi, Kenya (2011)

- Improving CIP's ability to prepare high quality grant proposals and reports building on story telling and advanced writing skills; Kigali, Rwanda (2017) 
PE\&RC Annual meetings, seminars and the PE\&RC weekend (1 ECTS)

- $\quad$ PE\&RC first year introduction weekend (2013)

- $\quad$ Careers after PhD - seminar; Wageningen (2018)

\section{Discussion groups / local seminars / other scientific meetings (5.7 ECTS)}

- $\quad$ N2Africa project planning meeting; Nairobi, Kenya (2010)

- Organized and attended seminars bringing together scientists from different research for development organizations to present research findings; Chitedze, Malawi (2011)

- $\quad$ R4D (research for development) annual planning meetings with all IITA scientists; Ibadan, Nigeria (2010, 2012)

- IFPRI Seminars: harnessing markets for improved nutrition: a case study of Zomba and improving food security, diets, and nutrition through multi-sectoral action: new evidence, challenges and opportunities; Lilongwe, Malawi (2017)

\section{International symposia, workshops and conferences (6.9 ECTS)}

- Tropentag conference: resilience of agricultural systems against crises; poster presentation; Göttingen, Germany (2012)

- ISFM-Africa conference: integrated soil fertility management in Africa: from microbes to markets; poster presentation; Nairobi, Kenya (2012)

- World soybean research conference; oral presentation; Durban, South Africa (2013)

\section{Lecturing / Supervision of practicals / tutorials (3 ECTS)}

- Development of curriculum and facilitate a lecture series: domain track crop production systems for the international food and agribusiness study program; HAS University of Applied Sciences, 's-Hertogenbosch, the Netherlands $(2014,2015)$

\section{Supervision of MSc students (1 ECTS)}

- Towards increased adoption of grain legumes among Malawian farmers - exploring opportunities and constraints through detailed farm characterization (Greta van der Brandt) 


\section{Financial support}

The research described in Chapters 2 and 3 of this thesis was financially supported by the Directorate for Development Cooperation of the Netherlands Ministry of Foreign affairs (DGIS) through funding of the author's APO position at the International Institute of Tropical Agriculture (IITA). The operational research costs were provided by IITA. HAS University of Applied Sciences supported time for the writing of Chapter 2. The Bill \& Melinda Gates Foundation supported the writing and publication of Chapter 3 through a grant to Wageningen University to support the project N2Africa: Putting Nitrogen Fixation to Work for Smallholder Farmers in Africa (www.N2Africa.org).

The research described in Chapters 4,5 and 6 of this thesis was undertaken at the International Potato Center (CIP) as part of the CGIAR Research Program on Roots, Tubers and Bananas (RTB). It was financially supported by the United States Agency for International Development (USAID) under the Feed the Future Malawi Improved Seed Systems and Technologies project [grant number AID-BFS-G-11-00002]. The trial establishment and data collection described in Chapter 5 was conducted by Farmers World Ltd under the Productivity Improvement Program for Smallholders (PIPS) supported by the African Fertilizer and Agribusiness Partnership (AFAP).

Financial support from Wageningen University for printing this thesis is gratefully acknowledged.

Printed by: Digiforce 